\title{
Trace Amines and Their Receptors
}

\author{
Raul R. Gainetdinov, Marius C. Hoener, and Mark D. Berry
}

Institute of Translational Biomedicine, St. Petersburg State University, St. Petersburg, Russia (R.R.G.); Skolkovo Institute of Science and Technology (Skoltech), Moscow, Russia (R.R.G.); Neuroscience, Ophthalmology, and Rare Diseases Discovery and Translational Area, pRED, Roche Innovation Centre Basel, F. Hoffmann-La Roche Ltd., Basel, Switzerland (M.C.H.); and Department of Biochemistry, Memorial University of Newfoundland, St. John's, Newfoundland and Labrador, Canada (M.D.B.)

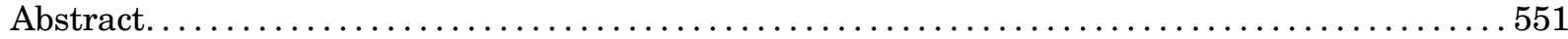

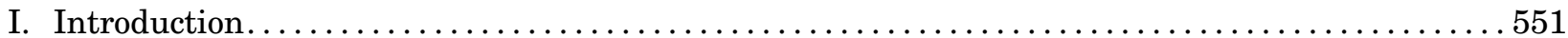

II. Vertebrate Trace Amines .............................................. 555

A. $\beta$-Phenylethylamine, p-Tyramine, and Related Compounds .................... 555

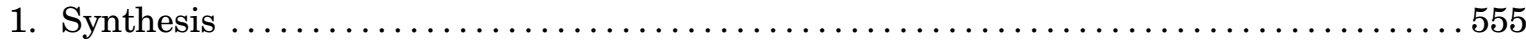

a. Regulation of Aromatic L-Amino Acid Decarboxylase ....................... 555

b. Other Sources of $\beta$-Phenylethylamine, p-Tyramine, and Related Compounds ...... 560

i. Microbiota-Derived Trace Amines................................ 560

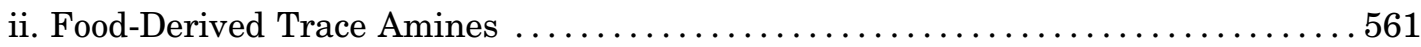

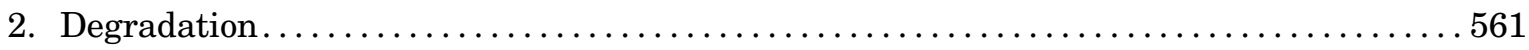

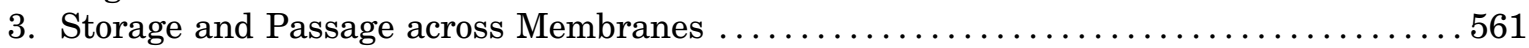

4. Cellular Effects ................................................. 562

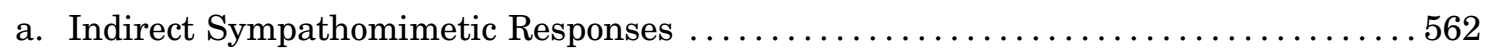

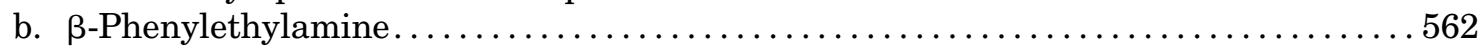

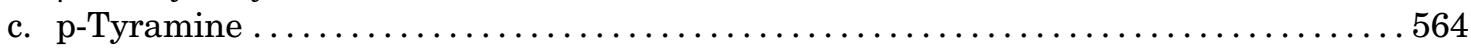

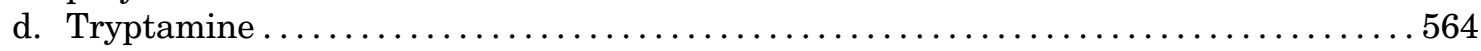

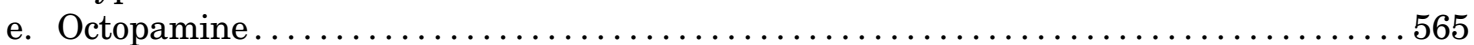

5. $\beta$-Phenylethylamine, p-Tyramine, and Tryptamine in Human Disorders ............ 565

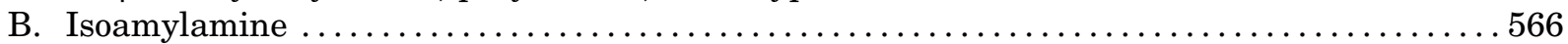

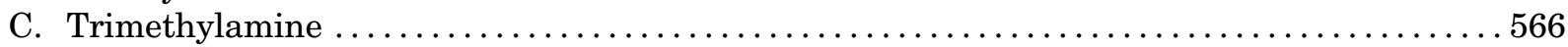

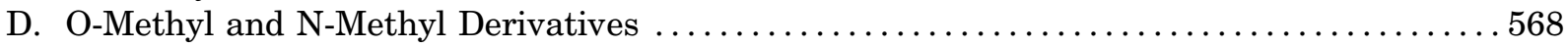

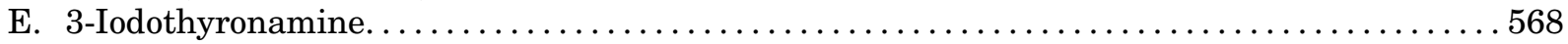

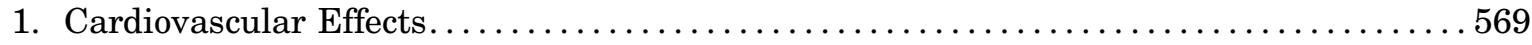

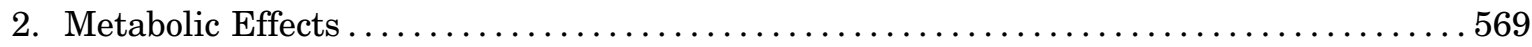

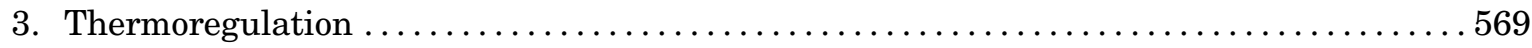

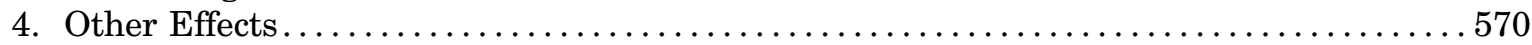

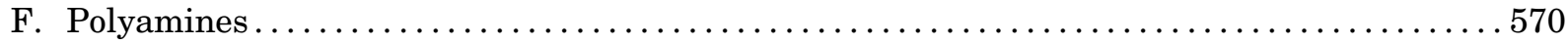

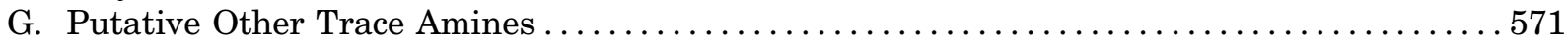

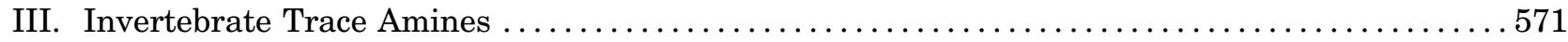

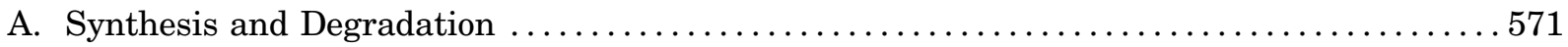

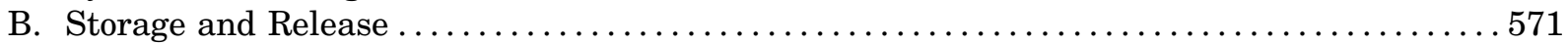

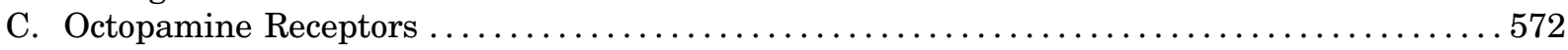

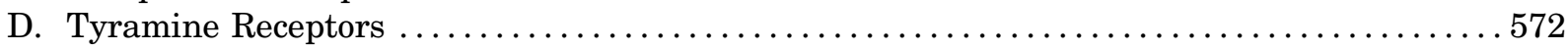

E. Physiologic Responses .............................................. 572

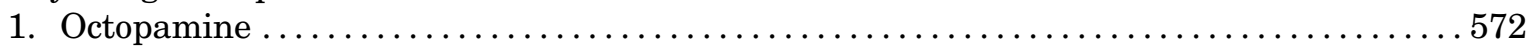

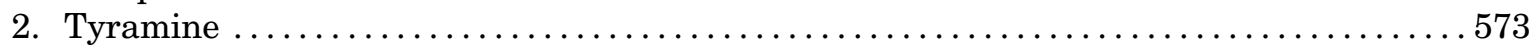

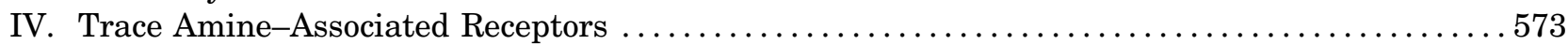

Address correspondence to: Raul R. Gainetdinov, Institute of Translational Biomedicine, St. Petersburg State University, Universitetskaya Emb. 7-9, 199034 St. Petersburg, Russia. E-mail: gainetdinov.raul@gmail.com

This work was supported by the Russian Science Foundation [Grant 14-50-00069 (to R.R.G.)] and the Research and Development Corporation of Newfoundland and Labrador and Memorial University of Newfoundland (to M.D.B.). 
A. Evolution of Trace Amine-Associated Receptors ............................ 577

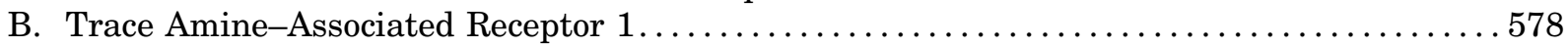

1. Pharmacology of Trace Amine-Associated Receptor $1 \ldots \ldots \ldots \ldots \ldots \ldots \ldots \ldots \ldots 4$

a. Trace Amine-Associated Receptor 1 Gene Conservation.................... 584

b. Expression of Trace Amine-Associated Receptor $1 \ldots \ldots \ldots \ldots \ldots \ldots \ldots \ldots \ldots \ldots 4$

c. Trace Amine-Associated Receptor 1 Ligands........................... 588

i. Development of Selective Agonists and Partial Agonists .................. 589

ii. Development of N-(3-Ethoxyphenyl)-4-(1-Pyrrolidinyl)-3-(Trifluoromethyl)

Benzamide, the First Selective Antagonist........................... 589

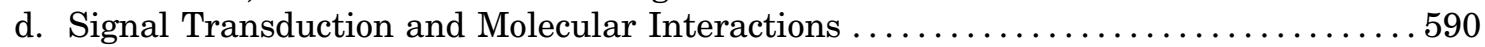

i. Adenylyl Cyclase ......................................... 590

ii. G Protein-Coupled Inwardly Rectifying Potassium Channels ............... 590

iii. Heterodimerization with the D2-Like Dopamine Receptor................. 590

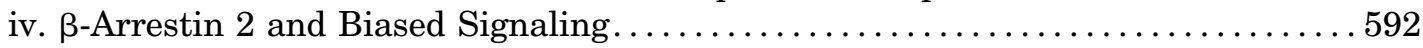

v. Other Signaling Cascades ....................................... 592

2. Central Nervous System Effects . . . . . . . . . . . . . . . . . . . . . . . . . 592

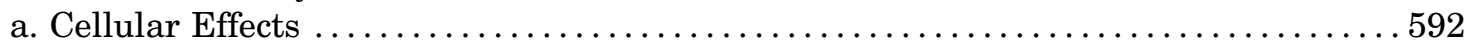

i. Dopaminergic Systems ....................................... 592

ii. Serotonergic Systems .......................................... 594

iii. Glutamatergic Systems . . . . . . . . . . . . . . . . . . . . . . . . . . . . 594

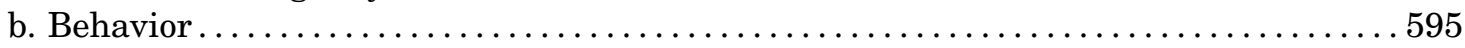

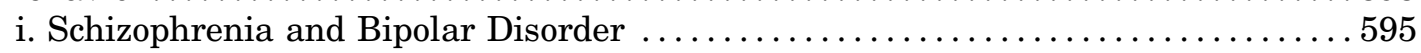

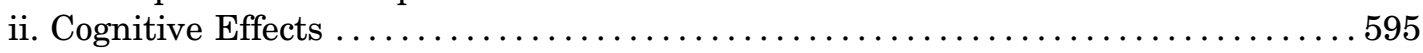

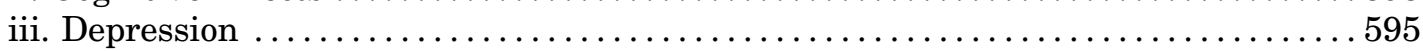

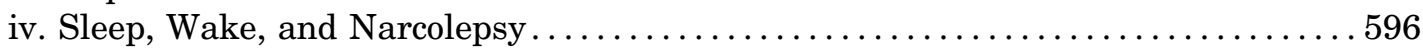

v. Addiction and Compulsive Behaviors ............................... 596

vi. Feeding Behavior ........................................... 597

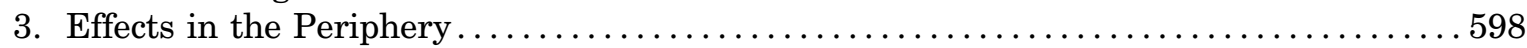

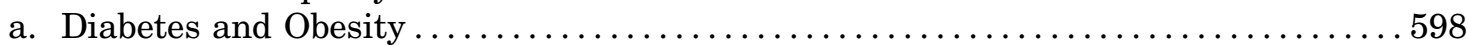

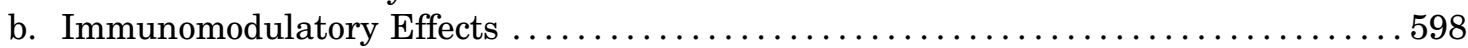

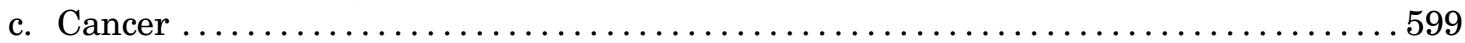

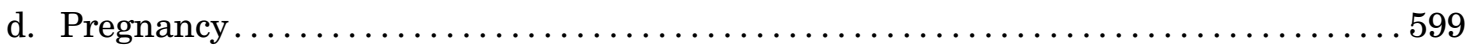

C. Other Tetrapod Trace Amine-Associated Receptors ............................ 599

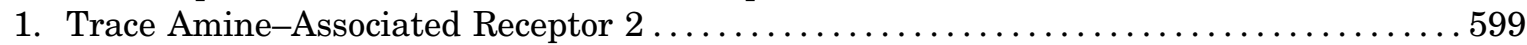

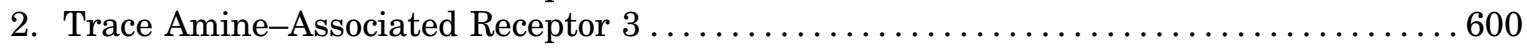

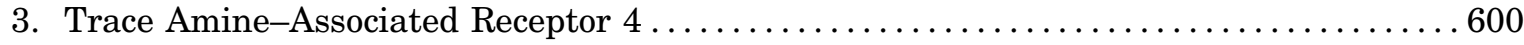

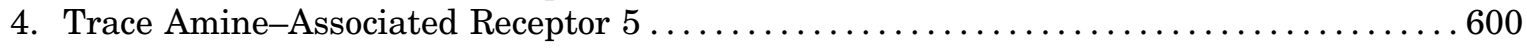

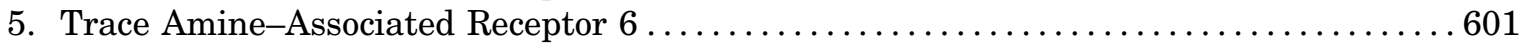

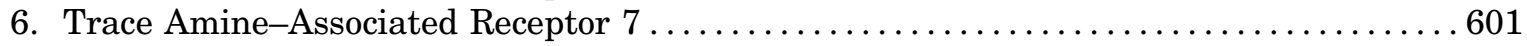

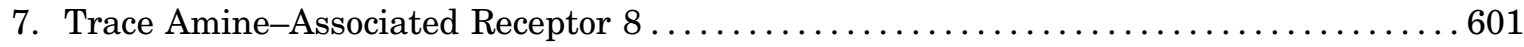

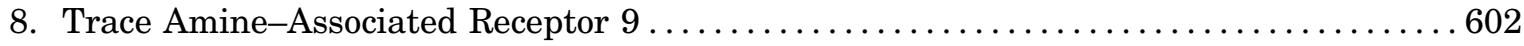

\begin{abstract}
ABBREVIATIONS: 3-MT, 3-methoxytyramine; 3IT, 3-iodothyronamine; 5-HT, 5-hydroxytryptamine; AADC, aromatic L-amino acid decarboxylase; AKT, protein kinase B; AMPA, $\alpha$-amino-3-hydroxy-5-methyl-4-isoxazolepropionic acid; AOC3, amine oxidase, copper containing 3; ASIC, acid-sensing ion channel; COMT, catechol-O-methyltransferase; CPP, conditioned place preference; D1R, $\mathrm{D}_{1}$-like dopamine receptor; D2R, $\mathrm{D}_{2}$-like dopamine receptor; DAT, dopamine transporter; DMT, $N, N$-dimethyltryptamine; DRL, differential reinforcement of low response rate; DRN, dorsal raphe nuclei; EAAT-2, excitatory amino acid transporter 2; EPPTB, $N$-(3-ethoxyphenyl)-4-(1pyrrolidinyl)-3-(trifluoromethyl)benzamide (also known as RO5212773); FMO3, flavin monooxygenase 3; GLP-1, glucagon-like peptide 1; GPCR, G protein-coupled receptor; GSK3 $\beta$, glycogen synthase kinase; HEK-293, human embryonic kidney 293; IUPHAR, International Union of Basic and Clinical Pharmacology; KO, knockout; L-687,414, (3S,4S)-3-amino-1-hydroxy-4-methylpyrrolidin-2-one; MAO, monoamine oxidase; MDMA, 3,4-methylenedioxymethamphetamine; MHC, major histocompatibility complex; NMDA, $N$-methyl-D-aspartate; NREM, nonrapid eye movement; OAMB, octopamine receptor in mushroom bodies; OCT, octopamine; OCT2, organic cation transporter 2; OE, overexpressing; PCP, phencyclidine; PEA, $\beta$-phenylethylamine, 2-phenylethylamine; phMRI, pharmacological magnetic resonance imaging; PKA, protein kinase A; PKC, protein kinase C; PNMT, phenylethanolamine- $N$-methyl transferase; PYY, peptide YY; RO5166017, $(S)$ 4-((ethyl(phenyl)amino)methyl)-4,5-dihydrooxazol-2-amine; RO5203648, (S)-4-(3,4-dichlorophenyl)-4,5-dihydrooxazol-2-amine; RO5256390, (S)-4-((S)-2-phenylbutyl)-4,5-dihydrooxazol-2-ylamine; RO5263397, (S)-4-(3-fluoro-2-methylphenyl)-4,5-dihydrooxazol-2-amine; S18616, (S)spiro[(1-oxa-2-amino-3azacyclopent-2-ene)-4,2' -(8'-chloro-1' $, 2^{\prime}, 3^{\prime}, 4^{\prime}$-tetrahydronaphthalene)]; SKF-82958, 6-chloro-7,8-dihydroxy-3-allyl-1phenyl-2,3,4,5-tetrahydro-1H-3-benzazepine; SSAO, semicarbazide-sensitive amine oxidase; TA, trace amine receptor; TAAR, trace amineassociated receptor; TMAO, trimethylamine- $N$-oxide; TRP, tryptamine; TYR, $p$-tyramine; UGT, uridine diphosphate glucuronosyltransferase; VAP-1, vascular adhesion protein-1; VTA, ventral tegmental area.
\end{abstract}


D. Trace Amine-Associated Receptors in Teleost and Other Fish . . . . . . . . . . . . . . . 602

E. Trace Amine-Associated Receptors in Olfaction ................................ 603

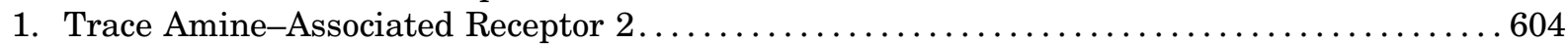

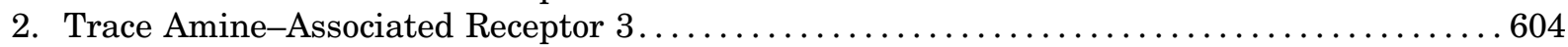

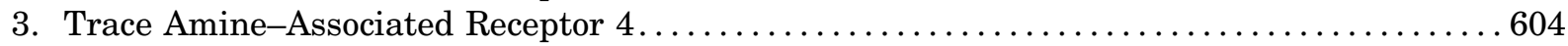

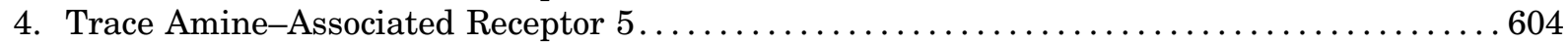

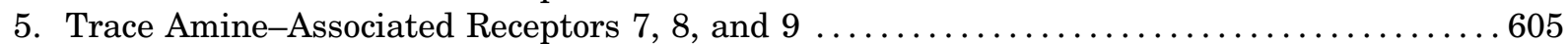

6. Teleost Olfactory Responses. ........................................... 605

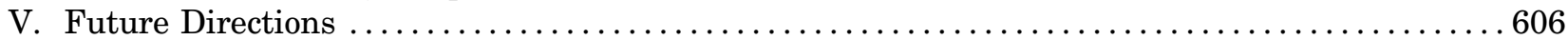

A. Better Understanding of the Physiologic Role(s) of Trace Amine-Associated Receptors

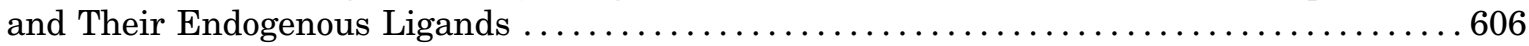

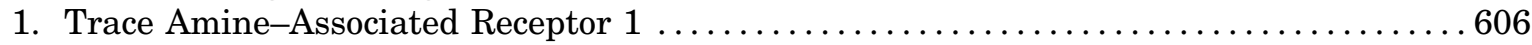

2. Other Trace Amine-Associated Receptors ..............................6 606

B. Development of Selective Trace Amine-Associated Receptor 1 Ligands as Therapeutics ...606

1. Schizophrenia and Bipolar Disorder ................................ 606

2. Addiction and Compulsive Behaviors .................................6 607

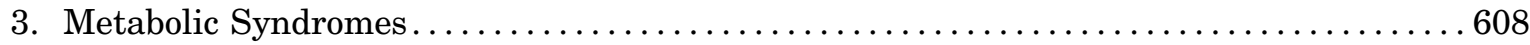

C. Trace Amine-Associated Receptors in Ecology ............................6 608

D. Trace Amine-Associated Receptors, Nutrition, the Microbiome, and Health ............6 609

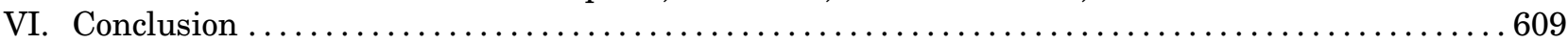

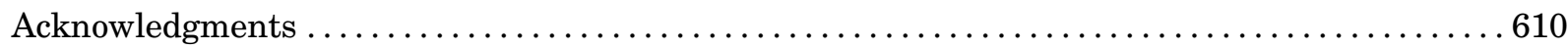

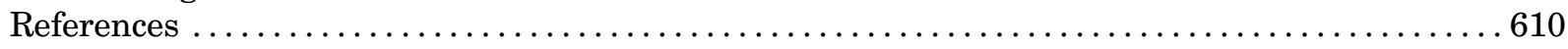

\begin{abstract}
Trace amines are endogenous compounds classically regarded as comprising $\beta$-phenylethyalmine, $p$-tyramine, tryptamine, p-octopamine, and some of their metabolites. They are also abundant in common foodstuffs and can be produced and degraded by the constitutive microbiota. The ability to use trace amines has arisen at least twice during evolution, with distinct receptor families present in invertebrates and vertebrates. The term "trace amine" was coined to reflect the low tissue levels in mammals; however, invertebrates have relatively high levels where they function like mammalian adrenergic systems, involved in "fight-or-flight" responses. Vertebrates express a family of receptors termed trace amine-associated receptors (TAARs). Humans possess six functional isoforms (TAAR1, TAAR2, TAAR5, TAAR6, TAAR8, and TAAR9), whereas some fish species express over 100 . With the exception of TAAR1, TAARs are expressed in
\end{abstract}

\section{Introduction}

Although vertebrate receptors showing a high selectivity for trace amines have been known for approximately 15 years (Borowsky et al., 2001; Bunzow et al., 2001), research and interest in the endogenous compounds now known as trace amines dates back almost 150 years. The term "trace amine" itself appears to have been coined in the early 1970s by Alan Boulton and his colleagues (Boulton, 1974) as a way to distinguish a group of endogenous vertebrate monoamines from their more abundant close structural relatives, the catecholamine and indoleamine neurotransmitters (Fig. 1). The original intent of the term "trace" was to emphasize the low endogenous tissue concentrations present $(<10 \mathrm{ng} / \mathrm{g} ; 100 \mathrm{nM})$, at levels that are at least 100 -fold olfactory epithelium neurons, where they detect diverse ethological signals including predators, spoiled food, migratory cues, and pheromones. Outside the olfactory system, TAAR1 is the most thoroughly studied and has both central and peripheral roles. In the brain, TAAR1 acts as a rheostat of dopaminergic, glutamatergic, and serotonergic neurotransmission and has been identified as a novel therapeutic target for schizophrenia, depression, and addiction. In the periphery, TAAR1 regulates nutrient-induced hormone secretion, suggesting its potential as a novel therapeutic target for diabetes and obesity. TAAR1 may also regulate immune responses by regulating leukocyte differentiation and activation. This article provides a comprehensive review of the current state of knowledge of the evolution, physiologic functions, pharmacology, molecular mechanisms, and therapeutic potential of trace amines and their receptors in vertebrates and invertebrates. below those of the corresponding neurotransmitters (Berry, 2004). With the close structural similarity to the monoamine neurotransmitters a central driving force behind much of the prereceptor research, the term trace amine subsequently became synonymous with just a small group of endogenous monoamines-in particular, $\beta$-phenylethylamine (PEA), $p$-tyramine (TYR), tryptamine (TRP), and $p$-octopamine (OCT), the compounds that have the most obvious similarity to the well established monoamine neurotransmitters (Fig. 1).

The earliest known reports of the presence of a compound with a chemical composition consistent with one of the trace amines (PEA) is from work in the laboratory of Marceli Nencki during the late 1870s (see Grandy, 2007), aimed at better understanding the bacterial processes of putrefaction and fermentation. 
During these studies, PEA was shown to be a product of bacterial decomposition of both gelatin and egg white, due to the anaerobic decarboxylation of L-phenylalanine. PEA was subsequently found to be produced as part of the decomposition processes of various other animal-derived proteins, along with the first reports of its presence in fermented foodstuffs. This ready production of trace amines by microbiota has often been overlooked in more recent years; as described in subsequent sections, however, recent increased interest in the role of host-microbiome interactions and dietary components in health and disease suggests that such production is likely to gather renewed interest.

The initial demonstrations of biologic effects of PEA and TYR are intricately linked to the very origins of the field of pharmacology. The isolation of both PEA and TYR from biologic sources such as rotting horsemeat and ergot-contaminated grains (the original use of the term ergotamine was to describe TYR) led to the pioneering studies of George Barger, George S. Walpole, Sir Henry Hallett Dale, and Alfred J. Clark (Barger and Walpole, 1909; Barger and Dale, 1910; Clark, 1911), demonstrating pronounced blood pressure-elevating effects of the purified extracts. Although interest in the compounds continued and their presence was confirmed in every species in which they were examined (see Berry, 2004), research into the trace amines gradually faded away as interest in the more abundant monoamine species norepinephrine, epinephrine, dopamine and serotonin surged. As the new discipline of pharmacology developed and the chemical basis of neurotransmission became accepted, the following criteria for endogenous compounds to be considered neurotransmitters were developed: 1 ) the presence of the compound and its biosynthetic enzymes limited to the sites at which application of the exogenous chemical (at physiologic concentrations) elicits responses; 2) release of the compound occurs on nerve stimulation with no (or minimal) release in the absence of nerve stimulation; 3) exogenous application of physiologic concentrations mimics the effects of nerve stimulation; and 4) responses to nerve stimulation and exogenous chemical application are affected in the same manner by pharmacological agents. Unfortunately, at least in vertebrate systems, none of the trace amines met most, if any, of these criteria, and the compounds became increasingly viewed as little more than metabolic by-products.

With the growing use of psychotropic drugs in the 1960 s, and amphetamine-based compounds in particular, a resurgence of interest in the trace amines was seen. Although researchers had struggled to demonstrate responses to PEA or TYR at endogenous tissue concentrations, both were well established to have indirect sympathomimetic properties at supraphysiologic concentrations (Fuxe et al., 1967), effects that were shared with the new amphetamine-based drugs of abuse. Furthermore, amphetamine (and its derivatives) has a strong structural similarity to the trace amines, particularly PEA (Fig. 2). As such, PEA and TYR, to a lesser extent, became of interest as potential "endogenous amphetamines" (Borison et al., 1975; Janssen et al., 1999). This also powered an interest in the trace amines as possible biomarkers and etiologic factors for psychiatric disorders, and extensive tabulations of changes in the levels of endogenous trace amines and their metabolites in various body fluids were compiled (Davis, 1989). Although most groups were content to rely on the amphetamine-like, indirect sympathomimetic effects of trace amines as a mechanistic explanation for observed effects, a small number of researchers began a careful examination of the neuropharmacology of more physiologically relevant concentrations. Most notable among this latter group were those affiliated with the Neuropsychiatry Research Unit in Saskatoon, Canada, under the directorship of Alan A. Boulton, and a number of their studies are described in later sections. Although a number of effects were observed, this second phase of studies in vertebrates stalled due to the lack of a selective receptor target through which the observed effects could be mediated. In contrast, TYR and OCT were established as bona fide invertebrate neurotransmitters during the same time period, with selective receptors identified (Morton and Evans, 1984; Roeder and Gewecke, 1989; Han et al., 1998; Consoulas et al., 1999). Thus, by the early $1990 \mathrm{~s}$, trace amine research was essentially restricted to invertebrate systems.

The picture changed again in 2001 when a family of vertebrate $G$ protein-coupled receptors (GPCRs) was identified, a subset of which showed high selectivity for PEA, TYR, and OCT (Borowsky et al., 2001; Bunzow et al., 2001). Interestingly, the receptors were found to be evolutionarily distinct from the invertebrate TYR and OCT receptors (Lindemann et al., 2005), indicating that the ability to detect trace amines has arisen at least twice during evolution. This resurrected interest in the vertebrate trace amine system. As detailed elsewhere (Berry et al., 2017), however, the new family of receptors has posed a number of unique challenges that have slowed progress and dissuaded many from establishing (and funding) dedicated trace amine research programs. A brief history of the discovery of this family of receptors, and their subsequent naming as trace amine-associated receptors (TAARs), is provided in IV. Trace Amine-Associated Receptors. Notwithstanding the difficulties, the last 15 years have seen a number of advances that have identified trace amines and their receptors as novel targets for the pharmacotherapy of various disorders, as well as being novel sites for environmental chemical interactions leading to behavioral ecology effects. Although a number of excellent reviews focusing on individual subareas of trace amine pharmacology, particularly in relation to TAAR1, have been published (Grandy, 2007; Sotnikova et al., 2008; Jing and Li, 2015; Lam et al., 


\section{Traditional Trace Amines}<smiles>NCCc1ccccc1</smiles>

$\beta$-phenylethylamine<smiles>NCC(O)c1ccc(O)cc1</smiles>

p-octopamine<smiles>CNCC(O)c1ccc(O)cc1</smiles><smiles>NCCc1ccc(O)cc1</smiles>

p-tyramine<smiles>NCCc1c[nH]c2ccccc12</smiles>

tryptamine

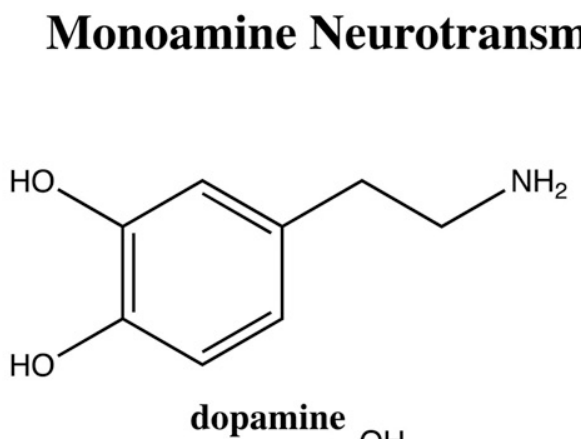<smiles>CNCC(O)c1ccc(O)c(O)c1</smiles>

epinephrine<smiles>NCC(O)c1ccc(O)c(O)c1</smiles><smiles>NCCc1c[nH]c2ccc(O)cc12</smiles>

serotonin

Fig. 1. Relationship of archetypal trace amines to the monoamine neurotransmitters.

2015; Liberles, 2015; Pei et al., 2016; Berry et al., 2017), a comprehensive review of all aspects of trace amine pharmacology is lacking. This article aims to provide such a comprehensive overview of the current state of the knowledge of trace amine systems throughout the body, in both vertebrates and invertebrates. 
Before we begin, however, it is worthwhile to discuss the definition of the term "trace amine." As described above, this term is generally accepted to comprise the group of compounds formed when the tyrosine hydroxylase or tryptophan hydroxylase step of catecholamine and indoleamine neurotransmitter synthesis is omitted. The pharmacological probing of the TAAR family in various species, however, indicates that this is far too narrow a definition. A variety of other endogenous amines that function as selective agonists at one or more TAAR family members are present in body fluids at low levels (Fig. 3) and these compounds are often associated with metabolic routes that are distinct from those of the compounds traditionally called trace amines. Such compounds include the endogenous thyroid hormone metabolite 3-iodothyronamine (3IT) (Scanlan et al., 2004; Dinter et al., 2015c), the catecholamine neurotransmitter metabolites 3-methoxytyramine (3-MT) and normetanephrine (Bunzow et al., 2001; Sotnikova et al., 2010), trimethylamine (Ferrero et al., 2012; Wallrabenstein et al., 2013; Li et al., 2015), isoamylamine (Liberles and Buck, 2006; Ferrero et al., 2012), the polyamines putrescine and cadaverine (Hussain et al., 2013), and possibly agmatine, spermine, and spermidine (Saraiva et al., 2016). In addition, the $N$-methylated metabolites of both PEA and TYR, $N$ methylphenylethylamine and $\mathrm{N}$-methyltyramine, are also TAAR agonists (Lindemann and Hoener, 2005), as is the $N$-methyl metabolite of TRP $N, N$-dimethyltryptamine (DMT); although in this latter instance, this shows a strong species dependence (Simmler et al., 2016). With a receptor family bearing the name trace amine now present, we propose that a formalized working definition of the trace amine term be adopted. The rather broad substrate tuning that the TAAR family exhibits (described in detail in subsequent sections) complicates the development of a clear definition. For example, both dopamine and serotonin show partial agonistic activity at TAAR1 at physiologically relevant concentrations (Lindemann et al., 2005) but would not be regarded as trace amines per se. The situation is further complicated by TAARs only being present in vertebrate systems, whereas invertebrates have receptors that are selectively activated by TYR and OCT but are distinct from TAARs and are much more closely related to vertebrate adrenergic receptors (Roeder, 2005; Lange, 2009). Indeed, as will be discussed below, TYR and OCT are thought to fulfill the
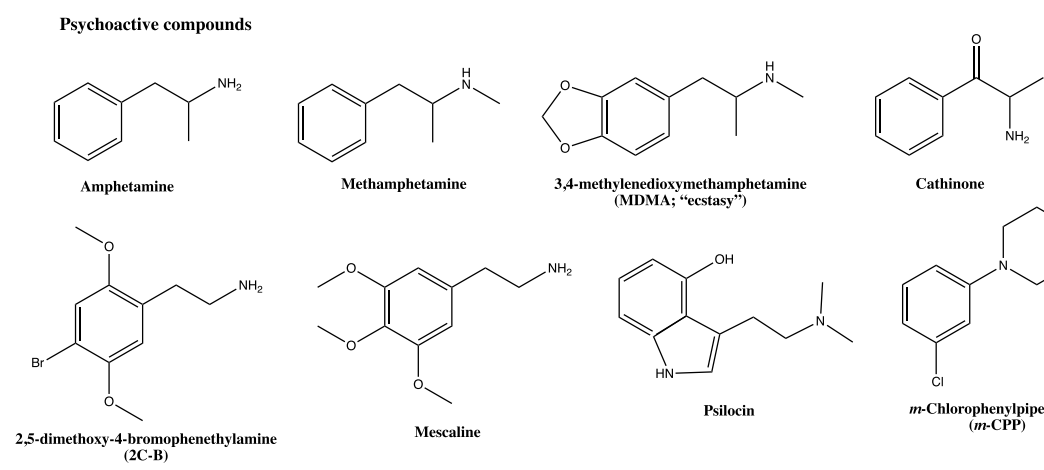

Cathinone<smiles>COc1cc(CCN)cc(OC)c1OC</smiles>
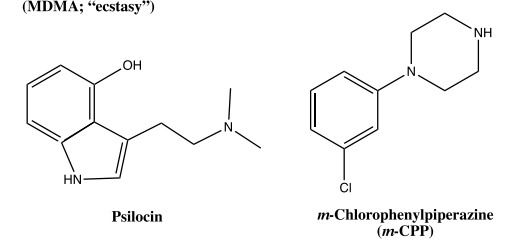

Hoffmann-La Roche compounds

Other compounds<smiles>CN1CCc2cccc3c2C1Cc1ccc(O)c(O)c1-3</smiles><smiles>Clc1cccc(Cl)c1NC1=NCCN1</smiles><smiles>N=C(N)/N=C/c1c(Cl)cccc1Cl</smiles><smiles>c1ccc2c(c1)OCC(C1=NCCN1)O2</smiles>

Guanabenz Idazoxan<smiles>CC(CCc1ccc(O)cc1)NCC(O)c1ccc(O)cc1</smiles>

Ractopamine

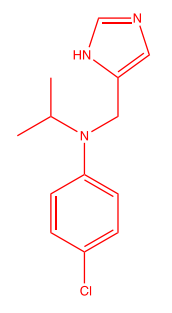

RO5073012

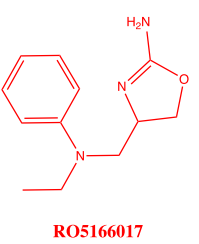

RO5166017
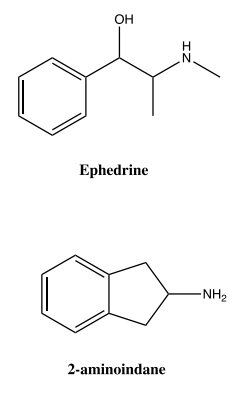

Sunovion compound
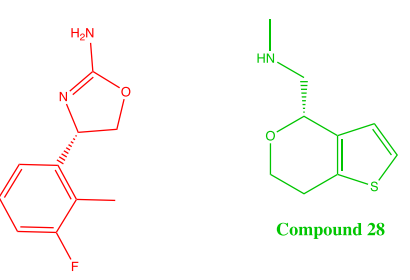

Compound 28

RO5263397
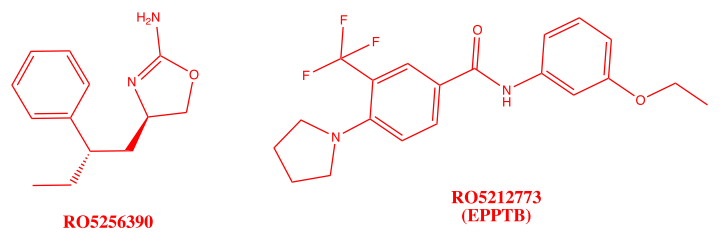

Fig. 2. Structures of synthetic TAAR1 ligands. 
role of adrenergic neurotransmission in invertebrates, a situation that is distinctly different from their roles in vertebrate species. Correspondingly, invertebrate endogenous levels of TYR and OCT are thought to be far greater than is the case for vertebrates (Roeder, 2016). Furthermore, as will be discussed in subsequent sections, some "endogenous" ligands for TAARs may be reliant on the constitutive microbiota for their production. We therefore propose that a working definition of the term trace amine should recognize the evolutionary separation of identical signaling molecules between vertebrates and invertebrates, and it should take account of both the generally low vertebrate tissue levels as well as a selective interaction with one or more TAARs. This is an area in which engagement between the International Union of Basic and Clinical Pharmacology (IUPHAR) nomenclature committee and those active in the trace amine field would be advantageous. For the purposes of this article, and as a starting point for future discussions, we suggest that trace amines be defined as follows: a trace amine is an amine that is endogenously present in vertebrate tissues and/ or bodily fluids at concentrations $<50 \mathrm{ng} / \mathrm{g}$ tissue $(\$ 500$ $\mathrm{nM}$ ) and selectively binds to one or more TAARs at these concentrations.

\section{Vertebrate Trace Amines}

\section{A. $\beta$-Phenylethylamine, $p$-Tyramine, and Related Compounds}

1. Synthesis. The archetypal trace amines are synthesized after initial decarboxylation of precursor amino acids (Fig. 4). This pathway is directly analogous to the synthesis of the monoamine neurotransmitters, with the trace amines being the end product if the tyrosine hydroxylase (EC 1.14.16.2) or tryptophan hydroxylase (EC 1.14.16.4) steps of neurotransmitter synthesis are omitted. As such, PEA, TYR, and TRP can be formed directly by the action of aromatic L-amino acid decarboxylase (AADC; EC 4.1.1.28) on L-phenylalanine, L-tyrosine, and L-tryptophan, respectively (Boulton and Wu, 1972, 1973; Saavedra, 1974; Snodgrass and Iversen, 1974; Silkaitis and Mosnaim, 1976; Dyck et al., 1983). Both $m$ - and $o$-isoforms of tyramine have also been identified but have rarely been studied, and they are present in even smaller quantities than the $p$-isoforms (Boulton, 1976; Davis, 1989). OCT and $p$-synephrine can subsequently be formed by the sequential action of dopamine- $\beta$-hydroxylase (EC 1.14.17.1) (Boulton and $\mathrm{Wu}, 1972,1973$ ) and phenylethanolamine- $N$-methyl transferase (PNMT; EC 2.1.1.28). The trace amines can also undergo $N$-methylation by action of the enzymes PNMT or indolethylamine $N$-methyltransferase (EC 2.1.1.49) to generate additional TAAR ligands, $N$-methylphenylethylamine, $\mathrm{N}$-methyltyramine, $\mathrm{N}$-methyltryptamine, and, at least in some species, DMT (Fig. 4).
The similarity to monoamine neurotransmitter synthesis has often led to the synthesis of trace amines being reported as neuronal. However, it should be borne in mind that $\mathrm{AADC}$ expression is not restricted to neuronal cells. AADC is present in a number of other cell types, including glia (Li et al., 1992b; Juorio et al., 1993), blood vessels ( $\mathrm{Li}$ et al., 2014), and cells of the gastrointestinal tract (Lauweryns and Van Ranst, 1988; Vieira-Coelho and Soares-da-Silva, 1993), kidney (Christenson et al., 1970; Lancaster and Sourkes, 1972; Aperia et al., 1990; Hayashi et al., 1990), liver (Bouchard and Roberge, 1979; Ando-Yamamoto et al., 1987; Dominici et al., 1987), lungs (Lauweryns and Van Ranst, 1988; Linnoila et al., 1993), pancreas (Lindström and Sehlin, 1983; Furuzawa et al., 1994; Rorsman et al., 1995), and stomach (Lichtenberger et al., 1982). In such cells, it can reasonably be expected that AADC will convert any precursor amino acids present into the corresponding trace amine(s). The physiologic function of AADC in non-neuronal tissue is generally poorly understood but it does provide a mechanism for the local production of ligands for TAARs that are localized to non-neuronal tissue, and investigation of possible colocalization of AADC with TAARs is an area for future studies. Furthermore, a distinct group of neurons that contain $\mathrm{AADC}$, but not tyrosine hydroxylase or serotonin, are present in the mammalian central nervous system (Jaeger et al., 1983, 1984; Fetissov et al., 2009; Kitahama et al., 2009). These D-neurons offer a potential trace aminergic neuronal system.

Although AADC is widely accepted as the vertebrate synthetic enzyme for PEA, TYR, and TRP, the precursor amino acids are in fact rather poor substrates for AADC. Indeed, the $K_{\mathrm{m}}$ values for decarboxylation of L-phenylalanine, L-tyrosine, and L-tryptophan approach the limits of solubility of each in aqueous media (Christenson et al., 1970; Juorio and Yu, 1985a). Although this is markedly, and selectively, improved both in vitro and in vivo by the presence of organic solvents (Lovenberg et al., 1962; Juorio and Yu, 1985a,b), this does raise questions about how PEA, TYR, and TRP are being synthesized in vivo. Substrate-selective regulation of AADC has been reported (Bender and Coulson, 1972; Sims and Bloom, 1973; Sims et al., 1973; Rahman et al., 1981; Siow and Dakshinamurti, 1985), along with a number of splice variants of the enzyme (O'Malley et al., 1995; Rorsman et al., 1995; Chang et al., 1996; Vassilacopoulou et al., 2004). Whether one or more of these exhibits enhanced selectivity for the production of PEA, TYR, and/or TRP requires systematic investigation. Furthermore, L-phenylalanine, L-tyrosine, and Ltryptophan are all also substrates for additional amino acid decarboxylase enzymes (Table 1), although the role of these putative additional sources of PEA, TYR, and TRP synthesis has not yet been investigated.

a. Regulation of Aromatic L-Amino Acid Decarboxylase. As described above, $\mathrm{AADC}$ is found in both neuronal and non-neuronal cells and alternative splicing of exons 


\section{New Trace Amines}<smiles>NCCc1ccc(Oc2ccc(O)cc2)c(I)c1</smiles>

3-iodothyronamine<smiles>CNCCc1ccc(O)cc1</smiles>

$N$-methyltyramine<smiles>CNCCc1c[nH]c2ccccc12</smiles>

$N$-methyltryptamine<smiles>COc1cc(CCN)ccc1O</smiles>

3-methoxytyramine<smiles>CNCCc1ccccc1</smiles>

$\mathrm{N}$-methylphenylethylamine<smiles>CN(C)CCc1c[nH]c2ccccc12</smiles>

$\mathrm{N}, \mathrm{N}$-dimethyltryptamine<smiles>COc1cc(C(O)CN)ccc1O</smiles>

normetanephrine<smiles>CNCC(O)c1ccc(O)c(OC)c1</smiles>

metanephrine<smiles>CN(C)C</smiles>

Trimethylamine<smiles>CC(C)CCN</smiles>

Isoamylamine<smiles>N=C(N)N=CCCCN</smiles>

Agmatine<smiles>NCCCCN</smiles>

Putrescine<smiles>NCCCCCN</smiles>

Cadaverine<smiles>NCCCCNCCCN</smiles><smiles>NCCCI</smiles><smiles>CCCN</smiles>

\section{Spermine}

Fig. 3. Structures of new members of the trace amine family. Based on demonstrated high-affinity binding to individual TAARs and low endogenous concentrations, the compounds shown are proposed as new members for inclusion in the trace amine family. 
PRECURSORS

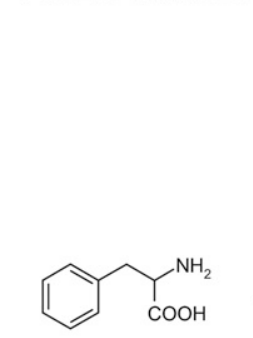

L-Phenylalanine<smiles>CCCCC</smiles><smiles>NC(Cc1ccc(O)cc1)C(=O)O</smiles>

L-Tyrosine<smiles>NC(Cc1ccc(O)c(O)c1)C(=O)O</smiles><smiles>CCCCCC(C)(C)C</smiles><smiles>NCCc1ccc(O)c(O)c1</smiles>

Dopamine<smiles>N[C@H](CC(=O)O)Cc1cn([PbH])c2ccccc12</smiles>

$\stackrel{\text { AADC }}{\longrightarrow}$<smiles>C1C[13CH]1</smiles>

$\stackrel{\text { COMT }}{\longrightarrow}$

\section{TRACE AMINES}

Primary Amines Secondary Amines<smiles>CNCCc1ccccc1</smiles>

N-Methylphenylethylamine

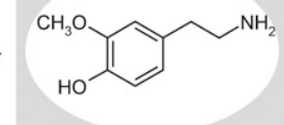

3-Methoxytyramine
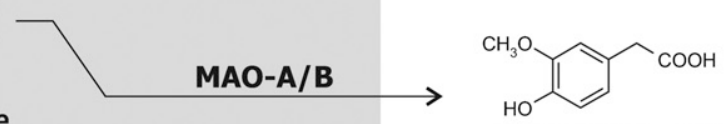

Homovanillic acid

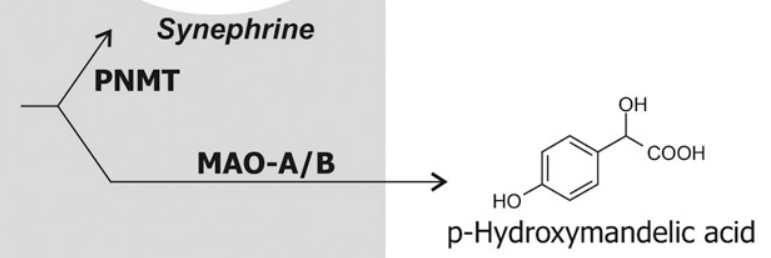

p-Hydroxymandelic acid
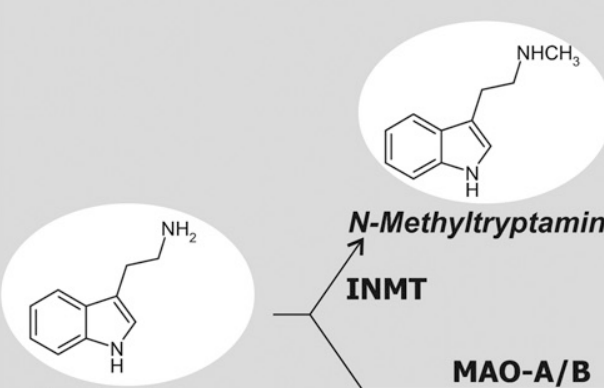

Tryptamine

MAO-A/B
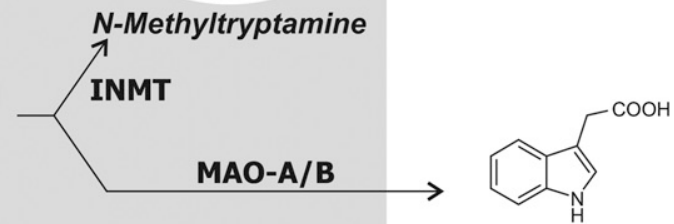

Indoleacetic acid

Fig. 4. Endogenous synthetic and metabolic routes for trace amines. DBH, dopamine- $\beta$-hydroxylase; INMT, indolethylamine $N$-methyltransferase; $\mathrm{PAH}$, phenylalanine hydroxylase; TH, tyrosine hydroxylase. 
1 and 2 within the $5^{\prime}$-untranslated region has been established as allowing for distinct control of neuronal and non-neuronal expression (Albert et al., 1992; Ichinose et al., 1992; Hahn et al., 1993; Sumi-Ichinose et al., 1995). A variety of transcription factor binding sites have been identified within both the neuronal (Chireux et al., 1994; Aguanno et al., 1995) and non-neuronal (Aguanno et al., 1996) promoter regions through which tissue-selective expression could occur. A variant on this alternative splicing, in which the non-neuronal variant was spliced to the neuronal acceptor site, has also been suggested in G cells of the rat stomach antrum (Djali et al., 1998), which may indicate cell type-selective plasticity in the control of AADC expression. Recently, a number of cis-acting polymorphisms of AADC have been identified with putative clinical relevance ( $\mathrm{Li}$ and Meltzer, 2014; Eisenberg et al., 2016), and disease-associated AADC coding variants are also known (Graziano et al., 2015; Kojima et al., 2016; Montioli et al., 2016).

The functional significance of alternative splicing within the coding region of AADC is poorly defined. A splice variant lacking exon 3 has been reported to be widely expressed in both neuronal and non-neuronal tissue (O’Malley et al., 1995; Chang et al., 1996), with this shorter variant suggested to be devoid of both L-DOPA and L-5-hydroxytryptophan decarboxylating activities (O'Malley et al., 1995). An even shorter variant, lacking exons 11-15, has also been reported to be expressed in non-neuronal tissues (Vassilacopoulou et al., 2004), although enzyme activity of this variant was not examined. Additional coding splice variants were also reported to be present in pancreatic $\beta$ cells (Rorsman et al., 1995), although again the functionality of these putative alternative forms does not appear to have been further investigated. Whether activity toward substrates other than L-DOPA and L-5-hydroxytryptophan is lost, or even enhanced, is unknown, but the apparent widespread expression of an ostensibly nonfunctional variant seems unlikely, and a role of one or more splice variants in selective trace amine synthesis could provide an answer to this paradox.

Although it is not a rate-limiting step in the synthesis of catecholamine and indoleamine neurotransmitters under physiologic conditions, AADC activity is regulated in a biphasic manner. Both early changes, consistent with alterations in phosphorylation status, and delayed, longer-lasting changes in enzyme expression have been reported (Buckland et al., 1992, 1996, 1997; Hadjiconstantinou et al., 1993; Berry et al., 1996). Multiple consensus phosphorylation sites for protein kinase A (PKA) (Young et al., 1993; Duchemin et al., 2000), protein kinase C (PKC) (Young et al., 1994; Zhu et al., 1994), protein kinase G (Duchemin et al., 2010), calmodulin-dependent kinase II (Hadjiconstantinou et al., 2010), and proline-directed kinase (Hadjiconstantinou et al., 2010) are present, and both site-directed mutagenesis of individual phosphorylation sites (Hadjiconstantinou et al., 2010) or selective activation/inhibition of individual protein kinases (Young et al., 1993, 1994; Zhu et al., 1994; Duchemin et al., 2000, 2010) alters AADC activity. Direct evidence for phosphorylation of AADC by PKA (Duchemin et al., 2000) and protein kinase G (Duchemin et al., 2010) has been provided, although PKC does not appear to directly increase phosphorylation despite the presence of consensus recognition sites (Duchemin et al., 2000).

In the retina, $\mathrm{AADC}$ activity is increased in response to light (Hadjiconstantinou et al., 1988) or selective antagonism of $\alpha_{2}$-adrenergic receptors (Rossetti et al., 1989) or $\mathrm{D}_{1}$-like dopamine receptors (D1Rs) (Rossetti et al., 1990). Consistent with this, light stress was recently reported to increase retinal PEA levels (de la Barca et al., 2017). In contrast, D1R agonists decrease both basal and lightinduced AADC activity (Rossetti et al., 1990). Similar responses to dopamine receptor ligands have also been observed in various rodent brain regions (Zhu et al., 1992, 1993, 1994; Hadjiconstantinou et al., 1993; Cho et al., 1997, 1999; Neff et al., 2006). Regulation of AADC by serotonergic receptors (Neff et al., 2006) and $N$ methyl-D-aspartate (NMDA) glutamatergic receptors (Hadjiconstantinou et al., 1995; Fisher et al., 1998) has also been reported. There is also some evidence for AADC regulation associated with systemic lupus erythematosus (Bengtsson et al., 2016), Parkinson' disease (Gjedde et al., 1993), and schizophrenia (Reith et al., 1994). In experimental animals, regulation of AADC after spinal cord injury has also been reported (Li et al., 2014; Wienecke et al., 2014; Azam et al., 2015).

In each of the above cases, the reported changes in AADC activity are normally rather modest (approximately 30\%) and insufficient to change endogenous dopamine levels (Berry et al., 1994; Cho et al., 1999). Such treatments have, however, been shown to change both PEA and TYR levels (Juorio, 1979; Juorio et al., 1991; Berry, 2004) and can generally be summarized as follows: treatments that increase monoamine neurotransmitter receptor activation decrease PEA/TYR synthesis, whereas treatments that decrease receptor activation increase PEA/TYR synthesis. In this respect, it is important to note that reports of changes in AADC activity have almost exclusively used only L-DOPA as a substrate. Whether greater changes in the activity of AADC toward other substrates (particularly L-phenylalanine, L-tyrosine, and/or L-tryptophan) occurs is unknown, although as described above there is evidence that substrate-dependent regulation of AADC is possible (Rahman et al., 1981; Juorio and Yu, 1985a,b; Siow and Dakshinamurti, 1985). Kinetic studies have reported alterations in AADC $V_{\max }$ in response to pharmacological agents (Zhu et al., 1992; Young et al., 1994; Duchemin et al., 2010) and both $V_{\max }$ and $K_{\mathrm{m}}$ in response to site-directed mutagenesis of consensus phosphorylation sites (Hadjiconstantinou et al., 2010). 
TABLE 1

Decarboxylated products of common amino acids, their known TAAR ligand status, and putative physiologic effects

Putative enzymes were obtained from the Brenda-enzymes.org database. Only those known or predicted to be present in eukaryotes are shown. See the text for citations, with the exception of entries with footnotes.

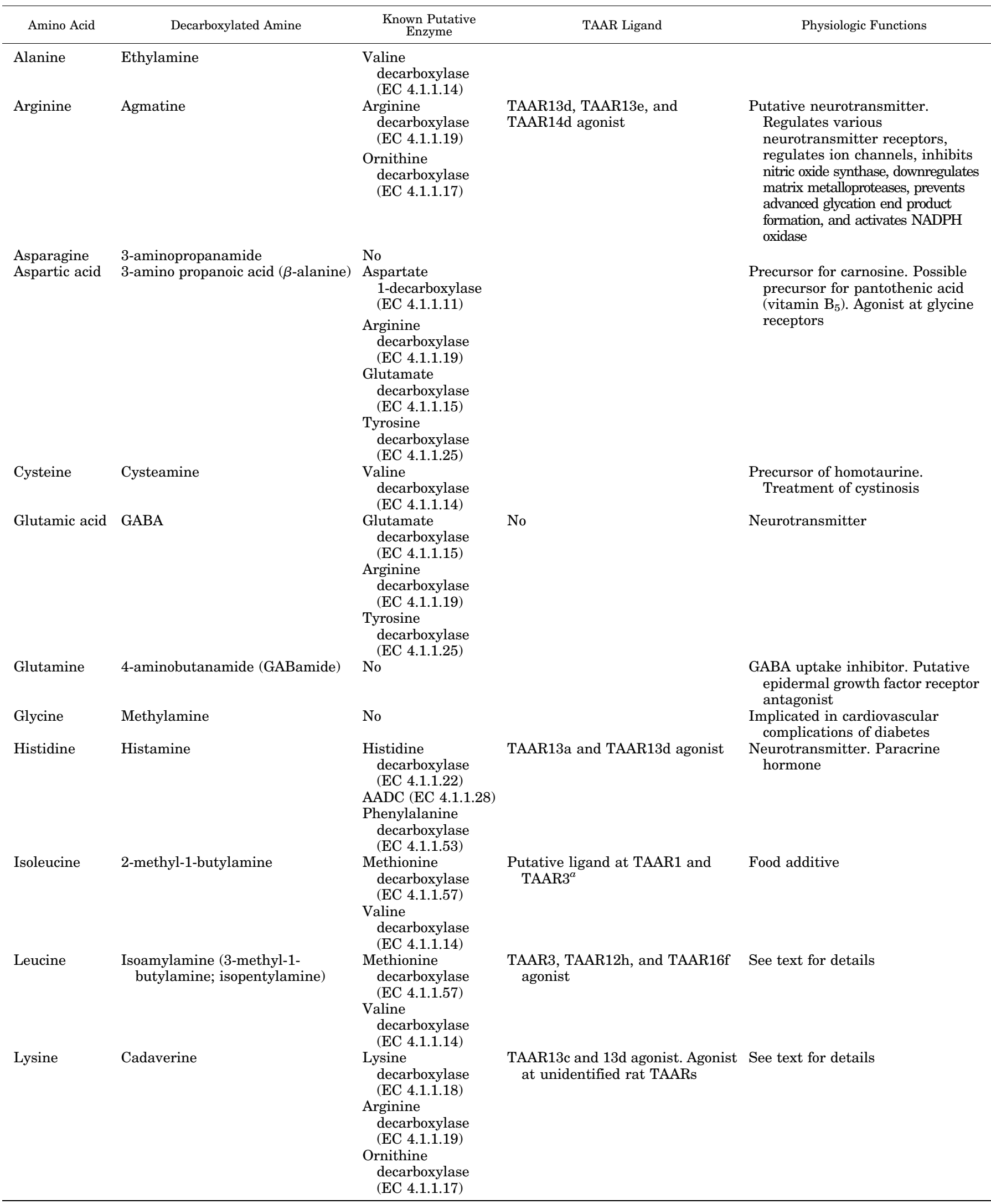


TABLE 1-Continued

\begin{tabular}{|c|c|c|c|c|}
\hline Amino Acid & Decarboxylated Amine & $\begin{array}{l}\text { Known Putative } \\
\text { Enzyme }\end{array}$ & TAAR Ligand & Physiologic Functions \\
\hline Methionine & 3-methylthiopropylamine & $\begin{array}{l}\text { Methionine } \\
\text { decarboxylase } \\
\text { (EC 4.1.1.57) } \\
\text { Valine } \\
\text { decarboxylase } \\
\text { (EC 4.1.1.14) }\end{array}$ & & $\begin{array}{l}\text { Interacts with enzymes in } \\
\text { polyamine metabolism }\end{array}$ \\
\hline Ornithine & Putrescine & $\begin{array}{l}\text { Ornithine } \\
\text { decarboxylase } \\
\text { (EC 4.1.1.17) } \\
\text { Lysine } \\
\text { decarboxylase } \\
\text { (EC 4.1.1.18) } \\
\text { Arginine } \\
\text { decarboxylase } \\
\text { (EC 4.1.1.19) }\end{array}$ & TAAR13d agonist & Spermine/spermidine precursor \\
\hline Phenylalanine & PEA & $\begin{array}{l}\text { AADC } \\
\text { (EC 4.1.1.28) } \\
\text { Phenylalanine } \\
\text { decarboxylase } \\
\text { (EC 4.1.1.53) } \\
\text { Tyrosine } \\
\text { decarboxylase } \\
\text { (EC 4.1.1.25) } \\
\text { Valine } \\
\text { decarboxylase } \\
\text { (EC 4.1.1.14) } \\
\text { Arginine } \\
\text { decarboxylase } \\
\text { (EC 4.1.1.19) }\end{array}$ & $\begin{array}{l}\text { TAAR1, TAAR4, and TAAR } 12 \mathrm{~h} \\
\text { agonist }\end{array}$ & See text for details \\
\hline Proline & Pyrrolidine & $\begin{array}{l}\text { Arginine } \\
\text { decarboxylase } \\
\text { (EC 4.1.1.19) }\end{array}$ & & Fish attractant $^{b}$ \\
\hline Serine & Ethanolamine & $\begin{array}{l}\text { Arginine } \\
\text { decarboxylase } \\
\text { (EC 4.1.1.19) }\end{array}$ & & $\begin{array}{l}\text { Membrane phospholipid head } \\
\text { group. Sclerosing agent }\end{array}$ \\
\hline Threonine & $\begin{array}{l}\text { 1-aminopropan-2-ol } \\
\text { (isopropanolamine) }\end{array}$ & No & & Present in saliva ${ }^{c}$ \\
\hline Tryptophan & TRP & $\begin{array}{l}\text { AADC (EC 4.1.1.28) } \\
\text { Phenylalanine } \\
\text { decarboxylase } \\
\text { (EC 4.1.1.53) }\end{array}$ & TAAR1 and TAAR10b agonist & See text for details \\
\hline Tyrosine & TYR & $\begin{array}{l}\text { AADC (EC 4.1.1.28) } \\
\text { Tyrosine } \\
\text { decarboxylase } \\
\text { (EC 4.1.1.25) } \\
\text { Phenylalanine } \\
\text { decarboxylase } \\
\text { (EC 4.1.1.53) }\end{array}$ & TAAR1 and TAAR4 agonist & See text for details \\
\hline Valine & $\begin{array}{l}\text { Isobutylamine } \\
\text { (2-methyl-1-propylamine) }\end{array}$ & $\begin{array}{l}\text { Valine } \\
\text { decarboxylase } \\
\text { (EC 4.1.1.14) } \\
\text { Methionine } \\
\text { decarboxylase } \\
\text { (EC 4.1.1.57) }\end{array}$ & & $\begin{array}{l}\text { Found in various foodstuffs. } \\
\text { Activates olfactory/vomeronasal } \\
\text { organ. Putative puberty- } \\
\text { accelerating pheromone }\end{array}$ \\
\hline
\end{tabular}

${ }^{a}$ Lindemann and Hoener (2008).

${ }^{b}$ Harada (1985).

${ }^{c}$ Sugimoto et al. (2013).

b. Other Sources of $\beta$-Phenylethylamine, p-Tyramine, and Related Compounds.

$i$. Microbiota-Derived Trace Amines. There is a growing recognition of the role of the commensal microbiota in health and disease, including neurologic and psychiatric disorders (Dinan and Cryan, 2015; Fung et al., 2017), cancer and its chemotherapy (Alexander et al., 2017; Roy and Trinchieri, 2017), metabolic disorders (Sonnenburg and Bäckhed, 2016; Brunkwall and Orho-Melander, 2017), and immune disorders (Honda and Littman, 2016; Thaiss et al., 2016; Fung et al., 2017; Luo et al., 2017). Prokaryotes contain a large array of decarboxylase enzymes, many of which include L-amino acids in their substrate profile (Zheng et al., 2011; Nelson et al., 2015). Indeed, the production of PEA, TYR, and TRP by commensal prokaryotes has been established (Marcobal et al., 2006; Irsfeld et al., 2013; Williams et al., 2014; Yang et al., 2015a), and bacterial production of these compounds was the original basis of Nencki's studies on putrefaction and fermentation (see Grandy, 2007). With TAARs established to be present throughout the body, it is expected that the role of trace amines and their receptors in mediating host-microbiota interactions will become a growing area of interest. 
ii. Food-Derived Trace Amines. PEA, TYR, and TRP, as well as other endogenous trace amines, have long been recognized as being abundant in commonly ingested foods (Coutts et al., 1986). Although this presence is often viewed from the perspective of bacterial-induced food spoilage (Naila et al., 2010), foods in which anaerobic fermentation is part of their production are enriched in trace amines (Toro-Funes et al., 2015; Gardini et al., 2016; Pessione and Cirrincione, 2016). Aged cheeses, fermented meats, red wine, soy products, and chocolate are well established as being enriched in one or more of PEA, TYR, and TRP (Coutts et al., 1986).

Another rich source of food-derived trace amines is seafood, from molluscs and crustaceans to fish, where high concentrations of agmatine, cadaverine, OCT, PEA, putrescine, spermidine, spermine, TRP, and TYR are found (An et al., 2015; Biji et al., 2016). In fact, the name octopamine originates from octopus from where it was first isolated (Erspamer, 1952). Although under normal conditions the concentrations of foodderived trace amines in the body are unlikely to reach sufficient levels to activate TAARs other than those expressed in the stomach (e.g., TAAR1 and TAAR9; Ohta et al., 2017) and certainly do not exert indirect sympathomimetic actions, there are conditions in which this may occur. Individuals who adversely react to trace amine-rich nutrients such as seafood, cheese, and wine are known (Finberg and Gillman, 2011; Biji et al., 2016), although the molecular basis of the sensitivities are not established in all cases. Genetic deficiency in monoamine oxidases (MAO)-A/B, which are key trace aminemetabolizing enzymes, are known to significantly increase urinary trace amine concentrations and pressor responses to TYR (Lenders et al., 1996). Furthermore, the well known "cheese effect" in patients treated with MAO-A inhibitors is explained by pronounced accumulation of TYR, sufficient to indirectly elevate blood norepinephrine concentrations to the point of inducing hypertensive crisis, severe migraine, and even death (Finberg and Gillman, 2011). With the growing acceptance of TAARs by the wider scientific community, the role of nutrient-derived TAAR ligands in health and disease is likely to become a growing area of nutritional biochemistry and food science interest and to overlap with studies of the molecular basis of host-microbiota interactions. Indeed, the possibility that food-derived trace amines can activate host TAARs has now begun to be recognized (Ohta et al., 2017).

A variety of herbal extracts and brews that are (or have been) used in various cultures as medicines, for religious ceremonies, or for their psychotropic effects are also reported to either contain high levels of trace amines or to alter their concentrations within the body, with such changes implicated in the subsequent physiologic responses. For example, $N$-methyltyramine has been identified in Ginkgo biloba preparations (Könczöl et al., 2016). Various trace amine compounds have also been suggested to be present in Chinese herbal medicines (Zhang et al., 2016) and in a variety of religious herbal brews (Leonti and Casu, 2014), including ayahuasca where DMT is thought to be one of the major active constituents (Riba et al., 2003).

2. Degradation. Catabolism occurs primarily via MAO (EC 1.4.3.4), with PEA being a highly selective substrate for MAO-B (Yang and Neff, 1973). Little selectivity is shown toward either MAO-A or MAO-B by other compounds (Philips and Boulton, 1979; Durden and Philips, 1980). All compounds have also been reported to be substrates for the enzyme variously known as semicarbazide-sensitive amine oxidase (SSAO; EC 1.4.3.21, formerly EC 1.4.3.6), vascular adhesion protein-1 (VAP-1), or amine oxidase, copper containing 3 (AOC3) (Elliott et al., 1989). Catabolism via cytochrome $\mathrm{P} 450$ isozymes has also been reported (Niwa et al., 2011), but this is thought to be a very minor route under physiologic conditions (Yu et al., 2003). Interconversion of the trace amines readily occurs (Fig. 4), including via methylation of the primary amine (Lindemann and Hoener, 2005) generating both $N$-methyl and $N, N$ dimethyl derivatives, presumably via indolethylamine $N$-methyltransferase for TRP and via PNMT for PEA, TYR, and OCT (Fig. 4). Some of these metabolites act on one or more TAARs in their own right, although this is species dependent with some such as DMT (Simmler et al., 2016). PEA can also be acted on directly by dopamine- $\beta$-hydroxylase generating phenylethanolamine (Saavedra and Axelrod, 1973; Danielson et al., 1977), which also has been reported to be a full, albeit weak, agonist at human TAAR1 (Wainscott et al., 2007). Interconversion with the catecholamine and indoleamine neurotransmitters (e.g., TYR conversion to dopamine) was originally not thought to occur (Dyck et al., 1983), although this may be an outcome of the limited cytochrome P450-mediated metabolism at least in some species (Hiroi, 1998; Bromek, 2010).

3. Storage and Passage across Membranes. Unlike their neurotransmitter structural analogs, PEA, TYR, and TRP do not appear to be stored. All three readily diffuse across synthetic lipid bilayers in the absence of transporters, with diffusion half-lives of 15 seconds or less (Berry et al., 2013). Consistent with this, PEA passage across the blood-brain barrier occurs by a mechanism consistent with passive diffusion (Mosnaim et al., 2013), whereas TYR passage across intestinal epithelial cells also appears to be diffusion mediated (Tchercansky et al., 1994). Release of PEA from the whole brain (Henry et al., 1988), striatal slices (Dyck, 1989), or synaptosomes (Berry et al., 2013) is not increased by $\mathrm{K}^{+}$-induced depolarization. Similar results were also obtained with TYR (Henry et al., 1988; Berry et al., 2013), with only a small increase in release in response to $\mathrm{K}^{+}$-induced depolarization observed in brain slices (Dyck, 1989). Likewise, no effect of depolarization on TRP release from striatal slices was 
present (Dyck, 1989). The lack of effect of $\mathrm{K}^{+}$-induced depolarization strongly suggests that these compounds are neither stored in synaptic vesicles nor released by exocytosis, presumably indicating "release" by simple diffusion across the membrane, consistent with previous reports of a lack of reserpine-sensitive vesicular storage (Juorio et al., 1988). In contrast, veratridine-induced depolarization does increase the release of TYR from striatal slices (Dyck, 1989), although whether similar effects occur with PEA and/or TRP was not studied. Whether this represents a subset of synaptic vesicles that TYR (and possibly other trace amines) can access requires further investigation. Consistent with a lack of vesicular storage, however, the half-life of the endogenous pool of PEA and TRP has been estimated to be less than 30 seconds (Durden and Philips, 1980). OCT has also been reported to have a markedly higher turnover rate than either norepinephrine or dopamine (Molinoff and Axelrod, 1972).

As recently discussed, the above-noted lack of effect of depolarization on PEA, TRP, and, to a less clear extent, TYR release from neuronal preparations is difficult to explain thermodynamically (Berry et al., 2016). Even if "release" is by diffusion, membrane depolarization should increase this due to the subsequent increase in the electrochemical gradient. The lack of such an effect may indicate the presence of a membrane transporter regulating the synaptic levels of PEA, TYR, and TRP. Consistent with such a conclusion, PEA transport into rabbit erythrocytes was previously reported to involve an unknown transporter (Blakeley and Nicol, 1978), as was transport across Caco-2 cells (Fischer et al., 2010). Through the use of pharmacological probes, organic cation transporter 2 (OCT2; Slc22A2) was recently identified as a likely transporter of TYR in rat brain synaptosomes, exhibiting a $K_{\mathrm{t}}$ approximately equal to $100 \mathrm{nM}$ (Berry et al., 2016), in reasonable agreement with estimates of endogenous TYR concentrations (Berry, 2004). OCT2 is widely regarded as a polyspecific transporter (Couroussé and Gautron, 2015) that interacts with a wide variety of therapeutics (Kido et al., 2011; Hacker et al., 2015), not dissimilar to the broad substrate tuning reported for TAAR1 (see IV.B.1.c. Trace Amine-Associated Receptor 1 Ligands). Should a role for OCT2 in regulating trace amine membrane passage at physiologically relevant concentrations be validated, this would implicate the trace amine/TAAR system as a new molecular target to be considered with respect to adverse drug interactions for therapeutics that interact with the OCT2 transporter.

In combination, the above studies suggest that the archetypal trace amines readily cross cell membranes by diffusion but that their levels are further regulated by one or more transporters. The current understanding of the synthesis, metabolism, and transport of PEA and TYR in neurons is summarized in Fig. 5.

4. Cellular Effects. Effects that are clearly demonstrated to be due to interaction with one or more TAARs are described in detail in subsequent sections dedicated to the individual TAAR subtypes. A number of cellular responses were described prior to the identification of TAARs, however, and these are summarized in the following paragraphs. Whether these effects are due to an interaction with TAARs is often unknown, although in many cases responses are strikingly similar to current thoughts on the physiologic function of TAARs.

a. Indirect Sympathomimetic Responses. The TAAR1 ligands PEA and TYR in particular have long been known to possess indirect sympathomimetic, amphetamine-like effects (Fuxe et al., 1967; Baker et al., 1976; Raiteri et al., 1977; Parker and Cubeddu, 1988). Such effects, which involve inhibition of reuptake processes and the displacement of monoamine neurotransmitters from their stores, generally require PEA/TYR concentrations of at least $10 \mu \mathrm{M}$ (Baker et al., 1976; Raiteri et al., 1977), which is thought to be at least 100-fold in excess of physiologic concentrations (see Berry, 2004). Amphetamine-like behavioral stereotypy is also induced by high-dose ( $>25 \mathrm{mg} /$ kg) PEA/TYR administration (Dourish, 1982; Stoff et al., 1984). Although they are less studied, similar indirect sympathomimetic responses to OCT have also been reported (Raiteri et al., 1977; Parker and Cubeddu, 1988). As previously described, such results led to suggestions that trace amines, and PEA in particular, serve the role of an endogenous amphetamine (Borison et al., 1975; Janssen et al., 1999). The initial pharmacological characterization of TAARs provided a further twist to this hypothesis, with various amphetaminederived compounds (Fig. 2) showing agonist activity at TAAR1 (Bunzow et al., 2001). Focusing exclusively on the so-called amphetaminergic-like effects does a considerable disservice to trace aminergic physiology, however, and subsequent pharmacological profiling of TAAR1 (described in detail in IV.B. Trace Amine-Associated Receptor 1) indicates that this is an oversimplification. Amphetamine-type drugs are rather promiscuous in their actions, and it is far more accurate to describe amphetamines as including trace amine-like effects as part of their spectrum of activity than to describe trace amines as being endogenous amphetamines. Consistent with this, differences in the aversive stimulus properties elicited by PEA and amphetamine were described as far back as the 1980s, such that unlike amphetamine (and other drugs of abuse), PEA does not induce a conditioned taste aversion response (Greenshaw, 1984; Greenshaw et al., 2002).

b. $\beta$-Phenylethylamine. Either iontophoretic or intra-arterial administration of low doses of PEA has been reported to cause changes in neuronal activity. Although the doses employed were insufficient to alter baseline neuronal activity, responses to norepinephrine (Paterson, 1988, 1993; Paterson and Boulton, 1988), electrical stimulation of the locus coeruleus (Paterson, 1993), dopamine (Jones and Boulton, 1980b), or synthetic dopamine agonists (Paterson et al., 1991) are all 


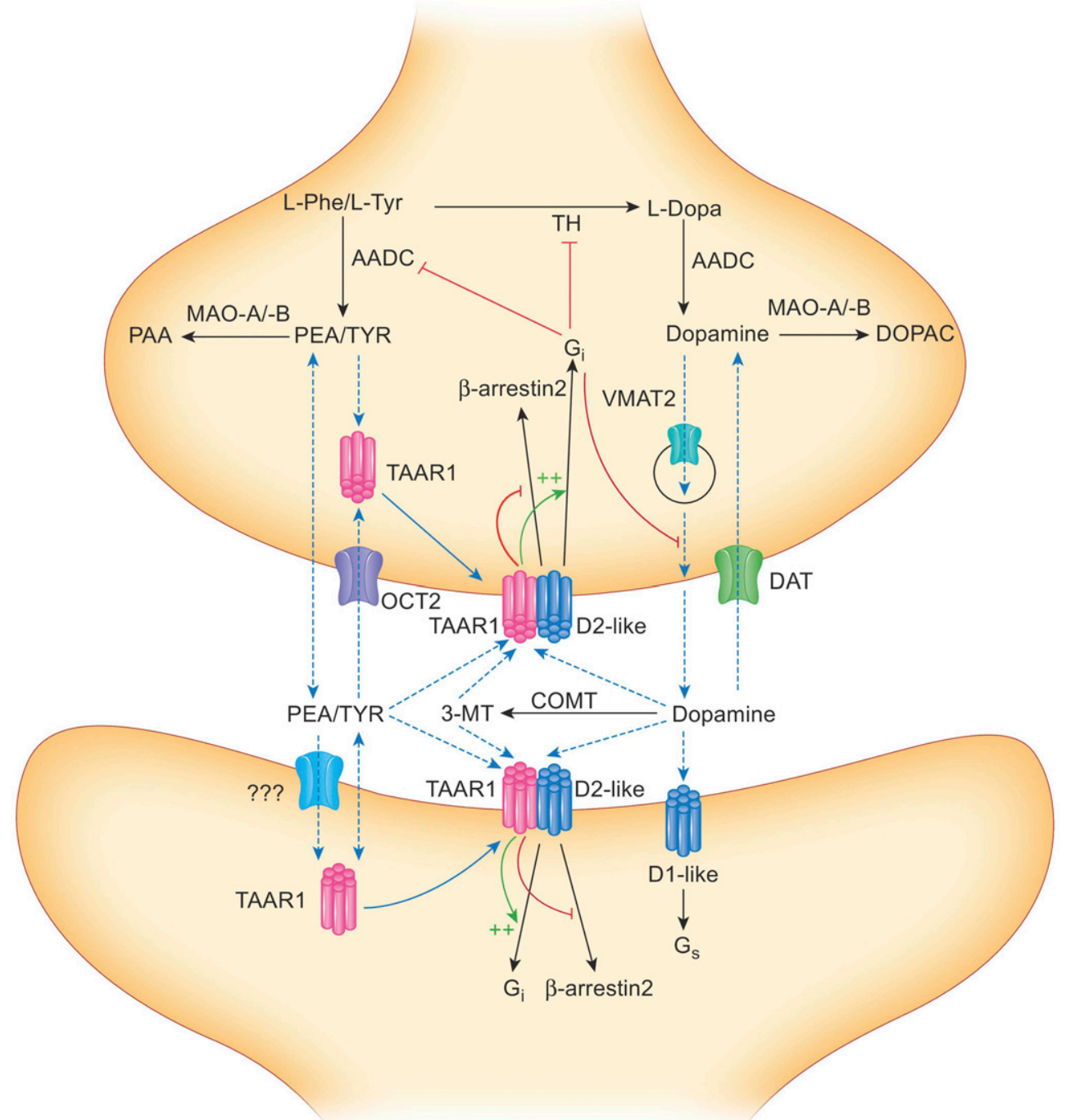

Fig. 5. Current understanding of the interplay between the TAAR 1 and dopamine systems. $\beta$-PEA and TYR are synthesized in dopaminergic terminals. Unlike dopamine, they are not stored within synaptic vesicles and readily diffuse across plasma membranes. Reuptake into presynaptic terminals appears to be aided by OCT2. TAAR1 has a predominantly intracellular location, in which both pre- and postsynaptic effects are possible. Whether a transporter contributes to postsynaptic uptake of trace amines is as yet unknown. TAAR1 may translocate to the cell surface after heterodimerization with $\mathrm{D} 2 \mathrm{R}$, an effect that promotes preferential D2R signaling through the $\mathrm{G}_{\mathrm{i}}$ signal transduction cascade rather than $\beta$-arrestin 2 pathway. TAAR1 interactions with D1R do not occur. A complex system of crosstalk between the dopamine and TAAR1 system is present. Presynaptic activation of D2R, via the $\mathrm{G}_{\mathrm{i}}$ signal transduction cascade, results in inhibition of PEA/TYR synthesis. Extracellular metabolism of dopamine by COMT generates 3-MT, an agonist at TAAR1 that like extracellular PEA and TYR can activate the TAAR1/D2R heteromer complex both at pre- and postsynaptic membranes. Dotted blue arrows indicate molecular movement, solid green arrows indicate receptor-mediated stimulation, and solid red lines indicate receptor-mediated inhibition. DOPAC, 3,4-dihydroxyphenylacetic acid; L-Phe, L-phenylalanine; L-Tyr, L-tyrosine; PAA, phenylacetic acid/4-hydroxyphenylacetic acid; TH, tyrosine hydroxylase; VMAT2, vesicular monoamine transporter 2.

modulated by PEA. Such effects do not require the presence of endogenous norepinephrine or dopamine (Paterson, 1988, 1993), nor are they mimicked by the exogenous application of dopamine (Jones and Boulton, 1980b). Furthermore, selective elevation of endogenous PEA levels through inhibition of MAO-B gives the same responses as exogenous PEA administration (Paterson et al., 1991; Berry et al., 1994) and effects are reversed by the subsequent selective reduction of PEA levels through partial inhibition of AADC. These modulatory responses show selectivity, with neuronal responses to serotonin (Paterson and Boulton, 1988), acetylcholine (Paterson and Boulton, 1988; Paterson,
1993), glutamate (Paterson and Boulton, 1988; Berry et al., 1994), and GABA (Paterson, 1988; Paterson and Boulton, 1988; Berry et al., 1994) remaining unaffected.

Similarly, dopamine-mediated effects on membrane fluidity are potentiated by the presence of low concentrations of PEA (Harris et al., 1988), although PEA alone shows no effect on membrane fluidity (Harris et al., 1988; Knight and Harris, 1993). These responses were suggested to represent a PEA-mediated change in both microtubule protein conformation and polymerization (Knight and Harris, 1993), although this does not appear to have been further studied. 
Chronic elevation of PEA has been reported to induce a downregulation of D1R but not $\mathrm{D}_{2}$-like dopamine receptors (D2Rs), as well as both $\beta_{1}$-and $\beta_{2}$-adrenergic receptors (Paetsch and Greenshaw, 1993; Paetsch et al., 1993). The mechanism by which such regulation occurs is unknown. Acutely, PEA only interacts with D1R once concentrations approach millimolar levels (Berry, 2011). Since brain levels of PEA were only reported to be increased 10-fold (Paetsch et al., 1993), a direct interaction with D1R is somewhat unlikely. Furthermore, the effect on $\beta$-adrenergic receptors was not seen in all brain regions, arguing against a response secondary to direct interaction of PEA with $\beta$-adrenoceptors. It is possible that these effects of chronic PEA elevations are secondary to increased synaptic monoamine concentrations after indirect sympathomimetic-like effects of PEA increasing transporter-mediated outflow (Sotnikova et al., 2004). Indeed, Sotnikova et al. observed that rapid, short-acting effects of PEA on extracellular dopamine levels were absent, and corresponding locomotor activation and stereotypies were not observed, if the dopamine transporter (DAT) was knocked out. Rather, spontaneous activity manifested by the DAT knockout (KO) mice during exposure to a novel environment was significantly inhibited for an extended period of time by PEA (Sotnikova et al., 2004). This indicates that, similar to previously observed responses with amphetamine (Gainetdinov et al., 1999), PEA can exert a paradoxical calming action on dopamine-mediated hyperactivity via mechanisms mediated by other monoamines, possibly also involving interaction with TAAR1 (Sotnikova et al., 2009).

Aside from a regulation of neurotransmitter receptors, PEA has been reported to stimulate gastrin secretion from $G$ cells of the antrum of rat stomach (Dial et al., 1991), an effect shared with other endogenous TAAR1 ligands TYR and TRP. This is particularly interesting, given subsequent studies showing TAAR1mediated effects on nutrient-induced hormone secretion from the gastrointestinal tract (see IV.B.3. Effects in the Periphery). Production of PEA (as well as TYR and TRP) has also been reported to enhance the ability of Staphylococcus (Luqman et al., 2018) and Enterococcus (Fernández de Palencia et al., 2011) species to adhere to epithelial cells, promoting subsequent internalization and enterocyte cytokine secretion. Finally, PEA has been proposed to be a tiger pheromone (Brahmachary and Dutta, 1979).

c. $p$-Tyramine. TYR has in general been reported to have similar effects to PEA. Potentiation of neuronal responses to both dopamine and norepinephrine has been seen after low-level iontophoretic administration of either $m$-tyramine (Jones and Boulton, 1980b) or TYR (Jones and Boulton, 1980b; Jones, 1983). As seen with PEA, selectivity of responses is present with no effect of TYR on responses to GABA (Jones and Boulton, 1980b), glutamate, or serotonin (Jones, 1982b, 1983). As before, the low-level supplemental iontophoretic application of dopamine (Jones and Boulton, 1980b) was unable to recapitulate the responses observed to TYR.

Both PEA and TYR have been reported to be released from activated platelets (D'Andrea et al., 2003), an observation that takes on added interest in light of TAAR-mediated chemotactic responses of leukocytes (see IV.B.3.b. Immunomodulatory Effects). Interestingly, species-dependent effects of TYR on leukocyte and erythrocyte chemotaxis and aggregation were described as far back as the early 1920s (Wolf, 1921, 1923). In this regard, it is interesting to note that TYR production by Enterococcus species found in cheese is enhanced by conditions that simulate passage through the gastrointestinal tract (Fernández de Palencia et al., 2011). As described above, such production promotes adherence of microbes to enterocytes (Fernández de Palencia et al., 2011; Luqman et al., 2018) and may modulate subsequent cytokine signaling by the enterocytes (Fernández de Palencia et al., 2011). TYR, along with TRP, has also recently been reported to regulate individual isoforms of neuronal acid-sensing ion channels (ASICs) (Barygin et al., 2017), an effect seen as a voltage-dependent inhibition of opening and a voltageindependent potentiation of closing of the ASIC1a isoform.

d. Tryptamine. Compared with PEA and TYR, electrophysiological responses to TRP are somewhat more complicated. Although TRP potentiates inhibitory serotonin responses, excitatory serotonin responses are either unaffected or converted to inhibitory responses in the presence of low-level TRP application (Jones and Boulton, 1980a; Jones, 1982b). Similar effects of TRP are seen on cortical neuron responses to electrical stimulation of the raphe nuclei. Here, the excitatory component of biphasic responses was markedly reduced by the presence of TRP, whereas the inhibitory component remained unaffected (Jones, 1982b). Cortical neuron excitation in response to raphe stimulation is normally followed by a long-lasting decrease in basal firing, and this secondary decrease was potentiated by the presence of TRP (Jones, 1982b). Such effects of TRP on electrical stimulation were not mimicked by the lowlevel iontophoretic application of serotonin itself (Jones, 1982b). In contrast, TRP application is without effect on acetylcholine-induced responses (Jones and Boulton, 1980a). Similarly, serotonin-induced contraction of smooth muscle is decreased in the presence of TRP at concentrations below those that mimic the effect of serotonin (Frenken and Kaumann, 1988), an effect suggested to be due to an increase in the proportion of 5 -hydroxytryptamine $2 \mathrm{a}\left(5-\mathrm{HT}_{2 \mathrm{a}}\right)$ receptors that are in the agonist high-affinity state (Frenken and Kaumann, 1988). Such an effect suggests a TRP-mediated regulation of receptor-G protein coupling mechanisms. As indicated above, TRP has also been reported to regulate ASIC1a ion channels (Barygin et al., 2017) and to 
promote the adherence of staphylococci species to gastrointestinal epithelial cells (Luqman et al., 2018).

e. Octopamine. Although OCT was first synthesized in 1910 (Barger and Dale, 1910), it was not identified in tissue extracts until 1952 (Erspamer, 1952), when it was found to be a component of the salivary gland of Octopus vulgaris. OCT was suggested to be a cotransmitter of norepinephrine over 40 years ago (Axelrod and Saavedra, 1977) and to possibly modify noradrenergic activity through an interaction with sites distinct from norepinephrine and dopamine receptors (Hicks and McLennan, 1978). Iontophoretic application of OCT in amounts insufficient to affect basal neuronal activity potentiates both inhibitory and excitatory responses to norepinephrine (Jones, 1982a). Unlike TYR and PEA, however, no effect was observed on responses to dopamine or serotonin (Jones, 1982a). As observed with other trace amines, low-dose norepinephrine application was unable to elicit a similar modification of responses (Jones, 1982a).

5. $\beta$-Phenylethylamine, $p$-Tyramine, and Tryptamine in Human Disorders. Historically, trace amines have been implicated in a diverse array of human disorders (Berry, 2007). Although there is a large body of literature describing altered levels of PEA, TYR, TRP, and their derivatives in various pathologies, and extensive tabulations of such have previously been published (Davis, 1989), many of these studies were performed in small cohorts and findings were not always confirmed in subsequent studies. Probably, the most convincing findings are observed in diseases involving altered biogenic amine synthesis or metabolism such as phenylketonuria, in which PEA levels are increased due to elevated L-phenylalanine concentrations caused by phenylalanine hydroxylase (EC 1.14.16.1) deficiency (Reynolds et al., 1978). In patients with MAO-A/B deficiencies, a dramatic increase of PEA, TYR, and TRP is also found (Lenders et al., 1996). The contribution of increased trace amine levels to the complex set of neurologic, cognitive, and psychiatric manifestations of these disorders remains to be determined and is an area for re-examination in light of the discovery of TAARs.

There are several lines of evidence supporting a role of trace amines in schizophrenia. The finding that the levels of "an endogenous amphetamine" (PEA) is increased in the urine of some patients with schizophrenia led to a general hypothesis that PEA plays a critical role in schizophrenia pathogenesis (Janssen et al., 1999). Increased levels of DMT, a potent hallucinogen that is produced endogenously in humans, have also been reported (Jacob and Presti, 2005). It should be noted in this respect, however, that although DMT is a TAAR1 agonist in common laboratory rodent species, this does not appear to be the case in humans (Simmler et al., 2016). This is perhaps not surprising, given that the current evidence indicates that TAAR 1 is primarily tuned toward primary amines (Ferrero et al., 2012).
Whether one of the tertiary amine-tuned TAAR5TAAR9 receptors is capable of binding DMT is an area for future studies.

Multiple studies have shown an association of schizophrenia with key enzymes involved in the synthesis and degradation of trace amines, particularly AADC and catechol-O-methyl transferase (COMT; EC 2.1.1.6) (Børglum et al., 2001; Shifman et al., 2006). Finally, a decrease in the number of brain D-neurons, groups of neurons that contain AADC but do not express tyrosine hydroxylase or tryptophan hydroxylase and thus represent potential trace aminergic neurons, has been reported in postmortem schizophrenia brains (Ikemoto et al., 2003).

Similarly, links between trace amines and drug abuse/dependence have long been noted, again based largely on the "PEA as an endogenous amphetamine" hypothesis. The discovery of TAARs, and in particular TAAR 1 , has considerably strengthened these links, and the role of TAAR 1 in various drug abuse paradigms is described in detail in IV.B.2.b.v. Addiction and Compulsive Behaviors. Prior to the establishment of the role of TAAR1, PEA was proposed to be involved in the neural mechanisms of reward and reinforcement (Greenshaw, 1984; Shannon and Thompson, 1984), as well as increases in brain PEA levels reported in response to $\Delta^{9}$-tetrahydrocannabinol (Sabelli et al., 1974). Alterations in the activity of the trace amine synthetic enzyme AADC have also been reported in alcohol-dependent patients (Tiihonen et al., 1998), along with single nucleotide polymorphisms of AADC (Ma et al., 2005) and the chromosomal region containing the AADC gene (Wang et al., 2005) being linked to nicotine dependence. The dopaminergic system, and in particular D2Rs, is well established to be important in reward circuitry and addiction. The A1 allele of the D2R, which has been linked with alcohol (Blum et al., 1990; Noble, 2003), nicotine (Spitz et al., 1998; Bierut et al., 2000), opioid (Lawford et al., 2000), psychostimulant (Persico et al., 1996; Noble, 2003), and polysubstance (Comings et al., 1991, 1994; O'Hara et al., 1993) abuse as well as pathologic gambling (Comings et al., 1996), has also been reported to be associated with an increase in AADC activity (Laakso et al., 2005).

A cohesive theory has also been put forth for a role of PEA in affective disorders, whereby deficits in PEA are associated with depression, whereas elevated PEA is associated with mania symptoms (Karoum et al., 1982; Davis, 1989; Sabelli and Javaid, 1995). Decreased levels of PEA are observed in patients with depression (Wolf and Mosnaim, 1983), whereas clinically effective MAO inhibitors are known to elevate trace amine levels (Sabelli and Mosnaim, 1974; Sabelli et al., 1996), and elevated PEA levels have been suggested to underlie the antidepressant effects of exercise (Szabo et al., 2001). An association of unipolar and bipolar depression with COMT and AADC genes has also been reported 
(Børglum et al., 2001; Shifman et al., 2006). Changes in PEA levels have also been found in patients with attention deficit hyperactivity disorder, for which amphetamine (a TAAR1 agonist) remains one of the most effective treatments (Baker et al., 1991).

A role for trace amines in Parkinson disease has also been suggested, with both COMT and MAO inhibitors being used in clinical practice (Espinoza et al., 2012). Intriguingly, levels of the extracellular dopamine metabolite and TAAR1 agonist 3-MT are significantly increased after chronic L-DOPA treatment (Rajput et al., 2004) and may contribute to L-DOPA-induced dyskinesia (Sotnikova et al., 2010). 3-MT levels are also markedly increased in patients with pheochromocytoma and are the most sensitive biomarker for this catecholamine-related disorder (Lenders and Eisenhofer, 2017). A role for trace amines in migraine and cluster headaches (D'Andrea et al., 2004) and foodrelated headache attacks (Smith et al., 1970) has been speculated, although certainly with respect to foodinduced migraines there is sparse supportive evidence (Berry, 2007).

Recent unbiased metabolomics studies indicated that elevated fecal PEA levels are present in patients with Crohn disease (Jacobs et al., 2016; Santoru et al., 2017), an effect that was suggested to contribute to the ability to discriminate these patients from healthy controls (Santoru et al., 2017). Similarly elevated TYR levels were reported in ulcerative colitis fecal samples (Santoru et al., 2017). Such studies are generally consistent with previous links between inflammatory bowel disorder pathology and altered L-phenylalanine and L-tyrosine metabolism (Burczynski et al., 2006; Jansson et al., 2009). Potential roles of trace amines in anxiety disorders, eating disorders, epilepsy, and Reye syndrome have been also been sporadically suggested (see Berry, 2007). Elevated urinary PEA levels are associated with general stress responses in both humans and rodents (Paulos and Tessel, 1982; Snoddy et al., 1985; Grimsby et al., 1997) and this could certainly be a confound in interpreting elevations of PEA in disease conditions.

\section{B. Isoamylamine}

Although isoamylamine was identified as a biologically active component of both decaying meat and tissue samples at the same time as PEA, TYR, and TRP (Barger and Dale, 1910), it has been far less studied in subsequent years, presumably due to less structural similarity to subsequently established neurotransmitters (c.f. Figs. 1 and 3). Isoamylamine can be produced by the decarboxylation of leucine (Table 1) and is a component of commonly consumed fermented foodstuffs (Cunha et al., 2011; Bach et al., 2012; Coton et al., 2012). Although a variety of leucine decarboxylase activities have been described in prokaryotes (Coton et al., 2012), including some commensal gut microbiota (Haughton and King, 1961), there is no known leucine decarboxylase enzyme in vertebrates (Table 1). Isoamylamine production could occur, however, via methionine decarboxylase (EC 4.1.1.57) or valine decarboxylase (EC 4.1.1.14), both of which include L-leucine in their substrate profile (Table 1).

The initial descriptions of MAO activity identified isoamylamine as a substrate (Blaschko et al., 1937; Pugh and Quastel, 1937) and further characterization has suggested that isoamylamine exhibits selectivity toward MAO-B, similar to that of PEA (Peers et al., 1980). In addition, isoamylamine is also a substrate for SSAO/VAP-1/AOC3 (Elliott et al., 1989). Isoamylamine is an agonist at TAAR3 (Liberles and Buck, 2006), and TAAR3 and its responses are described in section IV.E.2 Trace Amine-Associated Receptor 3. Isoamylamine is excreted in male mouse urine (Nishimura et al., 1989) and may induce puberty in female mice (Nishimura et al., 1989), suggesting a possible role as a pheromone, which would most likely require that a nonmicrobial synthetic pathway is present. Others, however, have failed to replicate the puberty-accelerating effect of isoamylamine (Price and Vandenbergh, 1992).

Previously, isoamylamine was reported to share a gastrin secretion-stimulating effect with PEA and TYR (Dial et al., 1991) and it has recently been reported to regulate gastrointestinal motility in a tetrodotoxinsensitive manner (Sánchez et al., 2017), possibly indicating a neuron-mediated mechanism. In this regard, it is interesting to note that isoamylamine was suggested to be an endogenous neurally active compound at least 40 years ago (Tashiro et al., 1974). More recently, cardiac levels of isoamylamine were reported to negatively correlate with septal wall thickness and to be increased in patients suffering cardiac arrest (Meana et al., 2016). Isoamylamine was also suggested to be beneficial in an animal model of endotoxemia (Yen et al., 2016). The mechanism and importance of these putative effects requires further study.

\section{Trimethylamine}

Although repeatedly identified as a component of various human bodily fluids between the mid-1850s and early 1910s (see Mitchell and Smith, 2016), a physiologic relevance of trimethylamine was not suggested until the 1930s when an increase in its excretion was reported to occur during menstruation (AshleyMontagu, 1938), an effect that has subsequently been confirmed (Shimizu et al., 2007). Although trimethylamine levels have been associated with various disease conditions (Chhibber-Goel et al., 2016), are sexually dimorphic (Gavaghan McKee et al., 2006), and a proposed male pheromone in mice (males having a genetic deficiency in trimethylamine metabolism) ( $\mathrm{Li}$ et al., 2013), there is no known endogenous synthetic pathway. Rather, trimethylamine production is thought to occur as a by-product of prokaryotic degradation of 
dietary choline, betaine, phosphatidylcholine, and Lcarnitine (Zhang et al., 1999; Craciun and Balskus, 2012; Zhu et al., 2014; Kalnins et al., 2015; Fennema et al., 2016). Such well documented production by the commensal microbiota, along with an established host receptor (TAAR5, see subsequent sections), makes trimethylamine an attractive candidate molecule for investigating the growing appreciation of the role of the microbiota in health and disease. The apparent lack of nonmicrobial production of trimethylamine raises questions as to whether it is the true endogenous ligand for TAAR5 and offers an interesting parallel to the archetypal trace amines TYR, PEA, and TRP, which were previously often consigned to the role of metabolic by-products (Berry, 2004). With a receptor that is selectively activated by trimethylamine now identified, a re-examination of whether trimethylamine production is solely dependent on the commensal microbiota is warranted.

Trimethylamine has been confirmed to be a highaffinity agonist at TAAR5 from multiple species (Liberles and Buck, 2006; Ferrero et al., 2012; Li et al., 2013; Wallrabenstein et al., 2013; Zhang et al., 2013). Effects clearly demonstrated to be TAAR5 mediated are described in sections IV.C.4 Trace AmineAssociated Receptor 5 and IV.E.4 Trace AmineAssociated Receptor 5, although these are rather few in number at present. The main interest in trimethylamine thus far has been with respect to its degradation. This primarily occurs via the enzyme flavin monooxygenase 3 (FMO3; EC 1.14.13.8), which is prevalent in hepatic tissue, including in humans (Fennema et al., 2016). This generates trimethylamine- $N$-oxide (TMAO), a compound that has been increasingly implicated as playing a role in both cardiovascular and metabolic disorders (Fennema et al., 2016; Zhang and Davies, 2016). Interestingly, the $K_{\mathrm{m}}$ for trimethylamine metabolism by FMO3 is rather high ( $28 \mu \mathrm{M}$; Lang et al., 1998) and is approximately 100 -fold in excess of the $\mathrm{EC}_{50}$ values of trimethylamine at TAAR5 from various species (Berry et al., 2017). This raises the possibility of previously unsuspected physiologic effects of nanomolar trimethylamine levels and that TAAR5 may be under tonic activation. As described in later sections, at least two receptor targets for trimethylamine are likely to be present, since TAAR5 KO prevents low-dose but not high-dose trimethylamine effects (Li et al., 2013).

An evolutionary deletion of FMO3 in male mice underlies their markedly increased urinary trimethylamine levels (Li et al., 2013). In humans, a genetic deficiency in FMO3 leads to the condition of trimethylaminuria (Humbert et al., 1970), in which large quantities of trimethylamine are excreted in sweat, urine, and exhaled air (Fennema et al., 2016). Kidney damage (Bain et al., 2006; Chhibber-Goel et al., 2016) and gut dysbiosis (Fennema et al., 2016) can also lead to trimethylaminuria, as can invasion by pathologic microflora associated with bacterial vaginosis or infections of the oral cavity (Fennema et al., 2016; Zhang and Davies, 2016). The increased trimethylamine urinary excretion associated with menstruation (Mitchell and Smith, 2010) may reflect regulation of FMO3 by female sex hormones (Coecke et al., 1998; Shimizu et al., 2007). Consistent with this, FMO3 activity is altered during pregnancy (Hukkanen et al., 2005). Interestingly, trimethylamine urinary levels were found to be very stable in a recent study in children, showing the least intraindividual variability during repeated sampling, whereas those of its metabolite TMAO were highly variable (Maitre et al., 2017), suggesting that trimethylamine levels are more tightly controlled than those of its primary metabolite. This could indicate a physiologic relevance of the parent compound. Trimethylamine has also been detected in the feces of at least one avian species (the black-bellied whistling duck) (Robacker et al., 2000), where it may play a role in either conspecific (Mueller et al., 2008) or heterospecific (Robacker et al., 2000) communication.

Trimethylaminuria is generally classified as a rather benign condition, except for the socially stigmatizing strong fish odor associated with afflicted individuals, and this is the basis of the more common name for the disorder-fish malodor syndrome. The pronounced malodor associated with trimethylaminuria does, however, result in a severe loss of quality of life for affected persons (Fennema et al., 2016).

TMAO can also be produced by bacterial action on trimethylamine through various oxygenase enzymes or by the nonenzymatic action of reactive oxygen species (Brown and Hazen, 2017). In addition, prokaryotes can convert TMAO back to trimethylamine (Zhang et al., 1999). Alternatively, dehydrogenase enzymes from at least some bacteria can convert trimethylamine into dimethylamine (Kim et al., 2001; Shi et al., 2005) with subsequent conversions to methylamine and ammonia (Kim et al., 2001), although whether this ability is shared by commensal bacteria is unknown.

At high concentrations trimethylamine has been reported to inhibit macromolecule synthesis, leading to teratogenesis in mouse embryos due to inhibition of receptor-mediated precursor uptake (Guest and Varma, 1992; Guest et al., 1994). This effect has been suggested to be more pronounced in male offspring due to trimethylamine-mediated inhibition of testosterone synthesis (Guest and Varma, 1993). FMO3 expression is regulated by both glucagon and insulin, with insulin decreasing FMO3 levels in a sexually dimorphic manner (Miao et al., 2015), and dysregulated trimethylamine metabolism has been implicated in the pathology of both obesity and diabetes (Dumas et al., 2006; Toye et al., 2007), including in humans (Elliott et al., 2015). Trimethylamine levels have also been correlated to the onset of symptoms in the interleukin-10 KO mouse model of inflammatory bowel disease (Murdoch et al., 
2008), although the basis of this relationship is unclear. As previously indicated, there is a growing body of work that implicates the trimethylamine metabolite TMAO in cardiovascular disease (Koeth et al., 2013; Miao et al., 2015). Although few studies have examined for a role of the parent compound, one study has linked trimethylamine to atherosclerosis in patients with human immunodeficiency virus infection (Srinivasa et al., 2015). Elevated trimethylamine levels have also been suggested in patients with a malignant peripheral nerve sheath tumor (Fayad et al., 2014) and glomerulosclerosis (Hao et al., 2013), although the relevance of these observations to disease processes has not been determined. High-altitude pulmonary edema has also been reported to be associated with a decrease in plasma trimethylamine levels (Luo et al., 2012), although the relevance of this beyond serving as a potential biomarker is unknown.

Trimethylaminuria has sporadically been reported to be associated with epilepsy (McConnell et al., 1997; Pellicciari et al., 2011), and a lowering of the epileptogenic threshold has been reported in experimental animals in response to trimethylamine (Gajda et al., 2003; Leniger et al., 2004; Sayyah et al., 2007; NassiriAsl et al., 2008), possibly as a consequence of the opening of gap junctions (Gajda et al., 2003; Bocian et al., 2011; Chang et al., 2013). That epileptic activity could be controlled by a diet restricted in trimethylamine precursors (McConnell et al., 1997; Pellicciari et al., 2011) raises the possibility of a direct causal link between elevated trimethylamine and a lowered epileptogenic threshold. Possibly related to this, trimethylamine has also been reported to increase the amplitude of theta wave oscillations (Bocian et al., 2011). A variety of psychiatric and behavioral disorders have been suggested to coexist with trimethylaminuria, although how many of these are either simply coincidental (McConnell et al., 1997) or secondary to the social stigma associated with the pronounced halitosis and body odor (Todd, 1979; Mitchell and Smith, 2001) is unclear. Some behavioral abnormalities have, however, been reported to be ameliorated with diets low in trimethylamine precursors (McConnell et al., 1997), indicating a possible link between trimethylamine metabolism and central neuronal function.

Lower maternal urinary trimethylamine levels have been reported to be associated with fetal growth retardation (Maitre et al., 2014), whereas maternal plasma trimethylamine levels may be a marker for discrimination of trisomy 18 from trisomy 21 (BahadoSingh et al., 2013). Interestingly, FMO3 expression is not turned on until after birth in humans and continues to increase until adulthood (Fennema et al., 2016), suggesting a developmental component to the trimethylamine/TMAO axis. Trimethylamine is present in breast milk and its concentration in amniotic fluid increases markedly during gestation (Lichtenberger et al., 1991). Together, these studies raise the possibility of an involvement of trimethylamine in programming fetal and neonatal metabolism.

\section{O-Methyl and N-Methyl Derivatives}

The $O$-methyl metabolites of the catecholamine neurotransmitters (3-MT, 4-methoxytyramine, metanephrine, and normetanephrine) were identified as agonists at TAAR1 during the initial characterization of the receptor family (Bunzow et al., 2001), with the effect of 3-MT being subsequently confirmed by others (Sotnikova et al., 2010). Although very few studies have examined the physiologic effects of these compounds, a complex spectrum of locomotor behaviors and the corresponding striatal intracellular signaling events are induced by intracerebroventricular 3-MT administration, and these are partially ameliorated in TAAR1-KO animals (Sotnikova et al., 2010). 3-MT levels are increased in brains with Parkinson disease during the development of dyskinesias after chronic LDOPA administration (Rajput et al., 2004). As such, TAAR1 may be a target for improving the on-off phenomenon associated with long-term L-DOPA therapy. Such effects certainly point to at least 3-MT having physiologic roles beyond being a mere marker of extracellular dopamine levels, and it is expected that the identification of TAAR1 as a receptor target for the $O$-methyl neurotransmitter metabolites will lead to further studies in these areas.

$\mathrm{N}$-methyl metabolites of trace amines have also been shown to be ligands for TAARs (Lindemann and Hoener, 2005); however, with at least some of these compounds, this is species dependent (Simmler et al., 2016; Berry et al., 2017). $N$-methyltyramine is widely distributed in plant species (Smith, 1977; Stohs and Hartman, 2015), where its presence has been known since 1950 (Kirkwood and Marion, 1950). In addition, $N$ methylphenylethylamine has been identified in human urine (Reynolds and Gray, 1978). Like the parent compounds, at high concentrations, $N$-methyl trace amines have long been known to cause pronounced pressor effects (Hjort, 1934), most likely due to either direct or indirect sympathomimetic effects (Stohs and Hartman, 2015). In addition, and at much lower concentrations, $N$-methyltyramine has been reported to stimulate gastric (Yokoo et al., 1999) and pancreatic (Tsutsumi et al., 2010) secretions. DMT is perhaps the most widely studied of the $N$-methyl derivatives due to its potent hallucinogenic properties, which likely have a polypharmacological basis (Carbonaro and Gatch, 2016). In addition to neural effects, DMT also appears to possess immunomodulatory properties (Szabo, 2015).

\section{E. 3-Iodothyronamine}

Like the archetypal trace amines, 3IT is an endogenous compound found at nanomolar levels throughout the body in both rodents and humans (Scanlan et al., 
2004; Zucchi et al., 2014). Although it is often reported as a derivative/metabolite of thyroid hormones (Hoefig et al., 2016), whether 3IT is indeed derived from either 3,3',5-triiodothyronine or thyroxine after decarboxylation and deiodination is a matter of some conjecture (Ackermans et al., 2010; Hoefig et al., 2011, 2015; Hackenmueller et al., 2012). The available evidence indicates that 3IT is not formed by the action of AADC (Hackenmueller et al., 2012; Hoefig et al., 2012) but may be formed by ornithine decarboxylase (EC 4.1.1.17) (Hoefig et al., 2015). Once formed, 3IT is a substrate for MAOs, SSAO/VAP-1/AOC3, and deiodinases, resulting in the production of 3-iodothyroacetic acid and thyronamine (Piehl et al., 2008; Wood et al., 2009; Saba et al., 2010; Hackenmueller and Scanlan, 2012; Laurino et al., 2015). In addition, $N$-acetyl, $O$-sulfonate, and glucuronide conjugates of 3IT have been reported to be widely distributed throughout the body (Pietsch et al., 2007; Hackenmueller and Scanlan, 2012).

In 2004, 3IT was identified as a high-affinity agonist at TAAR1 (Scanlan et al., 2004). This has subsequently been verified by numerous laboratories (Mühlhaus et al., 2014; Cöster et al., 2015; Chiellini et al., 2017), with 3IT also shown to act as an agonist at TAAR2 (Babusyte et al., 2013; Cichero and Tonelli, 2017) and as an inverse agonist at TAAR5 (Dinter et al., 2015c). 3IT is promiscuous, however, and also interacts with high affinity at $\alpha_{2}$-adrenoceptors (Regard et al., 2007; Dinter et al., 2015b), $\beta$-adrenergic receptors (Meyer and Hesch, 1983; Kleinau et al., 2011; Dinter et al., 2015a), muscarinic acetylcholine receptors (Laurino et al., 2016), transient receptor potential cation channel subfamily M member 8 ion channels (Khajavi et al., 2015; Lucius et al., 2016), various monoamine and organic anion transporters (Snead et al., 2007; Panas et al., 2010), and molecular target(s) within mitochondria, including the $\mathrm{F}_{1}-\mathrm{F}_{0}$ ATP synthase (Cumero et al., 2012) and possibly complex III (Venditti et al., 2011). 3IT also tightly binds to the plasma protein apolipoprotein B-100 (Roy et al., 2012).

The physiologic effects of 3IT are often, although not exclusively, opposite to those of the thyroid hormones. A variety of physiologic effects of 3IT have been reported and a number of reviews of such effects have previously been published to which the reader is referred for further details (Ianculescu and Scanlan, 2010; Zucchi et al., 2010, 2014; Piehl et al., 2011; Hoefig et al., 2016). Here, we will provide a brief overview of such effects with the following caveat: the promiscuous nature of 3IT makes it highly unlikely that all, or even most, of the physiologic effects described are mediated via one or more TAARs. Where there is unequivocal evidence of TAAR-mediated 3IT responses, these are discussed in the subsequent sections focused on those individual receptor subtypes. Furthermore, it was recently suggested that at least some of the effects previously ascribed to 3IT may in fact be a function of one or more of its metabolites (Hoefig et al., 2016; Laurino and Raimondi, 2017), adding a further level of complexity to the elucidation of the physiologic relevance and pharmacological effects of 3IT.

1. Cardiovascular Effects. Negative inotropic and chronotropic effects are observed both in vivo and in isolated heart preparations after 3IT administration (Scanlan et al., 2004; Chiellini et al., 2007), possibly due to an interference with release of $\mathrm{Ca}^{2+}$ from intracellular stores (Ghelardoni et al., 2009). At higher concentrations, a decrease in aortic flow and cardiac output is also observed (Frascarelli et al., 2011).

2. Metabolic Effects. Effects on energy metabolism have been seen after both intraperitoneal and intracerebroventricular administration of 3IT. Effects include hyperglycemia (Regard et al., 2007; Klieverik et al., 2009; Manni et al., 2012), reduced insulin and increased glucagon secretion (Regard et al., 2007; Manni et al., 2012), and ketonuria associated with a loss of body fat due to a switch from glucose to lipid metabolism (Braulke et al., 2008). Changes in gene expression consistent with increased lipolysis have also been reported to occur in response to 3IT (Mariotti et al., 2014). Some of these responses were suggested to be secondary to altered neuropeptide Y secretion (Dhillo et al., 2009). Interestingly, TAAR1 activation has separately been reported to regulate secretion of the closely related peptide YY (PYY) (Raab et al., 2015). Both increases (Dhillo et al., 2009) and decreases (Manni et al., 2012) in food intake have been observed in response to 3IT, effects that are dependent on the dose administered. Effects on in vivo energy metabolism and food consumption appear to have both central and peripheral components (Klieverik et al., 2009; Manni et al., 2012) and are almost certainly reflective of the promiscuity of 3IT's molecular targets (Regard et al., 2007).

3. Thermoregulation. Administration of 3IT induces a rapid, long-lasting hypothermia, with no compensatory induction of shivering or piloerection (Scanlan et al., 2004; Doyle et al., 2007; Braulke et al., 2008). These effects are maintained in TAAR1-KO animals (Panas et al., 2010) and are proposed to be due to a decrease in basal metabolic rate (Braulke et al., 2008). Indeed, 3IT has been reported to induce a hibernationlike torpidity in lizards (Ha et al., 2017) and mice (Ju et al., 2011). On the basis of the hypothermic effect, it was hypothesized that 3IT may reduce infarct size after ischemic injury, an effect that was subsequently seen in the middle cerebral artery occlusion model of stroke (Doyle et al., 2007). That effects were indeed due to hypothermia was suggested by the lack of a neuroprotective effect of $3 \mathrm{IT}$ in primary neuronal culture models and by a loss of in vivo protection when body temperature was maintained by use of a heating pad (Doyle et al., 2007). In contrast, in an isolated heart preparation, protection against ischemia was still seen 
(Frascarelli et al., 2011), an effect that occurred at concentrations below those that induced changes in cardiac output or aortic flow. This cardioprotective effect appeared to be due to an activation of PKC and subsequent opening of $\mathrm{K}_{\mathrm{ATP}}$ channels.

4. Other Effects. A modulation of pain pathways, seen as an antinociceptive effect, has been reported after 3IT administration (Manni et al., 2013), an effect suggested to be mediated after metabolism to 3 -iodothyroacetic acid, and subsequent modulation of histaminergic signaling (Laurino et al., 2015). Manni et al. (2013) have also reported procognitive effects of 3IT. Regulation of sleep, and in particular a decrease in nonrapid eye movement (NREM) sleep, has also been reported after 3IT dosing (James et al., 2013). Whether this relates to the NREM-suppressing, wakefulnesspromoting effects of TAAR1 activation (Black et al., 2017; Schwartz et al., 2017) is an open question.

\section{F. Polyamines}

Like the archetypal trace amines, polyamines are found in all species (Miller-Fleming et al., 2015). They are traditionally viewed as consisting of cadaverine, putrescine, spermidine, and spermine. Polyamine metabolism is complex, not least because of their ability to interconvert, and this has been detailed fully in numerous review articles (Miller-Fleming et al., 2015; Pegg, 2016). Putrescine is primarily derived from L-ornithine by the action of ornithine decarboxylase (EC 4.1.1.17; Table 1). Putrescine itself can be converted to spermidine by spermidine synthase (EC 2.5.1.16), which in turn can be converted to spermine by spermine synthase (EC 2.5.1.22). Both spermidine synthase and spermine synthase are dependent on the action of $S$ adenosylmethionine decarboxylase (EC 4.1.1.50) to generate decarboxylated $S$-adenosylmethionine as a donor of aminopropyl groups. Back conversion of spermine to spermidine, and spermidine to putrescine can occur after $N^{1}$-acetylation by spermidine/spermine $N^{1}$ acetyltransferase, and subsequent oxidation by polyamine oxidase (EC 1.5.3.11). A distinct spermine/ spermidine $N^{8}$-acetylation pathway is also present, which may generate substrates of MAO (Youdim et al., 1991). Cadaverine is produced by direct decarboxylation of lysine through the action of lysine decarboxylase (EC 4.1.1.18; Table 1).

Although polyamines are usually considered distinct from monoaminergic signaling systems, a putative diamine binding site was reported to be present in both human TAAR6 and TAAR8 (Li et al., 2015). Furthermore, at least in fish, olfactory detection of cadaverine was shown to be dependent on TAAR13c (Hussain et al., 2013), with other teleost-specific TAAR isoforms also recognizing diamines (Table 2). Although these TAAR isoforms are not found in terrestrial vertebrates, panTAAR-KO prevents the innate avoidance behavior shown by mice in response to the presence of both putrescine and cadaverine (Dewan et al., 2013). Which mouse TAAR isoform(s) is responsible, however, remains unknown. Furthermore, whether polyamines other than putrescine and cadaverine also act as ligands at tetrapod TAARs is an area for systematic study, but it is perhaps quite likely that spermine and/or spermidine will also interact with one or more TAARs, given their close structural homology to putrescine and cadaverine and similar ecological context to other TAAR ligands such as trimethylamine and isoamylamine.

The physiology of cadaverine and putrescine remains largely a mystery, beyond their association with decaying carcasses due to bacterial degradation of proteinaceous material and innate repulsive properties in most species. The classic polyamines as a whole have been implicated in a variety of mammalian cellular processes, most notably in the regulation of cell growth and proliferation, cellular stress responses, ion channel function, and as allosteric regulators of glutamatergic NMDA and $\alpha$-amino-3-hydroxy-5methyl-4-isoxazolepropionic acid (AMPA) receptors (Miller-Fleming et al., 2015; Pegg, 2016). One other polyamine perhaps deserves mention in these regards. Agmatine is formed by decarboxylation of arginine (Table 1), primarily via arginine decarboxylase (EC 4.1.1.19), and can itself be subsequently converted into putrescine after elimination of urea by the enzyme agmatinase (EC 3.5.3.11). A variety of physiologic and pathologic functions have been ascribed to agmatine (Table 1) (Piletz et al., 2013), many of which bear a striking overlap with the reported effects of TAARs and/ or trace amines. For example, agmatine has been shown to interact either directly or indirectly with the function of a variety of neurotransmitter receptors, including imidazoline receptors (Li et al., 1994; Raasch et al., 2001), NMDA receptors (Yang and Reis, 1999), and serotonin $5-\mathrm{HT}_{2 \mathrm{a}}$ receptors (Taksande et al., 2009). Agmatine also modulates the functions of $\mathrm{K}_{\mathrm{ATP}}$ channels (Shepherd et al., 1996) and ASICs (Li et al., 2010) and interacts with a variety of transporter proteins, including OCT2 (Gründemann et al., 2003), OCT3 (Gründemann et al., 2003), and mitochondrial transport systems (Grillo et al., 2007). Like the known TAAR ligands PEA, TYR, and isoamylamine, regulation of gastrin secretion by agmatine has also been reported (Dial et al., 1991). This is far from an exhaustive list; agmatine has been reported to have a wide variety of molecular targets and physiologic effects (Molderings and Haenisch, 2012; Piletz et al., 2013; Laube and Bernstein, 2017), and binding to one or more TAAR may just be one of many mechanisms by which agmatine can exert its effects.

Although the molecular basis of its effects remains largely unknown, agmatine dysregulation has been implicated in affective disorders, cognition, drug abuse/addiction, and metabolic disorders (Piletz et al., 2013). Although agmatine is known not to interact with 
TABLE 2

Identified ligands at teleost TAARs

\begin{tabular}{cl}
\hline \multicolumn{1}{c}{ TAAR } & \multicolumn{1}{c}{ Ligand } \\
\hline TAAR10a & Serotonin \\
TAAR10b & TRP \\
TAAR12h & PEA, isoamylamine \\
TAAR12i & 3-MT \\
TAAR13a & Histamine \\
TAAR13c & Cadaverine \\
TAAR13d & Putrescine, histamine, cadaverine, agmatine \\
TAAR13e & Agmatine \\
TAAR14d & Agmatine \\
TAAR16c & $N$-methylpiperidine, $N$-methylpyrrolidine \\
TAAR16e & $N, N$-dimethylcyclohexylamine \\
TAAR16f & Isoamylamine \\
\hline
\end{tabular}

TAAR1 (Hu et al., 2009), it does interact with multiple zebrafish TAARs, including TAAR13c (Table 2) (Hussain et al., 2013). Putative interaction at mammalian TAAR subtypes is an area for future study, particularly in light of the presence of a diamine binding pocket in TAAR6 and TAAR8 that is conserved with that present in TAAR13c ( $\mathrm{Li}$ et al., 2015).

\section{G. Putative Other Trace Amines}

The majority of TAARs remain orphan receptors with no known cognate ligand. Indeed, as described in subsequent sections, this is problematic with respect to following current IUPHAR conventions for naming the receptor family. From the preceding sections, however, it is readily apparent that a large number of TAAR ligands are the direct products of amino acid decarboxylation (Table 1), and this is perhaps a good place to start the search for endogenous ligands of currently orphaned TAARs. With this in mind, Table 1 provides, for reference, the decarboxylated products of common amino acids and, where known, their physiologic effects and TAAR binding activity.

\section{Invertebrate Trace Amines}

TYR and OCT are now well established signaling molecules in invertebrates (Downer et al., 1993; Kutsukake et al., 2000; Anton et al., 2006; Farooqui, 2007; Kononenko et al., 2009). Unlike in vertebrate species, however, they appear to serve the role of bona fide neurotransmitters in invertebrates, functioning as invertebrate versions of vertebrate adrenergic systems (Roeder, 2005; Lange, 2009; Homberg et al., 2013). Indeed, in invertebrate nervous systems, TYR and OCT are present at high concentrations, raising the question as to whether they should continue to be referred to as "trace" amines in these species (Roeder, 2016). Consistent with the divergence of physiologic roles of the ligands, invertebrates possess dedicated TYR and OCT receptors that are evolutionarily distinct from TAARs (see subsequent sections for further details). As such, current evidence indicates that the ability to use TYR and OCT has arisen at least twice during evolution. This also necessitates that caution be exercised, because it makes a number of common model systems (particularly Caenorhabditis elegans and Drosophila) not suitable for translational research with trace amines due to the independence of functions and divergence of receptors. The evolutionary distance between invertebrate OCT/TYR receptors and mammalian TAARs has made the invertebrate receptors an attractive target for the development of selectively acting insecticides, and some progress has been made in this area in recent years (Roeder et al., 1995, 2003). Although it is far less studied, isoamylamine has also been suggested to be an endogenous neuronally active compound in invertebrates (Tashiro et al., 1974), whereas trimethylamine-induced release of intracellular calcium stores has been reported in gastropod neurons (Willoughby et al., 2001).

\section{A. Synthesis and Degradation}

Although invertebrate synthesis and degradation of TYR and OCT occurs by analogous pathways to those of vertebrates, distinct enzymes are present (Blenau and Baumann, 2001; Roeder, 2005; Verlinden et al., 2010a). Dedicated tyrosine decarboxylase enzymes are found in various invertebrate species (Livingstone and Tempel, 1983; Ishida and Ozaki, 2012; McCoole et al., 2012; Christie et al., 2014) and, at least in Drosophila, distinct neuronal and non-neuronal isozymes exist (Cole et al., 2005). Although an AADC-like, DOPA decarboxylase enzyme may also be present, this does not appear to act on L-tyrosine (Han et al., 2010). In addition to being active in its own right, TYR can be further acted upon by tyramine- $\beta$-hydroxylase enzymes to generate OCT (Monastirioti et al., 1996; Alkema et al., 2005; Nishimura et al., 2008; Châtel et al., 2013). Again, multiple isozymic forms are present in some species (Châtel et al., 2013). Formation of TYR from dopamine via a dopamine dehydroxylase pathway is also possible in some species (Walker and Kerkut, 1978; Roeder, 2005).

Whereas vertebrate degradation of TYR and OCT occurs primarily by MAOs, the primary invertebrate degradative route is thought to be via $N$-acetylation and $N$-methylation (Dewhurst et al., 1972; Roeder, 2005; Verlinden et al., 2010a), with sulfate, $\beta$-alanyl, glycosyl, and $\gamma$-glutamyl conjugations also possible (Maxwell et al., 1980; Wright, 1987; Sloley, 2004; Roeder, 2005).

\section{B. Storage and Release}

OCT release has been demonstrated to occur from insect neuronal preparations in response to both electrical- and $\mathrm{K}^{+}$-induced depolarization (Morton and Evans, 1984; Orchard and Lange, 1987; Verlinden et al., 2010a), with typical neurotransmitter-like exocytotic release from synaptic vesicles (Consoulas et al., 1999). Released TYR and OCT are primarily removed from the synaptic cleft by dedicated transporter systems 
(Roeder and Gewecke, 1989; McClung and Hirsh, 1998; Gallant et al., 2003; Donly and Caveney, 2005), with some evidence for species specificity in the transporters present (Roeder, 2005).

\section{Octopamine Receptors}

The first invertebrate OCT receptor to be identified was found in the mushroom bodies of the D. melanogaster brain and was named OAMB (Han et al., 1998). More recently, it has been suggested that this receptor be renamed Oct $\alpha \mathrm{R}$, reflective of its homology to vertebrate $\alpha$-adrenergic receptors (Evans and Maqueira, 2005; Bayliss et al., 2013). The OAMB receptor is coupled to $\mathrm{Ca}^{2+}$ accumulation (Zeng et al., 1996; Han et al., 1998; Grohmann et al., 2003; Balfanz et al., 2005; Evans and Maqueira, 2005). Orthologs of OAMB have subsequently been identified in Apis (Blenau and Baumann, 2001; Grohmann et al., 2003; Balfanz et al., 2014), Anopheles (Kastner et al., 2014), Schistocerca (Verlinden et al., 2010b), and Locusta (Hiripi et al., 1994; Ma et al., 2015), among other invertebrate species. Whether the OAMB receptor is a true OCT receptor or a mixed OCT/TYR receptor has been a matter of some recent conjecture (El-Kholy et al., 2015). Very recently, a putative novel receptor with homology to $\alpha_{2}$-adrenoceptors was reported in Drosophila, coupled to $\mathrm{G}_{\mathrm{i}}$-mediated inhibition of adenylyl cyclase, and activated by both OCT and TYR (Qi et al., 2017).

Subsequent to the OAMB receptor discovery, three further invertebrate OCT receptors were identified (Oct $1 \beta R$, Oct $2 \beta R$, and Oct $3 \beta R$; Evans and Maqueira, 2005; El-Kholy et al., 2015), with strong homology to the vertebrate $\beta_{1-3}$ adrenergic receptors, respectively (Maqueira et al., 2005). Like their vertebrate counterparts, all three $\beta$-receptors are coupled to the cAMP signal transduction cascade through activation of adenylyl cyclase (Chang et al., 2000; Maqueira et al., 2005; Balfanz et al., 2014). A fourth $\beta$-like receptor has also been suggested to be present in honeybees (Hauser et al., 2006; Balfanz et al., 2014). For a more detailed review of species-specific expression of the various isoforms, the reader is referred to a number of excellent dedicated reviews on invertebrate OCT/TYR receptors (Hauser et al., 2006; Verlinden et al., 2010a).

\section{Tyramine Receptors}

Dedicated invertebrate TYR receptors were first suggested in 1990 (Arakawa et al., 1990; Saudou et al., 1990), with three GPCRs (TyrRI, TyrRII, and TyrRIII) subsequently identified. TyrRI is the least selective of the three, recognizing both OCT and TYR (Robb et al., 1994; Reale et al., 1997), although in most species there is a higher affinity for TYR (Vanden Broeck et al., 1995; Evans and Maqueira, 2005; Bayliss et al., 2013). TyrRI is homologous to vertebrate $\alpha_{2}$-adrenoceptors (Evans and Maqueira, 2005) and may exhibit agonist-dependent coupling, since TYR was reported to induce adenylyl cyclase inhibition (Vanden Broeck et al., 1995; Blenau and Baumann, 2001), whereas OCT induces an increase in cytosolic $\mathrm{Ca}^{2+}$ (Robb et al., 1994; Evans and Maqueira, 2005; Beggs et al., 2011). A second TyrRI isoform was very recently reported in the cockroach (Blenau et al., 2017).

TyrRII and TyrRIII show much greater selectivity toward TYR over OCT (Cazzamali et al., 2005; Bayliss et al., 2013), although TyrRIII also responds to a variety of other amines (Bayliss et al., 2013). Orthologs of TyrRII have been identified in multiple species (Cazzamali et al., 2005; Hauser et al., 2006; Huang et al., 2009; Bayliss et al., 2013; Wu et al., 2015), although TyrRIII has thus far only been identified in Drosophila. TyrRII activation is associated with a release of $\mathrm{Ca}^{2+}$ from intracellular stores (Cazzamali et al., 2005; Huang et al., 2009), whereas TyrRIII is coupled to an inhibition of adenylyl cyclase (Bayliss et al., 2013).

In addition to GPCRs, one ionotropic TYR receptor has been reported in C. elegans (Pirri et al., 2009; Ringstad et al., 2009). The ligand-gated ion channel LGC-55 receptor is a TYR-gated $\mathrm{Cl}^{-}$channel that can also be activated by PEA (Safratowich et al., 2014) and is involved in the control of locomotor activity. Orthologs of LGC-55 have also been identified in other nematode species (Pirri et al., 2009).

\section{E. Physiologic Responses}

TYR and more particularly OCT have been implicated in a variety of physiologic responses in invertebrates. Their receptors are not restricted to the nervous system but rather are distributed throughout the body (Saraswati et al., 2004; Roeder, 2005; Vierk et al., 2009; Ma et al., 2015). Although responses to TYR have generally received less attention, when both have been studied, TYR generally induces responses opposite to those of OCT (Saraswati et al., 2004; Ma et al., 2015). Although some of the responses (in particular those toward OCT) are similar to those that have been proposed to be mediated by TAARs in vertebrates, it is important to emphasize again that vertebrate TAARs and the invertebrate OCT/TYR receptors are evolutionarily very distant from each other (Gloriam et al., 2005; Lindemann et al., 2005; Hashiguchi and Nishida, 2007).

1. Octopamine. Consistent with serving the role of an invertebrate adrenergic system, OCT has been shown to modulate both peripheral and central responses in a manner consistent with a "fight-or-flight" response (Sotnikova and Gainetdinov, 2009). Among these effects are enhanced locomotion and flight muscle performance (Pribbenow and Erber, 1996; Saraswati et al., 2004; Fussnecker et al., 2006; Bloch and Meshi, 2007; Vierk et al., 2009), both direct and indirect mobilization of fat stores (Roeder, 2005), as well as increases in cardiac and respiratory rates (Zornik et al., 
1999). OCT-mediated regulation of immune responses (Huang et al., 2012) and a role in reproductive behavior have also been reported (Lee et al., 2003; Lim et al., 2014). In the firefly, OCT is well established to underlie the neural basis of light emission (Copeland and Robertson, 1982; Christensen et al., 1983; Hashemzadeh et al., 1985) and also regulates bioluminescent emissions in glow worms (Rigby and Merritt, 2011). Modulation of sensory inputs by OCT is also well established (Farooqui, 2007), with effects seen in relation to vision (Bacon et al., 1995; Scheiner et al., 2014), olfaction (Barron et al., 2002; Anton et al., 2006; Farooqui, 2007; Flecke and Stengl, 2009; Cassenaer and Laurent, 2012; Ma et al., 2015), hearing (Andrés et al., 2016), taste (Scheiner et al., 2002; Pankiw and Page, 2003), and touch and proprioception (Büschges et al., 1993; Skorupski, 1996).

Within the central nervous system, OCT has been established to play a role in sensitization responses (Sombati and Hoyle, 1984; Stelinski et al., 2003), as well as learning and memory (Hammer, 1997; Farooqui et al., 2003; Evans and Maqueira, 2005), reward circuitry (Unoki et al., 2005), and feeding behavior (Yang et al., 2015b). A role for OCT in kin recognition and other complex conspecific social behaviors within colonies has also been shown (Schulz and Robinson, 2001; Spivak et al., 2003; Lehman et al., 2006; Ma et al., 2015). Finally, OCT has been reported to play a role in mediating aggressive behaviors (Stevenson et al., 2005; Hoyer et al., 2008; Rillich et al., 2011).

2. Tyramine. As previously described, although less well studied, TYR effects generally appear to functionally oppose those of OCT. As such, TYR-mediated decreases in locomotion (Nagaya et al., 2002; Saraswati et al., 2004), flying behavior (Fussnecker et al., 2006; Vierk et al., 2009), and foraging (Barron et al., 2002; Schulz et al., 2003) have been seen. Roles in sensory perception, particularly taste (Scheiner et al., 2002; Pankiw and Page, 2003) and olfaction (Kutsukake et al., 2000; Anton et al., 2006; Kononenko et al., 2009; Ma et al., 2015), have also been ascribed to TYR. TYRinduced increases in the rate of habituation (Braun and Bicker, 1992) and modification of complex group dynamics (Ma et al., 2015) are reported to occur independently of the conversion of TYR to OCT.

\section{Trace Amine-Associated Receptors}

High-affinity mammalian receptors for the archetypal trace amines were long suspected. A saturable, high-affinity binding site for PEA was reported in 1982 (Hauger et al., 1982), although this was subsequently suggested to in fact represent binding to MAO-B (Li et al., 1992a). Similarly saturable, highaffinity binding sites for TYR (Ungar et al., 1977; Vaccari, 1986) and TRP (Kellar and Cascio, 1982; Altar et al., 1986; McCormack et al., 1986; Perry,
1986; van Nguyen et al., 1989) were sporadically reported but were rarely verified or characterized beyond the initial reports. Even the identification of invertebrate high-affinity receptors for TYR and OCT did little to help, with vertebrate homologs not present.

The receptor family now known as TAARs was initially discovered in 2001 by two separate groups (Borowsky et al., 2001; Bunzow et al., 2001). Borowsky et al. (2001) had been searching for novel 5-HT receptors, screening genomic DNA with primers designed to conserved regions of the sixth and seventh transmembrane regions of known 5-HT receptors. The novel family of GPCRs they identified was initially termed trace amine receptors on the basis of the high affinity for PEA and TYR of two of the family members identified. The authors proposed the new receptor family be abbreviated as $\mathrm{TA}_{\mathrm{x}}$, with $\mathrm{x}$ being a numeral to designate individual isoforms (Table 3), although the individual isoform identifiers were rarely subscripted in subsequent use. Bunzow et al. (2001), as part of their search for novel catecholamine receptors, screened cDNA obtained from rat pancreatic tumor cell lines using degenerate primers designed against the conserved third and sixth transmembrane regions of known catecholamine GPCRs. The novel GPCR they identified was termed trace amine receptor 1 or TAR1, based on their pharmacological profiling. In retrospect, the choice of pancreatic cell lines was remarkably prescient and was a factor that has subsequently been largely overlooked. Although many have struggled with the low expression levels of TAARs in most tissues, the pancreas and particularly $\beta$ cells have been shown to be uniquely abundant in their TAAR1 expression (Regard et al., 2007; Raab et al., 2015).

The identification of a family of trace amine receptors generated considerable interest in large part because the initial pharmacological profiling indicated that a number of psychotropic agents exhibited high affinity for one of the family members (TAAR1) (Bunzow et al., 2001). Furthermore, both original reports localized the new trace amine receptor family to human chromosome 6q23.2 (Borowsky et al., 2001; Bunzow et al., 2001), a replicated putative susceptibility locus for schizophrenia (Cao et al., 1997; Kaufmann et al., 1998; Levinson et al., 2000) and mood disorders (Venken et al., 2005). As such, it is not too surprising that the greater abundance of at least some of the receptor family in the pancreas became overlooked, and the field became devoted almost entirely to the central nervous system effects of TAAR1, the only functional family member in humans with a clearly demonstrated endogenous ligand. Unfortunately, there was little consistency in nomenclature in these early days (see Table 3), with some researchers using the nomenclature of Bunzow, others that of Borowsky, and some a third nomenclature system designated as TRAR (Duan et al., 2004). Not only were different nomenclatures used, but isoform identification was not consistent, 
TABLE 3

Relationship of different nomenclature systems to TAAR families

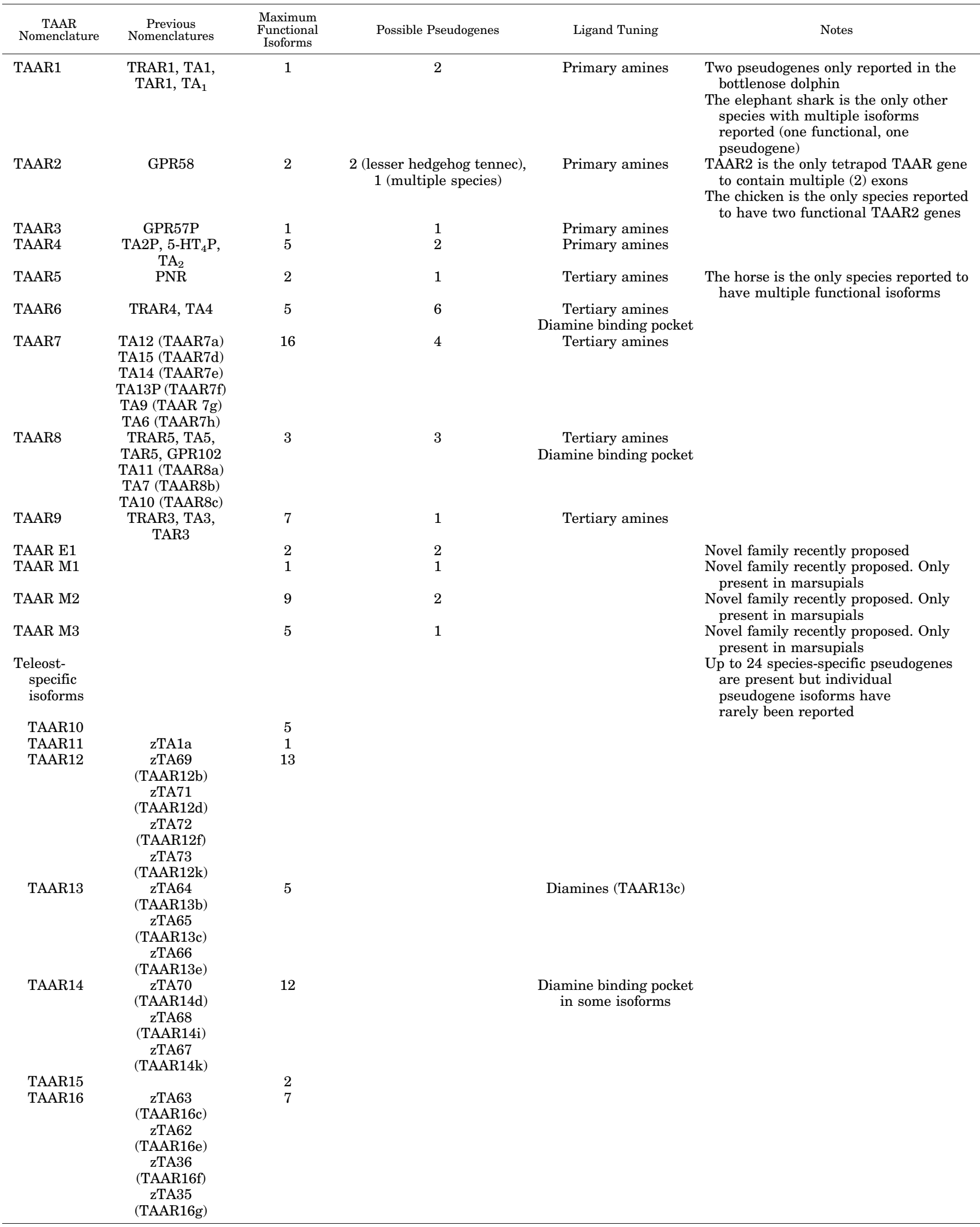


TABLE 3-Continued

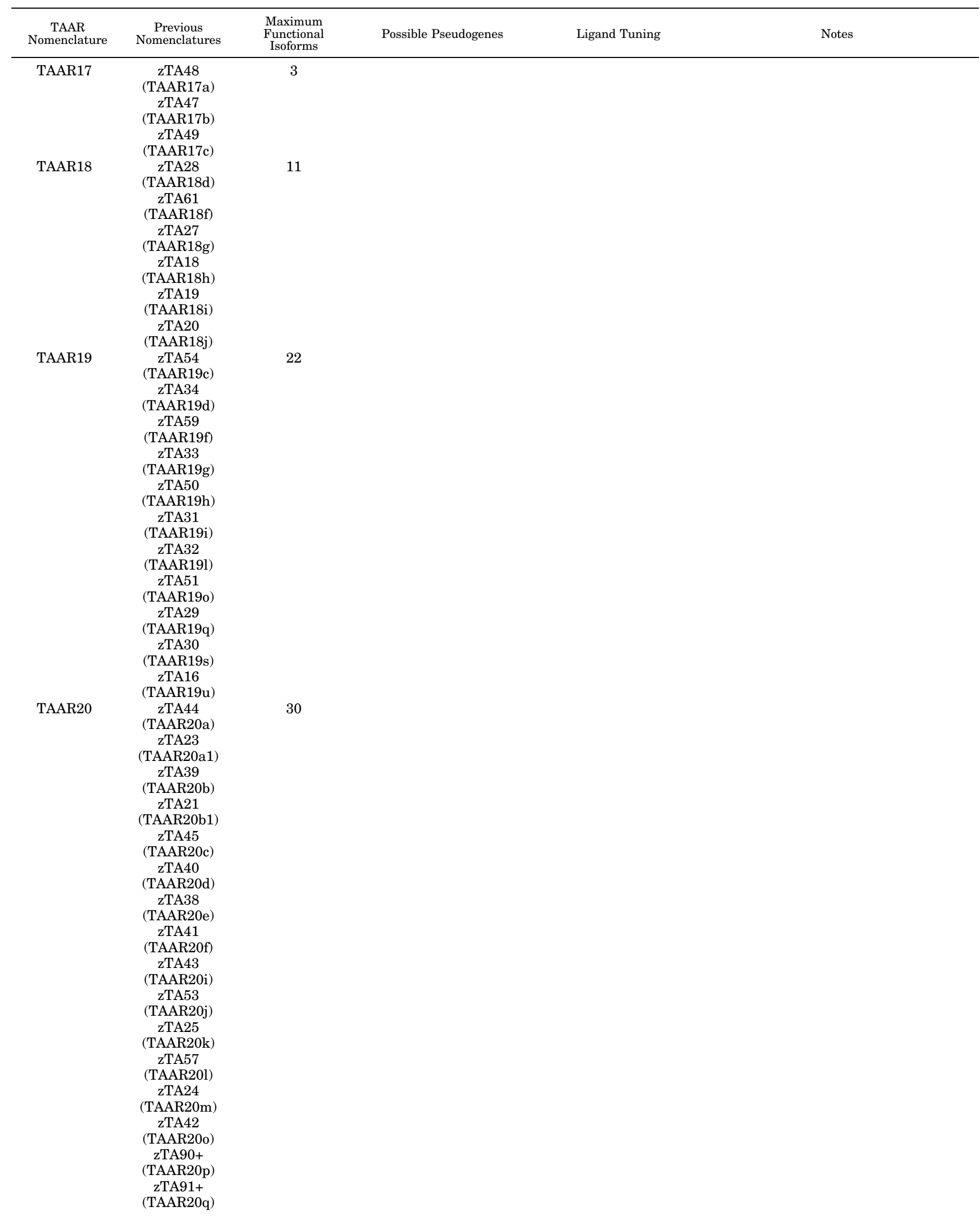




\begin{tabular}{|c|c|c|c|c|c|}
\hline $\begin{array}{c}\text { TAAR } \\
\text { Nomenclature }\end{array}$ & $\begin{array}{c}\text { Previous } \\
\text { Nomenclatures }\end{array}$ & $\begin{array}{l}\text { Maximum } \\
\text { Functional } \\
\text { Isoforms }\end{array}$ & Possible Pseudogenes & Ligand Tuning & Notes \\
\hline & $\begin{array}{c}\text { zTA37 } \\
\text { (TAAR20r) } \\
\text { zTA56 } \\
\text { (TAAR20t) } \\
\text { zTA55 } \\
\text { (TAAR20u) } \\
\text { zTA46 } \\
\text { (TAAR20w) } \\
\text { zTA26 } \\
\text { (TAAR20x) } \\
\text { zTA22 } \\
\text { (TAAR20y) } \\
\text { zTA52 } \\
\text { (TAAR20z) }\end{array}$ & & & & \\
\hline TAAR21 & & 6 & & & \\
\hline TAAR22 & & 6 & & & \\
\hline TAAR23 & & 15 & & & \\
\hline TAAR24 & & 3 & & & \\
\hline TAAR25 & & 12 & & & \\
\hline TAAR26 & & 28 & & & \\
\hline TAAR27 & & 6 & & & \\
\hline TAAR28 & & 8 & & & \\
\hline \multicolumn{6}{|l|}{$\begin{array}{l}\text { Lamprey } \\
\text { outgroups }\end{array}$} \\
\hline TAAR-like & & 25 & 17 & & \\
\hline
\end{tabular}

GPR57, G protein-coupled receptor 57; GPR58, G protein-coupled receptor 58; PNR, putative neurotransmitter receptor.

resulting in the same receptor sometimes being given different numerical designations in each system (Table 3). A standardized nomenclature system (TAAR) was proposed in 2005 based on a thorough examination of gene sequences, phylogenetic relationships, and chromosomal organization (Lindemann et al., 2005). This classification system has stood the test of time and been independently validated on numerous occasions (Hashiguchi and Nishida, 2007; Hussain et al., 2009; Libants et al., 2009; Vallender et al., 2010; Tessarolo et al., 2014; Azzouzi et al., 2015; Eyun et al., 2016; Gao et al., 2017). Indeed, the TAAR nomenclature system (Table 3) is now used exclusively by those active in the field. Despite this, controversy remains. The only family member to be deorphanized by IUPHAR has been designated $\mathrm{TA}_{1}$ (Maguire et al., 2009; Alexander et al., 2015), presenting an uncomfortable situation in which those working in the field and the official nomenclature committee are using different naming systems. The IUPHAR recommendation is based on the convention that receptors be named for their endogenous ligand. There is, however, no consensus ligand for the TAAR family as a whole (Lindemann et al., 2005; Ferrero et al., 2012), with some members (TAAR1-TAAR4) being tuned to primary amines, whereas other family members (TAAR5-TAAR9) are tuned toward tertiary amines (Ferrero et al., 2012). Some (TAAR6 and 8) may even be activated by diamines ( $\mathrm{Li}$ et al., 2015) (Table 3). Furthermore, as discussed earlier, there is no standard, accepted definition of what comprises a "trace amine." With the IUPHAR TA designation prone to confusion with the earlier nomenclature systems that were based on an incomplete phylogeny, we strongly advocate for a renewed, open dialog between IUPHAR and leading trace amine researchers to resolve this situation.

In 2006, a new and surprising arm to trace amine research was identified when Stephen Liberles and Linda Buck showed that the TAAR family also acted as a new class of receptors for olfaction (Liberles and Buck, 2006). This attracted a whole new cadre of researchers who have contributed to significant advancements of the TAAR field, in particular, with respect to the identification of putative endogenous ligands for family members other than TAAR1. As discussed fully in subsequent sections, the one notable exception is TAAR 1 , which is evolutionarily the oldest member of the family but the only family member with no role to play in the detection of olfactory cues (Liberles and Buck, 2006). The identification of the role of TAARs in the detection of olfactory cues was not without controversy, however, as it was also reported that no family member (other than TAAR1) was present outside of the olfactory epithelium (Liberles and Buck, 2006; Carnicelli et al., 2010). This now appears to not be the case (Table 4) and likely was due to the low expression levels of TAARs generally present, along with a lack of suitably sensitive and selective reagents at that time. This lack of research tools has been a recurring problem for the TAAR field (Berry et al., 2017), although it is slowly beginning to be addressed.

The identification of putative endogenous ligands for TAARs other than TAAR1 has provided an added impetus to the elucidation of TAAR pharmacology. That many of these ligands originate from ecologically significant sources, such as predators, spoiled food, and 
even putative pheromones, has further spurred research efforts to understand the evolution of TAARs. Although there are still many open questions, through these research efforts a picture has emerged of TAARs being intricately linked to the detection of olfactory cues associated with species-specific survival mechanisms. That TAARs are also distributed throughout the body (Table 4) and at least some of their endogenous ligands readily cross cell membranes (Berry et al., 2013) provides an interesting perspective, which potentially allows the same molecule that provides the environmental cue to directly affect various physiologic processes that could conceivably further aid in adaptation responses. Rather than existing as distinct fields, it is expected that in the upcoming years much closer links will be forged between the olfactory and nonolfactory TAAR communities, which will further speed the filling of current knowledge gaps with respect to the basic underlying physiology of TAAR systems.

\section{A. Evolution of Trace Amine-Associated Receptors}

At present, the majority of evidence suggests that an ancestral TAAR-like protein first emerged in lamprey (Gloriam et al., 2005; Hashiguchi and Nishida, 2007; Libants et al., 2009; Eyun et al., 2016), with a conserved TAAR signature motif appearing later, after the divergence of jawed vertebrates from jawless fish (Fig. 6). Others have, however, suggested that TAAR ancestral emergence only occurred after the divergence from lamprey (Hussain et al., 2009; Tessarolo et al., 2014) largely because of the absence of the conserved TAAR motif from the lamprey receptors. Lamprey do innately avoid PEA sources (Imre et al., 2014), a response known to be TAAR mediated in jawed vertebrates; although the molecular basis of this lamprey avoidance behavior is unknown, it is potentially consistent with ancestral TAARs being present.

Among mammals, the highest number of TAARs identified thus far is in the flying fox, with 26 functional genes, whereas the bottlenose dolphin is the only vertebrate species known to contain no functional TAAR genes (Eyun et al., 2016). Like in other tetrapods, mammalian TAARs generally belong to nine subfamilies (TAAR1-TAAR9). Within these, repeated speciesspecific expansion, duplication, and pseudogenization events have occurred. This has resulted in great variability in the total number of functional TAARs present between species (Table 5), including the appearance of species-specific isoforms (Lindemann et al., 2005; Vallender et al., 2010; Eyun et al., 2016). For example, four putative new subgroups of TAARs were recently described: TAAR E1, which is present in the common shrew, hedgehog, lesser hedgehog tenrec, and African elephant; and TAARs M1-M3 found in two marsupial species, tammar wallaby and opossum (Eyun et al., 2016), consistent with previous suggestions of marsupial-specific TAARs (Vallender et al., 2010). These new families appear to belong to the clade II, tertiary amine-recognizing group of TAARs, and as such are most closely related to TAAR5-TAAR9 (Eyun et al., 2016). Of these putative new TAARs, species-specific variants of TAAR E1, M2, and M3 were reported.

Two species appear rather unique (Table 5); the bottlenose dolphin, as previously described, has no functional TAAR genes, only possessing three pseudogenes (Eyun et al., 2016). Meanwhile, the dog is the only known species to express functional TAARs but no TAAR1, and its genome being represented with functional TAAR4 and TAAR5 plus a further two pseudogenes (Vallender et al., 2010).

Interestingly, the number of TAARs appears to be correlated with the number of olfactory receptors in most species, with the exception of Canis, which has more than 800 olfactory receptors but only two functional TAARs, with the olfactory receptors likely compensating for the majority of functions served by TAARs in other species (Eyun et al., 2016). There are up to seven functional genes in Xenopus (Mueller et al., 2008; Eyun et al., 2016), although the TAAR complement of the true frogs (Rana sp.) has not been determined. This is a notable knowledge gap for the determination of the evolutionary relationships of olfactory functions, with the amphibian olfactory system regarded as an evolutionary midpoint between teleosts and tetrapods (Duchamp-Viret and Duchamp, 1997; Gliem et al., 2013).

The mammalian TAAR1-TAAR9 family seems to have two distinct evolutionary patterns. Primary amine-detecting clade I TAARs (TAAR1-TAAR4) (Ferrero et al., 2012) appear to be evolving under strong negative (purifying) selection criteria, whereas the tertiary amine-detecting clade II TAARs (TAAR5TAAR9) (Ferrero et al., 2012) show significant variations in gene numbers and appear to evolve under the influence of positive selection pressures (Eyun et al., 2016). Similarly, clade III zebrafish TAARs have undergone strong positive selection (Hussain et al., 2009). Thus, the profiles of TAAR expression appear to be evolutionarily determined by adaptive responses; indeed, there is now evidence that TAAR expression can either be influenced by habitat changes or determine habitat choice (Churcher et al., 2015; Fatsini et al., 2016), consistent with a role in the detection and response to migratory cues.

As expected from the above, the primary aminedetecting TAAR1-TAAR4 appear to be evolutionarily older, more conserved, and are generally represented by a single isoform in the majority of genomes, with the exception of TAAR4 (in which a low level of speciesspecific expansion has occurred) (Hussain et al., 2009; Eyun et al., 2016). In contrast, the tertiary aminedetecting mammalian TAARs (TAAR5-TAAR9) have arisen more recently with multiple species-specific isoforms of each subtype present, with the exception of 
TABLE 4

Cellular and tissue expression profile of TAARs

\begin{tabular}{|c|c|c|c|}
\hline Mammalian TAAR & Species & Expression & Method \\
\hline TAAR1 & rat $^{j, m-p},{ }^{a-d}$ mouse,,$^{b, e-l}$ & 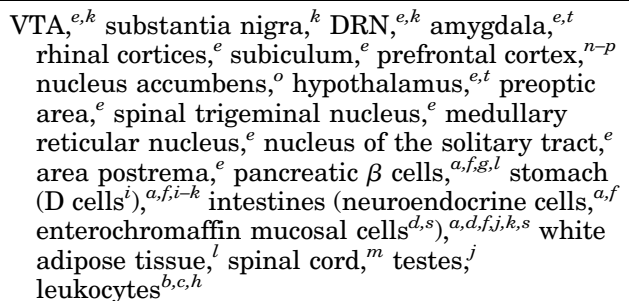 & $\begin{array}{l}\text { TAAR1-KO/lacZ KI mouse, }{ }^{e, f} \\
\text { immunohistochemistry, }{ }^{a, c, o, p} \mathrm{RT} \mathrm{PCR},{ }^{b, g-j, l, m, s} \\
\text { RNA sequencing, }{ }^{i, k} \text { in situ hybridization }{ }^{k, m}\end{array}$ \\
\hline TAAR2 & $\underset{\text { rat }^{j}}{\text { Human }},{ }^{b, q, r}$ mouse, $, h, q, s$ & $\begin{array}{l}\text { Olfactory epithelium, }{ }^{q, r} \text { intestines, }{ }^{s} \text { testes }{ }^{j} \\
\text { leukocytes }{ }^{b, h}\end{array}$ & $\mathrm{RT}^{\mathrm{P}} \mathrm{PCR}^{b, h-j, q-s}$ \\
\hline TAAR3 & Mouse, ${ }^{q}$ rat $^{j}$ & Olfactory epithelium, ${ }^{q}$ testes $^{j}$ & $\mathrm{RT}-\mathrm{PCR}^{q, j}$ \\
\hline TAAR4 & Mouse, ${ }^{l, q}$ rat $^{j, m}$ & $\begin{array}{l}\text { Olfactory epithelium, }{ }^{l, q} \text { trachea, }{ }^{l} \text { spinal cord, }{ }^{m} \\
\text { spleen },{ }^{j} \text { testes },{ }^{j} \text { muscle }\end{array}$ & $\mathrm{RT}^{-P C R},{ }^{j, l, m, q}$ in situ hybridization ${ }^{m}$ \\
\hline TAAR5 & $\underset{\text { rat }^{j, m, u}}{\text { Human, }},{ }^{q, r}$ mouse,${ }^{b, h, q, t}$ & 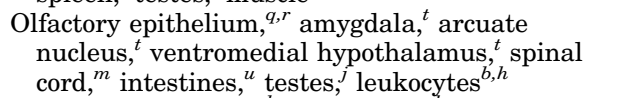 & $\mathrm{RT} \mathrm{PCR},{ }^{b, h, j, m, q, r, u}$ in situ hybridization ${ }^{t}$ \\
\hline TAAR6 & 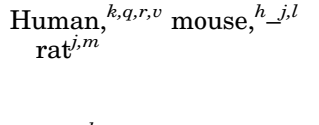 & $\begin{array}{l}\text { Olfactory epithelium, }{ }^{l, q, r} \text { amygdala }{ }^{k, v} \\
\text { hippocampus, }{ }^{, v} \text { basal ganglia, }{ }^{v} \text { frontal cortex, }{ }^{v} \\
\text { substantia nigra, }{ }^{v} \text { spinal cord, }{ }^{m} \text { intestines, }{ }^{s} \\
{\text { testes, }{ }^{j} \text { kidney, }{ }^{k} \text { leukocytes }}^{h}\end{array}$ & $\mathrm{RT}^{\mathrm{P}} \mathrm{PCR}^{h-l, q-s, v}$ \\
\hline TAAR7 & Mouse $^{l, q}$ & Olfactory epithelium ${ }^{l, q}$ & $\mathrm{RT}-\mathrm{PCR}^{l, q}$ \\
\hline TAAR8 & 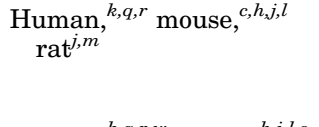 & 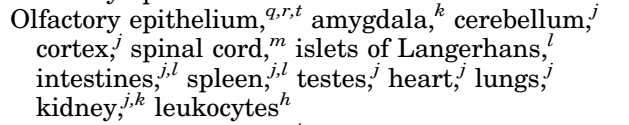 & $\mathrm{RT}-\mathrm{PCR}^{c, h, j-m, q, r}$ \\
\hline TAAR9 & $\begin{array}{l}\text { Human } \\
\text { rat }^{k, q, r, w}\end{array}$ & $\begin{array}{l}\text { Olfactory epithelium, }{ }^{q, r, t} \text { pituitary gland, }{ }^{w} \text { skeletal } \\
\text { muscle, }{ }^{w} \text { spinal cord, }{ }^{m} \text { intestines, }{ }^{l, s} \text { spleen, }{ }^{l} \\
\text { kidney, }{ }^{k} \text { leukocytes }\end{array}$ & RT-PCR, ${ }^{h, k-m, q-s}$ Northern blot ${ }^{w}$ \\
\hline
\end{tabular}

KI, knock-in; RT-PCR, reverse transcription polymerase chain reaction.

${ }^{a}$ Raab et al. (2015).

${ }^{b}$ Nelson et al. (2007).

${ }^{c}$ Wasik et al. (2012).

${ }^{d}$ Kidd et al. (2008).

${ }^{e}$ Lindemann et al. (2008)

${ }^{f}$ Revel et al. (2013).

${ }^{g}$ Regard et al. (2007).

${ }^{h}$ Babusyte et al. (2013).

${ }^{i}$ Adriaenssens et al. (2015).

${ }^{j}$ Chiellini et al. (2012).

${ }^{k}$ Borowsky et al. (2001)

${ }^{l}$ Regard et al. (2008).

${ }^{m}$ Gozal et al. (2014).

${ }^{n}$ Espinoza et al. (2015b).

${ }^{o}$ Liu et al. (2018).

${ }^{p}$ Ferragud et al. (2017).

${ }^{q}$ Liberles and Buck (2006).

${ }^{r}$ Carnicelli et al. (2010).

${ }^{s}$ Ito et al. (2009).

${ }^{t}$ Dinter et al. (2015c).

${ }^{u}$ Kubo et al. (2015).

${ }^{v}$ Duan et al. (2004)

${ }^{w}$ Vanti et al. (2003)

TAAR5 (the oldest of the clade II genes) (Eyun et al., 2016). The only TAAR that is not expressed in the olfactory system (TAAR1) is the oldest member of the family, with TAAR4 the second oldest, and these two family members share considerable overlap in their ligand selectivity (Lindemann et al., 2005). Other evolutionarily ancient members of the family (TAAR2, TAAR3, and TAAR5) are also thought to predate the origin of amniotes (Eyun et al., 2016). All other mammalian TAAR subfamilies are currently thought to derive from a single copy of one of these ancestral TAARs via gene duplication (Eyun et al., 2016). The teleost-specific clade III TAARs are thought to be the most recent family members to have emerged (Hussain et al., 2009).

\section{B. Trace Amine-Associated Receptor 1}

TAAR1 is the best characterized of the TAAR family and is currently regarded as the main target for PEA and TYR, although in this respect it should be noted that TAAR4, a pseudogene in humans, is also a target but has rarely been studied. TAAR1 is expressed in brain structures associated with psychiatric disorders, in particular in key areas where modulation of dopamine [ventral tegmental area (VTA)] and serotonin [dorsal raphe nuclei (DRN)] occurs (Table 4), and the presence of TAAR1 variants was recently reported to be associated with schizophrenia (John et al., 2017). In the periphery, TAAR1 expression suggests putative roles in regulating immune system responses and controlling energy metabolism. The current understanding of the 


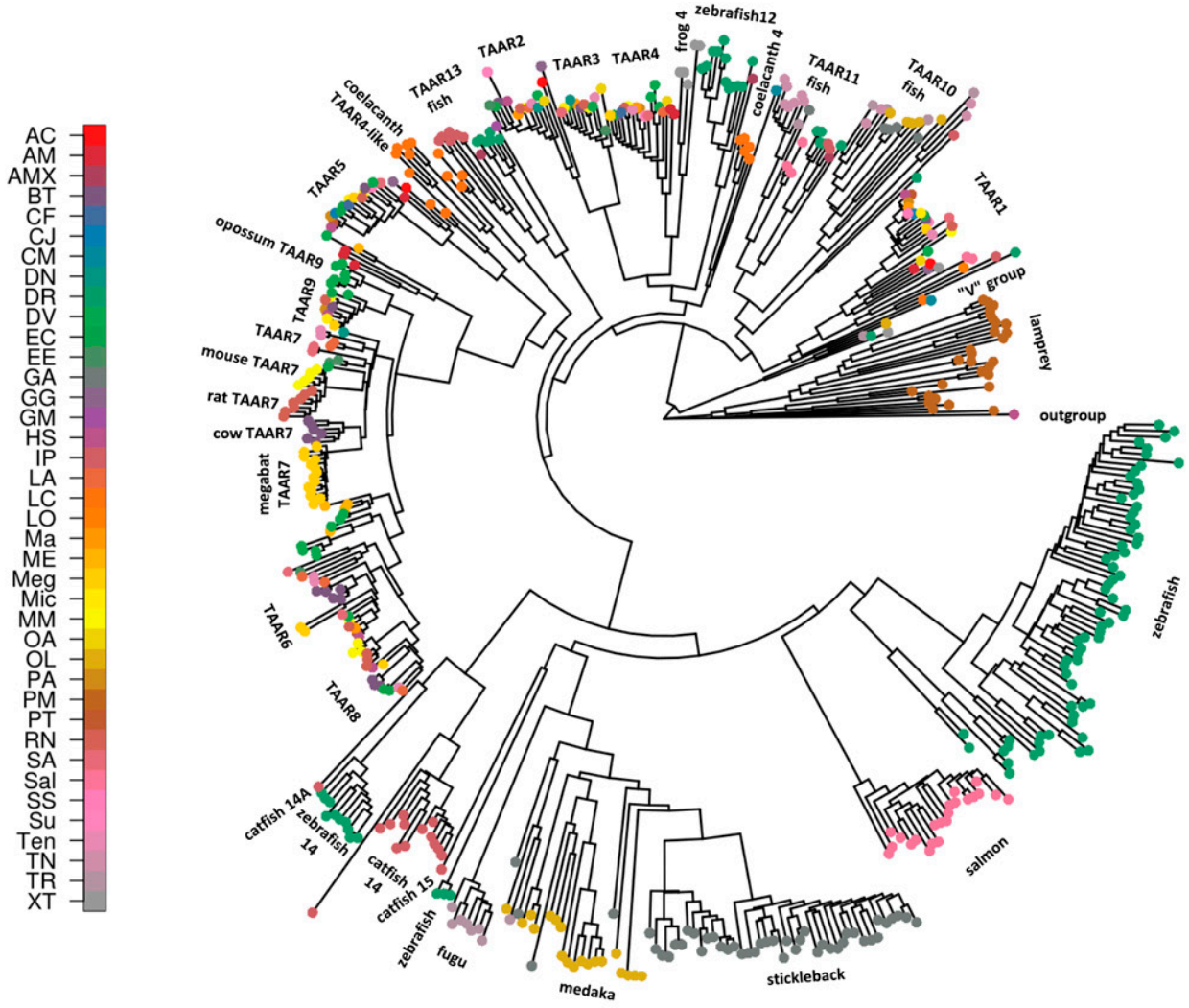

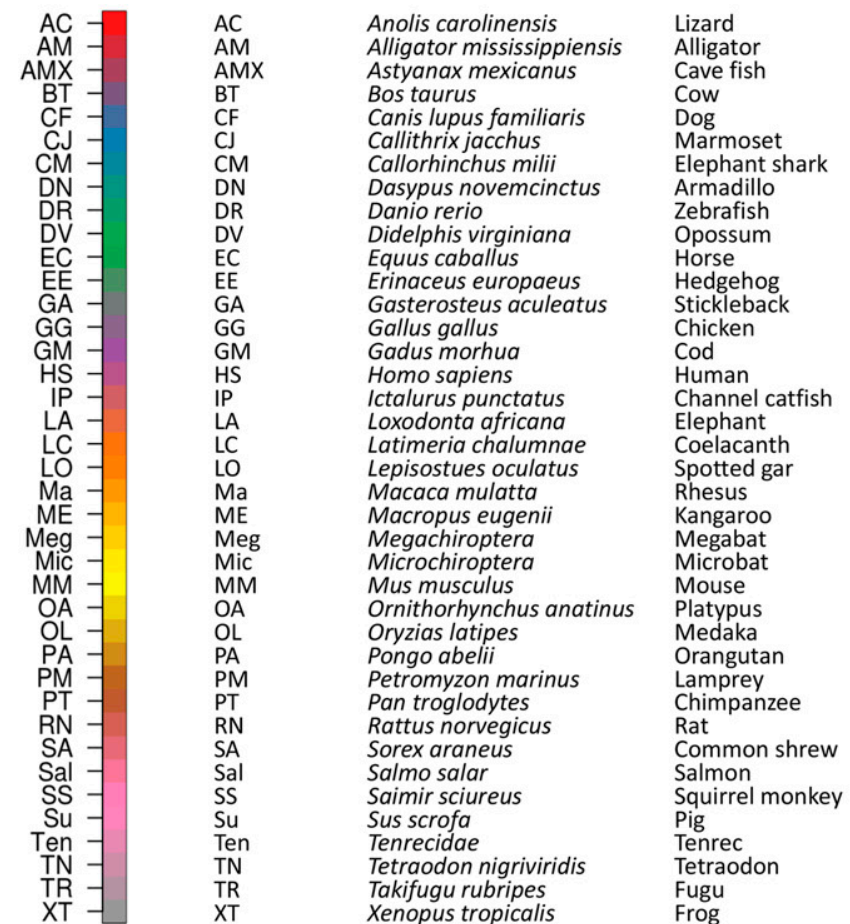

Fig. 6. Phylogenetic tree of TAARs. Sequences from the publications by Azzouzi et al. (2015), Gao et al. (2017), Eyun et al. (2016), Tessarolo et al. (2014), and Vallender et al. (2010) were used. Using the jackhmmer program from the hmmer-3.1b1 software package (http:/hmmer.org, Howard Hughes Medical Institute) and chimpanzee TAAR1 as a seed, we iteratively built a hidden Markov model (HMM) representing TAARs. All of the sequences were scored and aligned against this HMM (which has 339 match positions). Next, all sequences between 250 and 450 amino acids long, with at least 280 match positions to the HMM, and with a starting methionine were selected. We made the selection nonredundant, correcting apparent sequencing errors in a few cases where the different sources above disagreed. Based on the alignment of the selected sequences to the TAAR-HMM, protein distances were calculated using the protdist program from the phylip software package version 3.69 (with default parameters, http://evolution.genetics.washington.edu/phylip.html, University of Washington). A tree was then generated using the neighbor program from the same package, with default parameters, and using human histamine receptor $\mathrm{H} 2$ as an outgroup. 
TABLE 5

Species variation in TAAR isoforms

Some of the studies used incompletely characterized or draft genomes resulting in markedly lower TAAR numbers identified than in studies using more rigorous protocols.

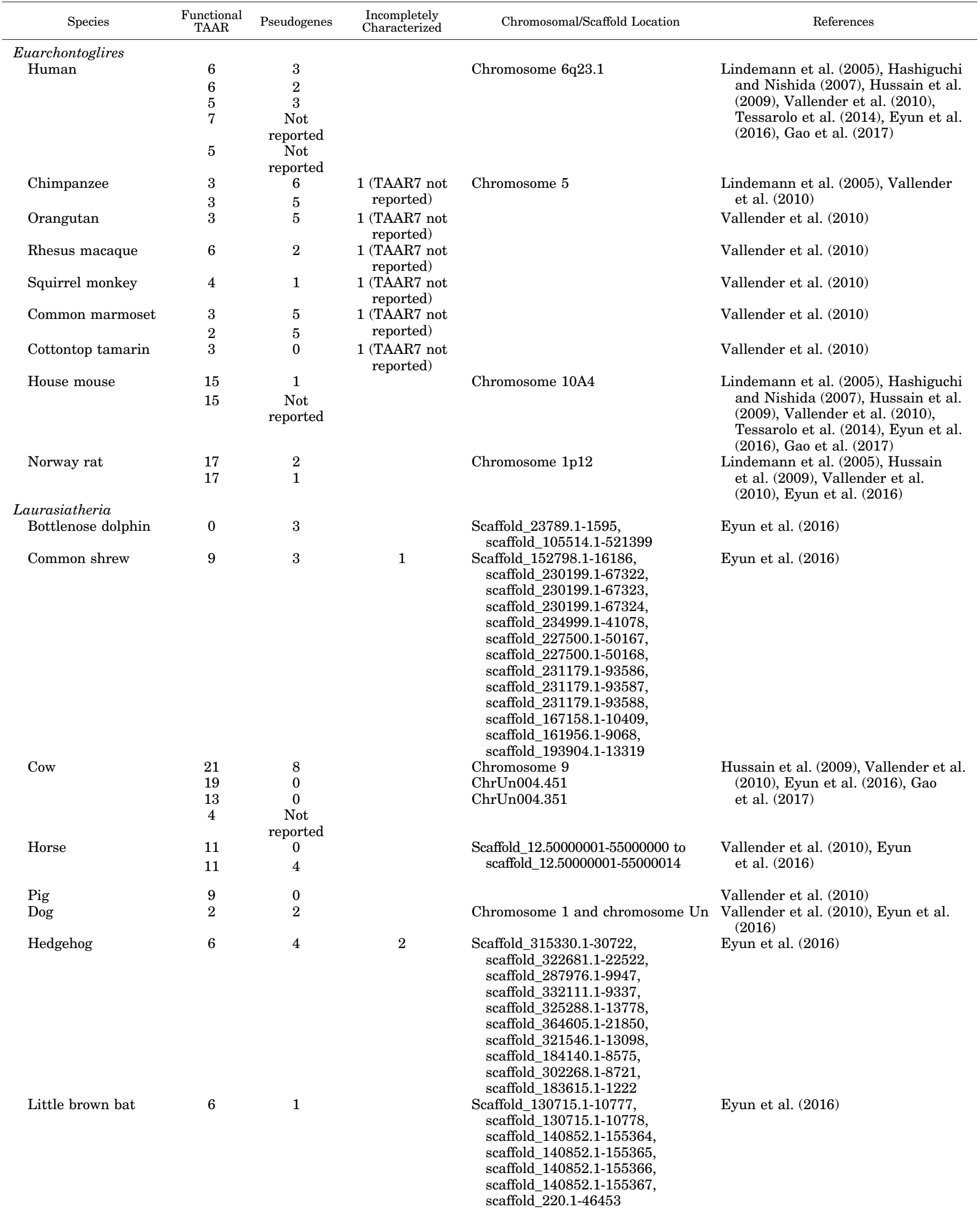


TABLE 5-Continued

\begin{tabular}{|c|c|c|c|c|c|}
\hline Species & $\begin{array}{c}\text { Functional } \\
\text { TAAR }\end{array}$ & Pseudogenes & $\begin{array}{l}\text { Incompletely } \\
\text { Characterized }\end{array}$ & Chromosomal/Scaffold Location & References \\
\hline Malayan flying fox & 26 & 10 & & $\begin{array}{l}\text { Scaffold_12831.1-39811, } \\
\text { scaffold_12831.1-39812, } \\
\text { scaffold_12831.1-39813, } \\
\text { scaffold_12831.1-39814, } \\
\text { scaffold_17466.1-19369, } \\
\text { scaffold_17466.1-19370, } \\
\text { scaffold_18837.1-16342, } \\
\text { scaffold_18837.1-16343, } \\
\text { scaffold_18973.1-15890, } \\
\text { scaffold_19339.1-14625, } \\
\text { scaffold_19339.1-14626, } \\
\text { scaffold19375.1-14563, } \\
\text { scaffold_19997.1-13482, } \\
\text { scaffold_19997.1-13483, } \\
\text { scaffold_20227.1-12945, } \\
\text { scaffold_20465.1-15670, } \\
\text { scaffold_20465.1-15671, } \\
\text { scaffold_22299.1-9969, } \\
\text { scaffold_24703.1-7136, } \\
\text { scaffold_25351.1-11297, } \\
\text { scaffold_25351.1-11298, } \\
\text { scaffold_26592.1-7418, } \\
\text { scaffold_29671.1-4951, } \\
\text { scaffold_34747.1-4153, } \\
\text { scaffold_35764.1-2782, } \\
\text { scaffold_36915.1-2635, } \\
\text { scaffold_38546.1-2466, } \\
\text { scaffold_44184.1-2021, } \\
\text { scaffold_8480.1-69282, } \\
\text { scaffold_8480.1-69283, } \\
\text { scaffold_8480.1-69284, } \\
\text { scaffold_8949.1-64714, } \\
\text { scaffold_8949.1-64715, } \\
\text { scaffold_8949.1-64716, } \\
\text { scaffold_8949.1-64717, } \\
\text { scaffold_8949.1-64718 }\end{array}$ & Eyun et al. (2016) \\
\hline $\begin{array}{l}\text { Afrotheria } \\
\quad \text { African elephant }\end{array}$ & 9 & 3 & 3 & $\begin{array}{l}\text { Scaffold_7842.1-91204, } \\
\text { scaffold_7842.1-91205, } \\
\text { scaffold_7842.1-91206, } \\
\text { scaffold_7842.1-91207, } \\
\text { scaffold_0.25000001-30000000, } \\
\text { scaffold_7842.1-91209, } \\
\text { scaffold_23946.1-26436, } \\
\text { scaffold_23946.1-26437, } \\
\text { scaffold_23946.1-26438, } \\
\text { scaffold_3583.1-140411, } \\
\text { scaffold_3583.1-140412, } \\
\text { scaffold_3583.1-140413, } \\
\text { scaffold_19337.1-58480, } \\
\text { scaffold_19337.1-58481, } \\
\text { scaffold_79621.1-6335 }\end{array}$ & Eyun et al. (2016) \\
\hline $\begin{array}{l}\text { Lesser hedgehog } \\
\text { tenec }\end{array}$ & 9 & 7 & 1 & $\begin{array}{l}\text { Scaffold_96430.1-8246, } \\
\text { scaffold_161156.1-8572, } \\
\text { scaffold_231756.1-18732, } \\
\text { scaffold_198886.1-11295, } \\
\text { scaffold_167756.1-3881, } \\
\text { scaffold_167122.1-3947, } \\
\text { scaffold_256442.1-4595, } \\
\text { scaffold_262922.1-7019, } \\
\text { scaffold_229023.1-10280, } \\
\text { scaffold_228176.1-10370, } \\
\text { scaffold_10127.1-6004, } \\
\text { scaffold_232273.1-5125, } \\
\text { scaffold_47746.1-4410, } \\
\text { scaffold_250749.1-11800, } \\
\text { scaffold_234201.1-11315, } \\
\text { scaffold_173561.1-5671, } \\
\text { scaffold_187047.1-4403 }\end{array}$ & Eyun et al. (2016) \\
\hline $\begin{array}{l}\text { Xenarthra } \\
\text { Nine-banded } \\
\text { armadillo }\end{array}$ & 5 & 4 & & $\begin{array}{l}\text { Scaffold_13715, scaffold_68458, } \\
\text { scaffold_106240, scaffold_58549, } \\
\text { scaffold_181544, scaffold_31645, } \\
\text { scaffold_31595 }\end{array}$ & Eyun et al. (2016) \\
\hline
\end{tabular}


TABLE 5-Continued

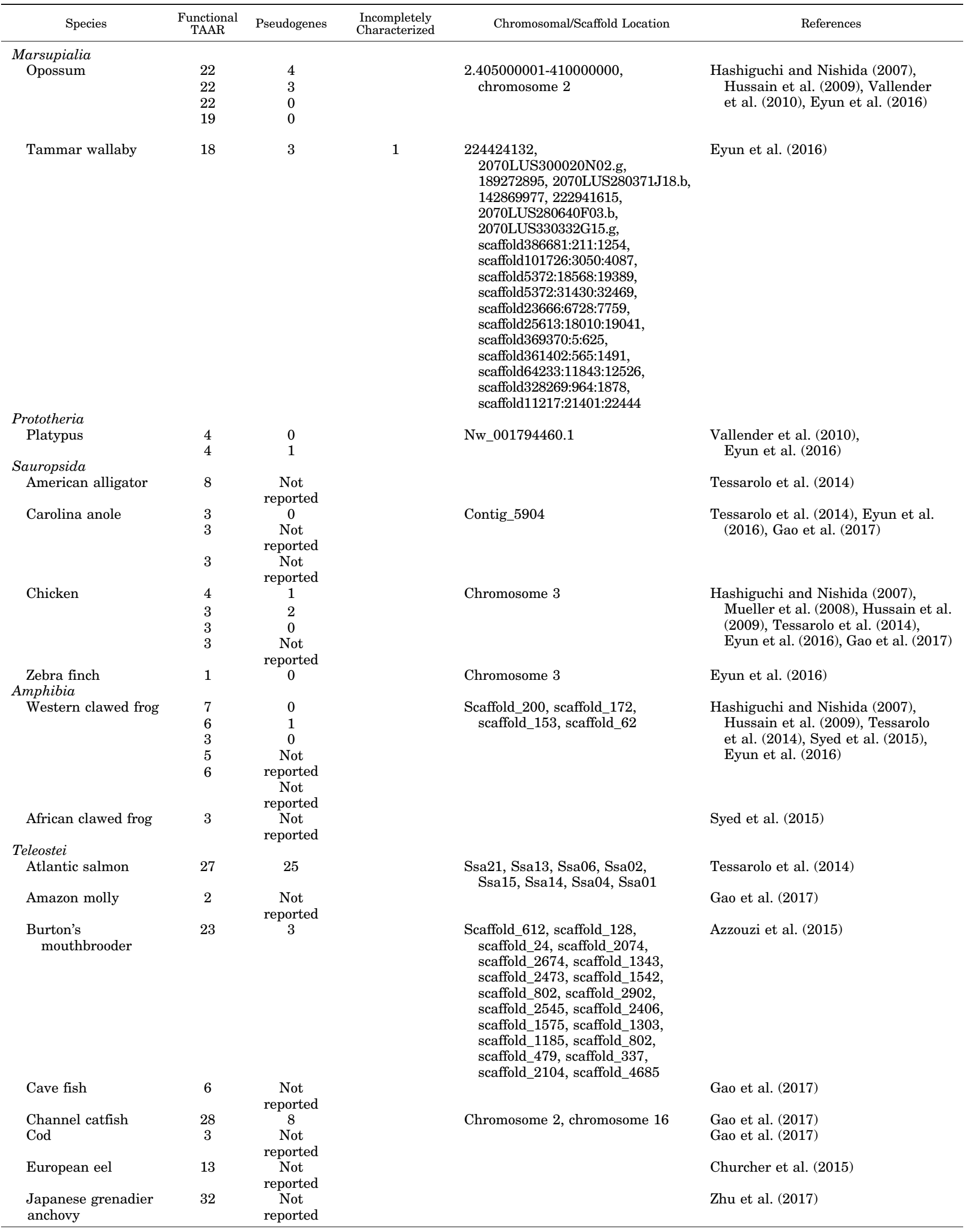


TABLE 5-Continued

\begin{tabular}{|c|c|c|c|c|c|}
\hline Species & $\begin{array}{l}\text { Functional } \\
\text { TAAR }\end{array}$ & Pseudogenes & $\begin{array}{l}\text { Incompletely } \\
\text { Characterized }\end{array}$ & Chromosomal/Scaffold Location & References \\
\hline $\begin{array}{l}\text { Japanese pufferfish } \\
\text { (fugu) }\end{array}$ & $\begin{array}{c}18 \\
13 \\
18 \\
6 \\
\\
2\end{array}$ & $\begin{array}{l}1 \\
6 \\
0 \\
\text { Not } \\
\text { reported } \\
\text { Not } \\
\text { reported }\end{array}$ & & $\begin{array}{l}\text { Scaffold_144, scaffold_2286, } \\
\text { scaffold_682, scaffold_2971, } \\
\text { scaffold_347, scaffold_36, } \\
\text { scaffold_3984, scaffold_5473, } \\
\text { scaffold_55, scaffold_62, } \\
\text { scaffold_7591, scaffold_3049, } \\
\text { scaffold_510, scaffold_2618, } \\
\text { scaffold_375 }\end{array}$ & $\begin{array}{l}\text { Hashiguchi and Nishida (2007), } \\
\text { Hashiguchi et al. (2008), Hussain } \\
\text { et al. (2009), Tessarolo et al. (2014), } \\
\text { Eyun et al. (2016), Gao et al. (2017) }\end{array}$ \\
\hline $\begin{array}{l}\text { Japanese rice fish } \\
\text { (medaka) }\end{array}$ & $\begin{array}{c}27 \\
25 \\
25 \\
6 \\
2\end{array}$ & $\begin{array}{l}7 \\
7 \\
1 \\
\text { Not } \\
\text { reported } \\
\text { Not } \\
\text { reported }\end{array}$ & & $\begin{array}{l}\text { Chromosome 2, chromosome 21, } \\
\text { chromosome 24, scaffold_2442, } \\
\text { scaffold_2165, scaffold_2246, } \\
\text { scaffold_3620, scaffold_4535, } \\
\text { scaffold_691 }\end{array}$ & $\begin{array}{l}\text { Hashiguchi and Nishida (2007), } \\
\text { Hashiguchi et al. (2008), Hussain } \\
\text { et al. (2009), Tessarolo et al. (2014), } \\
\text { Gao et al. (2017) }\end{array}$ \\
\hline $\begin{array}{l}\text { Makobe Island } \\
\text { cichlid }\end{array}$ & 18 & 3 & & $\begin{array}{l}\text { Scaffold_133, scaffold_193, } \\
\text { scaffold_490, scaffold_295, } \\
\text { scaffold_238, scaffold_947, } \\
\text { scaffold_857, scaffold_159, } \\
\text { scaffold_1502, scaffold_2325, } \\
\text { scaffold_1573, scaffold 698 }\end{array}$ & Azzouzi et al. (2015) \\
\hline Maylandia zebra & 20 & 5 & & $\begin{array}{l}\text { Scaffold00183, scaffold00006, } \\
\text { scaffold00127, scaffold00676, } \\
\text { scaffold00347, scaffold00068, } \\
\text { scaffold02965, scaffold00108, } \\
\text { scaffold02487, scaffold02369, } \\
\text { scaffold02115, scaffold01981, } \\
\text { scaffold00834, scaffold00561, } \\
\text { scaffold00347, scaffold02144 }\end{array}$ & Azzouzi et al. (2015) \\
\hline Nile tilapia & $\begin{array}{l}44 \\
2\end{array}$ & $\begin{array}{c}8 \\
\text { Not } \\
\text { reported }\end{array}$ & & $\begin{array}{l}\text { Scaffold_195, scaffold_84, } \\
\text { scaffold_005, scaffold_374, } \\
\text { scaffold_16, scaffold_242, } \\
\text { scaffold_183, scaffold_78 }\end{array}$ & $\begin{array}{l}\text { Azzouzi et al. (2015), } \\
\text { Gao et al. (2017) }\end{array}$ \\
\hline Platyfish & 2 & $\begin{array}{l}\text { Not } \\
\text { reported }\end{array}$ & & & Gao et al. (2017) \\
\hline Princess cichlid & 12 & 2 & & $\begin{array}{l}\text { Scaffold_18, scaffold_25, scaffold_31, } \\
\text { scaffold_166, scaffold_1763, } \\
\text { scaffold_26, scaffold_160 }\end{array}$ & Azzouzi et al. (2015) \\
\hline Spotted gar & 3 & $\begin{array}{l}\text { Not } \\
\text { reported }\end{array}$ & & & Gao et al. (2017) \\
\hline $\begin{array}{l}\text { Spotted green } \\
\text { pufferfish }\end{array}$ & $\begin{array}{l}34 \\
12 \\
18 \\
17 \\
11 \\
\\
2\end{array}$ & $\begin{array}{c}3 \\
4 \\
0 \\
\text { Not } \\
\text { reported } \\
\text { Not } \\
\text { reported } \\
\text { Not } \\
\text { reported }\end{array}$ & & $\begin{array}{l}\text { Chromosomes 3-7, chromosomes } \\
\text { 14-21, chrUN_random }\end{array}$ & $\begin{array}{l}\text { Hashiguchi et al. (2008), Hussain } \\
\text { et al. (2009), Tessarolo et al. (2014), } \\
\text { Eyun et al. (2016), Gao et al. (2017) }\end{array}$ \\
\hline $\begin{array}{r}\text { Three-spined } \\
\text { stickleback }\end{array}$ & $\begin{array}{l}50 \\
49 \\
48 \\
5 \\
2\end{array}$ & $\begin{array}{l}15 \\
15 \\
0 \\
\text { Not } \\
\text { reported } \\
\text { Not } \\
\text { reported }\end{array}$ & & $\begin{array}{l}\text { LG 9, LG 16, LG 18, scaffold_37, } \\
\text { scaffold_160, scaffold_56 }\end{array}$ & $\begin{array}{l}\text { Hashiguchi and Nishida (2007), } \\
\text { Hashiguchi et al. (2008), Tessarolo } \\
\text { et al. (2014), Gao et al. (2017) }\end{array}$ \\
\hline $\begin{array}{l}\text { West Indian ocean } \\
\text { coelacanth }\end{array}$ & 18 & $\begin{array}{l}\text { Not } \\
\text { reported }\end{array}$ & & & Tessarolo et al. (2014) \\
\hline Zebrafish & $\begin{array}{l}110 \\
109 \\
112 \\
102 \\
94\end{array}$ & $\begin{array}{l}10 \\
10 \\
4 \\
\text { Not } \\
\text { reported } \\
\text { Not } \\
\text { reported }\end{array}$ & & $\begin{array}{l}\text { Chromosome 1, chromosome } 7, \\
\text { chromosome 10, chromosome } 12, \\
\text { chromosome 13, chromosome } 15, \\
\text { chromosome } 20, \text { Zv6_NA2102 }\end{array}$ & $\begin{array}{l}\text { Hashiguchi and Nishida (2007), } \\
\text { Hashiguchi et al. (2008), Hussain } \\
\text { et al. (2009), Tessarolo et al. (2014), } \\
\text { Eyun et al. (2016), Gao et al. (2017) }\end{array}$ \\
\hline $\begin{array}{l}\text { Chondrichthyes } \\
\text { Elephant shark }\end{array}$ & $\begin{array}{l}2 \\
2 \\
2\end{array}$ & $\begin{array}{c}3 \\
0 \\
\text { Not } \\
\text { reported }\end{array}$ & & $\begin{array}{l}\text { AAVX01005735.1, } \\
\text { AAVX01475249.1, } \\
\text { AAVX01045569.1, } \\
\text { AAVX01508596.1, } \\
\text { AAVX01365441.1 }\end{array}$ & $\begin{array}{l}\text { Hussain et al. (2009), Tessarolo et al. } \\
\text { (2014), Eyun et al. (2016), Gao } \\
\text { et al. (2017) }\end{array}$ \\
\hline
\end{tabular}


TABLE 5-Continued

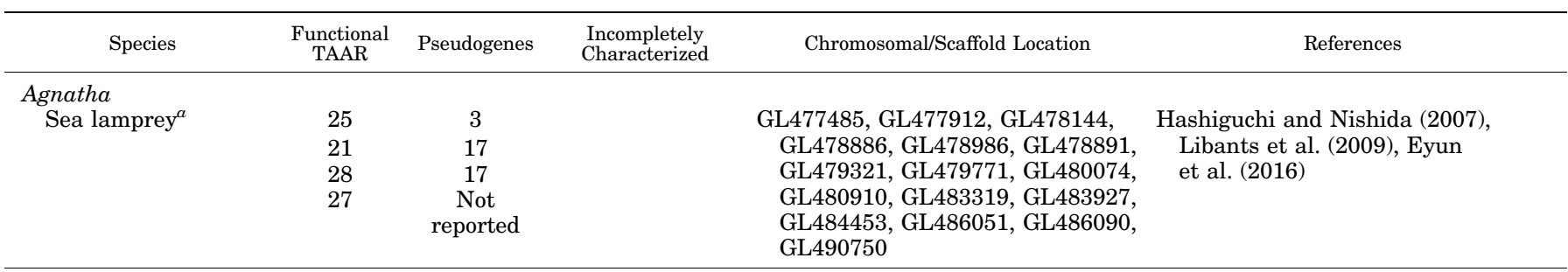

${ }^{a}$ There is still some debate about whether lamprey contain TAAR, TAAR-like, or a completely separate family of receptors.

cellular distribution and pharmacological profile of TAAR 1 in validated disease models is summarized in Tables 4 and 6 and described in detail in the following sections.

Characterization of TAAR1-KO and TAAR1overexpressing (OE) mouse and rat lines has greatly contributed to a better understanding of TAAR1 function (Wolinsky et al., 2007; Lindemann et al., 2008; Di Cara et al., 2011; Revel et al., 2011, 2012a; Espinoza et al., 2015a; Harmeier et al., 2015; Black et al., 2017; Schwartz et al., 2017). TAAR1-KO mice exhibit an enhanced response to amphetamine, resulting in an increased hyperlocomotion that is correlated with more pronounced increases of dopamine, norepinephrine, and serotonin (Wolinsky et al., 2007; Lindemann et al., 2008). TAAR1-OE mice show phenotypically opposite effects with lowered sensitivity to amphetamine, whereas their wild-type littermates maintain a normal hyperlocomotion response (Revel et al., 2012a). Furthermore, the spontaneous firing rate of dopaminergic neurons in the VTA and serotonergic neurons in the DRN is increased in TAAR1-KO mice (Bradaia et al., 2009; Revel et al., 2011). Thus, TAAR 1 plays an active role in the expression of behaviors traditionally associated with classic neurotransmitters, supporting its potentially important role in the modulation of neurotransmitter functions and, hence, in mental illness.

1. Pharmacology of Trace Amine-Associated Receptor 1.

a. Trace Amine-Associated Receptor 1 Gene Conservation. The intronless TAAR1 gene is conserved across mammals, avians, and amphibians and, based on the rates of amino acid fixation compared with neutral mutations, is under strong purifying selection (Hussain et al., 2009). TAAR1 gene homology between humans and cynomolgus monkeys and between rats and mice is $97 \%$ and $77 \%$, respectively. Interestingly, in dogs (Vallender et al., 2010) and dolphins (Eyun et al., 2016), TAAR1 has become a pseudogene, resulting in an uncompensated loss of function. Comparative genetics analysis in dogs revealed that this pseudogenization event predated the emergence of the Canini tribe and is not coincident with canine domestication (Vallender et al., 2010). All other vertebrates have maintained a functional TAAR1.

b. Expression of Trace Amine-Associated Receptor 1. Compared with most other GPCRs, one of the defining features of TAAR 1 is its generally low expression levels, and this has contributed to a number of initial reports of TAAR1 expression failing to be validated with more robust reagents. Overall advancements in the field have been further hampered by a slow development of suitably selective pharmacological tools for the systematic probing of tissue and cellular expression profiles (Berry et al., 2017). In mice, replacement of the Taar1 coding sequence with a $L a c Z$ reporter construct under the control of the endogenous Taar1 promoter has allowed demonstration of a heterogenous distribution of TAAR 1 within the central nervous system (Lindemann et al., 2008; Table 4). This distribution generally mirrors that of the known dopaminergic, glutamatergic, and serotonergic systems, with both mRNA and protein confirmed in the amygdala, basal ganglia, limbic areas, prefrontal cortex, raphe nuclei, substantia nigra pars compacta, and VTA (Borowsky et al., 2001; Lindemann et al., 2008). Such a distribution is generally seen in both rodents and primates and is consistent with the effects of TAAR1directed ligands described in other sections. At least in humans, expression may not be limited to neurons with one report of astrocytic TAAR1 (Cisneros and Ghorpade, 2014). Spinal cord expression may also occur, at least in rats (Gozal et al., 2014).

One of the other defining features of TAAR 1 expression is its absence from the olfactory epithelium, in stark contrast to all other TAAR family members (Liberles and Buck, 2006; Carnicelli et al., 2010). In the periphery, TAAR1 is prominently located throughout the gastrointestinal system in cells involved in hormone secretion in response to the presence of nutrients (Table 4). This includes the D cells of the stomach (Chiellini et al., 2012; Revel et al., 2013; Adriaenssens et al., 2015; Raab et al., 2015), pancreatic $\beta$ cells (Regard et al., 2007; Revel et al., 2013; Raab et al., 2015), and intestinal enterochromaffin mucosal cells (Kidd et al., 2008; Ito et al., 2009; Revel et al., 2013; Raab et al., 2015) of both rodents and humans. Multiple groups have also reported the presence of TAAR1 mRNA and protein in various populations of mouse and human leukocytes (D'Andrea et al., 2003; Nelson et al., 2007; Wasik et al., 2012; Babusyte et al., 2013), and the presence of TAAR1 protein in breast tissue was suggested very recently (Vattai et al., 2017), although in this latter instance no details on the cell type(s) in which staining was observed were provided. Furthermore, 
TABLE 6

In vivo pharmacological effects of TAAR1-selective agonists

\begin{tabular}{|c|c|c|c|c|c|}
\hline Study Type & Species/Test System & $\begin{array}{l}\text { Pretreatment/ } \\
\text { Duration }\end{array}$ & $\begin{array}{l}\text { Animals per } \\
\text { Group }(\mathrm{M} / \mathrm{F})\end{array}$ & $\begin{array}{l}\text { RO5166017 Dose/ } \\
\text { Concentration }\end{array}$ & Key Results \\
\hline & & $\min$ & $n$ & $\mathrm{mg} / \mathrm{kg}$ & \\
\hline $\begin{array}{l}\text { Cocaine-induced } \\
\text { hyperlocomotion }^{a}\end{array}$ & C57Bl6 mice & $30 / 30$ & $8 \mathrm{M}$ & $0.03-3$ p.o. & $\begin{array}{l}\text { Attenuation at } 0.3,1 \text {, and } \\
3 \mathrm{mg} / \mathrm{kg} \text { p.o. }\end{array}$ \\
\hline $\begin{array}{l}\text { Cocaine-induced } \\
\text { hyperlocomotion }^{a}\end{array}$ & $\begin{array}{l}\text { C57Bl6 TAAR1-KO and WT } \\
\text { littermate mice }\end{array}$ & $30 / 30$ & $10 \mathrm{M}$ & $0.3-1$ p.o. & $\begin{array}{l}\text { Attenuation at } 0.3 \text { and } 1 \mathrm{mg} / \mathrm{kg} \text { p.o. } \\
\text { in WT mice, no effect in } \\
\text { TAAR1-KO mice }\end{array}$ \\
\hline $\begin{array}{l}\text { Spontaneous } \\
\text { hyperlocomotion in } \\
\text { DAT-KO mice }\end{array}$ & $\begin{array}{l}\text { C57Bl6 DAT-KO and WT } \\
\text { littermate mice }\end{array}$ & None/90 & $8 \mathrm{M}$ & $0.2-1$ p.o. & Attenuation at 0.5 and $1 \mathrm{mg} / \mathrm{kg}$ p.o. \\
\hline $\begin{array}{l}\text { L-687,414-induced } \\
\text { hyperlocomotion }^{a}\end{array}$ & NMRI mice & $30 / 30$ & $8 \mathrm{M}$ & $0.01-0.1$ p.o. & Attenuation at $0.1 \mathrm{mg} / \mathrm{kg}$ p.o. \\
\hline $\begin{array}{l}\text { L-687,414-induced } \\
\text { hyperlocomotion }^{a}\end{array}$ & $\begin{array}{l}\text { C57Bl6 TAAR1-KO and WT } \\
\text { littermate mice }\end{array}$ & $60 / 30$ & $8 \mathrm{M}$ & 1 p.o. & $\begin{array}{l}\text { Attenuation at } 1 \mathrm{mg} / \mathrm{kg} \text { p.o. in WT } \\
\text { mice, no effect in TAAR1-KO } \\
\text { mice }\end{array}$ \\
\hline $\mathrm{SIH}^{a}$ & NMRI mice & $45 / 15$ & $8-16 \mathrm{M}$ & 0.01-1 p.o. & $\begin{array}{l}\text { Reversal of SIH }(\mathrm{dT}) \text { at doses } \\
0.1 \text { and } 0.3 \mathrm{mg} / \mathrm{kg} \text { without } \\
\text { affecting } \mathrm{T}_{\mathrm{b}}\end{array}$ \\
\hline $\mathrm{SIH}^{a}$ & $\begin{array}{l}\text { C57Bl6 TAAR1-KO and WT } \\
\text { littermate mice }\end{array}$ & $45 / 15$ & $8-10 \mathrm{M}$ & 0.1 p.o. & $\begin{array}{l}\text { Reversal of SIH }(\mathrm{dT}) \text { at } \\
0.1 \mathrm{mg} / \mathrm{kg} \text { in WT mice, no effect } \\
\text { in TAAR1-KO mice }\end{array}$ \\
\hline Cocaine-induced $\mathrm{CPP}^{b}$ & Sprague-Dawley rats & 10 & 9 to $10 \mathrm{M}$ & 10 i.p. & $\begin{array}{l}\text { Inhibition of expression, but not } \\
\text { retention of cocaine reward } \\
\text { memory at } 10 \mathrm{mg} / \mathrm{kg} \text { i.p. }\end{array}$ \\
\hline $\begin{array}{l}\text { Abuse-related effects of } \\
\text { nicotine }^{c}\end{array}$ & Sprague-Dawley rats & 10 & $6-9 \mathrm{M}$ & 3.2-10 i.p. & $\begin{array}{l}\text { Reduction of nicotine self- } \\
\text { administration (at } 5.6 \text { and } \\
10 \mathrm{mg} / \mathrm{kg} \text { i.p.) and attenuation of } \\
\text { cue- and drug-induced } \\
\text { reinstatement of nicotine- } \\
\text { seeking (at } 10 \mathrm{mg} / \mathrm{kg} \text { i.p.) }\end{array}$ \\
\hline $\mathrm{oGTT}^{d}$ & $\begin{array}{l}\text { C57Bl6 TAAR1-KO and WT } \\
\text { littermate mice }\end{array}$ & $45 / 120$ & $5-8 \mathrm{M}$ & $0.3 \mathrm{mg} / \mathrm{kg}$ p.o. & $\begin{array}{l}\text { Glucose-lowering effect at } \\
0.3 \mathrm{mg} / \mathrm{kg} \text { p.o. in WT mice and } \\
\text { increased PYY and GLP-1 } \\
\text { levels, no effect in TAAR1-KO } \\
\text { mice }\end{array}$ \\
\hline $\mathrm{oGTT}^{d}$ & $\begin{array}{l}\text { Diabetic db/db C57Bl6 mice, } \\
\text { DIO mice, DIO Glp1R-KO } \\
\text { mice }\end{array}$ & $45 / 120$ & $8 \mathrm{M}$ & 0.3 mg/kg p.o. & $\begin{array}{l}\text { Glucose-lowering effect at } \\
0.3 \mathrm{mg} / \mathrm{kg} \text { p.o. in diabetic } \\
\mathrm{db} / \mathrm{db} \text { mice }\end{array}$ \\
\hline ivGTT $^{d}$ & C57Bl6 mice & $30 / 10$ & $10 \mathrm{M}$ & $3 \mathrm{mg} / \mathrm{kg}$ s.c. & $\begin{array}{l}\text { Lower amount of meal emptied at } \\
0.3 \mathrm{mg} / \mathrm{kg} \text { p.o. }\end{array}$ \\
\hline Gastric emptying $^{d}$ & C57Bl6 mice & $45 / 30$ & $8 \mathrm{M}$ & $0.3 \mathrm{mg} / \mathrm{kg}$ p.o. & $\begin{array}{l}\text { Lower amount of meal emptied at } \\
0.3 \mathrm{mg} / \mathrm{kg} \text { p.o. }\end{array}$ \\
\hline $\begin{array}{l}\text { Food intake and body } \\
\text { weight }^{d}\end{array}$ & C57Bl6 mice, DIO mice, & $45 / 60$ & $6 \mathrm{M}$ & $0.3 \mathrm{mg} / \mathrm{kg}$ s.c. & $\begin{array}{l}\text { Reduction in food intake and body } \\
\text { weight, reduced triglyceride } \\
\text { levels, increased insulin } \\
\text { sensitivity at } \\
0.3 \mathrm{mg} / \mathrm{kg} \mathrm{p.o.}\end{array}$ \\
\hline Study Type & Species/Test System & $\begin{array}{l}\text { Pretreatment/ } \\
\text { Duration }\end{array}$ & $\begin{array}{l}\text { Animals per } \\
\text { Group }(\mathrm{M} / \mathrm{F})\end{array}$ & $\begin{array}{l}\text { RO5203648 Dose/ } \\
\text { Concentration }\end{array}$ & Key Results \\
\hline & & $\min$ & $n$ & $m g / k g$ & \\
\hline $\begin{array}{l}\text { Cocaine-induced } \\
\text { hyperlocomotion }^{e}\end{array}$ & C57Bl6 mice & $30 / 30$ & $8-16 \mathrm{M}$ & $0.3-10$ p.o. & Attenuation at 1 and $3 \mathrm{mg} / \mathrm{kg}$ p.o. \\
\hline $\begin{array}{l}\text { Cocaine-induced } \\
\text { hyperlocomotion }\end{array}$ & Wistar rats & $60 / 30$ & 7 to $8 \mathrm{M}$ & 1-10 p.o. & Attenuation at $10 \mathrm{mg} / \mathrm{kg}$ p.o. \\
\hline $\begin{array}{l}\text { Spontaneous } \\
\text { hyperlocomotion in } \\
\text { DAT-KO mice }\end{array}$ & $\begin{array}{l}\text { C57Bl6 DAT-KO and WT } \\
\text { littermate mice }\end{array}$ & None/60 & $5-9 \mathrm{M}$ & 1 p.o. & $\begin{array}{l}\text { Attenuation at } 1 \mathrm{mg} / \mathrm{kg} \text { p.o. in } \\
\text { DAT-KO mice, but no effect in } \\
\text { DAT-KO/TAAR1-KO mice }\end{array}$ \\
\hline $\begin{array}{l}\text { Spontaneous } \\
\text { hyperlocomotion in } \\
\text { DAT-KO mice }\end{array}$ & $\begin{array}{l}\text { C57Bl6 DAT-KO, TAAR1-KO, } \\
\text { and WT littermate mice }\end{array}$ & None/60 & $8-11 \mathrm{M}$ & 0.1-1 p.o. & $\begin{array}{l}\text { Attenuation at } 0.1,0.3 \text {, and } \\
1 \mathrm{mg} / \mathrm{kg} \text { p.o. }\end{array}$ \\
\hline $\begin{array}{l}\text { L-687,414-induced } \\
\text { hyperlocomotion }\end{array}$ & NMRI mice & $15 / 30$ & $8 \mathrm{M}$ & $0.01-0.1$ p.o. & Attenuation at $0.1 \mathrm{mg} / \mathrm{kg}$ p.o. \\
\hline $\begin{array}{l}\text { Spontaneous } \\
\text { hyperlocomotion in NR1 } \\
\text { KD mice }\end{array}$ & $\begin{array}{l}\text { C57Bl6 NR1 KD and WT } \\
\text { littermate mice }\end{array}$ & None/60 & 6 to $7 \mathrm{M}$ & 0.3-1 p.o. & $\begin{array}{l}\text { Attenuation at } 0.3 \text { and } 1 \mathrm{mg} / \mathrm{kg} \text { p.o. } \\
\text { in WT mice, no effect in NR1-KD } \\
\text { mice }\end{array}$ \\
\hline $\mathrm{SIH}^{e}$ & NMRI mice & $45 / 15$ & $6-8 \mathrm{M}$ & 0.1-1 p.o. & $\begin{array}{l}\text { Reversal of SIH (dT) at } \\
0.3 \mathrm{mg} / \mathrm{kg} \text { without affecting } \mathrm{T}_{\mathrm{b}}\end{array}$ \\
\hline Forced swim stress ${ }^{e}$ & Wistar rats & $\begin{array}{l}24 \mathrm{~h}, 18 \mathrm{~h} \\
1 \mathrm{~h} / 60\end{array}$ & $8 \mathrm{~F}$ & $3-30$ p.o. & $\begin{array}{l}\text { Significant decrease in immobility } \\
\text { time at } 10 \text { and } 30 \mathrm{mg} / \mathrm{kg} \text { p.o. }\end{array}$ \\
\hline $\begin{array}{l}\text { Cocaine self- } \\
\text { administration }^{e}\end{array}$ & Long-Evans rats & $60 / 60$ & 7 to $8 \mathrm{M}$ & $3-10$ i.p. & $\begin{array}{l}\text { Reduction of cocaine intake in rats } \\
\text { with a stable history of } \\
\text { intravenous cocaine self- } \\
\text { administration at } 3 \text { and } \\
10 \mathrm{mg} / \mathrm{kg} \text { i.p. }\end{array}$ \\
\hline
\end{tabular}


TABLE 6-Continued

\begin{tabular}{|c|c|c|c|c|c|}
\hline Study Type & Species/Test System & $\begin{array}{l}\text { Pretreatment/ } \\
\text { Duration }\end{array}$ & $\begin{array}{l}\text { Animals per } \\
\text { Group }(\mathrm{M} / \mathrm{F})\end{array}$ & $\begin{array}{l}\text { RO5203648 Dose/ } \\
\text { Concentration }\end{array}$ & Key Results \\
\hline & & min & \multicolumn{2}{|r|}{$m g / k g$} & \\
\hline $\begin{array}{l}\text { Context-induced cocaine } \\
\text { relapse }^{f}\end{array}$ & Long-Evans rats & $15 / 90$ & $6-8 \mathrm{M}$ & $3-10$ i.p. & $\begin{array}{l}\text { Suppression of cocaine seeking } \\
\text { after a } 2 \text {-wk period of } \\
\text { withdrawal from chronic cocaine } \\
\text { self-administration at } 3 \text { and } \\
10 \mathrm{mg} / \mathrm{kg} \text { i.p. }\end{array}$ \\
\hline $\begin{array}{l}\text { Methamphetamine self- } \\
\text { administration }^{g}\end{array}$ & Long-Evans rats & $10 / 60$ & $6-10 \mathrm{M}$ & 3-10 i.p. & $\begin{array}{l}\text { Reduction of methamphetamine } \\
\text { intake in rats with a stable } \\
\text { history of intravenous } \\
\text { methamphetamine self- } \\
\text { administration at } 3 \text { and } \\
10 \mathrm{mg} / \mathrm{kg} \text { i.p. }\end{array}$ \\
\hline $\begin{array}{l}\text { Methamphetamine- } \\
\text { stimulated } \\
\text { hyperactivity }^{g}\end{array}$ & Long-Evans rats & $70 / 60$ & 5 to $6 \mathrm{M}$ & $1.67-5$ i.p. & $\begin{array}{l}\text { Attenuation of methamphetamine- } \\
\text { induced hyperactivity and } \\
\text { prevention of development of } \\
\text { methamphetamine sensitization } \\
\text { at } 1.67 \text { and } 5 \mathrm{mg} / \mathrm{kg} \text { i.p. }\end{array}$ \\
\hline $\begin{array}{l}\text { Differential reinforcement } \\
\text { of low-rate behavior }\end{array}$ & Cynomolgus macaques & $\begin{array}{l}\text { 4-h injection } \\
\text { test interval }\end{array}$ & 5 to $6 \mathrm{M}$ & 1-30 p.o. & $\begin{array}{l}\text { Reduced response rate at } 10 \text { and } \\
30 \mathrm{mg} / \mathrm{kg} \text { p.o. and increased } \\
\text { inter-response time at } \\
30 \mathrm{mg} / \mathrm{kg} \text { p.o. }\end{array}$ \\
\hline Object retrieval $^{e}$ & Cynomolgus macaques & $90 / 90$ & $12 \mathrm{M}$ & 1-10 p.o. & Procognitive effect at $10 \mathrm{mg} / \mathrm{kg}$ p.o. \\
\hline $\begin{array}{l}\text { Haloperidol-induced } \\
\text { catalepsy }^{e}\end{array}$ & Wistar rats & $60 / 10$ & $12 \mathrm{M}$ & $0.3-10$ p.o. & $\begin{array}{l}\text { Reduction of catalepsy at } 0.3,3, \\
\text { and } 10 \mathrm{mg} / \mathrm{kg} \text { p.o. }\end{array}$ \\
\hline Sleep/wake parameters ${ }^{e}$ & Sprague-Dawley rats & $6 \mathrm{~h}$ & $8 \mathrm{M}$ & 1-10 p.o. & $\begin{array}{l}\text { Wake-promoting activity at } \\
10 \mathrm{mg} / \mathrm{kg} \text { p.o. }\end{array}$ \\
\hline Study Type & Species/Test System & $\begin{array}{l}\text { Pretreatment/ } \\
\text { Duration }\end{array}$ & $\begin{array}{l}\text { Animals per } \\
\text { Group }(\mathrm{M} / \mathrm{F})\end{array}$ & $\begin{array}{l}\text { RO5263397 Dose/ } \\
\text { Concentration }\end{array}$ & Key Results \\
\hline & & $\min$ & $n$ & $m g / k g$ & \\
\hline $\begin{array}{l}\text { Cocaine-induced } \\
\text { hyperlocomotion }^{h}\end{array}$ & C57Bl6 mice & $60 / 30$ & $6-8 \mathrm{M}$ & 0.3-3 p.o. & Attenuation at 1 and $3 \mathrm{mg} / \mathrm{kg}$ p.o. \\
\hline $\begin{array}{l}\text { PCP-induced } \\
\text { hyperlocomotion }^{h}\end{array}$ & C57Bl6 mice & $30 / 60$ & $7-16 \mathrm{M}$ & $0.003-1$ p.o. & $\begin{array}{l}\text { Attenuation at } 0.01,0.03,0.1 \text {, and } \\
0.3 \mathrm{mg} / \mathrm{kg} \text { p.o. }\end{array}$ \\
\hline $\begin{array}{l}\text { L-687,414-induced } \\
\quad \text { hyperlocomotion }^{h}\end{array}$ & NMRI mice & $15 / 30$ & $8-24 \mathrm{M}$ & 0.0003-1 p.o. & $\begin{array}{l}\text { Attenuation at } 0.003,0.01,0.03 \\
0.1,0.3, \text { and } 1 \mathrm{mg} / \mathrm{kg} \text { p.o. }\end{array}$ \\
\hline $\begin{array}{l}\text { Olanzapine-induced weight } \\
\text { gain }^{h}\end{array}$ & Sprague-Dawley rats & None/14 d & $8 \mathrm{M}$ & 1 p.o. & $\begin{array}{l}\text { Reduction of fat mass change } \\
\text { induced by olanzapine at } 1 \mathrm{mg} / \\
\mathrm{kg} \text { p.o. }\end{array}$ \\
\hline $\operatorname{ICSS}^{i}$ & Wistar rats & $60 / 20$ & $8 \mathrm{M}$ & 1-10 i.p. & $\begin{array}{l}\text { Reversal of cocaine ( } 1 \mathrm{mg} / \mathrm{kg} \text { i.p. }) \\
\text { induced facilitation of changes } \\
\text { in ICSS threshold at } 1,3 \text {, and } \\
10 \mathrm{mg} / \mathrm{kg} \text { i.p.; no significant } \\
\text { change by RO5263397 alone and } \\
\text { therefore no reinforcing effects } \\
\text { and no abuse potential } \\
\text { anticipated }\end{array}$ \\
\hline $\begin{array}{l}\text { Abuse-related effects of } \\
\text { cocaine }^{j}\end{array}$ & Sprague-Dawley rats & $10 / 15$ & $6-18 \mathrm{M}$ & 1-10 i.p. & $\begin{array}{l}\text { Reduction of expression of cocaine } \\
\text { behavioral sensitization (at } \\
3.2 \mathrm{mg} / \mathrm{kg} \text { i.p.), cue- and cocaine } \\
\text { prime-induced reinstatement of } \\
\text { cocaine seeking (at } 3.2 \text { and } \\
5.6 \mathrm{mg} / \mathrm{kg} \text { i.p.), and expression } \\
\text { but not development of cocaine- } \\
\text { induced place preference (at } \\
10 \mathrm{mg} / \mathrm{kg} \text { i.p.) }\end{array}$ \\
\hline $\begin{array}{l}\text { Abuse-related effects of } \\
\text { methamphetamine }^{k}\end{array}$ & Sprague-Dawley rats & $10 / 15$ & 7 to $8 \mathrm{M}$ & $3.2-10$ i.p. & $\begin{array}{l}\text { Reduction of expression of } \\
\text { behavioral sensitization (at } \\
10 \mathrm{mg} / \mathrm{kg} \text { i.p.), } \\
\text { methamphetamine self- } \\
\text { administration (at } 3.2 \mathrm{mg} / \mathrm{kg} \\
\text { i.p.), and both cue- and a } \\
\text { priming dose of } \\
\text { methamphetamine-induced } \\
\text { reinstatement of drug-seeking } \\
\text { behaviors (at } 3.2 \text { and } \\
10 \mathrm{mg} / \mathrm{kg} \text { i.p.) }\end{array}$ \\
\hline $\begin{array}{l}\text { Chronic methamphetamine- } \\
\text { treatment 5-CSRTT }\end{array}$ & Sprague-Dawley rats & $3 \mathrm{~d} / 60$ & $8 \mathrm{M}$ & 5.6 i.p. & $\begin{array}{l}\text { Attenuation of forced abstinence- } \\
\text { induced impulsivity } \\
\text { (at } 5.6 \mathrm{mg} / \mathrm{kg} \text { ) }\end{array}$ \\
\hline
\end{tabular}


TABLE 6-Continued

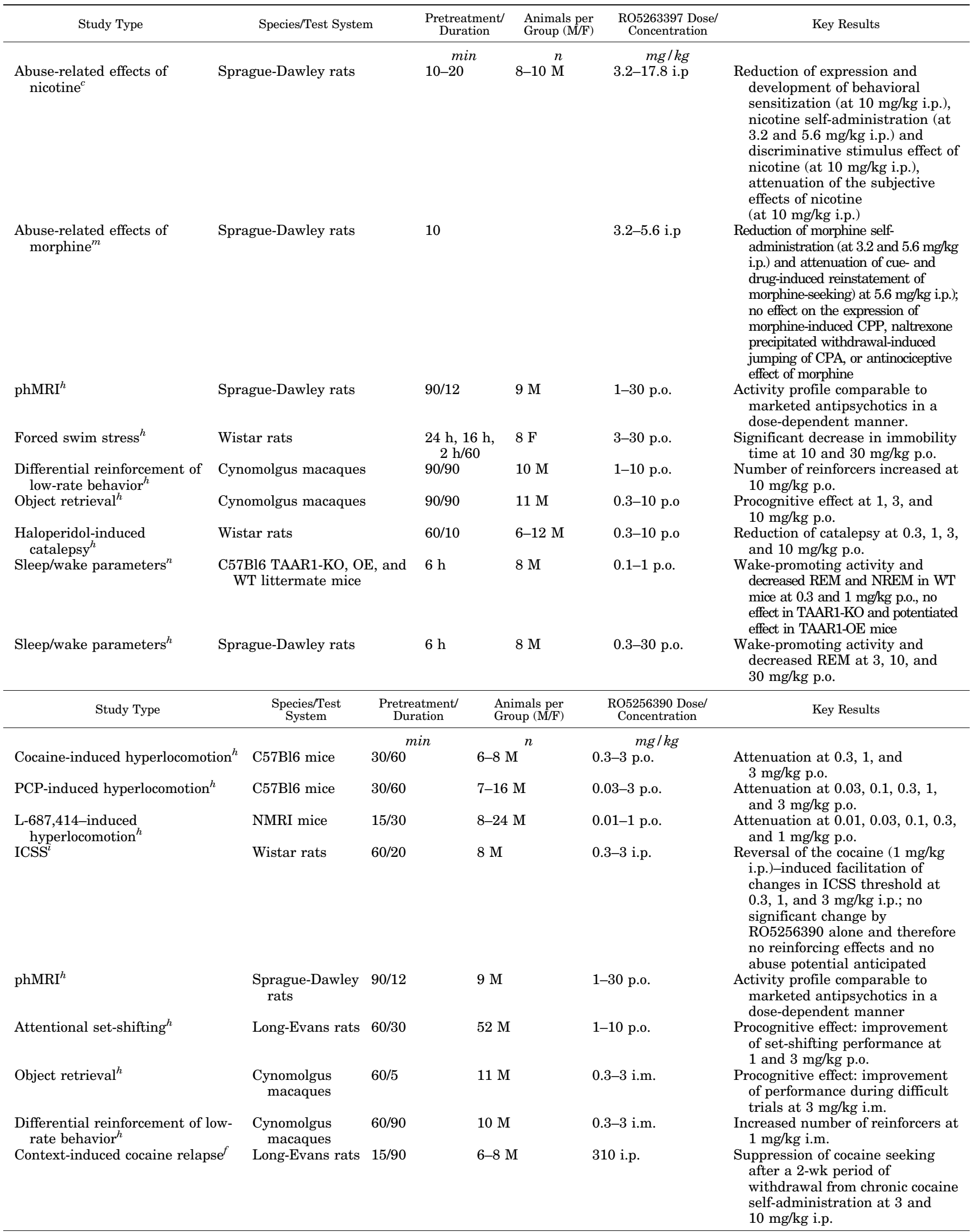


TABLE 6-Continued

\begin{tabular}{|c|c|c|c|c|c|}
\hline Study Type & $\begin{array}{l}\text { Species/Test } \\
\text { System }\end{array}$ & $\begin{array}{l}\text { Pretreatment/ } \\
\text { Duration }\end{array}$ & $\begin{array}{l}\text { Animals per } \\
\text { Group }(\mathrm{M} / \mathrm{F})\end{array}$ & $\begin{array}{l}\text { RO5256390 Dose/ } \\
\text { Concentration }\end{array}$ & Key Results \\
\hline & & $\min$ & $n$ & $m g / k g$ & \\
\hline Compulsive binge-like eating $^{o}$ & Wistar rats & $30 / 60$ & $12 \mathrm{M}$ & $1-10$ i.p. & $\begin{array}{l}\text { Inhibition of binge-like eating } \\
\text { behavior at } 3 \text { and } 10 \mathrm{mg} / \mathrm{kg} \text { i.p. }\end{array}$ \\
\hline Haloperidol-induced catalepsy ${ }^{h}$ & Wistar rats & $60 / 10$ & $6-12 \mathrm{M}$ & $0.3-3$ p.o & $\begin{array}{l}\text { Reduction of catalepsy at } \\
0.3 \mathrm{mg} / \mathrm{kg} \text { p.o. }\end{array}$ \\
\hline Sleep/wake parameters ${ }^{h}$ & $\begin{array}{l}\text { Sprague-Dawley } \\
\text { rats }\end{array}$ & $6 \mathrm{~h}$ & $8 \mathrm{M}$ & 1-10 p.o. & $\begin{array}{l}\text { No significant effect at } 1,3 \text {, and } \\
10 \mathrm{mg} / \mathrm{kg} \text { p.o. on sleep/wake } \\
\text { cycle and core body temperature }\end{array}$ \\
\hline
\end{tabular}

5-CSRTT, five-choice serial reaction time task; F, female; ICSS, intracranial self-stimulation; ivGTT, intravenous glucose tolerance test; KD, knockdown; M, male; NMRI,

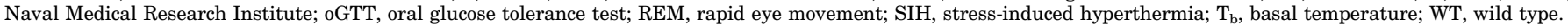

${ }^{a}$ Revel et al. (2011)

${ }^{b}$ Liu et al. (2016).

${ }^{c}$ Liu et al. (2018).

${ }^{d}$ Raab et al. (2015).

${ }^{e}$ Revel et al. (2012b).

$f_{\text {Pei et al. (2014). }}$

${ }^{g}$ Cotter et al. (2015)

${ }^{h}$ Revel et al. (2013).

${ }^{i}$ Pei et al. (2015).

${ }^{j}$ Thorn et al. (2014b).

${ }^{k}$ Jing and $\mathrm{Li}$ (2015).

${ }^{l}$ Xue et al. (2018).

${ }^{m}$ Liu et al. (2017a).

${ }^{n}$ Schwartz et al. (2017).

${ }^{o}$ Ferragud et al. (2017).

details of the antibody used were not provided, and this putative localization in one or more populations of cells in breast tissue should be regarded with caution until validation with well defined reagents has been provided. TAAR1 presence in thyroid gland epithelial cells has also been suggested (Szumska et al., 2015), although, again, validation of these findings is required. In contrast to earlier reports of TAAR 1 presence in adipose tissue, blood vessels, heart, kidney, liver, lung, and testes (Borowsky et al., 2001; Chiellini et al., 2007, 2012; Regard et al., 2008; Fehler et al., 2010), more recent studies with more robust protocols and reagents have failed to provide replication of the presence of TAAR1 (Revel et al., 2013; Raab et al., 2015).

Somewhat surprisingly for a GPCR, when TAAR1 protein has been identified, it has almost always been reported to exhibit a predominantly intracellular localization (Bunzow et al., 2001; Lindemann and Hoener, 2005; Miller et al., 2005; Revel et al., 2013; Raab et al., 2015; Pei et al., 2016), possibly due to the absence of one or more $N$-terminal glycosylation sites (Barak et al., 2008). Intracellular TAAR1 may be associated with membrane structures (Xie et al., 2008a; Szumska et al., 2015), although the identity of these is unknown. Although reagents appropriate for ultrastructural studies await development, there is good evidence that TAAR1 is present both pre- (Bradaia et al., 2009; Revel et al., 2011; Leo et al., 2014) and postsynaptically within neurons (Espinoza et al., 2015a).

c. Trace Amine-Associated Receptor 1 Ligands. The archetypal trace amines PEA, TYR, TRP, and OCT, as well as the dopamine metabolite $3-\mathrm{MT}$ and the thyroid hormone metabolite 3IT, are high-affinity endogenous agonists at TAAR 1 (see Table 7 and references therein). In addition, dopamine and serotonin show partial agonism at physiologically relevant concentrations
(Lindemann et al., 2005). Studies with synthetic compounds have revealed a quite remarkably broad ligand tuning of the receptor (Fig. 2; Table 7), with a number of psychotropic agents also showing high-affinity agonism at TAAR1 (Simmler et al., 2016). It should be stressed, however, that such effects often show pronounced species dependence, and this is perhaps most notable with the endogenous hallucinogen DMT and lysergic acid diethylamide, both of which show limited, if any, activity at the human isoform (Table 7). In addition to psychotropic agents, a variety of other synthetic compounds have been reported to exhibit agonistic activity at TAAR1, including apomorphine (Sukhanov et al., 2014), ractopamine (Liu et al., 2014), and the imidazoline ligands clonidine, guanabenz, and idazoxan (Hu et al., 2009) (Fig. 2; Table 7). Given this broad substrate tuning of TAAR1, it is interesting to note that OCT2, often described as a polyspecific (i.e., broad substrate tuning) transporter, carries TYR across biologic membranes with a nanomolar affinity (Berry et al., 2016).

All of the above-mentioned compounds are agonists at TAAR1, and only a single antagonist has been described (which is discussed in detail in section IV.B.1.c.ii). The apparent resistance of TAAR1 to standard medicinal chemistry approaches toward the development of antagonist compounds is one of the unique aspects of the receptor. Recently, two in silico quantitative structureactivity relationship models were developed to further probe the basis of the broad substrate tuning, species specificity, and lack of antagonist binding (Guariento et al., 2018). On the basis of the two quantitative structure-activity relationship models developed, biguanides were identified as a useful chemical skeleton from which novel TAAR1 ligands could be developed. It is expected that further development of such models will aid in the development of much needed TAAR1 antagonists. 
i. Development of Selective Agonists and Partial Agonists. TAAR1 functionally couples to $\mathrm{G}_{\mathrm{s}}$ proteins, and activation of the receptor by trace amines results in an intracellular increase in cAMP (Grandy, 2007). Since TAAR1-independent effects of endogenous trace amines are possible through other targets, including monoaminergic transporters and receptors, as well as the $\sigma$ receptor (Revel et al., 2011), the development of selective TAAR1 ligands was important for the identification of specific TAAR1-mediated biologic functions.

Starting from the known adrenergic ligand S18616 [(S)-spiro[(1-oxa-2-amino-3azacyclopent-2-ene)-4,2' -(8' chloro-1', $2^{\prime}, 3^{\prime}, 4^{\prime}$-tetrahydronaphthalene)]], modifying the linker region and exploring additional structureactivity relationships, 2-aminooxazolines were discovered as a chemical series of novel, highly potent, selective, and orally active TAAR1 full and partial agonists (Galley et al., 2015). Besides functional activity at human TAAR1 and selectivity versus the adrenergic $\alpha_{2 \mathrm{~A}}$ receptor, metabolic stability as measured in hepatocytes was used as a key parameter to select the four molecules that have been extensively characterized in the literature: RO5166017 [(S)-4-((ethyl(phenyl)amino)methyl)-4,5-dihydrooxazol-2-amine)], RO5203648 [(S)-4-(3,4-dichlorophenyl)-4,5-dihydrooxazol-2-amine], R05263397 [ $(S)$-4-(3-fluoro-2-methylphenyl)-4,5dihydrooxazol-2-amine], and RO5256390 [(S)-4-((S)-2phenylbutyl)-4,5-dihydrooxazol-2-ylamine] (Fig. 2) (Galley et al., 2015). The safety, tolerability, pharmacokinetics, and pharmacodynamics after oral administration of one of these molecules, RO5263397, a TAAR1 partial agonist that is well tolerated in rat and cynomolgus monkey toxicity studies, was determined in a singleascending dose, randomized, double-blind, placebocontrolled study in healthy male volunteers. Although the compound was found to be generally safe, a 136-fold above-average systemic exposure to the parent compound was found in one participant (Fowler et al., 2015). An additional two poor metabolizers were subsequently identified, and all three were of African origin. Additional in vitro studies with recombinant uridine diphosphate glucuronosyltransferases (UGTs) showed that the contribution of UGT2B10 to RO5263397 glucuronidation was much higher at clinically relevant concentrations than the UGT1A4 that had been predicted to be the main metabolic enzyme in preclinical enzyme studies. DNA sequencing identified a previously uncharacterized splice site mutation that prevented assembly of full-length UGT2B10 mRNA and thus functional UGT2B10 protein expression in all of the poor metabolizers (Fowler et al., 2015). Subsequent DNA database analyses revealed the UGT2B10 splice site mutation was highly frequent in individuals of African origin (45\%), compared with only moderate frequency in Asians (8\%) and an almost complete absence in Caucasians $(<1 \%)$. A prospective study using hepatocytes from 20 individual African donors demonstrated a greater than 100-fold lower intrinsic clearance of RO5263397 in cells homozygous for the splice site variant allele (Fowler et al., 2015). Based on this unexpected finding in the phase I study, a novel chemical series of potent and selective TAAR1 agonists with improved pharmacokinetic properties will be required to allow further clinical development. Notwithstanding this setback, the four compounds that are extensively used in the literature remain excellent tools for the characterization of TAAR1-mediated effects in animals and nonhuman primates.

These TAAR1 partial and full agonists have been extensively profiled preclinically. A summary of the preclinical efficacy of the individual compounds in behavioral in vivo animal models is shown in Tables 6 and 8. Notably, the compounds show activity in five distinct paradigms based on the modulation of dopaminergic and/or glutamatergic pathways that are suggestive of antipsychotic activity. Furthermore, TAAR1 agonists also show antidepressant/stress-reducing activity; procognitive, wake-promoting, antinarcolepsy, and anticataleptic effects; glucose and weight gaincontrolling responses; as well as antiaddiction effects in a wide-range of rodent and nonhuman primate paradigms (see Tables 6 and 8 and references therein). Thus, TAAR1 agonists may constitute a completely new drug class with a fundamentally new mechanism of action based on the modulation of dopaminergic, glutamatergic, and serotonergic neurotransmission for the treatment of schizophrenia, mood disorders, narcolepsy, addiction, or diabetes. Importantly, these compounds appear to target symptoms in these diseases that currently are not treatable, including cognitive and negative symptoms in schizophrenia and substance abuse with no concomitant inherent abuse potential. Full details of these effects of TAAR1 agonists in preclinical models are provided in sections IV.B.2 and IV.B.3.

ii. Development of N-(3-Ethoxyphenyl)-4-(1Pyrrolidinyl)-3-(Trifluoromethyl)Benzamide, the First Selective Antagonist. Unlike for most GPCRs, it has been particularly challenging for standard medicinal chemistry approaches to identify selective TAAR1 antagonists. Thus far, only one such compound, EPPTB [N-(3-ethoxyphenyl)-4-(1-pyrrolidinyl)3-(trifluoromethyl)benzamide (RO5212773)] (Fig. 2), has been identified and characterized (Bradaia et al., 2009; Stalder et al., 2011). EPPTB is a highly potent mouse TAAR1-selective antagonist that is largely inactive at the rat and human isoforms (Berry et al., 2017); unfortunately, even in mice, the pharmacokinetic properties prevent the in vivo use of EPPTB (Bradaia et al., 2009). This limitation on the use of EPPTB for research and drug discovery has considerably slowed progress in elucidating TAAR1-dependent mechanisms. Ex vivo it has been shown that EPPTB prevents the reduction of the firing frequency of dopaminergic neurons induced by TYR (Bradaia et al., 2009). When applied alone, EPPTB increases the firing frequency of dopaminergic 
neurons, suggesting that TAAR1 either exhibits constitutive activity or is tonically activated by ambient levels of an endogenous agonist(s). Clear differentiation between these two possible scenarios has not been possible. Further confusing the situation are suggestions that EPPTB may in fact be an inverse agonist (Bradaia et al., 2009; Stalder et al., 2011). EPPTB also blocks the TAAR1-mediated activation of an inwardly rectifying $\mathrm{K}^{+}$current in VTA slices (Bradaia et al., 2009). When applied alone, EPPTB induced an apparent inward current, suggesting the closure of tonically activated $\mathrm{K}^{+}$channels. Importantly, all of these EPPTB effects were absent in TAAR1-KO mice, ruling out off-target effects. Together, the above studies suggest that tonic activation of inwardly rectifying $\mathrm{K}^{+}$-channels by TAAR1 leads to a reduction in the basal firing frequency of dopaminergic neurons in the VTA.

d. Signal Transduction and Molecular Interactions.

i. Adenylyl Cyclase. As a $\mathrm{G}_{\mathrm{s}}$-coupled receptor, TAAR1 promotes cAMP production via stimulation of adenylyl cyclase (Borowsky et al., 2001; Bunzow et al., 2001; Lindemann and Hoener, 2005). This has been confirmed after expression of TAAR 1 in a variety of cell types and with various approaches to analyze cAMP concentrations used (Reese et al., 2007; Wainscott et al., 2007; Barak et al., 2008; Hu et al., 2009; Espinoza et al., 2011; Revel et al., 2011; Liu et al., 2014). In fact, cAMP assays are now a central component of TAAR1 ligand screening programs (Bradaia et al., 2009; Revel et al., 2011, 2012a, 2013; Stalder et al., 2011; Galley et al., 2012, 2015).

ii. G Protein-Coupled Inwardly Rectifying Potassium Channels. TAAR1-mediated reduction in the firing rate of VTA dopaminergic neurons appears to occur subsequent to activation of $\mathrm{G}$ protein-coupled inwardly rectifying potassium channels (Bradaia et al., 2009). TYR activation of TAAR1 in VTA slices induces a $G$ protein-dependent, inwardly rectifying $\mathrm{K}^{+}$current, consistent with an activation of $\mathrm{G}$ protein-coupled inwardly rectifying potassium channels. Furthermore, in TAAR1 transfected Xenopus oocytes, TAAR1 directly activated Kir3 channels via pertussis toxin-insensitive $\mathrm{G}$ proteins in Xenopus oocytes (Bradaia et al., 2009), most likely the aforementioned $\mathrm{G}_{\mathrm{s}}$ proteins. As described above (section IV.B.1.c.ii) inwardly rectifying $\mathrm{K}^{+}$currents are also modified by the TAAR1-selective antagonist EPPTB.

In the same manner as TYR, the synthetic full TAAR1 agonist RO5166017 also inhibited neuron firing frequency by activating a $\mathrm{K}^{+}$-mediated outward current in both VTA and DRN slices. Such effects are seen at comparable agonist potencies to those obtained for TAAR1 activation in cAMP assays (Revel et al., 2011). These effects of RO5166017 and TYR on the firing rate of dopamine and serotonin neurons were absent in TAAR1-KO mice and were completely prevented by
EPPTB in wild-type animals (Revel et al., 2011). Indeed, EPPTB reduced the current beyond the pretreatment baseline values, providing further evidence for TAAR1 being either constitutively active or under tonic stimulation from an endogenous agonist.

iii. Heterodimerization with the D2-Like Dopamine Receptor. A functional physical interaction between D2R and TAAR1 has been shown in a number of studies both in vitro and in vivo. Cellular studies have revealed that TAAR1 forms heteromers with the postsynaptic D2R-long isoform when coexpressed in human embryonic kidney 293 (HEK-293) cells, and that the application of D2R antagonists enhances TAAR1 signaling in these cells (Espinoza et al., 2011). Although normally TAAR 1 is mainly located intracellularly, coexpression with D2R causes TAAR1 appearance at the plasma membrane (Espinoza et al., 2011; Harmeier et al., 2015). Furthermore, coimmunoprecipitation of TAAR1 and D2R, directly reflecting heterodimerization, was convincingly demonstrated not only in vitro in HEK-293 cells (Espinoza et al., 2011) but also in vivo in midbrain and cortex membrane preparations from TAAR1-OE rats (Harmeier et al., 2015).

Such heterodimerization provides an attractive molecular basis for TAAR1-mediated regulation of D2R functioning. In the striatum of TAAR1-KO mice, an increased expression of D2Rs, but not D1Rs, has been observed at both the mRNA and protein levels (Espinoza et al., 2015a). This is in addition to previous observations of an increased proportion of striatal D2Rs in the high-affinity state after TAAR1-KO (Wolinsky et al., 2007). Furthermore, the locomotor activation induced by high doses of the D2R agonist quinpirole, but not by the D1R agonist SKF-82958 (6-chloro-7,8dihydroxy-3-allyl-1-phenyl-2,3,4,5-tetrahydro- $1 \mathrm{H}$-3benzazepine), are significantly increased in TAAR1-KO mice (Espinoza et al., 2015a). Recently, quinpiroleinduced yawning, a behavioral response thought to reflect the $\mathrm{D}_{3}$ isoform of D2Rs, was reported to be decreased in the presence of selective TAAR1 agonists (Siemian et al., 2017). In contrast, the purportedly $\mathrm{D}_{2}$ isoform-mediated hypothermic effect of quinpirole was not affected by TAAR1 activation (Siemian et al., 2017), raising the possibility that TAAR1 may differentiate between D2R isoforms. The effects of D2R antagonists are also modified by TAAR1, with haloperidol treatment causing significantly less catalepsy and striatal c-fos expression in TAAR1-KO animals (Espinoza et al., 2011). An altered function of presynaptic $D_{2}$ autoreceptors has also been observed in TAAR1-KO mice, as reflected by an increase in the firing rate of VTA neurons (Bradaia et al., 2009) and deficits in autoinhibitory control of dopamine release (Leo et al., 2014). Taken together, these data clearly demonstrate that the close interaction of TAAR1 and D2R has significant functional consequences at both the preand postsynaptic levels. 
TABLE 7

Functional activity $\left(\mathrm{EC}_{50}\right)$ and binding potency $\left(K_{\mathrm{i}}\right)$ of endogenous, selected psychoactive, nonselective, and selective TAAR1 agonists in rats, mice, and humans

Values for $\mathrm{EC}_{50}$ and $K_{\mathrm{i}}$ are given in micromolar, whereas values for efficacy are given in percentages and indicate maximal cAMP levels reached compared with $10 \mu \mathrm{M}$ 2-phenylethylamine.

\begin{tabular}{|c|c|c|c|c|c|c|c|c|c|}
\hline \multirow{2}{*}{ TAAR1 Agonist } & \multicolumn{3}{|c|}{ Rat TAAR1 } & \multicolumn{3}{|c|}{ Mouse TAAR1 } & \multicolumn{3}{|c|}{ Human TAAR1 } \\
\hline & $\mathrm{EC}_{50}$ & Efficacy & $K_{\mathrm{i}}$ & $\mathrm{EC}_{50}$ & Efficacy & $K_{\mathrm{i}}$ & $\mathrm{EC}_{50}$ & Efficacy & $K_{\mathrm{i}}$ \\
\hline \multicolumn{10}{|l|}{ Endogenous ligands } \\
\hline $\mathrm{PEA}^{a}$ & 0.11 & 100 & 0.24 & 0.20 & 102 & 0.31 & 0.26 & 104 & \\
\hline TYR $^{a}$ & 0.030 & 94 & 0.059 & 0.28 & 88 & 0.38 & 0.99 & 91 & \\
\hline $\operatorname{TRP}^{a}$ & 0.41 & 91 & 0.13 & 2.7 & 117 & 1.4 & 21 & 73 & \\
\hline Octopamine $^{b}$ & 2.1 & 100 & & 20 & 100 & & 10 & 100 & \\
\hline Dopamine $^{b}$ & 5.1 & 50 & & 12 & 50 & & 16 & 50 & \\
\hline Serotonin $b$ & 5.2 & 50 & & $>50$ & & & $>50$ & 100 & \\
\hline $3-\mathrm{MT}^{c}$ & & & & & & & 0.70 & & \\
\hline \multicolumn{10}{|l|}{ Amphetamine like $e^{a}$} \\
\hline Amphetamine & 0.66 & 91 & 0.23 & 0.53 & 90 & 0.089 & 2.8 & 91 & \\
\hline 4-fluoroamphetamine & 0.069 & 78 & 0.081 & 0.13 & 77 & 0.32 & 3.5 & 67 & \\
\hline 4-methylamphetamine & 0.11 & 93 & 0.10 & 0.071 & 94 & 0.15 & $>30$ & & \\
\hline Methamphetamine & 0.85 & 73 & 0.35 & 0.73 & 78 & 0.55 & 5.3 & 70 & \\
\hline 4-fluoromethamphetamine & 0.16 & 76 & 0.24 & 0.46 & 69 & 1.7 & 6.2 & 44 & \\
\hline MDMA & 1.0 & 56 & 0.37 & 4.0 & 71 & 2.4 & 35 & 26 & \\
\hline MDA & 0.74 & 86 & 0.25 & 0.58 & 102 & 0.16 & 3.6 & 11 & \\
\hline Cathinone & 1.2 & 28 & 2.2 & 1.2 & 66 & 2.1 & 6.9 & 53 & \\
\hline Methcathinone & 8.2 & 41 & 4.1 & 6.8 & 64 & $>10$ & $>30$ & & \\
\hline \multicolumn{10}{|l|}{ Benzofurans $^{a}$} \\
\hline 4-(2-aminopropyl)benzofuran (4-APB) & 0.16 & 75 & 0.11 & 0.85 & 72 & 2.1 & 4.1 & 50 & \\
\hline 5-(2-aminopropyl)benzofuran (5-APB) & 0.067 & 88 & 0.042 & 0.13 & 67 & 0.11 & 6.1 & 43 & \\
\hline 6-(2-aminopropyl)benzofuran (6-APB) & 0.042 & 90 & 0.052 & 0.067 & 93 & 0.056 & 7.2 & 47 & \\
\hline 7-(2-aminopropyl)benzofuran (7-APB) & 0.058 & 109 & 0.066 & 0.11 & 95 & 0.13 & 0.63 & 89 & \\
\hline $\begin{array}{l}\text { 6-aminopropyl-2,3-dihydrobenzofuran } \\
\text { (6-APDB) }\end{array}$ & 1.0 & 83 & 1.0 & 0.51 & 95 & 0.21 & $>10$ & & \\
\hline \multicolumn{10}{|l|}{ Phenethylamines $^{a}$} \\
\hline $\begin{array}{l}\text { 2,5-dimethoxy-4-bromo-phenethylamine } \\
\text { (2C-B) }\end{array}$ & 0.24 & 57 & 0.079 & 2.3 & 69 & 2.2 & 3.3 & 10 & \\
\hline $\begin{array}{l}\text { 8-bromo-2,3,6,7-benzodihydro-difuran- } \\
\text { ethylamine (2C-B-Fly) }\end{array}$ & 0.27 & 48 & 0.029 & 1.8 & 49 & 0.71 & $>30$ & & \\
\hline $\begin{array}{l}\text { 4-ethyl-2,5-dimethoxyphenethylamine } \\
\text { (2C-E) }\end{array}$ & 0.18 & 72 & 0.066 & 1.1 & 64 & 1.2 & $>10$ & & \\
\hline $\begin{array}{l}\text { 2,5-dimethoxyphenethylamine } \\
\text { (2C-H) }\end{array}$ & 1.5 & 80 & 0.90 & 7.5 & 56 & 11 & 6.5 & 53 & \\
\hline $\begin{array}{l}\text { 2,5-dimethoxy-4-propyl-phenethylamine } \\
\text { (2C-P) }\end{array}$ & 0.030 & 84 & 0.020 & 0.56 & 91 & 0.28 & 4.2 & 72 & \\
\hline Mescaline & 3.7 & 37 & 3.3 & 4.8 & 25 & 11 & $>10$ & & \\
\hline$(-)$-Ephedrine & 2.5 & 42 & 3.7 & 14 & 31 & $>15$ & $>10$ & & \\
\hline \multicolumn{10}{|l|}{ 4-thio-substituted phenethylamines ${ }^{d}$} \\
\hline $2 \mathrm{C}-\mathrm{T}-3$ & & & 0.0080 & & & 0.47 & $>30$ & & \\
\hline 2C-T-7 ("blue mystic") & & & 0.010 & & & 0.31 & $>30$ & & \\
\hline 2C-T-19 & & & 0.0048 & & & 0.096 & $>30$ & & \\
\hline $2 \mathrm{C}-\mathrm{T}-31$ & & & 0.0052 & & & 0.055 & $>30$ & & \\
\hline \multicolumn{10}{|l|}{$\operatorname{TRPs}^{a}$} \\
\hline Psilocin & 0.92 & 85 & 1.4 & 2.7 & 80 & 17 & $>30$ & & \\
\hline DMT & 1.5 & 81 & 2.2 & 1.2 & 73 & 3.3 & $>10$ & & \\
\hline \multicolumn{10}{|l|}{ Ergolines } \\
\hline Lysergic acid diethylamide (LSD) ${ }^{a}$ & 1.4 & 29 & 0.45 & 9.7 & 13 & 10 & $>20$ & & \\
\hline \multicolumn{10}{|l|}{ Piperazines $^{a}$} \\
\hline$m$-Chlorophenylpiperazine (m-CPP) & 0.15 & 60 & 0.054 & 3.2 & 40 & 6.6 & $>30$ & & \\
\hline Trifluoromethylphenylpiperazine (TFMPP) & 0.75 & 59 & 0.38 & 3.8 & 44 & 2.3 & $>30$ & & \\
\hline \multicolumn{10}{|l|}{ Aminoindanes $^{a}$} \\
\hline 2 -aminoindane $(2-\mathrm{AI})$ & 0.11 & 90 & 0.31 & 0.33 & 54 & 2.1 & 1.5 & 110 & \\
\hline$N$-methyl-2-AI & 0.37 & 63 & 0.53 & 0.94 & 108 & 2.6 & 3.3 & 54 & \\
\hline 5-iodo-2-aminoindane (5-IAI) & 0.033 & 96 & 0.030 & 0.41 & 36 & 1.1 & 3.2 & 33 & \\
\hline 5,6-methylenedioxy-2-aminoindane (MDAI) & 0.22 & 95 & 0.57 & 0.52 & 99 & 1.8 & 4.1 & 30 & \\
\hline Miscellaneous nonselective compounds & & & & & & & & & \\
\hline Apomorphine $e^{e}$ & 0.99 & 79 & 0.37 & 2.5 & 59 & 0.37 & $>20$ & & 0.70 \\
\hline Ractopamine $^{f}$ & & & & 0.016 & 100 & & & & \\
\hline $3 \mathrm{IT}^{g, h}$ & 0.014 & & & 0.090 & 61 & & 1.7 & 56 & \\
\hline Clonidine $^{i}$ & & & & 0.21 & & & 0.97 & & \\
\hline Guanabenz $z^{i}$ & & & & 0.007 & & & 0.025 & & \\
\hline Idazoxan $^{i}$ & & & & 0.11 & & & 6.7 & & \\
\hline Selective compounds & & & & & & & & & \\
\hline RO5073012 & 0.025 & 24 & 0.0011 & 0.023 & 26 & 0.0032 & 0.025 & 34 & 0.0058 \\
\hline $\mathrm{RO} 5166017^{k}$ & 0.014 & 90 & 0.0027 & 0.0033 & 65 & 0.0019 & 0.055 & 95 & 0.031 \\
\hline $\mathrm{RO}^{2} 203648^{l}$ & 0.0068 & 59 & 0.0010 & 0.0040 & 48 & 0.0005 & 0.030 & 73 & 0.0068 \\
\hline
\end{tabular}


TABLE 7-Continued

\begin{tabular}{|c|c|c|c|c|c|c|c|c|c|}
\hline \multirow{2}{*}{ TAAR1 Agonist } & \multicolumn{3}{|c|}{ Rat TAAR1 } & \multicolumn{3}{|c|}{ Mouse TAAR 1} & \multicolumn{3}{|c|}{ Human TAAR1 } \\
\hline & $\mathrm{EC}_{50}$ & Efficacy & $K_{\mathrm{i}}$ & $\mathrm{EC}_{50}$ & Efficacy & $K_{\mathrm{i}}$ & $\mathrm{EC}_{50}$ & Efficacy & $K_{\mathrm{i}}$ \\
\hline RO5256390 ${ }^{m}$ & 0.0051 & 107 & 0.0029 & 0.0020 & 79 & 0.0044 & 0.016 & 98 & 0.024 \\
\hline $\mathrm{RO5263397^{m }}$ & 0.047 & 76 & 0.0091 & 0.0013 & 59 & 0.0009 & 0.017 & 81 & 0.0041 \\
\hline \multicolumn{10}{|l|}{ Selective inverse agonist } \\
\hline RO5212773 (EPPTB) ${ }^{n}$ & 4.5 & 0 & 0.94 & 0.028 & -12 & 0.0009 & 7.5 & 0 & $>5.0$ \\
\hline
\end{tabular}

${ }^{a}$ Simmler et al. (2016).

${ }^{b}$ Lindemann et al. (2005).

${ }^{c}$ Sotnikova et al. (2010).

${ }^{d}$ Luethi et al. (2017).

${ }^{e}$ Sukhanov et al. (2014).

$f_{\text {Liu et al. (2014). }}$

${ }^{g}$ Scanlan et al. (2004).

${ }^{h}$ Coster et al. (2015).

${ }^{i} \mathrm{Hu}$ et al. (2009).

${ }^{j}$ Revel et al. (2012a).

${ }^{k}$ Revel et al. (2011).

${ }^{l}$ Revel et al. (2012b).

${ }^{m}$ Revel et al. (2013)

${ }^{n}$ Stalder et al. (2011). $\mathrm{IC}_{50}$ values are presented in lieu of $\mathrm{EC}_{50}$ values.

iv. $\beta$-Arrestin 2 and Biased Signaling. In addition to the well established cAMP cascade, TAAR1 is also able to signal via $\beta$-arrestin 2 (Harmeier et al., 2015), a multifunctional scaffolding protein classically associated with GPCR desensitization (Gainetdinov et al., 2004). It is well established that $D 2 R$ signals through $G_{i}$ proteins to reduce cAMP levels. At the same time, however, D2R can also recruit $\beta$-arrestin 2 in a G protein-independent manner, a pathway that leads to the dephosphorylation of protein kinase B (AKT) and the subsequent activation of glycogen synthase kinase $3 \beta$ (GSK3 $\beta$ ) (Beaulieu et al., 2009). Both of these pathways have been shown to be important for dopamine-mediated behaviors (Beaulieu and Gainetdinov, 2011). By using specific $\beta$-arrestin 2 complementation assays, it has been demonstrated that whereas TAAR 1 normally interacts poorly with $\beta$-arrestin 2 , the heterodimerization of TAAR1 with D2R significantly enhances the TAAR1- $\beta$-arrestin 2 interaction that results in reduced GSK3 $\beta$ activation (Harmeier et al., 2015). Furthermore, both TAAR1-induced cAMP accumulation and $\beta$-arrestin 2 recruitment to $\mathrm{D} 2 \mathrm{R}$ were reduced in the presence of the TAAR1-D2R complex.

Further confirmation of heterodimerization of TAAR1 and D2R modulating the AKT/GSK3 $\beta$ pathway was obtained in striatal tissues from TAAR1-KO mice (Espinoza et al., 2015a). As measured by Western blot, a basal decrease in the phosphorylation of AKT and GSK $3 \beta$ was found in the striatum of TAAR1-KO mice. Furthermore, the levels of $\beta$-catenin, a target of GSK3 $\beta$ that is degraded in response to increased GSK3 $\beta$ activity, were also decreased in mutant mice. In contrast, no alterations were observed in the phosphorylated forms of extracellular signal-regulated kinase 1/2, cAMP response element binding protein, or dopamine and cAMP-regulated phosphoprotein (32 kDa) (DARPP32), all of which are regulated by both $\mathrm{D} 1 \mathrm{R}$ and $\mathrm{D} 2 \mathrm{R}$ in a $\mathrm{G}$ protein-dependent manner (Espinoza et al., 2015a).
Taken together, these results demonstrate that the activation of the TAAR1-D2R complex negatively modulates GSK3 $\beta$ signaling, a situation with important clinical and pharmacological implications. The AKT/GSK3 $\beta$ pathway is increasingly implicated in the pathology of schizophrenia, bipolar disorder, and depression, with growing evidence that antipsychotics and antidepressants influence this pathway (Beaulieu et al., 2009). An opportunity to affect D2R signaling mediated by the $\beta$-arrestin 2-dependent AKT/GSK3 $\beta$ cascade via targeting the endogenous TAAR1 pathway provides an exciting new avenue in the pharmacology of these disorders, which is expected to garner considerable interest over the next few years.

$v$. Other Signaling Cascades. Different downstream targets of TAAR1 signaling were described in activated rhesus monkey lymphocytes, in which activation of the transcription factors, cAMP response element binding protein and nuclear factor of activated $\mathrm{T}$ cells (both of which are associated with immune activation), was observed (Panas et al., 2012). TAAR1-dependent phosphorylation of PKA and PKC after treatment with methamphetamine has been reported in transfected HEK-293 cells, immortalized rhesus monkey B cells, and activated rhesus monkey lymphocytes, suggesting that the high levels of inducible TAAR1 observed in activated lymphocytes are functionally active (Panas et al., 2012). Whether the PKC activation was downstream of PKA activation due to TAAR1 coupling to the $\mathrm{G}_{\mathrm{S}}$ protein was not determined, although this is perhaps the most likely scenario.

\section{Central Nervous System Effects}

a. Cellular Effects.

$i$. Dopaminergic Systems. From the first studies on TAAR1-KO mice, it was clear that TAAR1 is a potent modulator of dopaminergic neurotransmission (Wolinsky et al., 2007; Lindemann et al., 2008), consistent with its expression in the major dopaminergic cell 
TABLE 8

Summary of in vivo pharmacological effects of TAAR1-selective agonists

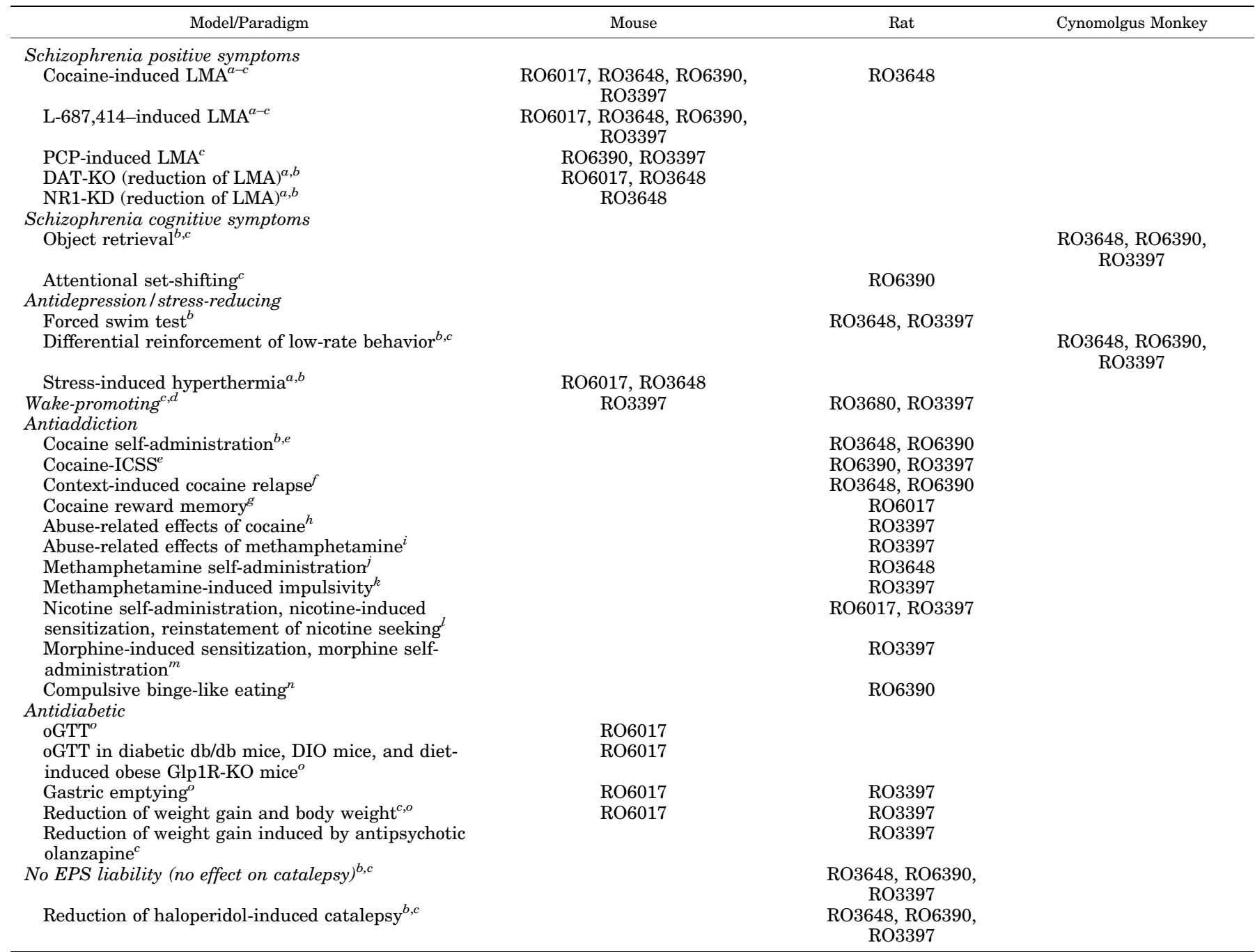

DIO, diet-induced obese; EPS, extrapyramidal side-effects; ICSS, intracranial self-stimulation; LMA, locomotor activity; oGTT, oral glucose tolerance test; RO3397, RO5263397; RO3648, RO5203648; RO6017, RO5166017; RO6390, RO5256390;.

${ }^{a}$ Revel et al. (2011).

${ }^{b}$ Revel et al. (2012b).

${ }^{c}$ Revel et al. (2013).

${ }^{d}$ Schwartz et al. (2017)

${ }^{e}$ Pei et al. (2015).

${ }^{f}$ Pei et al. (2014).

${ }^{g}$ Liu et al. (2016).

${ }^{h}$ Thorn et al. (2014a).

${ }^{i}$ Jing and $\mathrm{Li}(2015)$.

${ }^{j}$ Cotter et al. (2015).

${ }^{k}$ Xue et al. (2018).

${ }^{l}$ Liu et al. (2018).

${ }^{m}$ Liu et al. (2017a).

${ }^{n}$ Ferragud et al. (2017)

${ }^{\circ}$ Raab et al. (2015).

groups of the VTA and to lesser extent the substantia nigra (Lindemann et al., 2008; Di Cara et al., 2011; Berry et al., 2017). An enhanced stimulation of locomotor activity with concomitant increased dopamine efflux after amphetamine administration was observed after TAAR1-KO (Wolinsky et al., 2007; Lindemann et al., 2008). Electrophysiological investigations on brain slice preparations revealed that the lack of TAAR1 causes an increase in the firing rate of dopaminergic neurons of the VTA while simultaneously increasing D2R agonist potency (Bradaia et al., 2009). Consistent with this, the firing rate of these neurons in wild-type but not TAAR1-KO mice is potently enhanced by the TAAR1 antagonist EPPTB and decreased by a variety of agonists (Bradaia et al., 2009). In vivo microdialysis coupled with fast-scan cyclic voltammetry revealed that these changes in TAAR1-KO mice were associated with an elevated extracellular level of dopamine in the nucleus accumbens, whereas synthetic TAAR1 ligands (both antagonist and agonists) produced the 
corresponding changes in evoked dopamine release from slices of both the nucleus accumbens and striatum of wild-type but not TAAR1-KO animals (Leo et al., 2014). Direct evidence for decreased $D_{2} / D_{3}$ autoreceptor functionality was also demonstrated using paired-pulse fast-scan cyclic voltammetry (Leo et al., 2014).

In transfected cells and brain synaptosome preparations, evidence for PEA (Xie and Miller, 2008) and dopamine (Xie et al., 2008b) modulation of DAT (Slc6A3) function via both TAAR 1 and $\mathrm{D}_{2}$ autoreceptors has been presented. With respect to potential TAAR1mediated regulation of DAT, it should be noted that in other studies, no difference in dopamine uptake rate was observed in either the nucleus accumbens or striatum of TAAR1-KO mice or after TAAR1 agonist/ antagonist treatment of wild-type animals (Leo et al., 2014). Furthermore, the partial TAAR1 agonist RO5203648 prevents cocaine-induced dopamine overflow in the nucleus accumbens without altering dopamine uptake (Pei et al., 2014), and TAAR1 agonists are effective in inhibiting dopamine-dependent hyperactivity in DAT-KO mice (Revel et al., 2011, 2012b; Leo et al., 2018) and when DAT has been inhibited by administration of cocaine (Revel et al., 2013). As such, it now appears unlikely that TAAR1-mediated effects occur after a regulation of DAT function. Indeed, rather than modulation of DAT, the full TAAR1 agonist RO5256390 blocks cocaine-induced inhibition of dopamine clearance in nucleus accumbens slices via a mechanism that requires simultaneous D2R activation and GSK3 $\beta$ signaling, likely originating from TAAR1-D2R heterodimerization (Asif-Malik et al., 2017), as observed in other systems (see sections IV. B.1.d.iii and IV.B.1.d.iv).

When functionality of postsynaptic striatal dopamine receptors was assessed in TAAR1-KO animals, an increased expression and pronounced supersensitivity of D2Rs was observed (Wolinsky et al., 2007; Espinoza et al., 2015a), indicating that TAAR1 modulation of dopaminergic systems also occurs postsynaptically. Furthermore, this postsynaptic supersensitivity was mediated via the $\mathrm{G}$ protein-independent, $\beta$-arrestin 2 -dependent, AKT/GSK3 $\beta$ pathway, and not cAMP/ PKA/DARPP32 signaling (Espinoza et al., 2015a). That TAAR1-mediated effects can be directed at both preand postsynaptic D2R considerably complicates the interpretation of in vivo findings.

ii. Serotonergic Systems. TAAR1 is expressed within the DRN, the key area where cell bodies of serotonin neurons are located (Lindemann et al., 2008), suggesting that TAAR1 may modulate brain serotoninergic activity. Indeed, the full TAAR1 agonist RO5166017 inhibits the firing rate of DRN serotonergic neurons while modulation of TAAR1 activity alters the desensitization rate and agonist potency at $5-\mathrm{HT}_{1 \mathrm{~A}}$ receptors (Revel et al., 2011). In brain slices of TAAR1-KO mice, the spontaneous firing frequency of serotonin neurons was markedly increased compared with wildtype controls, and this increased firing rate was not affected by RO5166017 (Revel et al., 2011). In wild-type animals, however, the TAAR1 partial agonist RO5203648 increases the firing frequency of serotonergic neurons in the DRN (Revel et al., 2012b). Furthermore, in a transgenic TAAR1-OE mouse line, an augmented extracellular level of serotonin in the medial prefrontal cortex was found along with an elevated spontaneous firing rate of DRN neurons (Revel et al., 2012a). The molecular basis of these effects has not been studied in the same detail as those mediated at dopaminergic systems, and further detailed investigations of the mechanisms of influence of TAAR1 on brain serotonin functions are warranted. Using transfected cells and brain synaptosome preparations, evidence was presented that PEA (Xie and Miller, 2008) and serotonin can modulate serotonin transporter function via both TAAR 1 and $5-\mathrm{HT}_{1 \mathrm{~A}} / 5-\mathrm{HT}_{1 \mathrm{~B}}$ autoreceptors (Xie et al., 2008b). Notwithstanding the lack of a molecular mechanism, the evidence suggests that TAAR1 likely functions as an endogenous mechanism to maintain a balance in serotonergic neuronal activity, similar to its effects in gating dopaminergic systems.

iii. Glutamatergic Systems. As previously described, TAAR1 agonists can overcome both the hyperlocomotion and cognitive impairments induced by administration of NMDA receptor antagonists (Revel et al., 2011, 2013). That TAAR1 can regulate glutamatergic transmission is further suggested by the significant alterations in glutamate transmission found in the prefrontal cortex of TAAR1-KO mice (Espinoza et al., 2015b), a location where TAAR $1 \mathrm{mRNA}$ is found in wild-type mice. Application of a patch-clamp electrophysiological approach to cortical slices revealed deficient glutamate NMDA receptor function in prefrontal cortex layer $\mathrm{V}$ pyramidal neurons of TAAR1-KO mice (Espinoza et al., 2015b). This was associated with a decrease in the expression of the GluN1 and GluN2B subunits, as well as a decrease in the phosphorylation of the $\mathrm{Ser}^{896}$ residue of GluN1. In contrast, the levels of GluN2A, the AMPA receptor subunit GluA1, and the phosphorylation status of postsynaptic density 95 (a postsynaptic protein critical to the proper organization and integrity of postsynaptic structures) were not altered in TAAR1-KO animals. That TAAR 1 activation acutely regulates the glutamatergic system was supported by the observation that cultured cortical neurons treated with the TAAR1 agonist RO5166017 showed a modest increase in GluN1 expression and a significant increase in the phosphorylation of the $\mathrm{Ser}^{896}$ residue (Espinoza et al., 2015b). Furthermore, TAAR1 expression was mapped to layer V cortical neurons in TAAR1-KO/dsRed knock-in rats, a recently developed transgenic rat model in which the fluorescent marker dsRed is expressed under the control of the TAAR1 promoter (Espinoza et al., 2015b). Since many cortical neurons in layer $\mathrm{V}$ project to the striatum, these data suggest that TAAR1 may modulate corticostriatal 
glutamatergic transmission. Consistent with this hypothesis, significant alterations in the total levels and phosphorylation of GluN1 were found in the striatum of TAAR1-KO mice (Sukhanov et al., 2016). Together, the above-described studies provide a molecular basis for the ability of TAAR1 to prevent hypoglutamatergic states as well as the pronounced increase in prefrontal cortex activity seen in pharmacological magnetic resonance imaging (phMRI) studies with selective TAAR1 agonists (Revel et al., 2013).

The TAAR1 agonist RO5166017 has also been reported to counteract L-DOPA-induced phosphorylation of AMPA receptors resulting in an inhibition of evoked corticostriatal glutamate release in animals with nigrostriatal lesions (Alvarsson et al., 2015), effects that were reversed by the TAAR1 antagonist EPPTB. Such an effect has potentially significant functional consequences for Parkinson disease-related abnormalities. Interestingly, methamphetamine-induced activation of TAAR1 leads to intracellular cAMP accumulation in human astrocytes, an effect that decreased glutamate clearance abilities due to a downregulation of excitatory amino acid transporter 2 (EAAT-2) (Cisneros and Ghorpade, 2014). Although methamphetamine has a promiscuous pharmacology, molecular alterations in astrocyte TAAR 1 levels also induced changes in EAAT-2 levels and function, consistent with the methamphetamine response being TAAR1 mediated (Cisneros and Ghorpade, 2014). More recently, it has been shown that high concentrations of dopamine upregulate TAAR1, consistent with TAAR1 acting to prevent dopamine hyperactivity, and this also leads to reduced EAAT-2 expression and glutamate clearance in primary cortical astrocytes (Ding et al., 2017). In total, the above studies indicate that TAAR1 activity can modulate glutamatergic responses by selective regulation of both receptors and transporter-mediated clearance mechanisms.

\section{b. Behavior.}

i. Schizophrenia and Bipolar Disorder. TAAR1 agonists have the potential to be effective in the treatment of psychiatric disorders, both directly, as well as indirectly, through acting as a cellular rheostat of neurotransmitter pathways. Activation of TAAR1 has been shown to downregulate dopaminergic neurotransmission, whereas inhibition of TAAR 1 enhances it (Lindemann et al., 2008). Data from studies in several rodent models-including cocaine-, phencyclidine (PCP)-, and L-687,414 [(3S,4S)-3-amino-1-hydroxy-4methylpyrrolidin-2-one]-induced hyperlocomotor activity tests; cocaine-induced facilitation of intracranial self-stimulation, and phMRI-indicate that TAAR1 agonists exhibit antipsychotic-like activity (Revel et al., 2013; Table 8). At doses that only caused modest effects on baseline locomotor activity, TAAR1 agonists significantly antagonized cocaine-induced hyperlocomotor activity in mice as well as in rats (Revel et al., 2011, 2012b, 2013;
Table 6). In addition, partially active doses of TAAR1 agonists and olanzapine, when combined, fully reversed the hyperlocomotion induced by cocaine (Revel et al., 2013), indicating that TAAR1 agonists can also have an additive effect on those of the marketed antipsychotic olanzapine. In mice, TAAR1 agonists also inhibited hyperactivity induced by the noncompetitive NMDA receptor antagonist PCP, as well as that induced by L-687,414, an NMDA glycine-site inhibitor (Revel et al., 2013; Table 6). These are both mechanistic assays that mimic the NMDA hypofunction seen in schizophrenic patients. Moreover, modulation of VTA activity in the intracranial self-stimulation test was observed in rats after TAAR1 agonist administration (Table 6), further demonstrating regulation of key circuitry known to be associated with the negative symptoms of schizophrenia (Revel et al., 2013). A series of mixed 5-HT 12 TAAR1 agonists from Sunovion Pharmaceutical Inc. (Marlborough, MA) (Nazimek et al., 2016) (see Fig. 2 for a representative example) have also been shown to be beneficial in prepulse inhibition and PCP-induced hyperactivity models of schizophrenia (Shao et al., 2011).

In summary, preclinical testing indicates that TAAR1 agonists have the potential to treat patients with schizophrenia with better efficacy and improved tolerability, due to their lack of polypharmacology and unique ability to normalize both dopamine hyper-reactive and glutamate hyporesponsive circuitry. Furthermore, given the beneficial metabolic and antidiabetic effects (see section IV.B.3.a), they may also provide an additional benefit by not increasing the metabolic syndrome, a major side effect of current antipsychotic drugs.

ii. Cognitive Effects. Cognitive deficits are one of the core symptoms of schizophrenia, symptoms that are only poorly controlled by current treatment approaches (Miyamoto et al., 2012; Citrome, 2014). In the primate object retrieval test, TAAR1 agonists improved the accuracy of object retrieval in difficult trials, such as those when the object to be retrieved was placed at a distance from the test subject (Revel et al., 2013), indicative of enhanced cognition (Tables 6 and 8). Similar effects were also observed in a rat attentional set-shifting paradigm. Here, deficits induced by 7 days of PCP treatment in the ability to discriminate between a variety of tactile and olfactory cues were reversed by TAAR 1 agonists (Revel et al., 2013), indicating a normalization of cognitive deficits caused by hypoglutamatergic signaling. Such effects are consistent with the enhanced prefrontal cortical activity seen in phMRI studies after TAAR1 agonist treatment (Revel et al., 2013).

iii. Depression. TAAR1 agonists have been assessed for antidepressant-like activity in two validated paradigms: the forced swim stress test in rats and the differential reinforcement of low response rate (DRL) behavior schedule in cynomolgus monkeys (Tables 6 and 8). The forced swim stress test relies on the principle that when rodents are placed in water in an inescapable 
environment, they adopt a characteristic immobile posture after an initial period of vigorous activity and make only the minimal movements necessary to stay afloat. A reduction in the time of immobility is considered indicative of potential antidepressant-like properties, and such an effect was seen in a dose-dependent manner after administration of TAAR1 partial agonists (Revel et al., 2012b, 2013). DRL is a schedule-controlled behavioral test that involves prefrontal cortex and hippocampus activity, in which subjects are reinforced to withhold a response over a specified unsignaled delay interval. Antidepressants from a number of different pharmacological classes, including selective serotonin reuptake inhibitors, tricyclic antidepressants, and MAO inhibitors, are active in the DRL schedule by increasing the number of reinforcers obtained and decreasing intertrial response rates (McGuire and Seiden, 1980; O’Donnell and Seiden, 1983). Consistent with potential antidepressant activity, TAAR1 agonists significantly increased the number of reinforcers obtained (Revel et al., 2012b, 2013). Together, the above studies suggest that TAAR1 agonists warrant further investigation of their putative antidepressant-like properties. In combination with the antipsychotic activity profile, these results suggest TAAR1 agonists may also be useful in bipolar disorder, being able to address both manic phases and acute depressive episodes.

iv. Sleep, Wake, and Narcolepsy. Although the above studies have indicated the potential utility of TAAR1 agonists and partial agonists, a different spectrum is seen when examining sleep. Here, only partial agonists show effects (Revel et al., 2012b, 2013; Table 6), which is thought to possibly reflect antagonism of endogenous TAAR1 tone. Unfortunately, the lack of suitable TAAR1 antagonists prevents the most direct testing of this hypothesis, and the putative benefit of antagonists has to be inferred from the combinatorial effects of agonists in the presence of partial agonists or from the effects of TAAR1-KO where secondary compensatory effects could also be involved. TAAR1 partial agonists have been shown to cause a generalized increase in wakefulness, decreased latency to sleep, and both decreased and lighter NREM sleep in both rats and mice (Revel et al., 2012b, 2013; Black et al., 2017; Schwartz et al., 2017; Table 6). Furthermore, manipulation of TAAR1 levels through either $\mathrm{OE}$ or $\mathrm{KO}$ also alters sleep architecture and electroencephalogram spectral activity, consistent with putative TAAR1-mediated changes in cortical neuron activity (Schwartz et al., 2017). Such effects were not, however, associated with the hyperactive phenotype seen with general central nervous system stimulants (Schwartz et al., 2017). In fact, lack of TAAR1 attenuates the locomotor activation and electroencephalogram spectral changes induced by two unrelated central nervous system stimulants, caffeine and modafinil, neither of which is a TAAR1 ligand (Schwartz et al., 2018). TAAR1-OE meanwhile produced opposite effects, exacerbating the induced hyperactivity.
That TAAR1-mediated changes in sleep architecture have clinical relevance is strengthened by the subsequent demonstration that TAAR1 partial and full agonists are effective in two mouse models of narcolepsy, both involving hypocretin neuronal degeneration (Black et al., 2017). Again, effects appeared to be dependent on the strength of agonism, suggesting that a centrally active, TAAR1 antagonist with appropriate pharmacokinetic properties might be the optimal treatment. In the two models used (Atax and DTA mice), beneficial effects of a TAAR1 partial agonist were observed in decreasing the cataplexy that is the central characteristic symptom seen in narcolepsy. In total, there is now good evidence for a role of TAAR1 in regulating sleep architecture, and a putative therapeutic utility for partial TAAR1 agonists and TAAR1 antagonists in sleep-related disorders such as narcolepsy. It is expected that this will reinvigorate the search for TAAR1 antagonists that show suitable pharmacokinetic properties for use in vivo, the identification of which would also be of considerable benefit to the further pharmacological probing of TAAR1.

$v$. Addiction and Compulsive Behaviors. There is now considerable evidence that TAAR 1 is a new target for the pharmacotherapy of addiction disorders (Tables 6 and 8). Intriguingly, this does not appear to be limited to drugs of abuse that directly interact with TAAR1; rather, this is a general phenomenon for any agent that mediates its effects through the dopaminergic reward system, and it likely has its cellular and molecular basis in the prevention of dopaminergic hyperactivity described elsewhere (see sections IV.B.1.d.iii, IV.B.1.d.iv, and IV.B.2.a.i). Indeed, TAAR1 regulation of cocainemediated effects was very recently shown to be a function of the ability of TAAR1 to form heterodimers with D2R, and of those heterodimers to recruit the $\beta$-arrestin 2 pathway (Asif-Malik et al., 2017). In general, TAAR1 agonism appears to prevent the rewarding, pleasurable effects of compounds that mediate these responses via stimulation of the dopaminergic system; as such, TAAR1 agonists themselves do not appear to support self-administration (Cotter et al., 2015; Jing and Li, 2015; Pei et al., 2016; Table 6). The dopamine reward system has been reported to be a target of SEP-363856 (a mixed 5- $\mathrm{HT}_{1 \mathrm{a}}$ /TAAR1 agonist) in healthy human volunteers (Nazimek et al., 2016).

Given their demonstrated efficacy at TAAR1, much of the initial work focused on amphetamine-type drugs of abuse. In animals with decreased TAAR1 levels either due to KO (Di Cara et al., 2011; Achat-Mendes et al., 2012; Sukhanov et al., 2016) or an endogenous defunctionalizing mutation (Harkness et al., 2015; Reed et al., 2018), increases in acquisition and retention of conditioned place preference (CPP) (Achat-Mendes et al., 2012), hyperlocomotion (Achat-Mendes et al., 2012; Sukhanov et al., 2016), reinstatement (Sukhanov et al., 2016), self-administration (Harkness et al., 
2015; Reed et al., 2018), and toxicity (Miner et al., 2017), along with decreased autoinhibitory effects (Di Cara et al., 2011), were seen in response to either amphetamine, methamphetamine, or 3,4-methylenedioxymethamphetamine (MDMA). Such effects suggested that TAAR1 agonists may be beneficial in reducing the abuse potential of amphetamines and TAAR 1 agonists have now been confirmed to decrease the behavioral sensitization, self-administration, reinstatement, drug-seeking behavior, and withdrawalinduced impulsivity observed in response to methamphetamine administration (Jing et al., 2014; Cotter et al., 2015; Pei et al., 2017; Xue et al., 2018). Consistent with the TAAR1-mediated effects being due to an interaction with D2R, the above-described effects are associated with a decrease in nucleus accumbens dopamine overflow (Cotter et al., 2015; Pei et al., 2017).

In addition to amphetamines, a number of other addictive/abused agents are known to involve the dopaminergic reward systems, including cocaine, ethanol, food, and nicotine. Intriguingly, TAAR1 agonists appear to have a similar beneficial anticraving effect in all such instances (Tables 6 and 8). Responses to cocaine (which itself is not a ligand for TAAR1), as well as drugtaking behaviors induced by its administration, are modified by TAAR1 agonists such that agonist-induced decreases in cocaine CPP (Thorn et al., 2014a), both cueand drug-primed reinstatement (Pei et al., 2014; Thorn et al., 2014a), hyperactivity (Revel et al., 2011, 2013), reward memory (Liu et al., 2016), self-administration (Pei et al., 2015), sensitization (Thorn et al., 2014a,b), and withdrawal-induced drug seeking (Pei et al., 2014) have all been reported. Furthermore, TAAR1 activation causes a downward shift in dose-response curves for cocaine reward efficacy, confirming lesser rewarding properties. Again, effects appear to be focused on TAAR1 activation within the nucleus accumbens as well as the VTA and prelimbic cortex (Liu et al., 2017b).

A similar spectrum of beneficial effects after TAAR1 agonism has recently been reported for a second addictive compound that is not a TAAR1 ligand, nicotine (Tables 6 and 8). Administration of TAAR1 agonists was able to decrease nicotine-induced hyperactivity (Liu et al., 2018; Sukhanov et al., 2018), sensitization (Liu et al., 2018; Sukhanov et al., 2018), self-administration (Liu et al., 2018), cue- and drugprimed reinstatement (Liu et al., 2018), and discriminative stimulus effects (Liu et al., 2018), while simultaneously increasing the elasticity of the nicotine demand curve (Liu et al., 2018). These beneficial effects of TAAR 1 activation were associated with a decrease in the nicotine-induced dopamine release and c-fos expression in the nucleus accumbens, confirming prevention of hyperactivity of the dopamine reward centers (Liu et al., 2018). Furthermore, direct infusion of a TAAR1 agonist into the nucleus accumbens also prevented drug-seeking behaviors, whereas TAAR1-KO enhanced nicotine-seeking behaviors. Intriguingly, chronic nicotine administration selectively decreased nucleus accumbens TAAR1 expression (Liu et al., 2018). In this way, chronic nicotine administration may be removing a cellular brake on dopaminergic activity in the central reward centers, thereby promoting its rewarding and addicting properties.

With respect to other addictive agents, TAAR1 agonists also decrease compulsive binge eating of highly palatable diets (Ferragud et al., 2017), whereas increased ethanol consumption and reward responses are seen after TAAR1-KO (Lynch et al., 2013) or in animals now known to contain a defunctionalizing TAAR1 mutation (Fish et al., 2010). Although there is a lack of effect of TAAR1-KO (Achat-Mendes et al., 2012) and TAAR1 agonists (Liu et al., 2017a) on morphineinduced CPP, morphine self-administration and cueand drug-induced reinstatement are decreased by TAAR1 agonism (Liu et al., 2017a). Importantly, these beneficial effects of decreasing the reinforcing properties of morphine are obtained without any change in morphine-induced analgesia (Liu et al., 2017a). In contrast, addictive agents that do not strongly invoke the dopamine reward pathways are not affected by manipulation of TAAR 1 activity. TAAR 1 agonists do not affect the propensity of rodents to self-administer sucrose (Revel et al., 2012b; Jing et al., 2014; Pei et al., 2014, 2017; Cotter et al., 2015). Likewise, TAAR1-KO also does not affect sucrose self-administration (Lynch et al., 2013).

vi. Feeding Behavior. As described above, within the central nervous system TAAR1 is found in brain areas known to be associated with the regulation of feeding behavior, including the area postrema, cortex, hypothalamus, limbic system, and nucleus tractus solitarii (Table 4). This distribution, along with the ease with which TAAR1 ligands are produced from dietary amino acids, makes TAAR1 an attractive putative molecular target for involvement in the control of energy metabolism and nutrient intake. Furthermore, the well documented beneficial effects of TAAR 1 agonism in reducing addiction-associated compulsive behaviors mediated by the dopaminergic reward system raise the possibility that TAAR1 agonists may also be beneficial in controlling compulsive overeating, since food rewards are well established to be dopaminergic and/or glutamatergic in origin (Michaelides et al., 2012; Moore et al., 2018). Indeed, TAAR1 agonists have been reported to decrease food intake in diet-induced obese mice (Raab et al., 2015), resulting in weight loss and improved insulin sensitivity (Table 6). Furthermore, a TAAR1 agonist has recently been shown to prevent rodent binge eating of highly palatable food by preventing the conditioned rewarding properties of the food, preventing compulsive consumption behavior, and decreasing food-seeking behavior during a reinforcement paradigm (Ferragud et al., 2017; Table 6). Similar to the situation seen with nicotine exposure, chronic 
availability of palatable food resulted in a decrease in TAAR1 expression (Ferragud et al., 2017), again providing a link between the development of an addiction phenotype and TAAR1. In contrast, standard chow overeating after food restriction was not affected. Together, the results suggest that TAAR1 may uniquely act to normalize central drives underlying overeating of palatable food while also normalizing hormonal disruptions in the periphery associated with metabolic disorders (see section IV.B.3.a).

\section{Effects in the Periphery}

a. Diabetes and Obesity. TAAR1 is expressed in the main tissues of the gut-brain axis in addition to specific areas of the brain involved in the control of energy metabolism (Lindemann et al., 2008; Table 4). In both rodents and humans, the highest peripheral expression of TAAR 1 is seen in the stomach, neuroendocrine cells of the intestine, and $\beta$ cells of the pancreas (Regard et al., 2007; Revel et al., 2013; Raab et al., 2015). In contrast to earlier studies (Borowsky et al., 2001; Fehler et al., 2010; Chiellini et al., 2012; Gozal et al., 2014), no expression of TAAR1 was observed in the liver, kidney, or skeletal muscle when higher-quality, fully validated reagents were used (Raab et al., 2015). This expression pattern of TAAR 1 is quite specific and partially overlaps with that of the glucagon-like peptide 1 (GLP-1) receptor, consistent with the colocalization of TAAR1 with GLP-1 and PYY in the intestines (Raab et al., 2015).

GLP-1 analogs represent a recently developed class of novel type 2 diabetes mellitus drugs, which improve glucose homeostasis by stimulating insulin secretion from pancreatic $\beta$ cells and inhibiting gastrointestinal motility and secretion (Baggio and Drucker, 2007). Combined with the at least partially overlapping expression pattern of TAAR1 and GLP-1, this prompted investigation into the role of TAAR1 as a potential novel therapeutic target for type 2 diabetes mellitus. Using selective small-molecule TAAR 1 agonists, in vitro studies demonstrated that activation of TAAR1 results in increases in glucose-stimulated insulin secretion from pancreatic $\beta$-cell lines and isolated human islets (Raab et al., 2015). Importantly, the effect on insulin secretion was only seen at elevated glucose concentrations, thereby reducing the risk for induction of hypoglycemia. Very recently, signal transduction-altering single nucleotide polymorphisms of TAAR1 were reported in some patients with impaired insulin secretion and were suggested to be a possible predisposing factor for dysfunctional glucose homeostasis (Mühlhaus et al., 2017). The potential utility of TAAR 1 agonists was further supported by studies in rodent models of type 2 diabetes mellitus (Table 6). Here, TAAR1 agonists were shown to reduce fasting blood glucose levels and improve glucose tolerance acutely after either oral or intraperitoneal glucose challenge (Raab et al., 2015). No effect of TAAR1 agonists on glucose control was observed in TAAR1-KO mice, verifying that effects were indeed TAAR1-mediated.

TAAR1 agonism may also be useful in promoting weight loss in obese individuals. Not only do agonists prevent the pronounced weight gain associated with olanzapine treatment (Revel et al., 2013), but they also bring about a significant loss of excess body weight in diet-induced obese mice (Raab et al., 2015). Mechanistically, this likely relates to the demonstration that TAAR 1 activation induces a delay in gastric emptying and decreased food intake (Raab et al., 2015). Furthermore, TAAR1 regulates nutrient-induced hormone secretion seen as increases in plasma levels of GLP-1 and PYY (Raab et al., 2015) and somatostatin release from stomach D cells (Adriaenssens et al., 2015).

b. Immunomodulatory Effects. Not only is TAAR1 differentially expressed between leukocyte populations (Babusyte et al., 2013), but its expression, along with that of TAAR2, is increased at both mRNA and protein levels after leukocyte activation (Nelson et al., 2007; Wasik et al., 2012; Table 4). As previously noted, PEA and TYR may be released from activated platelets (D'Andrea et al., 2003) and have been reported to be positive chemotactic agents for leukocytes (Babusyte et al., 2013). The joint regulation of TAAR1 and TAAR2 is important from this aspect, as the chemoattractant response of leukocytes toward TAAR1-selective agonists appears to be dependent on the presence of both TAAR1 and TAAR2, possibly due to the need for heterodimerization of the two (Babusyte et al., 2013). From this perspective, the TAAR1/TAAR2 axis may provide a molecular explanation for the well known immune dysfunction that is associated with amphetamine-like drugs of abuse (Boyle and Connor, 2010; Sriram et al., 2015), many of which are TAAR1 agonists. Indeed, methamphetamine has been reported to increase T-cell TAAR 1 expression, an effect that resulted in a decrease in T-cell interleukin 2 levels (Sriram et al., 2016). In addition to these decreases, TAAR1 agonists have also been reported to affect $T$ helper cell differentiation, decreasing the levels of secreted phosphoprotein 1 while simultaneously increasing interleukin 4 secretion (Babusyte et al., 2013). Together, the effects on these cytokines suggest that TAAR1 activation may preferentially promote differentiation into the T helper 2 phenotype, an effect that would be expected to lead to B-cell activation. Consistent with this, PEA and TYR have been shown to increase immunoglobulin $\mathrm{E}$ secretion from B cells (Babusyte et al., 2013).

Although many of the above effects require independent verification, in combination with TAAR1 ligand ready availability from various environmental sources, they raise the possibility of TAAR1, or indeed other TAARs, being novel therapeutic targets for environmental hyper-reactivity disorders of the immune system. Consistent with this, TAAR1 has been proposed to play a role in the susceptibility to fibromyalgia (Smith et al., 2012), TAAR6 implicated in treatment outcomes 
in asthma (Chang et al., 2015), and TAAR2, TAAR5, and TAAR9 among the most highly upregulated genes in the inflamed zones of patients with Crohn disease (Taquet et al., 2012), an effect that allowed discrimination of these patients from those with irritable bowel syndrome. As previously indicated, two recent unbiased metabolomic studies have also identified elevated endogenous TAAR1 ligands in Crohn disease fecal samples (Jacobs et al., 2016; Santoru et al., 2017). Together, these studies indicate that a careful, systematic investigation of the ability of TAAR isoforms to regulate the immune system is warranted.

c. Cancer. A recent study reported that an increase in TAAR1 expression in breast cancer cells is associated with longer survival times for patients (Vattai et al., 2017). TAAR1 expression was further suggested to correlate with that of the human epidermal growth factor receptor Her2 and to be related to tumor cell differentiation. Unfortunately, no details were provided on the TAAR1 antibody used; given the generally poor quality and selectivity of commercial anti-TAAR1 antibodies (Berry et al., 2017), although this study is of interest it should be regarded with considerable caution until such time that replication has occurred with fully validated reagents.

d. Pregnancy. Very recently, TAAR1 has been suggested as a novel target for the treatment of miscarriages. An increased expression of TAAR1 was seen in syncytiotrophoblasts, cytotrophoblasts, decidua, and glands of placentas obtained from patients suffering spontaneous or recurrent miscarriages (Stavrou et al., 2018). Furthermore, this increased expression was associated with elevated levels of phosphorylated GSK3 $\beta$, suggesting elevated $\beta$-arrestin 2 signaling. Whether this requires heterodimerization of TAAR1, and if so with what, is an area for further investigation. The authors also provided evidence of TAAR1 agonist-induced increased expression of TAAR1 (Stavrou et al., 2018) suggestive of a positive feedback loop. This is not too dissimilar to the reported elevations of TAAR1 expression in T leukocytes after treatment with methamphetamine (Sriram et al., 2016), itself a TAAR1 agonist. Agonist-induced expression would add a new level of complexity to TAAR1 pharmacology and may be an area for future systematic study.

Although the antibodies used to identify TAAR1 have previously been reported to be problematic with respect to their selectivity (Berry et al., 2017), these studies do suggest a new area for future studies. Intriguingly, the placenta and umbilical cord are well known to be abundant sources of SSAO/VAP-1/AOC3 (Sikkema et al., 2002), an enzyme that includes TAAR1 ligands in its substrate profile, which in light of these new studies may be indicative of a need to tightly control the endogenous TAAR1 agonist levels.

\section{Other Tetrapod Trace Amine- Associated Receptors}

TAARs are found in all vertebrate species examined: mammalia (including marsupiala), aves, amphibia, reptilia, osteichthyes (bony fish; teleost), and chondrichthyes (cartilaginous fish) (Fig. 6; Table 5) (Gloriam et al., 2005; Lindemann et al., 2005; Hashiguchi and Nishida, 2007; Grus and Zhang, 2008; Mueller et al., 2008; Eyun et al., 2016). TAAR (or TAAR-like) family members are also reported to be present in petromyzontida (jawless fish; lamprey) (Hashiguchi and Nishida, 2007; Eyun et al., 2016), and they likely represent the evolutionary origin of the family, although this has been debated (Hussain et al., 2009; Tessarolo et al., 2014). At least in mammals and chickens, TAAR genes are clustered on a single chromosome, whereas teleost and amphibian TAARs are spread across multiple chromosomes/scaffolds (Lindemann et al., 2005; Hashiguchi and Nishida, 2007; Eyun et al., 2016).

In addition to TAAR1, five other functional TAAR isoforms are expressed in humans, with single variants of TAAR2, TAAR5, TAAR6, TAAR8, and TAAR9 present, all of which contain seven putative transmembrane domains, as expected for GPCRs (Lee et al., 2000). The individual genes for TAAR3, TAAR4, and TAAR7 have undergone defunctionalizing, pseudogenization events (Lindemann et al., 2005). Comparison of the human TAAR complement to those of non-human primates suggests that the pseudogenization of TAAR3 likely occurred before the divergence of humans and orangutans, with TAAR4 pseudogenization occurring between humans and gorillas (Stäubert et al., 2010). By comparison, the marmoset genome was reported to contain only two functional TAAR genes (TAAR1 and TAAR5) (Eyun et al., 2016), although a functional marmoset TAAR2 gene has been reported elsewhere (Vallender et al., 2010), whereas the chimpanzee genome contains three functional genes (TAAR1, TAAR5, and TAAR6) and six pseudogenes (Lindemann and Hoener, 2005; Eyun et al., 2016).

\section{Trace Amine-Associated Receptor 2}

Whereas all other TAAR genes have a single exon, TAAR2 (previously known as GPR58 or G proteincoupled receptor 58; Table 3) contains two exons, encoding a functional protein of 351 amino acids in humans (Lindemann et al., 2005). TAAR2 shares closest homology with TAAR5 (previously known as the putative neurotransmitter receptor, PNR; Table 3) at $42 \%$ identity, and with the $5-\mathrm{HT}_{4}$ serotonin receptor at $34 \%$ identity (Lindemann et al., 2005). Ligands for TAAR2 have not been identified thus far, either among known endogenous trace amines or other volatile amines. Evolutionary mapping, however, suggests that the receptor will be tuned toward activation by primary amines (Ferrero et al., 2012). Like all TAARs, with the exception of TAAR1, TAAR2 is found within the olfactory epithelium where it is coupled to $\mathrm{G}_{\text {olf }}$ stimulation of cAMP accumulation (Liberles and Buck, 2006). The role of TAAR2 and other TAARs in olfactory sensory function is discussed in detail in section IV.E. 
Beyond the olfactory system, TAAR2 mRNA is found in various leukocyte populations in humans and mice, including B cells, granulocytes, monocytes, natural killer cells, and $\mathrm{T}$ cells, a pattern that mirrors the expression of TAAR1 (Nelson et al., 2007; Babusyte et al., 2013; Table 4). The presence of TAAR2 at the protein level has been confirmed in granulocytes (Babusyte et al., 2013), although it should be noted that validation of the selectivity of the antibody used was not provided. It has been noted previously that leukocyte stimulation results in an increase in both TAAR1 and TAAR2 mRNA levels (Nelson et al., 2007). Furthermore, it has been shown that PEA and TYR can be released from activated platelets (D'Andrea et al., 2003). Babusyte et al. (2013) also showed that these TAAR1 ligands, as well as 3IT, can act as chemoattractants for neutrophils, with subnanomolar $\mathrm{EC}_{50}$ values. Such a chemoattractant action requires the presence of both TAAR1 and TAAR2, as evidenced by the selective small interfering RNA knockdown of individual receptors eliminating the chemotactic responses (Babusyte et al., 2013). Since neither PEA nor TYR is an agonist at TAAR2, a heterodimerization between TAAR1 and TAAR2 to initiate neutrophil migration has been hypothesized (Babusyte et al., 2013). Indeed, direct coimmunoprecipitation experiments indicated that such a heterodimerization is involved in the regulation of chemotactic responses to PEA (Babusyte et al., 2013). Taken together, the above studies suggest that TAAR2 is required for the expression of TAAR1-mediated recruitment of leukocytes to the sites of injury, and that this involves heterodimerization with TAAR1.

TAAR2 mRNA transcripts have also been reported in nonsensory cells in other mammalian species, in duodenal mucosal cells of the gastrointestinal system in mice (Ito et al., 2009), and in the rat heart and testis (Chiellini et al., 2012). Whether a similar pattern of expression is observed in human tissues requires further study. In a study with a small sample size, defunctionalizing single nucleotide polymorphisms of TAAR2 were reported in up to $10 \%$ of humans, with a further minor increase in patients with schizophrenia (Bly, 2005). These studies have not been replicated thus far and their clinical relevance remains unclear, especially given the lack of reports of TAAR2 presence in the brain.

Recent attempts have been made to apply structurebased in silico computational protocols to the development of TAAR2 homology models for the prediction of TAAR2 ligands (Cichero and Tonelli, 2017). With a consensus TAAR defining motif now identified, further development of such models is expected to provide new leads and the identification of TAAR2-selective ligands, which will be a major boost to elucidating its physiologic roles.

\section{Trace Amine-Associated Receptor 3}

TAAR3 (previously known as GPR57 or G proteincoupled receptor 57; Table 3 ) is a pseudogene in humans
(Lindemann et al., 2005), although a functional protein with defined physiologic roles in olfaction is encoded in other species (discussed in detail in section IV.E.2).

\section{Trace Amine-Associated Receptor 4}

TAAR4 (previously known as trace amine receptor 2 or TA2, $5-\mathrm{HT}_{4} \mathrm{P}$; Table 3 ) is also a pseudogene in humans (Lindemann et al., 2005) but encodes a functional protein in other species, where an overlapping ligand selectivity with TAAR1 is present (discussed in section IV.E.3).

\section{Trace Amine-Associated Receptor 5}

The TAAR5 gene encodes a functional protein of 337 amino acids in humans. The most prominent expression of TAAR5 is in the olfactory epithelium, where it plays a role in the detection of socially relevant odor cues (Li et al., 2013; Wallrabenstein et al., 2013; Zhang et al., 2013) (discussed in detail in section IV. E.4). In the olfactory system, TAAR5 appears to be coexpressed with $\mathrm{G}_{\text {olf }}$ and stimulates cAMP accumulation (Liberles and Buck, 2006). It has also been shown that human TAAR5 can couple to the $G_{s}$ cascade (Wallrabenstein et al., 2013), the $\mathrm{G}_{\mathrm{q} / 11}$ cascade (Dinter et al., 2015c), and $\mathrm{G}_{12 / 13}$-dependent mitogen-activated protein kinase pathways (Dinter et al., 2015c), suggesting that in different cell groups TAAR5 might demonstrate functional selectivity by coupling to different signaling modalities. Whether such an effect is due to receptor heterodimerization, as seen with other TAAR isoforms, with different partners present in different cell types, or due to ligand bias, requires systematic study.

Beyond the olfactory system, low levels of TAAR5 mRNA have been reported in various leukocyte populations, with the greatest expression seen in B cells (Babusyte et al., 2013). Others, however, have reported that TAAR5 is only found in mouse, and not in human, leukocytes (Nelson et al., 2007). Expression of TAAR5 mRNA has also been reported in several mouse brain regions such as the amygdala, arcuate nucleus, and ventromedial hypothalamus, with an overlapping localization of TAAR 1 and TAAR5 in the amygdala and ventromedial hypothalamus (Dinter et al., 2015c; Table 4). Spinal cord (Gozal et al., 2014), testis (Chiellini et al., 2012), and intestinal (Kubo et al., 2015) expression has also been reported in rats, although it should be noted that, at least with TAAR1, such expression patterns could not be validated with higherquality reagents. Whether similar patterns of TAAR5 expression occur in humans requires further detailed studies.

As previously described, TAAR5 is predicted to be tuned to activation by tertiary amines (Ferrero et al., 2012), and trimethylamine has consistently been found to be the most active and selective agonist at human TAAR5, with dimethylethylamine a less potent partial agonist (Liberles and Buck, 2006; Wallrabenstein et al., 2013; Zhang et al., 2013). One group, however, found 
activity of trimethylamine only at rodent, and not human, TAAR5 (Stäubert et al., 2010). Several synthetic ligands and one additional natural ligand for TAAR5 have also been identified. Interestingly, the putative thyroid hormone metabolite and TAAR1 agonist 3IT has been reported to be a TAAR5 inverse agonist (Dinter et al., 2015c). The activity of 3IT, trimethylamine, and dimethylethylamine at TAAR5 has been confirmed by recent docking studies using homology models (Cichero et al., 2016). Furthermore, these studies identified two TAAR5 antagonists (Fig. 7), each of which was active at micromolar concentrations. The synthetic chemical 1-(2,2,6-trimethylcyclohexyl)hexan-3-ol (Timberol; Symrise AG, Holzminden, Germany) (Fig. 7) has also been identified as an antagonist of TAAR5 (Wallrabenstein et al., 2015). Although none of these antagonists have to date been tested in animals to better evaluate TAAR5 functionality, this is a considerable advance given the lack of goodquality antagonists at all other TAAR isoforms, making this is an exciting area for future development. A synthetic TAAR5-selective agonist, 2-( $\alpha$-naphthoyl)ethyltrimethylammonium iodide (alpha-NETA) (Fig. 7), has also recently been described (Aleksandrov et al., 2018a; Aleksandrov et al., 2018b). Using the brain event-related potentials in the paired-click paradigm, a model that directly recapitulates sensory gating deficits seen in schizophrenia, alpha-NETA was shown to decrease sensory gating in rats (Aleksandrov et al., 2018a), suggesting that TAAR5 may be a novel molecular locus for sensory gating deficits seen in schizophrenia. Furthermore, alpha-NETA affected mismatch negativity-like response in rats, a cognitive paradigm known to be reflective of schizophrenia-related cognitive deficits described in experimental animal models and humans (Aleksandrov et al., 2018b). It is also worth noting that a protocol for the generation of large (milligram) quantities of human TAAR5 has been described (Wang et al., 2011), providing an additional approach to further understanding TAAR5 structure and functions.

\section{Trace Amine-Associated Receptor 6}

The TAAR6 gene (previously known as TRAR4, TA4, or trace amine receptor 4; Table 3) encodes a functional human protein of 345 amino acids. Similar to TAAR2, no ligands for TAAR6 have been found thus far, although it is predicted to be activated by tertiary amines (Ferrero et al., 2012) and/or diamines (Li et al., 2015). The signal transduction events occurring at TAAR6 have also not been investigated but it is expected that like other olfactory TAARs, TAAR6 will be coupled to $\mathrm{G}_{\text {olf }}$ and subsequent cAMP accumulation. Beyond the olfactory system, TAAR6 mRNA has been found in mouse duodenal mucosal cells (Ito et al., 2009), in the rat spinal cord (Gozal et al., 2014) but not in the human spinal cord (Duan et al., 2004), and in the rat testis (Chiellini et al., 2012) (Table 4). TAAR6 transcripts have been reported in several human brain regions, including the amygdala and hippocampus (Borowsky et al., 2001; Duan et al., 2004), basal ganglia, and frontal cortex and substantia nigra (Duan et al., 2004), and these levels may exceed those of the most thoroughly investigated member of the TAAR family, TAAR1 (Duan et al., 2004). In the periphery, TAAR6 mRNA has been reported to be present in the human kidney (Borowsky et al., 2001) and in various human leukocyte populations (D'Andrea et al., 2003; Babusyte et al., 2013). In all cases, the functional consequences of TAAR6 activation are unknown. The flying fox TAAR gene family expansion ( 26 genes and 10 pseudogenes) is in part due to an expansion of its TAAR6 (four functional, six pseudogenes) complement (Eyun et al., 2016).

Despite minimal knowledge on the biology and physiologic role(s) of TAAR6, several studies have identified single nucleotide polymorphisms (Duan et al., 2004; Chang et al., 2015) and other genetic variants (Pae et al., 2010) in patients with schizophrenia (Duan et al., 2004; Pae et al., 2008a) and affective disorders (Abou Jamra et al., 2005; Pae et al., 2008b, 2010). Particularly interesting are the investigations of the potential role of TAAR6 single nucleotide polymorphisms in schizophrenia etiology and treatment, even though results of these studies are somewhat conflicting. Although several studies indicated a link in patients of Korean, European, and AfroAmerican origin (Duan et al., 2004; Vladimirov et al., 2007; Pae et al., 2008a,b), later studies failed to confirm associations in Japanese, Chinese, and European populations (Ikeda et al., 2005; Duan et al., 2006; Ludewick et al., 2008; Sanders et al., 2008; Vladimirov et al., 2009). TAAR6 polymorphisms have also been reported to be connected with therapeutic responses to the antipsychotic aripiprazole (Serretti et al., 2009), whereas a more complex epistatic relationship between TAAR6 and heat shock protein 70 polymorphisms has been associated with both the development of schizophrenia and treatment outcomes (Pae et al., 2009). TAAR6 variants have also been suggested to influence asthma patient responsivity to corticosterone (Chang et al., 2015).

\section{Trace Amine-Associated Receptor 7}

TAAR7 is a pseudogene in humans (Lindemann et al., 2005) but is a major site of mammalian species variation in other species. The increased TAAR repertoire in standard laboratory rodents - the mouse genome contains 15 functional receptors and one pseudogene, whereas the rat genome contains 17 functional TAAR genes and two pseudogenes (Borowsky et al., 2001; Lindemann et al., 2005; Lindemann and Hoener, 2005; Eyun et al., 2016)is primarily due to an expansion of the TAAR7 subfamily. Likewise, the flying fox possesses a pronounced TAAR7 expansion with 16 functional variants (Eyun et al., 2016).

\section{Trace Amine-Associated Receptor 8}

The TAAR8 gene (previously known as GPR102, TRAR5, TAR5, TA5, or trace amine receptor 5; Table 3) 
encodes a functional protein of 342 amino acids in humans. At present, only tertiary volatile amine ligands, $N$-methylpiperidine and $N, N$-dimethylcyclohexylamine, for nonhuman TAAR8 isoforms have been identified (Ferrero et al., 2012; Li et al., 2015). TAAR8, including the human isoform, does contain a putative diamine binding domain ( $\mathrm{Li}$ et al., 2015), suggesting the existence of diamine ligands as well and this is described in more detail in IV.E. Trace Amine-Associated Receptors in Olfaction.

Like other olfactory TAARs, TAAR8 is coupled to $\mathrm{G}_{\text {olf }}$, stimulating cAMP accumulation (Li et al., 2015), but has also been reported to be coupled to $G_{i}$ (Mühlhaus et al., 2014). Beyond the olfactory system, TAAR8 mRNA has been reported in the human amygdala (Borowsky et al., 2001) and leukocytes (D'Andrea

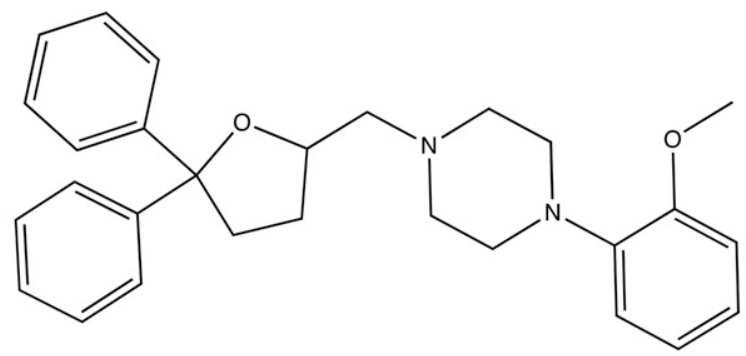

Cichero et al. (2016) unnamed compound 1

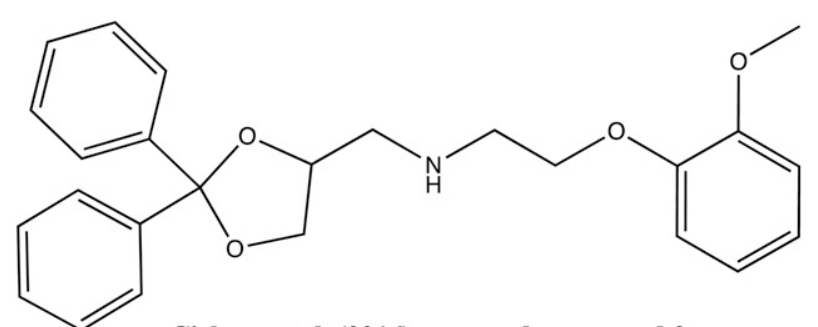

Cichero et al. (2016) unnamed compound 2

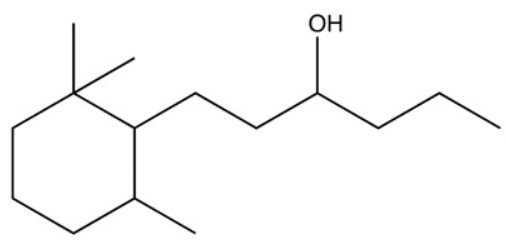

Timberol®

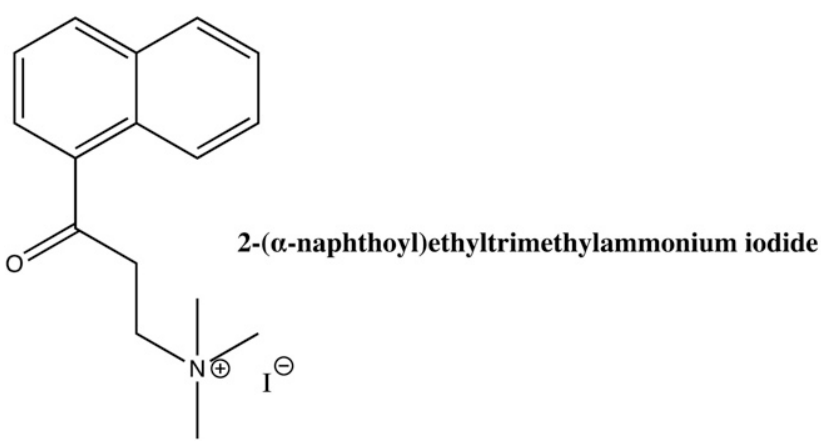

Fig. 7. Recently described synthetic TAAR5 ligands. et al., 2003; Babusyte et al., 2013; Table 4). Multiple isoforms of TAAR8 were found in various tissues from other species, including the rat cortex and cerebellum (Chiellini et al., 2012) and spinal cord (Gozal et al., 2014). In astroglia, expression was increased by lipopolysaccharide activation (D'Andrea et al., 2012). Lowlevel expression of the TAAR8b isoform was reported in various mouse brain regions (Mühlhaus et al., 2014), leukocytes (Nelson et al., 2007), kidney (Borowsky et al., 2001; Chiellini et al., 2012), heart, intestines, lung, skeletal muscle, spleen, stomach, and testis (Chiellini et al., 2012).

\section{Trace Amine-Associated Receptor 9}

The TAAR9 gene (previously known as TRAR3, TAR3, or trace amine receptor 3; Table 3) encodes a functional human protein of 348 amino acids. TAAR9 is thought to be tuned toward activation by tertiary amines, and like the case of TAAR8c, rat TAAR9 can be activated by $N$ methylpiperidine and $N, N$-dimethylcyclohexylamine, although only at micromolar concentrations (Liberles and Buck, 2006; Ferrero et al., 2012). It is notable that rat TAAR9 can also be activated by a currently unknown component(s) of both carnivore and noncarnivore urine (Ferrero et al., 2011), and this provides a good starting point for identifying putative endogenous ligands. As with other olfactory TAARs, TAAR9 is coupled to $\mathrm{G}_{\text {olf }}$-mediated cAMP accumulation (Ferrero et al., 2011). Beyond its role in the mammalian olfactory system, TAAR9 mRNA has been found in the full range of human leukocytes (D'Andrea et al., 2003; Babusyte et al., 2013), in addition to the pituitary gland and skeletal muscle (Vanti et al., 2003) (Table 4). TAAR9 mRNA has also been reported to be present in the mouse gastrointestinal tract, where it is preferentially localized to duodenal mucosal cells (Ito et al., 2009), as well as the spleen (Regard et al., 2008) and spinal cord (Gozal et al., 2014). A loss-of-function mutation in the TAAR9 gene with unknown clinical relevance has been reported to be present in up to $20 \%$ of the human population (Vanti et al., 2003; Müller et al., 2010).

\section{Trace Amine-Associated Receptors in Teleost and Other Fish}

Like in mammals, the number of functional TAAR genes varies significantly among teleost fish but is generally higher than in tetrapod genomes, ranging from approximately 18 in fugu to 112 in zebrafish (Hussain et al., 2009), with only minor differences generally observed between independent studies of individual species (Fig. 6; Table 5). Although some zebrafish TAARs (27 of 112), like all human TAARs (six of six) and most mouse TAARs (13 of 15), share the ability with other biogenic amine receptors to recognize monoamines via a specific, conserved binding site, the majority of zebrafish TAARs ( 85 of 112 ) evolved to a new 
way to recognize amines, losing the classic monoamine binding pocket and acquiring an inverted binding pocket, thus giving a rise to a distinct, third clade of TAARs that is unique to teleosts and Xenopus (Hussain et al., 2009, 2013; Li et al., 2015). In total, teleost TAARs span at least three separate phylogenetic groups, two of which have not been fully characterized (Hashiguchi and Nishida, 2007; Eyun et al., 2016). By comparison, cartilaginous fish (e.g., elephant shark) are evolutionarily the earliest representatives of jawed vertebrates and have two TAAR genes, both of which maintain the TAAR signature motif (Eyun et al., 2016). Sea lamprey may be the evolutionary origin of TAARs and have been reported to contain 25 TAAR-like proteins that form a separate family (Hashiguchi and Nishida, 2007; Eyun et al., 2016). Whether these lamprey receptors are indeed true TAAR family members has been debated (Hussain et al., 2009; Tessarolo et al., 2014) largely due to the TAAR signature motif that is well represented in the TAAR1-TAAR9 family being only weakly conserved in the sea lamprey TAAR-like genes.

Ligands for 12 teleost TAARs have been identified (Table 2), including members of the classic amine-sensing clade I receptors (TAAR10a, TAAR10b, TAAR12h, and TAAR12i) and the clade III representatives TAAR16c, TAAR16e, and TAAR16f, as well as TAAR13a, TAAR13c, TAAR13d, TAAR13e, and TAAR14d, which contain both classic and inverted binding pockets that combine to create a potential diamine binding site (Hussain et al., 2013; Li et al., 2015; Gao et al., 2017).

\section{E. Trace Amine-Associated Receptors in Olfaction}

Although TAARs are only distantly related to biogenic amine receptors and they also have no phylogenetic relationship with classic chemosensory receptors, it appears that all subfamilies of TAARs, with the exception of TAAR1, serve chemosensory functions in detecting socially or ecologically relevant olfactory cues (Liberles and Buck, 2006; Hussain et al., 2009; Horowitz et al., 2014; Liberles, 2015). Indeed, mammalian TAAR2-TAAR9 subfamilies, as well as teleost-specific TAARs, have distinct expression patterns in the olfactory system, being present in the olfactory epithelium, and neonatal Grueneberg ganglion but not in the vomeronasal organ (Liberles and Buck, 2006; Fleischer et al., 2007; Hussain et al., 2009). Like olfactory receptors, each TAAR is expressed in sparsely distributed sensory neurons $(<0.1 \%$ of the total), with a specific spatial distribution (Liberles and Buck, 2006). Neurons expressing a functional TAAR do not express other TAARs or olfactory receptors, whereas neurons expressing a TAAR pseudogene may express a second TAAR (Liberles and Buck, 2006; Johnson et al., 2012; Pacifico et al., 2012). Expressed TAAR proteins are found in the olfactory cilia, the site of odor detection, and axons project to distinct glomeruli within the dorsomedial domain of the olfactory bulb (Pacifico et al., 2012; Dieris et al., 2017), although this may be developmentally regulated in some species (Gliem et al., 2009; Shao et al., 2017). Like classic olfactory receptor neurons, TAAR neurons express $\mathrm{G}_{\mathrm{olf}}$ and related signaling proteins, and inhibition of adenylyl cyclase blocks the odor-related responses of TAAR neurons (Liberles and Buck, 2006; Ferrero et al., 2012; Zhang et al., 2013). It has, however, been reported that innate behavioral responses to the TAAR4 ligand PEA are not attenuated after conditional $\mathrm{G}_{\text {olf }}$ knockdown (Pérez-Gómez et al., 2015), raising the possibility of currently unknown coupling mechanisms in vivo.

In vitro screening for odorant TAAR ligands using cAMP reporter assays in HEK-293 cells transfected with individual TAARs has identified a number of small, volatile molecules that activate individual TAARs in several species, with affinities comparable to those of known ligands for olfactory receptors $\left(\mathrm{EC}_{50}<10 \mu \mathrm{M}\right)$. Thus far, such agonists have been identified for one human, one macaque, six mouse, three rat, and 12 zebrafish TAARs (Table 2 and Table 9) (Liberles and Buck, 2006; Ferrero et al., 2012; Wallrabenstein et al., 2013; Horowitz et al., 2014; Liberles, 2015; Saraiva et al., 2016). In many of these cases, however, further investigation of receptor and species specificity, as well as the physiologic functions mediated by receptor activation, is required to fully validate the identified chemical cues as the true ligands of individual TAAR (Liberles, 2015).

Notwithstanding the need for further validation, an emerging picture is developing of TAARs playing a role in detecting socially relevant odors from diverse ecological sources, in particular those originating from urine or the microbial metabolism of decomposing flesh, resulting in the induction of innate behavioral responses (Liberles, 2015). As such, individual TAARs have been implicated in the detection and avoidance of predators, avoidance (or more rarely attraction) to rotting food sources, and even the detection of putative pheromones. For example, urine has been shown to activate mouse TAAR4, TAAR5, TAAR7f, TAAR8c, and TAAR9 (Liberles and Buck, 2006; Ferrero et al., 2011; Li et al., 2013), although the specific component responsible has not always been identified. Recent comprehensive screening for olfactory TAAR ligands and analysis of their attractive and avoidance properties in mice has revealed a complex organization of TAAR-mediated innate behavioral effects. These innate behavioral responses are not only both context and concentration dependent, but they are also subject to modification by other odorants (Saraiva et al., 2016). Thus, it is likely that TAAR-mediated hard-wired behavioral responses to socially relevant odorant cues are further modulated in brain circuitry due to interactions with signals derived from other odorant receptors or environmental cues.

Two notes of caution are necessary, however, with respect to the interpretation of olfaction-mediated 
behaviors. First, in particular with respect to dose dependence, none of the studies in terrestrial vertebrates have measured the ligand concentration present in the vapor phase, a major confound with respect to trying to compare the potency of effects across independent studies. Even with a defined liquid concentration used, the vapor phase concentration can vary markedly as a result of variations in the surface area of the liquid phase, temperature of the testing environment, and volume of the testing chamber, as well as the nature of any device used to prevent physical contact of experimental animals with the liquid phase. Although this does not diminish the importance of the observed behavioral changes, it does necessitate that caution be used in making dose-dependent comparisons across studies. Second, studies have so far assumed that all responses are downstream of olfactory epithelium TAAR activation. At least some of the ligands (e.g., PEA) have been shown to readily cross lipid bilayers (Berry et al., 2013), and individual TAARs are present in peripheral cell populations (see previous sections). As such, it is possible that the physiologic responses to some olfactory delivered trace amines may occur due to a combination of downstream central nervous system signaling after olfactory epithelium TAAR activation, and systemic responses after ligand entry in to the bloodstream after passage across pulmonary membranes.

The current state of knowledge of olfaction-mediated responses of individual TAARs is presented in the following sections.

\section{Trace Amine-Associated Receptor 2}

Potent ligands for TAAR2 are yet to be identified, although several compounds that can activate this receptor at high concentrations were recently reported (Saraiva et al., 2016).

\section{Trace Amine-Associated Receptor 3}

Isoamylamine, a biogenic amine produced by leucine decarboxylation and known to be innately aversive to mice, was identified as an agonist of mouse TAAR3 (Liberles and Buck, 2006; Liberles, 2015), a receptor that is a pseudogene in humans (Lindemann and Hoener, 2005). Isoamylamine has been proposed to act as a pheromone in mice, inducing puberty in females (Nishimura et al., 1989), although this has also been questioned (Price and Vandenbergh, 1992). Intriguingly, strong class I major histocompatibility complex (MHC)-dependent female choice for genetically diverse and dissimilar males in the greater sac-winged bat (Saccopteryx bilineata) was recently correlated with the female TAAR3 genotype (Santos et al., 2016), indicating that TAARs and olfactory cues may be key mediators in mammalian MHC and immune system-based mate choice. The MHC-based ligand responsible for this response is currently unknown.

\section{Trace Amine-Associated Receptor 4}

TAAR4, which is a functional protein in many mammalian species but not in humans, has an overlapping pharmacological profile with TAAR1, being potently activated by the archetypal trace amine PEA (Liberles and Buck, 2006; Dewan et al., 2013). PEA is a component of urine, and analysis of 38 mammalian species indicated significantly higher PEA concentrations in carnivore urine, with some producing in excess of 1000 -fold more than herbivores (Dewan et al., 2013). Mice, as well as rats, are known to innately avoid a PEA odor source (Ferrero et al., 2011) and enzymatic depletion of PEA from carnivore urine reduced the repellant properties of the urine (Dewan et al., 2013). Furthermore, TAAR4-KO mice show no avoidance response to either PEA or carnivore urine (Dewan et al., 2013). Thus, at least in mice, PEA activation of TAAR4 underlies innate avoidance responses to predator urine. Consistent with this, PEA olfactory exposure sufficient to induce an innate avoidance response has been reported to result in activation (as measured by increased c-fos expression) of the posteroventral region of the medial amygdala and the dorsomedial region of the ventromedial hypothalamus (Pérez-Gómez et al., 2015), brain areas implicated in fear, anxiety, panic, and defensive behaviors in rodents. Interestingly, PEA urinary levels have also been reported to be increased in response to stress (Grimsby et al., 1997; Paulos and Tessel, 1982); as such, PEA may serve as both a conspecific and heterospecific urinary warning cue. In tigers, PEA has also been proposed to serve a pheromone function (Brahmachary and Dutta, 1979), although the TAAR4 expression profile of tigers is currently unknown.

\section{Trace Amine-Associated Receptor 5}

Human, macaque, rat, and mouse TAAR5 are potently activated by trimethylamine (Liberles and Buck, 2006; Horowitz et al., 2014), which is most often regarded as a product of choline and/or L-carnitine metabolism in the body by the microflora of the gastrointestinal tract, oral cavity, and vagina, as described above (Fennema et al., 2016; Zhang and Davies, 2016). TAAR5 is also activated by spoiled fish, likely due to the presence of trimethylamine (Horowitz et al., 2014), and might serve as a mechanism for the innate avoidance of foods that could harbor pathogenic microorganisms and thus pose a danger to health.

In mice, trimethylamine is a sexually dimorphic odor that can evoke sex-specific, concentration-dependent behaviors (Liberles and Buck, 2006; Li et al., 2013), and this has led to suggestions that trimethylamine is a murine pheromone (Liberles, 2014). Trimethylamine is present in male mouse urine from where it is detected by TAAR5 (Liberles and Buck, 2006); enzymatic elimination of urinary trimethylamine disrupts behavioral responses to male mouse urine ( $\mathrm{Li}$ et al., 2013). Male mice have 
TABLE 9

Functional activity $\left(\mathrm{EC}_{50}\right)$ of endogenous and synthetic agonists of rat, mouse, human, and zebrafish olfactory TAARs

\begin{tabular}{|c|c|c|c|}
\hline Mammalian TAAR & Species & Ligand & $\mathrm{EC}_{50}$ \\
\hline & \multirow{5}{*}{ Rat, mouse } & & $\mu M$ \\
\hline \multirow[t]{4}{*}{ TAAR3 } & & Cyclohexylamine & 7 (mouse) ${ }^{b} 20$ (mouse) $^{c}$ \\
\hline & & Isoamylamine & 10 (mouse) $^{b, c}$ \\
\hline & & Octylamine & 50 (mouse) $^{b}$ \\
\hline & & PEA & $40{\text { (mouse })^{b}}^{2}$ \\
\hline TAAR4 & Rat, mouse & PEA & 0.7 (mouse) $^{b} 1$ (mouse) $^{c}$ \\
\hline \multirow[t]{9}{*}{ TAAR5 } & \multirow[t]{9}{*}{ Human, rat, mouse } & Trimethylamine & $\begin{array}{c}0.7 \text { (mouse) }^{b} 0.3 \text { (mouse) } \\
1 \text { (rat) }{ }^{d} 0.12 \text { (human) }\end{array}$ \\
\hline & & $N, N$-dimethylethylamine & 1 (mouse) ${ }^{b} 0.17$ (human) ${ }^{e}$ \\
\hline & & $N, N$-dimethyloctylamine & 1 (mouse) $^{b}$ \\
\hline & & N-methylpiperidine & $\begin{array}{l}3 \text { (mouse) }^{b} 20 \text { (mouse) }{ }^{c} \\
>10(\text { human })^{e}\end{array}$ \\
\hline & & Pyrrolidine & $17{\text { (mouse })^{b}}^{b}$ \\
\hline & & Triethylamine & 22 (mouse) $^{b}$ \\
\hline & & 3-pyrroline & 42 (mouse) $^{b}$ \\
\hline & & 2-methy-1-pyrroline & $46{\text { (mouse })^{b}}^{b}$ \\
\hline & & $3 \mathrm{IT}^{a}$ & $4.4(\text { human })^{f}$ \\
\hline \multirow[t]{2}{*}{ TAAR7b } & \multirow[t]{2}{*}{ Rat, mouse } & $N, N$-dimethyloctylamine & 3 (mouse) $^{b}$ \\
\hline & & $N, N$-dimethylbutylamine & $30{\text { (mouse })^{b}}^{b}$ \\
\hline \multirow[t]{3}{*}{ TAAR7e } & \multirow{3}{*}{ Rat, mouse } & Octylamine & 28 (mouse) $^{b}$ \\
\hline & & Heptylamine & 34 (mouse) $^{b}$ \\
\hline & & 2-methy-1-pyrroline & $48{\text { (mouse })^{b}}^{b}$ \\
\hline \multirow[t]{6}{*}{ TAAR7d } & \multirow[t]{6}{*}{ Rat, mouse } & $N, N$-dimethylcyclohexylamine & 0.5 (mouse) $^{b}$ \\
\hline & & $N$-methylpiperidine & 16 (mouse) $^{b}$ \\
\hline & & $N, N$-dimethylbutylamine & $30{\text { (mouse })^{b}}^{b}$ \\
\hline & & 1-(2-aminoethyl)piperidine & 30 (mouse $^{b}$ \\
\hline & & Heptylamine & $33{\text { (mouse })^{b}}^{b}$ \\
\hline & & 2-methy-1-pyrroline & $50{\text { (mouse })^{b}}^{b}$ \\
\hline \multirow[t]{2}{*}{ TAAR8c } & \multirow[t]{2}{*}{ Human, rat, mouse } & $N$-methylpiperidine & $0.5(\text { rat })^{g}$ \\
\hline & & $N, N$-dimethylcyclohexylamine & $13(\mathrm{rat})^{g}$ \\
\hline \multirow[t]{2}{*}{ TAAR9 } & \multirow[t]{2}{*}{ Human, rat, mouse } & $N$-methylpiperidine & $18(\text { rat })^{g}$ \\
\hline & & $N, N$-dimethylcyclohexylamine & $27(\text { rat })^{g}$ \\
\hline \multicolumn{4}{|l|}{ Zebrafish TAARs } \\
\hline \multirow[t]{2}{*}{ TAAR10a } & \multirow[t]{2}{*}{ Zebrafish } & Serotonin & $0.5^{h}$ \\
\hline & & 5-methoxytryptamine & $20^{h}$ \\
\hline TAAR10b & Zebrafish & TRP & $50^{h}$ \\
\hline TAAR $12 \mathrm{~h}$ & Zebrafish & $\beta$-phenyethylamine & $0.3^{h}$ \\
\hline TAAR13a & Zebrafish & Histamine & $20^{h}$ \\
\hline TAAR13c & Zebrafish & Cadaverine & $20{ }^{i} 10^{h}$ \\
\hline TAAR13d & Zebrafish & Putrescine & $1^{h}$ \\
\hline TAAR16c & Zebrafish & $N$-methylpiperidine & $10^{h}$ \\
\hline TAAR16e & Zebrafish & $N, N$-dimethylcyclohexylamine & $30^{h}$ \\
\hline
\end{tabular}

Only compounds with $<50 \mu \mathrm{M}$ activity are listed.

${ }^{a}$ Inverse agonist.

${ }^{b}$ Saraiva et al. (2016).

${ }^{c}$ Liberles and Buck (2006).

${ }^{d} \mathrm{Li}$ et al. (2015).

${ }^{e}$ Wallrabenstein et al. (2013).

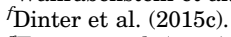

${ }^{g}$ Ferrero et al. (2012).

${ }^{h} \mathrm{Li}$ et al. (2015).

${ }^{i}$ Hussain et al. (2013).

particularly high concentrations of trimethylamine in urine (up to $5 \mathrm{mM}$; >1000-fold higher than in female mice or rats) due to a genetic deficiency in FMO3 (Li et al., 2013; Liberles, 2015) preventing its metabolism. Whereas rats (like humans) find trimethylamine innately aversive, mice demonstrate attraction to lower (urinary) concentrations, with aversion occurring to higher levels (Li et al., 2013; Liberles, 2015). Mice lacking TAAR5 demonstrate no attraction to trimethylamine but still avoid high concentrations (Li et al., 2013), suggesting that TAAR5 mediates the attractive responses due to high-affinity detection of trimethylamine, whereas a second, low-affinity, unknown receptor is responsible for the aversive behavior. Interestingly, specific anosmia for trimethylamine in humans was reported to be unrelated to polymorphisms in the coding sequence of the TAAR5 gene (Wallrabenstein et al., 2013).

\section{Trace Amine-Associated Receptors 7, 8, and 9}

It has been shown that unknown components of carnivore and noncarnivore urine can activate rat TAAR7f, TAAR8c, and TAAR9 (Ferrero et al., 2011). TAAR8c and TAAR9 can also be activated by $N$-methylpiperidine and $N$, $\mathrm{N}$-dimethylcyclohexylamine, respectively (Liberles and Buck, 2006; Ferrero et al., 2012).

\section{Teleost Olfactory Responses}

The archetypal diamine cadaverine is a major component of rotting flesh that potently activates zebrafish TAAR13c present in olfactory sensory neurons that 
project to dorsolateral glomeruli of the olfactory bulb, evoking innate avoidance behavior (Hussain et al., 2013; Dieris et al., 2017). Structure-activity analysis indicated that TAAR13c has a preference for medium-sized diamines containing an odd number of carbons and contains a nonclassic monoamine recognition pocket with two distinct cation recognition sites (Hussain et al., 2013). Intriguingly, cadaverine also induces avoidance responses in mice, and this behavior is lost in mice with a cluster TAAR2-TAAR9-KO, suggesting that at least one of these receptors is responsible for the detection (Dewan et al., 2013). Interestingly, human TAAR6 and TAAR8, mouse TAAR6 and TAAR8b, and rat TAAR6 and TAAR8a also have TAAR13c-like diamine binding pockets and thus are likely candidates for cadaverine-detecting TAARs (Li et al., 2015). Ecologically relevant ligands for a number of other teleost TAARs have been identified (Table 2), although the physiologic responses to these ligands of other teleost TAARs have not yet been investigated ( $\mathrm{Li}$ et al., 2015). As previously described, lamprey have also been reported to innately avoid a PEA source (Imre et al., 2014), although whether this is TAAR mediated is unknown.

\section{Future Directions}

\section{A. Better Understanding of the Physiologic Role(s) of Trace Amine-Associated Receptors and Their Endogenous Ligands}

1. Trace Amine-Associated Receptor 1. Although great advances have occurred in understanding the physiologic roles of TAAR1 in the central nervous system, its functions in peripheral tissues remain largely unknown. Advances in these areas have begun, in particular in establishing TAAR1 as playing a role in the control of nutrient-induced hormone secretion throughout the gastrointestinal system, with particularly robust effects demonstrated in the pancreas. Unfortunately, further progress has been hindered by a lack of suitable pharmacological tools (particularly useable receptor antagonists). In addition, it is only in the last 2 years that well validated antibodies have been described, one suitable for immunohistochemistry of human tissue and one for Western blot of rat tissues. Although progress has been made through the use of transgenic and gene silencing technologies, again the development of missing high-quality pharmacological tools such as receptor antagonists and validated selective antibodies will be crucial to furthering these endeavors and this was discussed more fully recently (Berry et al., 2017). Application of modern optogenetic and DREADD (designer receptors exclusively activated by designer drugs) technologies will also be of considerable benefit to further understanding the homeostatic physiologic properties of TAAR1 as well as other TAAR isoforms.

Outside of the central nervous system and tissues controlling energy metabolism, the role of TAAR 1 in modulating the immune system is a notable area for future study. Although this area is currently not as well developed as others, there is slowly accumulating evidence that TAAR1 and its ligands exert immunomodulatory effects. With endogenous TAAR1 ligands appearing to readily cross cell membranes and TAAR 1 seemingly present in a variety of leukocyte populations where it may regulate cytokine and immunoglobulin secretion, a particularly intriguing possibility is that TAAR1 activation may play a role in environmental hypersensitivity reactions, particularly in the pulmonary and gastrointestinal systems.

There also remains a surprising sparsity of knowledge about the basic homeostatic mechanisms that control trace aminergic functioning. Although endogenous ligands for TAAR1 are now well established, questions remain about their synthesis and how cellular levels and access to receptors are controlled. The possibility that the TAAR1 system serves as an endogenous mechanism for promoting biased agonism at one or more neurotransmitter receptors is intriguing and something that, should it be firmly established, is expected to generate considerable interest within the pharmaceutical industry.

2. Other Trace Amine-Associated Receptors. The establishment of TAARs as a new class of receptor for olfaction has allowed the first steps to be taken in determining the function of the wider TAAR family, with the identification of ligands for several TAARs, including putative endogenous ligands for TAAR3, TAAR4, and TAAR5. As progress continues to be made in establishing physiologic roles for olfactory TAARs in detecting environmental cues that induce innate behavioral responses related to survival and species propagation, it will be important not to lose sight of the presence of these receptors in other tissues as well. Furthermore, identification of the neural pathways activated downstream of individual olfactory TAAR isoforms will allow a greater understanding of conspecific and heterospecific signaling mechanisms.

Clarifying the cellular distribution of each TAAR throughout the body will be an important early step in future studies, along with development of high-selectivity synthetic ligands. In this latter aspect, the identification of a consensus TAAR binding pocket and development of in silico molecular docking programs, allowing for high-throughput virtual screening of vast chemical libraries, is expected to be of considerable utility. As endogenous ligands for individual TAARs are identified, the identification of synthetic and degradative routes will be required. A number of pharmacological tools have been developed for the study of olfactory TAARs, and application of these tools to nonolfactory systems will be useful in allowing a more rapid identification of physiologic responses than was possible with TAAR1.

\section{B. Development of Selective Trace Amine-Associated Receptor 1 Ligands as Therapeutics}

1. Schizophrenia and Bipolar Disorder. Schizophrenia and bipolar disorders are world-leading causes of 
disability, with a combined lifetime prevalence of approximately 3\% in the general population (Perälä et al., 2007). Symptoms and signs of schizophrenia are clustered into three major domains: positive (e.g., delusions or hallucinations), negative (e.g., blunted affect, amotivation), and cognitive (e.g., executive dysfunction, poor verbal memory), with frequent occurrences of comorbid depressive symptoms. The primary symptom domain of bipolar disorder is the presence of a sustained abnormality of mood state, including abnormal mood elevation, depression, irritability of mood, and so-called "mixed states" of all three symptom clusters. In cases of psychotic bipolar disorder, co-occurring psychotic symptoms also appear during severe phases.

Antipsychotic treatment of schizophrenia and bipolar disorders mainly targets the symptoms found during acute exacerbations, in particular acute positive symptoms and mania. These drugs act as antagonists at D2Rs, and they act on serotonergic (e.g., 5- $\mathrm{HT}_{2 \mathrm{~A}}$ ), cholinergic (e.g., muscarinic M1), and histaminergic (e.g., H1) receptors as well (Kim et al., 2009). These include first-generation drugs such as the phenothiazines and butyrophenones, which are associated with frequent and severe extrapyramidal symptoms such as drug-induced parkinsonism and the neuroleptic malignant syndrome despite having great potency as antipsychotics. Second-generation (atypical) antipsychotics are currently the mainstay of therapy for both disorders and include compounds such as clozapine, olanzapine, quetiapine, risperidone, and aripiprazole. These second-generation compounds are associated with less severe extrapyramidal symptoms but are associated with a metabolic syndrome (dyslipidemia, insulin resistance, pronounced weight gain, and elevations in blood pressure), which can unfavorably alter the benefit-risk ratio (Gründer et al., 2009; Kim et al., 2009; Meyer and Stahl, 2009; Thomas et al., 2009). The metabolic syndrome and obesity are estimated to occur in 33\% of patients with schizophrenia and bipolar disorders. In particular, patients who require treatment with olanzapine, clozapine, risperidone, or quetiapine have high rates of these conditions. Even before the advent of modern pharmacotherapy, however, patients with schizophrenia and related-disorders were known to suffer disproportionately from chronic disorders such as cardiovascular disease and diabetes (Reynolds and Kirk, 2010), suggesting a potential molecular commonality. Until recently, the excess dopamine hypothesis was the major pathophysiological theory of psychosis, based largely on the effectiveness of D2R antagonists. More recently, dysfunctions in other neurotransmitters, in particular glutamate, have been identified and are being explored as new therapeutic targets (Moghaddam and Javitt, 2012).

As described in previous sections, abnormalities in trace amine physiology have long been associated with schizophrenia and bipolar disorders. In schizophrenia, increased urinary levels of PEA and alterations in the metabolism of TRP and TYR have been proposed, including enzymes involved in the synthetic and catabolic pathways of these molecules. TAAR1 is expressed in brain structures associated with psychiatric disorders, in particular in key areas where modulation of dopamine (VTA) and serotonin (DRN) occurs, but also in the amygdala, hypothalamus, rhinal cortices, and subiculum (Lindemann et al., 2008) where it modulates dopaminergic, serotonergic, and glutamatergic neurotransmission. As such, TAAR1 may be a novel target for development of novel antipsychotic, potentially mood-stabilizing, and antidepressant drugs with high potential for differentiation, by exploiting the fundamentally new mechanism and target of action. Furthermore, given their positive energy metabolism profile, TAAR1 agonists may provide additional benefit for patients with schizophrenia or bipolar disorder and the comorbidities of associated metabolic syndrome. Indeed, the first TAAR1-directed agent (SEP-363856) is currently in clinical trials for schizophrenia (Berry et al., 2017).

Given that TAAR1 is the only validated receptor target of the amphetamines and there is an abundant literature linking amphetamine-like effects to schizophrenia, it may appear counterintuitive that TAAR1 agonists exert antipsychotic actions. As described, however, TAAR1 agonism only recapitulates a small portion of the physiologic responses to amphetamine and none of the pleasurable, reinforcing properties. Indeed, TAAR1 agonism counteracts these reinforcing properties. As such, it is incorrect to regard TAAR1 agonists as amphetamine like. Rather, TAAR1 agonism is just one of the many molecular mechanisms by which the promiscuous amphetamines exert their effects.

2. Addiction and Compulsive Behaviors. Since the identification that a number of psychotropic drugs of abuse were agonists at TAAR1, there has been considerable interest in determining the role(s) that TAAR1 might play in drug abuse and compulsive behaviors in general. These studies have firmly established TAAR1 as a novel target for the treatment of addiction, an effect that relates to TAAR1 localization in the central dopamine reward centers and regulation of D2R signaling. Not only does this realize control of cravings and relapse toward psychotropic agents that are agonists at TAAR1 (amphetamine, methamphetamine, MDMA), but also to other addictive agents (cocaine, morphine, nicotine, and ethanol) and behaviors (binge eating) where TAAR 1 is not a direct target of the addictive agent. Importantly, the effects of TAAR1 agonists do not merely substitute for the agent of abuse, with TAAR1 agonists alone not supporting self-administration; rather, they address the underlying overactivity of dopaminergic neural drives of drug-seeking behavior. Although no known clinical trials have yet occurred, dopamine reward pathways were identified as a TAAR1 target in healthy human volunteers and it is anticipated that TAAR1 agonists will be the subject of future 
development activities for the control of drug-taking behavior. Such development activities may also include environmental stress disorders such as post-traumatic stress disorder, in which an increased susceptibility to drug abuse is prevalent. In this regard, it is interesting to note that the possible beneficial effects of the psychotropic TAAR1 ligand MDMA in post-traumatic stress disorder are being actively investigated (Amoroso and Workman, 2016; Sessa, 2017).

3. Metabolic Syndromes. Diabetes is one of the fastest growing health concerns worldwide. The total number of people with all types of diabetes is projected to rise from approximately 285 million in 2010 to 439 million in 2030, primarily due to population growth, aging, urbanization, and an increasing prevalence of obesity and physical inactivity (Shaw et al., 2010). Type 2 diabetes mellitus accounts for $90 \%-95 \%$ of all cases of diabetes in patients older than 20 years of age. It occurs more frequently in adults but is also being increasingly diagnosed in adolescents (Aye and Levitsky, 2003). Type 2 diabetes mellitus is a chronic metabolic disease characterized by hyperglycemia resulting from pancreatic $\beta$-cell dysfunction, deficiency in insulin secretion, insulin resistance, and/or increased hepatic glucose production. Current antidiabetic medications are often inefficient at achieving glycemic control because they predominantly address only a single underlying defect (namely, the insulin secretion deficits). In addition, they tend to be associated with undesirable side effects such as weight gain and episodes of hypoglycemia, congestive heart failure, and impaired renal function. New and more effective drugs for the prevention and treatment of type 2 diabetes mellitus are therefore urgently required. The emerging profile of TAAR 1 agonists possessing incretin-like effects, increasing insulin secretion at elevated, but not basal, glucose levels, makes them an attractive prospect for further development. Furthermore, the unique ability of TAAR1 agonists to also regulate hormone secretion from the stomach and gastrointestinal tract in response to nutrients, decrease diabetes-associated obesity, as well as decrease the propensity for binge eating and addictive behaviors in general suggests that TAAR1 agonists may be uniquely able to address both central and peripheral aspects of metabolic disorders.

\section{Trace Amine-Associated Receptors in Ecology}

The demonstration that olfactory TAARs are involved in the initiation of innate behavioral responses to diverse environmental cues has generated interest in TAARs within the olfaction research community. Interest is also beginning to be shown by those studying ecology and there have been the first suggestions that TAARs may be involved in migration and mate choice of individual species. It is expected that these initial results will generate further interest that will allow further advances to be made in identifying innate behaviors that are controlled by olfactory TAARs. Such advances will almost certainly also lead to the identification of new TAAR ligands, which it is hoped will allow for the deorphaning of additional TAAR family members. With a select number of compounds that are associated with diverse ecological contexts and selective toward individual TAARs already identified, the olfactory TAARs offer an amenable system to probing the neural basis of survival behaviors associated with different ecological contexts. Currently, only one neural pathway involved in the innate behaviors initiated in response to olfactory TAAR activation has begun to be mapped. It is expected that this will be resolved in the coming years, providing a major breakthrough in understanding the cellular basis of the drives for various vertebrate behaviors.

With large variations in the complement of TAARs between species and activation of individual TAARs demonstrated in response to both conspecific and heterospecific urines, it seems clear that TAARs are involved in species-specific adaptation responses. As such, the evolution of TAARs appears to be a good option for studying the evolution of olfactory systems, at least with respect to innate survival mechanisms. From this perspective, amphibians are of particular interest because their olfactory systems have been suggested to represent an evolutionary midpoint between teleosts and mammals. There are few complete genome sequences available for amphibia and the TAAR complement of two Xenopus species are the only ones to have been reported. Unfortunately, Xenopus are evolutionarily rather distant from the true frogs (Ranitidae sp.). Determining the TAAR complement of representative true frog species would be advantageous and provide a starting point for addressing evolutionary questions about the origins of vertebrate olfactory systems.

One interesting aspect that the TAAR system may offer is the ability of a single cue to directly activate both centrally and peripherally mediated responses. Certainly, centrally mediated behaviors are induced by activation of TAARs in the olfactory passages. In addition, however, at least some TAAR ligands can readily cross cell membranes; with TAARs present throughout the body, direct activation of systemic responses may also be possible. In this regard, it is particularly interesting that the strongest evidence for peripheral TAAR responses so far is in cells controlling energy metabolism and those of the immune system. These are two systems that depending on the precise context would, on the surface, appear to be advantageous to activate in response to the possible presence of predators, pathogenic microbes (spoiled food), or in preparation for mating. Such a situation could provide an explanation for why the evolutionary origin of the entire family (TAAR1) is not involved in the detection of olfactory cues. 


\section{Trace Amine-Associated Receptors, Nutrition, the Microbiome, and Health}

The roles of nutrition and the constitutive microbiota in health and disease are a growing area of research. The presence within various foodstuffs of compounds that are now known to be selective ligands for individual TAARs has long been known. Within the food science community, the presence of these compounds has been almost exclusively studied from the point of view of food spoilage and microbial contamination. With the growing recognition and acceptance of TAAR functions throughout the body, but particularly in the gastrointestinal tract and immune system, it is expected that over the next few years there will be a growing interest in whether there is a role to play for TAARs in both the beneficial and adverse effects of food in some individuals.

The search for metabolites that can link the constitutive microbiota to health outcomes has become an active area considerably aided by the development of powerful metabolomic techniques. With the levels of known TAAR ligands readily modified by the microbiota and a defined family of receptors present, it is expected that the trace amine system will develop into a locus for such studies. Besides the potential of the trace amine system providing a molecular pathway for the putative link between the microbiota, gastrointestinal tract, and central nervous system disorders, particularly intriguing is the molecular link that the trace amine system could provide between nutrient intake, the microbiota, and the immune system.

\section{Conclusion}

The identification of the TAAR family has resurrected interest in a series of compounds that had originally been identified as a topic for study at the advent of the 20th century by some of the founding fathers of the fields of biochemistry, cellular physiology, and pharmacology. Some basic knowledge gaps remain; for example, many TAARs remain orphan receptors with no known defining ligand, there is sparse information on cellular and tissue distribution of receptors, even the term "trace amine" has become nebulous and poorly defined, and suitably selective pharmacological reagents remain at a premium. Yet an exciting field with broad multidisciplinary implications has begun to emerge. Although the 1960s and 1970s focus of trace amines (and thereby the subsequently identified TAARs) as putative etiologic factors in drug abuse and psychiatric disorders continues to be a driving force, hitherto unsuspected roles have emerged. Prominent among those are roles in the peripheral control of energy metabolism as well as a growing recognition of a putative role in the control of cellular immune responses. Even with respect to psychiatric disorders, the journey of the last few years has taken a number of unexpected twists and turns. Whereas TAAR1 is a direct target of a number of psychotropic drugs of abuse, activation of TAAR1 unexpectedly shows considerable promise as a novel therapeutic target for the pharmacotherapy of schizophrenia and drug abuse, with available evidence indicating no abuse potential of TAAR1-directed agents. This likely reflects the promiscuity of molecular action of many of the drugs of abuse, in particular those that are amphetamine like. Although TAAR1 agonism is one of those sites of action, this is not related to their reinforcing properties and, hence, abuse potential. As such, TAAR1 agonists should not be viewed as amphetamine like. Rather, amphetaminergic compounds include TAAR1 agonism as one of their many molecular sites of action.

After the identification of TAARs, the unexpected demonstration that they also serve a role as a new class of receptors for olfaction has opened up new vistas. Diverse environmental sources of ligands for individual TAARs have been identified, making the TAAR family of interest for investigating ecological questions around predator-prey interactions, mate selection, nutrient, and habitat choices. Furthermore, with TAARs being unique to vertebrates and showing a high degree of interspecies variability, the ability to detect trace amines having arisen independently in invertebrates and vertebrates, and different TAAR isoforms under either positive or negative selection pressures, TAARs have emerged as an excellent system for addressing questions of the evolutionary origin of vertebrate olfactory systems. The independence of evolution between invertebrate and vertebrate trace amine systems has also seen the invertebrate trace amine systems emerge as potential targets for development of novel pest control agents that may have a better safety profile with respect to vertebrate exposure.

TAAR ligands are readily produced and metabolized by microbes, and as TAARs become more widely recognized and their cellular effects more fully established, they are likely to attract the interest of microbiologists studying host-microbe interactions, food scientists studying fermentation processes in food production and quality control, and nutritional biochemists interested in the role of nutrients in health and disease. Although the journey from Nencki's products of putrid flesh is far from complete, the last decade has seen considerable advances and new avenues discovered. With a critical mass of trace amine researchers originating from diverse scientific backgrounds now emerging, it is expected that an accelerated phase of advancement of the field will occur over the next few years, including an increased understanding of the evolution of environmental adaptation strategies and the clinical testing of the first pharmacotherapies directed toward individual TAARs. 


\section{Acknowledgments}

We thank Martin Ebeling and Jitao David Zhang (F. Hoffmann-La Roche, Basel, Switzerland) for kind help and excellent technical assistance in preparation of the phylogenetic tree of TAARs.

\section{Authorship Contributions}

Wrote or contributed to the writing of the manuscript: Gainetdinov, Hoener, Berry.

\section{References}

Abou Jamra R, Sircar I, Becker T, Freudenberg-Hua Y, Ohlraun S, Freudenberg J, Brockschmidt F, Schulze TG, Gross M, Spira F, et al. (2005) A family-based and case-control association study of trace amine receptor genes on chromosome $6 \mathrm{q} 23$ in bipolar affective disorder. Mol Psychiatry 10:618-620.

Achat-Mendes C, Lynch LJ, Sullivan KA, Vallender EJ, and Miller GM (2012) Augmentation of methamphetamine-induced behaviors in transgenic mice lacking the trace amine-associated receptor 1. Pharmacol Biochem Behav 101:201-207.

Ackermans MT, Klieverik LP, Ringeling P, Endert E, Kalsbeek A, and Fliers E (2010) An online solid-phase extraction-liquid chromatography-tandem mass spectrometry method to study the presence of thyronamines in plasma and tissue and their putative conversion from 13C6-thyroxine. J Endocrinol 206:327-334.

Adriaenssens A, Lam BY, Billing L, Skeffington K, Sewing S, Reimann F, and Gribble F (2015) A transcriptome-led exploration of molecular mechanisms regulating somatostatin-producing D-cells in the gastric epithelium. Endocrinology 156:3924-3936.

Aguanno A, Afar R, and Albert VR (1996) Tissue-specific expression of the nonneuronal promoter of the aromatic L-amino acid decarboxylase gene is regulated by hepatocyte nuclear factor 1. J Biol Chem 271:4528-4538.

Aguanno A, Lee MR, Marden CM, Rattray M, Gault A, and Albert VR (1995) Analysis of the neuronal promoter of the rat aromatic L-amino acid decarboxylase gene. $J$ Neurochem 65:1944-1954.

Albert VR, Lee MR, Bolden AH, Wurzburger RJ, and Aguanno A (1992) Distinct promoters direct neuronal and nonneuronal expression of rat aromatic L-amino acid decarboxylase. Proc Natl Acad Sci USA 89:12053-12057.

Aleksandrov AA, Dmitrieva ES, Volnova AB, Knyazeva VM, Gerasimov AS, and Gainetdinov RR (2018a) TAAR5 receptor agonist affects sensory gating in rats. Neurosci Lett 666:144-147.

Aleksandrov AA, Knyazeva VM, Volnova AB, Dmitrieva ES, Korenkova O, Espinoza S, Gerasimov A, and Gainetdinov RR (2018b) Identification of TAAR5 agonist activity of alpha-NETA and its effect on mismatch negativity amplitude in awake rats. Neurotox Res DOI:10.1007/s12640-018-9902-6 [published ahead of print].

Alexander JL, Wilson ID, Teare J, Marchesi JR, Nicholson JK, and Kinross JM (2017) Gut microbiota modulation of chemotherapy efficacy and toxicity. Nat Rev Gastroenterol Hepatol 14:356-365.

Alexander SPH, Kelly E, Marrion N, Peters JA, Benson HE, Faccenda E, Pawson AJ, Sharman JL, Southan C, Buneman OP, et al.; CGTP Collaborators (2015) The concise guide to pharmacology 2015/16: overview. Br J Pharmacol 172:5729-5743.

Alkema MJ, Hunter-Ensor M, Ringstad N, and Horvitz HR (2005) Tyramine functions independently of octopamine in the Caenorhabditis elegans nervous system. Neuron 46:247-260.

Altar CA, Wasley AM, and Martin LL (1986) Autoradiographic localization and pharmacology of unique $[3 \mathrm{H}]$ tryptamine binding sites in rat brain. Neuroscience 17:263-273.

Alvarsson A, Zhang X, Stan TL, Schintu N, Kadkhodaei B, Millan MJ, Perlmann T, and Svenningsson P (2015) Modulation by trace amine-associated receptor 1 of experimental parkinsonism, L-DOPA responsivity, and glutamatergic neurotransmission. J Neurosci 35:14057-14069.

Amoroso T and Workman M (2016) Treating posttraumatic stress disorder with MDMA-assisted psychotherapy: a preliminary meta-analysis and comparison to prolonged exposure therapy. $J$ Psychopharmacol 30:595-600.

An D, Chen Z, Zheng J, Chen S, Wang L, Huang Z, and Weng L (2015) Determination of biogenic amines in oysters by capillary electrophoresis coupled with electrochemiluminescence. Food Chem 168:1-6.

Ando-Yamamoto M, Hayashi H, Sugiyama T, Fukui H, Watanabe T, and Wada H (1987) Purification of L-dopa decarboxylase from rat liver and production of polyclonal and monoclonal antibodies against it. $J$ Biochem 101:405-414.

Andrés M, Seifert M, Spalthoff C, Warren B, Weiss L, Giraldo D, Winkler M, Pauls S, and Göpfert MC (2016) Auditory efferent system modulates mosquito hearing. Curr Biol 26:2028-2036.

Anton S, Dufour M-C, and Gadenne C (2006) Plasticity of olfactory-guided behaviour and its neurobiological basis. Entomol Experiment Appl 123:1-11.

Aperia A, Hökfelt T, Meister B, Bertorello A, Fryckstedt J, Holtbäck U, and Seri I (1990) The significance of L-amino acid decarboxylase and DARPP-32 in the kidney. Am J Hypertens 3:11S-13S.

Arakawa S, Gocayne JD, McCombie WR, Urquhart DA, Hall LM, Fraser CM, and Venter JC (1990) Cloning, localization, and permanent expression of a Drosophila octopamine receptor. Neuron 4:343-354.

Ashley-Montagu MF (1938) Trimethylamine in menstruous women. Nature 142: $1121-1122$

Asif-Malik A, Hoener MC, and Canales JJ (2017) Interaction between the trace amine-associated receptor 1 and the dopamine $D_{2}$ receptor controls cocaine's neurochemical actions. Sci Rep 7:13901.

Axelrod J and Saavedra JM (1977) Octopamine. Nature 265:501-504

Aye T and Levitsky LL (2003) Type 2 diabetes: an epidemic disease in childhood. Curr Opin Pediatr 15:411-415.
Azam B, Wienecke J, Jensen DB, Azam A, and Zhang M (2015) Spinal cord hemisection facilitates aromatic L-amino acid decarboxylase cells to produce serotonin in the subchronic but not the chronic phase. Neural Plast 2015:549671.

Azzouzi N, Barloy-Hubler F, and Galibert F (2015) Identification and characterization of cichlid TAAR genes and comparison with other teleost TAAR repertoires. BMC Genomics 16:335.

Babusyte A, Kotthoff M, Fiedler J, and Krautwurst D (2013) Biogenic amines activate blood leukocytes via trace amine-associated receptors TAAR1 and TAAR2. $J$ Leukoc Biol 93:387-394.

Bach B, Le Quere S, Vuchot P, Grinbaum M, and Barnavon L (2012) Validation of a method for the analysis of biogenic amines: histamine instability during wine sample storage. Anal Chim Acta 732:114-119.

Bacon JP, Thompson KS, and Stern M (1995) Identified octopaminergic neurons provide an arousal mechanism in the locust brain. $J$ Neurophysiol 74:2739-2743.

Baggio LL and Drucker DJ (2007) Biology of incretins: GLP-1 and GIP. Gastroenterology 132:2131-2157.

Bahado-Singh RO, Akolekar R, Chelliah A, Mandal R, Dong E, Kruger M, Wishart DS, and Nicolaides K (2013) Metabolomic analysis for first-trimester trisomy 18 detection. Am J Obstet Gynecol 209:65.e1-65.e9.

Bain MA, Faull R, Fornasini G, Milne RW, and Evans AM (2006) Accumulation of trimethylamine and trimethylamine-N-oxide in end-stage renal disease patients undergoing haemodialysis. Nephrol Dial Transplant 21:1300-1304.

Baker GB, Bornstein RA, Rouget AC, Ashton SE, van Muyden JC, and Coutts RT (1991) Phenylethylaminergic mechanisms in attention-deficit disorder. Biol Psychiatry 29:15-22.

Baker GB, Raiteri M, Bertollini A, and del Carmine R (1976) Interaction of betaphenethylamine with dopamine and noradrenaline in the central nervous system of the rat. J Pharm Pharmacol 28:456-457.

Balfanz S, Jordan N, Langenstück T, Breuer J, Bergmeier V, and Baumann A (2014) Molecular, pharmacological, and signaling properties of octopamine receptors from honeybee (Apis mellifera) brain. J Neurochem 129:284-296.

Balfanz S, Strünker T, Frings S, and Baumann A (2005) A family of octopamine [corrected] receptors that specifically induce cyclic AMP production or $\mathrm{Ca} 2+$ release in Drosophila melanogaster [published correction appears in $J$ Neurochem $(2005)$ 94:1168]. J Neurochem 93:440-451.

Barak LS, Salahpour A, Zhang X, Masri B, Sotnikova TD, Ramsey AJ, Violin JD Lefkowitz RJ, Caron MG, and Gainetdinov RR (2008) Pharmacological characterization of membrane-expressed human trace amine-associated receptor 1 (TAAR1) by a bioluminescence resonance energy transfer cAMP biosensor. Mol Pharmacol 74:585-594.

Barger G and Dale HH (1910) Chemical structure and sympathomimetic action of amines. J Physiol 41:19-59.

Barger G and Walpole GS (1909) Isolation of the pressor principles of putrid meat. $J$ Physiol 38:343-352.

Barron AB, Schulz DJ, and Robinson GE (2002) Octopamine modulates responsiveness to foraging-related stimuli in honey bees (Apis mellifera). J Comp Physiol A Neuroethol Sens Neural Behav Physiol 188:603-610.

Barygin OI, Komarova MS, Tikhonova TB, Korosteleva AS, Nikolaev MV, Magazanik LG, and Tikhonov DB (2017) Complex action of tyramine, tryptamine and histamine on native and recombinant ASICs. Channels (Austin) 11:648-659.

Bayliss A, Roselli G, and Evans PD (2013) A comparison of the signalling properties of two tyramine receptors from Drosophila. J Neurochem 125:37-48.

Beaulieu JM and Gainetdinov RR (2011) The physiology, signaling, and pharmacology of dopamine receptors. Pharmacol Rev 63:182-217.

Beaulieu JM, Gainetdinov RR, and Caron MG (2009) Akt/GSK3 signaling in the action of psychotropic drugs. Annu Rev Pharmacol Toxicol 49:327-347.

Beggs KT, Tyndall JD, and Mercer AR (2011) Honey bee dopamine and octopamine receptors linked to intracellular calcium signaling have a close phylogenetic and pharmacological relationship. PLoS One 6:e26809.

Bender DA and Coulson WF (1972) Variations in aromatic amino acid decarboxylase activity towards DOPA and 5-hydroxytryptophan caused by $\mathrm{pH}$ changes and denaturation. J Neurochem 19:2801-2810.

Bengtsson AA, Trygg J, Wuttge DM, Sturfelt G, Theander E, Donten M, Moritz T, Sennbro CJ, Torell F, Lood C, et al. (2016) Metabolic profiling of systemic lupus erythematosus and comparison with primary Sjögren's syndrome and systemic sclerosis. PLoS One 11:e159384.

Berry MD (2004) Mammalian central nervous system trace amines. Pharmacologic amphetamines, physiologic neuromodulators. J Neurochem 90:257-271.

Berry MD (2007) The potential of trace amines and their receptors for treating neurological and psychiatric diseases. Rev Recent Clin Trials 2:3-19.

Berry MD (2011) The effects of pargyline and 2-phenylethylamine on D1-like dopamine receptor binding. J Neural Transm (Vienna) 118:1115-1118.

Berry MD, Gainetdinov RR, Hoener MC, and Shahid M (2017) Pharmacology of human trace amine-associated receptors: therapeutic opportunities and challenges. Pharmacol Ther 180:161-180.

Berry MD, Hart S, Pryor AR, Hunter S, and Gardiner D (2016) Pharmacological characterization of a high-affinity p-tyramine transporter in rat brain synaptosomes. Sci Rep 6:38006.

Berry MD, Juorio AV, Li XM, and Boulton AA (1996) Aromatic L-amino acid decarboxylase: a neglected and misunderstood enzyme. Neurochem Res 21:1075-1087.

Berry MD, Scarr E, Zhu M-Y, Paterson IA, and Juorio AV (1994) The effects of administration of monoamine oxidase-B inhibitors on rat striatal neurone responses to dopamine. $\mathrm{Br} J$ Pharmacol 113:1159-1166.

Berry MD, Shitut MR, Almousa A, Alcorn J, and Tomberli B (2013) Membrane permeability of trace amines: evidence for a regulated, activity-dependent, nonexocytotic, synaptic release. Synapse 67:656-667.

Bierut LJ, Rice JP, Edenberg HJ, Goate A, Foroud T, Cloninger CR, Begleiter H, Conneally PM, Crowe RR, Hesselbrock V, et al. (2000) Family-based study of the association of the dopamine D2 receptor gene (DRD2) with habitual smoking. Am J Med Genet 90:299-302. 
Biji KB, Ravishankar CN, Venkateswarlu R, Mohan CO, and Gopal TK (2016) Biogenic amines in seafood: a review. J Food Sci Technol 53:2210-2218.

Black SW, Schwartz MD, Chen TM, Hoener MC, and Kilduff TS (2017) Trace amineassociated receptor 1 agonists as narcolepsy therapeutics. Biol Psychiatry 82 623-633.

Blakeley AG and Nicol CJ (1978) Accumulation of amines by rabbit erythrocytes in vitro. $J$ Physiol 277:77-90.

Blaschko H, Richter D, and Schlossmann H (1937) The oxidation of adrenaline and other amines. Biochem $J$ 31:2187-2196.

Blenau W, Balfanz S, and Baumann A (2017) PeaTAR1B: characterization of a second type 1 tyramine receptor of the American cockroach, Periplaneta americana. Int $J$ Mol Sci 18:E2279.

Blenau W and Baumann A (2001) Molecular and pharmacological properties of insect biogenic amine receptors: lessons from Drosophila melanogaster and Apis mellifera. Arch Insect Biochem Physiol 48:13-38.

Bloch $\mathrm{G}$ and Meshi A (2007) Influences of octopamine and juvenile hormone on locomotor behavior and period gene expression in the honeybee, Apis mellifera. J Comp Physiol A Neuroethol Sens Neural Behav Physiol 193:181-199.

Blum K, Noble EP, Sheridan PJ, Montgomery A, Ritchie T, Jagadeeswaran P, Nogami H, Briggs AH, and Cohn JB (1990) Allelic association of human dopamine D2 receptor gene in alcoholism. JAMA 263:2055-2060.

Bly M (2005) Examination of the trace amine-associated receptor 2 (TAAR2). Schizophr Res 80:367-368.

Bocian R, Posluszny A, Kowalczyk T, Kazmierska P, and Konopacki J (2011) Gap junction modulation of hippocampal formation theta and local cell discharges in anesthetized rats. Eur J Neurosci 33:471-481.

Børglum AD, Hampson M, Kjeldsen TE, Muir W, Murray V, Ewald H, Mors O, Blackwood D, and Kruse TA (2001) Dopa decarboxylase genotypes may influence age at onset of schizophrenia. Mol Psychiatry 6:712-717.

Borison RL, Mosnaim AD, and Sabelli HC (1975) Brain 2-phenylethylamine as a major mediator for the central actions of amphetamine and methylphenidate. Life Sci 17:1331-1343.

Borowsky B, Adham N, Jones KA, Raddatz R, Artymyshyn R, Ogozalek KL, Durkin MM, Lakhlani PP, Bonini JA, Pathirana S, et al. (2001) Trace amines: identification of a family of mammalian G protein-coupled receptors. Proc Natl Acad Sci USA 98:8966-8971.

Bouchard S and Roberge AG (1979) Biochemical properties and kinetic parameters of dihydroxyphenylalanine-5-hydroxytryptophan decarboxylase in brain, liver, and adrenals of cat. Can J Biochem 57:1014-1018.

Boulton AA (1974) Letter: amines and theories in psychiatry. Lancet 2:52-53.

Boulton AA (1976) Identification, distribution, metabolism, and function of meta and para tyramine, phenylethylamine and tryptamine in brain. Adv Biochem Psychopharmacol 15:57-67.

Boulton AA and Wu PH (1972) Biosynthesis of cerebral phenolic amines. I. In vivo formation of p-tyramine, octopamine, and synephrine. Can J Biochem 50:261-267.

Boulton AA and Wu PH (1973) Biosynthesis of cerebral phenolic amines. II. In vivo regional formation of p-tyramine and octopamine from tyrosine and dopamine. Can $J$ Biochem 51:428-435.

Boyle NT and Connor TJ (2010) Methylenedioxymethamphetamine ('Ecstasy')-induced immunosuppression: a cause for concern? $\mathrm{Br} J$ Pharmacol 161:17-32

Bradaia A, Trube G, Stalder H, Norcross RD, Ozmen L, Wettstein JG, Pinard A Buchy D, Gassmann M, Hoener MC, et al. (2009) The selective antagonist EPPTB reveals TAAR1-mediated regulatory mechanisms in dopaminergic neurons of the mesolimbic system. Proc Natl Acad Sci USA 106:20081-20086.

Brahmachary RL and Dutta J (1979) Phenylethylamine as a biochemical marker of tiger. $Z$ Naturforsch $C$ 34:632-633.

Braulke LJ, Klingenspor M, DeBarber A, Tobias SC, Grandy DK, Scanlan TS, and Heldmaier G (2008) 3-Iodothyronamine: a novel hormone controlling the balance between glucose and lipid utilisation. J Comp Physiol B 178:167-177.

Braun G and Bicker G (1992) Habituation of an appetitive reflex in the honeybee. $J$ Neurophysiol 67:588-598.

Bromek E, Haduch A, and Daniel WA (2010) The ability of cytochrome P450 2D isoforms to synthesize dopamine in the brain: An in vitro study. Eur J Pharmacol 626:171-178.

Brown JM and Hazen SL (2017) Targeting of microbe-derived metabolites to improve human health: the next frontier for drug discovery. J Biol Chem $\mathbf{2 9 2}$ 8560-8568.

Brunkwall L and Orho-Melander M (2017) The gut microbiome as a target for prevention and treatment of hyperglycaemia in type 2 diabetes: from current human evidence to future possibilities. Diabetologia 60:943-951.

Buckland PR, Marshall R, Watkins P, and McGuffin P (1997) Does phenylethylamine have a role in schizophrenia?: LSD and PCP up-regulate aromatic L-amino acid decarboxylase mRNA levels. Brain Res Mol Brain Res 49:266-270.

Buckland PR, O'Donovan MC, and McGuffin P (1992) Changes in dopa decarboxylase mRNA but not tyrosine hydroxylase mRNA levels in rat brain following antipsychotic treatment. Psychopharmacology (Berl) 108:98-102.

Buckland PR, Spurlock G, and McGuffin P (1996) Amphetamine and vigabatrin down regulate aromatic L-amino acid decarboxylase mRNA levels. Brain Res Mol Brain Res 35:69-76.

Bunzow JR, Sonders MS, Arttamangkul S, Harrison LM, Zhang G, Quigley DI, Darland T, Suchland KL, Pasumamula S, Kennedy JL, et al. (2001) Amphetamine, 3,4-methylenedioxymethamphetamine, lysergic acid diethylamide, and metabolites of the catecholamine neurotransmitters are agonists of a rat trace amine receptor. Mol Pharmacol 60:1181-1188.

Burczynski ME, Peterson RL, Twine NC, Zuberek KA, Brodeur BJ, Casciotti L, Maganti V, Reddy PS, Strahs A, Immermann F, et al. (2006) Molecular classification of Crohn's disease and ulcerative colitis patients using transcriptional profiles in peripheral blood mononuclear cells. J Mol Diagn 8:51-61.

Büschges A, Kittmann R, and Ramirez JM (1993) Octopamine effects mimick statedependent changes in a proprioceptive feedback system. J Neurobiol 24:598-610.
Cao Q, Martinez M, Zhang J, Sanders AR, Badner JA, Cravchik A, Markey CJ, Beshah E, Guroff JJ, Maxwell ME, et al. (1997) Suggestive evidence for a schizophrenia susceptibility locus on chromosome $6 \mathrm{q}$ and a confirmation in an independent series of pedigrees. Genomics 43:1-8.

Carbonaro TM and Gatch MB (2016) Neuropharmacology of N,N-dimethyltryptamine. Brain Res Bull 126:74-88.

Carnicelli V, Santoro A, Sellari-Franceschini S, Berrettini S, and Zucchi R (2010) Expression of trace amine-associated receptors in human nasal mucosa. Chemosens Percept 3:99-107.

Cassenaer S and Laurent G (2012) Conditional modulation of spike-timingdependent plasticity for olfactory learning. Nature 482:47-52.

Cazzamali G, Klaerke DA, and Grimmelikhuijzen CJ (2005) A new family of insect tyramine receptors. Biochem Biophys Res Commun 338:1189-1196.

Chang D-J, Li X-C, Lee Y-S, Kim H-K, Kim US, Cho NJ, Lo X, Weiss KR, Kandel ER, and Kaang B-K (2000) Activation of a heterologously expressed octopamine receptor coupled only to adenylyl cyclase produces all the features of presynaptic facilitation in aplysia sensory neurons. Proc Natl Acad Sci USA 97:1829-1834.

Chang HS, Heo JS, Shin SW, Bae DJ, Song HJ, Jun JA, Kim JD, Park JS, Park BL, Shin HD, et al. (2015) Association between TAAR6 polymorphisms and airway responsiveness to inhaled corticosteroids in asthmatic patients. Pharmacogenet Genomics 25:334-342.

Chang WP, Wu JJ, and Shyu BC (2013) Thalamic modulation of cingulate seizure activity via the regulation of gap junctions in mice thalamocingulate slice. PLoS One 8:e62952.

Chang YT, Mues G, and Hyland K (1996) Alternative splicing in the coding region of human aromatic L-amino acid decarboxylase mRNA. Neurosci Lett 202:157-160.

Châtel A, Murillo L, Bourdin CM, Quinchard S, Picard D, and Legros C (2013) Characterization of tyramine $\beta$-hydroxylase, an enzyme upregulated by stress in Periplaneta americana. J Mol Endocrinol 50:91-102.

Chhibber-Goel J, Gaur A, Singhal V, Parakh N, Bhargava B, and Sharma A (2016) The complex metabolism of trimethylamine in humans: endogenous and exogenous sources. Expert Rev Mol Med 18:e8.

Chiellini G, Bellusci L, Sabatini M, and Zucchi R (2017) Thyronamines and analogues - the route from rediscovery to translational research on thyronergic amines. $\mathrm{Mol}$ Cell Endocrinol 458:149-155.

Chiellini G, Erba P, Carnicelli V, Manfredi C, Frascarelli S, Ghelardoni S, Mariani G, and Zucchi R (2012) Distribution of exogenous [125I]-3-iodothyronamine in mouse in vivo: relationship with trace amine-associated receptors. $J$ Endocrinol 213: $223-230$

Chiellini G, Frascarelli S, Ghelardoni S, Carnicelli V, Tobias SC, DeBarber A, Brogioni S, Ronca-Testoni S, Cerbai E, Grandy DK, et al. (2007) Cardiac effects of 3 -iodothyronamine: a new aminergic system modulating cardiac function. FASEB $J \mathbf{2 1}$ : 1597-1608.

Chireux M, Raynal JF, Le Van Thai A, Cadas H, Bernard C, Martinou I, Martinou JC, and Weber MJ (1994) Multiple promoters of human choline acetyltransferase and aromatic L-amino acid decarboxylase genes. J Physiol Paris 88:215-227.

Cho S, Duchemin A-M, Neff NH, and Hadjiconstantinou M (1999) Tyrosine hydroxylase, aromatic L-amino acid decarboxylase and dopamine metabolism after chronic treatment with dopaminergic drugs. Brain Res 830:237-245.

Cho S, Neff NH, and Hadjiconstantinou M (1997) Regulation of tyrosine hydroxylase and aromatic L-amino acid decarboxylase by dopaminergic drugs. Eur J Pharmacol 323:149-157.

Christensen TA, Sherman TG, McCaman RE, and Carlson AD (1983) Presence of octopamine in firefly photomotor neurons. Neuroscience 9:183-189.

Christenson JG, Dairman W, and Udenfriend S (1970) Preparation and properties of a homogeneous aromatic L-amino acid decarboxylase from hog kidney. Arch Biochem Biophys 141:356-367.

Christie AE, Fontanilla TM, Roncalli V, Cieslak MC, and Lenz PH (2014) Identification and developmental expression of the enzymes responsible for dopamine, histamine, octopamine and serotonin biosynthesis in the copepod crustacean Calanus finmarchicus. Gen Comp Endocrinol 195:28-39.

Churcher AM, Hubbard PC, Marques JP, Canário AV, and Huertas M (2015) Deep sequencing of the olfactory epithelium reveals specific chemosensory receptors are expressed at sexual maturity in the European eel Anguilla anguilla. Mol Ecol 24:822-834.

Cichero E, Espinoza S, Tonelli M, Franchini S, Gerasimov AS, Sorbi C, Gainetdinov RR, Brasili L, and Fossa P (2016) A homology modelling-driven study leading to the discovery of the first mouse trace amine-associated receptor 5 (TAAR5) antagonists. MedChem Comm 7:353-364.

Cichero E and Tonelli M (2017) New insights into the structure of the trace amineassociated receptor 2: homology modelling studies exploring the binding mode of 3-iodothyronamine. Chem Biol Drug Des 89:790-796.

Cisneros IE and Ghorpade A (2014) Methamphetamine and HIV-1-induced neurotoxicity: role of trace amine associated receptor 1 cAMP signaling in astrocytes. Neuropharmacology 85:499-507.

Citrome L (2014) Unmet needs in the treatment of schizophrenia: new targets to help different symptom domains. J Clin Psychiatry 75 (Suppl 1):21-26.

Clark A (1911) The clinical application of ergotamine (tyramine). Biochem $J$ 5: 236-242.

Coecke S, Debast G, Phillips IR, Vercruysse A, Shephard EA, and Rogiers V (1998) Hormonal regulation of microsomal flavin-containing monooxygenase activity by sex steroids and growth hormone in co-cultured adult male rat hepatocytes. Biochem Pharmacol 56:1047-1051.

Cole SH, Carney GE, McClung CA, Willard SS, Taylor BJ, and Hirsh J (2005) Two functional but noncomplementing Drosophila tyrosine decarboxylase genes: distinct roles for neural tyramine and octopamine in female fertility. J Biol Chem 280 : 14948-14955.

Comings DE, Comings BG, Muhleman D, Dietz G, Shahbahrami B, Tast D, Knell E, Kocsis P, Baumgarten R, Kovacs BW, et al. (1991) The dopamine D2 receptor locus as a modifying gene in neuropsychiatric disorders. JAMA 266:1793-1800. 
Comings DE, Muhleman D, Ahn C, Gysin R, and Flanagan SD (1994) The dopamine D2 receptor gene: a genetic risk factor in substance abuse. Drug Alcohol Depend 34:175-180. Comings DE, Rosenthal RJ, Lesieur HR, Rugle LJ, Muhleman D, Chiu C, Dietz G, and Gade R (1996) A study of the dopamine D2 receptor gene in pathological gambling. Pharmacogenetics 6:223-234

Consoulas C, Johnston RM, Pflüger HJ, and Levine RB (1999) Peripheral distribution of presynaptic sites of abdominal motor and modulatory neurons in Manduca sexta larvae. J Comp Neurol 410:4-19.

Copeland $J$ and Robertson HA (1982) Octopamine as the transmitter at the firefly lantern: presence of an octopamine-sensitive and a dopamine-sensitive adenylate cyclase. Comp Biochem Physiol C Toxicol Pharmacol 72:125-127.

Cöster M, Biebermann H, Schöneberg T, and Stäubert C (2015) Evolutionary conservation of 3-iodothyronamine as an agonist at the trace amine-associated receptor 1. Eur Thyroid J 4 (Suppl 1):9-20.

Coton M, Delbés-Paus C, Irlinger F, Desmasures N, Le Fleche A, Stahl V, Montel MC, and Coton E (2012) Diversity and assessment of potential risk factors of Gramnegative isolates associated with French cheeses. Food Microbiol 29:88-98.

Cotter R, Pei Y, Mus L, Harmeier A, Gainetdinov RR, Hoener MC, and Canales JJ (2015) The trace amine-associated receptor 1 modulates methamphetamine's neurochemical and behavioral effects. Front Neurosci 9:39.

Couroussé T and Gautron S (2015) Role of organic cation transporters (OCTs) in the brain. Pharmacol Ther 146:94-103.

Coutts RT, Baker GB, and Pasutto FM (1986) Foodstuffs as sources of psychoactive amines and their precursors: content, significance and identification. Adv Drug Res 15:169-232.

Craciun S and Balskus EP (2012) Microbial conversion of choline to trimethylamine requires a glycyl radical enzyme. Proc Natl Acad Sci USA 109:21307-21312.

Cumero S, Fogolari F, Domenis R, Zucchi R, Mavelli I, and Contessi S (2012) Mitochondrial $\mathrm{F}(0) \mathrm{F}(1)$-ATP synthase is a molecular target of 3-iodothyronamine, an endogenous metabolite of thyroid hormone. $\mathrm{Br} J$ Pharmacol 166:2331-2347.

Cunha SC, Faria MA, and Fernandes JO (2011) Gas chromatography-mass spectrometry assessment of amines in Port wine and grape juice after fast chloroformate extraction/derivatization. J Agric Food Chem 59:8742-8753.

D'Andrea G, D'Arrigo A, Facchinetti F, Del Giudice E, Colavito D, Bernardini D, and Leon A (2012) Octopamine, unlike other trace amines, inhibits responses of astroglia-enriched cultures to lipopolysaccharide via a $\beta$-adrenoreceptor-mediated mechanism. Neurosci Lett 517:36-40.

D'Andrea G, Perini F, Terrazzino S, and Nordera GP (2004) Contributions of biochemistry to the pathogenesis of primary headaches. Neurol Sci 25 (Suppl 3): S89-S92.

D’Andrea G, Terrazzino S, Fortin D, Farruggio A, Rinaldi L, and Leon A (2003) HPLC electrochemical detection of trace amines in human plasma and platelets and expression of mRNA transcripts of trace amine receptors in circulating leukocytes. Neurosci Lett 346:89-92.

Danielson TJ, Boulton AA, and Robertson HA (1977) m-Octopamine, p-octopamine and phenylethanolamine in rat brain: a sensitive, specific assay and the effects of some drugs. J Neurochem 29:1131-1135.

Davis BA (1989) Biogenic amines and their metabolites in body fluids of normal, psychiatric and neurological subjects. J Chromatogr A 466:89-218.

de la Barca JMC, Huang NT, Jiao H, Tessier L, Gadras C, Simard G, Natoli R Tcherkez G, Reynier P, and Valter K (2017) Retinal metabolic events in preconditioning light stress as revealed by wide-spectrum targeted metabolomics. Metabolomics 13:22

Dewan A, Pacifico R, Zhan R, Rinberg D, and Bozza T (2013) Non-redundant coding of aversive odours in the main olfactory pathway. Nature 497:486-489.

Dewhurst SA, Croker SG, Ikeda K, and McCaman RE (1972) Metabolism of biogenic amines in Drosophila nervous tissue. Comp Biochem Physiol B 43 975-981.

Dhillo WS, Bewick GA, White NE, Gardiner JV, Thompson EL, Bataveljic A, Murphy KG, Roy D, Patel NA, Scutt JN, et al. (2009) The thyroid hormone derivative 3-iodothyronamine increases food intake in rodents. Diabetes Obes Metab 11 251-260.

Di Cara B, Maggio R, Aloisi G, Rivet JM, Lundius EG, Yoshitake T, Svenningsson P, Brocco M, Gobert A, De Groote L, et al. (2011) Genetic deletion of trace amine 1 receptors reveals their role in auto-inhibiting the actions of ecstasy (MDMA). $J$ Neurosci 31:16928-16940.

Dial EJ, Cooper LC, and Lichtenberger LM (1991) Amino acid- and amine-induced gastrin release from isolated rat endocrine granules. Am $J$ Physiol 260: G175-G181.

Dieris M, Ahuja G, Krishna V, and Korsching SI (2017) A single identified glomerulus in the zebrafish olfactory bulb carries the high-affinity response to death-associated odor cadaverine. Sci Rep 7:40892.

Dinan TG and Cryan JF (2015) The impact of gut microbiota on brain and behaviour: implications for psychiatry. Curr Opin Clin Nutr Metab Care 18:552-558.

Ding S, Wang X, Zhuge W, Yang J, and Zhuge Q (2017) Dopamine induces glutamate accumulation in astrocytes to disrupt neuronal function leading to pathogenesis of minimal hepatic encephalopathy. Neuroscience 365:94-113.

Dinter J, Khajavi N, Mühlhaus J, Wienchol CL, Cöster M, Hermsdorf T, Stäubert C, Köhrle J, Schöneberg T, Kleinau G, et al. (2015a) The multitarget ligand 3 -iodothyronamine modulates $\beta$-adrenergic receptor 2 signaling. Eur Thyroid $J \mathbf{4}$ (Suppl 1):21-29.

Dinter J, Mühlhaus J, Jacobi SF, Wienchol CL, Cöster M, Meister J, Hoefig CS, Müller A, Köhrle J, Grüters A, et al. (2015b) 3-iodothyronamine differentially modulates $\alpha$-2A-adrenergic receptor-mediated signaling. $J$ Mol Endocrinol 54: 205-216.

Dinter J, Mühlhaus J, Wienchol CL, Yi CX, Nürnberg D, Morin S, Grüters A, Köhrle J, Schöneberg T, Tschöp M, et al. (2015c) Inverse agonistic action of 3-iodothyronamine at the human trace amine-associated receptor 5. PLoS One 10:e0117774.

Djali PK, Dimaline R, and Dockray GJ (1998) Novel form of L-aromatic amino acid decarboxylase mRNA in rat antral mucosa. Exp Physiol 83:617-627.
Dominici P, Tancini B, Barra D, and Voltattorni CB (1987) Purification and characterization of rat-liver 3,4-dihydroxyphenylalanine decarboxylase. Eur J Biochem 169:209-213.

Donly BC and Caveney S (2005) A transporter for phenolamine uptake in the arthropod CNS. Arch Insect Biochem Physiol 59:172-183.

Dourish CT (1982) An observational analysis of the behavioural effects of betaphenylethylamine in isolated and grouped mice. Prog Neuropsychopharmacol Biol Psychiatry 6:143-158.

Downer RG, Hiripi L, and Juhos S (1993) Characterization of the tyraminergic system in the central nervous system of the locust, Locusta migratoria migratoides. Neurochem Res 18:1245-1248.

Doyle KP, Suchland KL, Ciesielski TM, Lessov NS, Grandy DK, Scanlan TS, and Stenzel-Poore MP (2007) Novel thyroxine derivatives, thyronamine and 3 -iodothyronamine, induce transient hypothermia and marked neuroprotection against stroke injury. Stroke 38:2569-2576.

Duan J, Martinez M, Sanders AR, Hou C, Saitou N, Kitano T, Mowry BJ, Crowe RR, Silverman JM, Levinson DF, et al. (2004) Polymorphisms in the trace amine receptor 4 (TRAR4) gene on chromosome 6q23.2 are associated with susceptibility to schizophrenia. Am J Hum Genet 75:624-638.

Duan S, Du J, Xu Y, Xing Q, Wang H, Wu S, Chen Q, Li X, Li X, Shen J, et al. (2006) Failure to find association between TRAR4 and schizophrenia in the Chinese Han population. J Neural Transm (Vienna) 113:381-385.

Duchamp-Viret P and Duchamp A (1997) Odor processing in the frog olfactory system. Prog Neurobiol 53:561-602.

Duchemin AM, Berry MD, Neff NH, and Hadjiconstantinou M (2000) Phosphorylation and activation of brain aromatic L-amino acid decarboxylase by cyclic AMPdependent protein kinase. J Neurochem 75:725-731.

Duchemin AM, Neff NH, and Hadjiconstantinou M (2010) Aromatic L-amino acid decarboxylase phosphorylation and activation by PKGIalpha in vitro. J Neurochem 114:542-552.

Dumas ME, Barton RH, Toye A, Cloarec O, Blancher C, Rothwell A, Fearnside J, Tatoud R, Blanc V, Lindon JC, et al. (2006) Metabolic profiling reveals a contribution of gut microbiota to fatty liver phenotype in insulin-resistant mice. Proc Natl Acad Sci USA 103:12511-12516.

Durden DA and Philips SR (1980) Kinetic measurements of the turnover rates of phenylethylamine and tryptamine in vivo in the rat brain. $J$ Neurochem 34:1725-1732.

Dyck LE (1989) Release of some endogenous trace amines from rat striatal slices in the presence and absence of a monoamine oxidase inhibitor. Life Sci 44:1149-1156.

Dyck LE, Yang CR, and Boulton AA (1983) The biosynthesis of p-tyramine, m-tyramine, and beta-phenylethylamine by rat striatal slices. J Neurosci Res 10:211-220.

Eisenberg DP, Kohn PD, Hegarty CE, Ianni AM, Kolachana B, Gregory MD, Masdeu JC, and Berman KF (2016) Common variation in the DOPA decarboxylase (DDC) gene and human striatal DDC activity in vivo. Neuropsychopharmacology 41:2303-2308.

El-Kholy S, Stephano F, Li Y, Bhandari A, Fink C, and Roeder T (2015) Expression analysis of octopamine and tyramine receptors in Drosophila. Cell Tissue Res 361: $669-684$

Elliott J, Callingham BA, and Sharman DF (1989) Semicarbazide-sensitive amine oxidase (SSAO) of the rat aorta. Interactions with some naturally occurring amines and their structural analogues. Biochem Pharmacol 38:1507-1515.

Elliott P, Posma JM, Chan Q, Garcia-Perez I, Wijeyesekera A, Bictash M, Ebbels TM Ueshima H, Zhao L, van Horn L, et al. (2015) Urinary metabolic signatures of human adiposity. Sci Transl Med 7:285ra62.

Erspamer V (1952) Identification of octopamine as l-p-hydroxyphenylethanolamine. Nature 169:375-376

Espinoza S, Ghisi V, Emanuele M, Leo D, Sukhanov I, Sotnikova TD, Chieregatti E, and Gainetdinov RR (2015a) Postsynaptic D2 dopamine receptor supersensitivity in the striatum of mice lacking TAAR1. Neuropharmacology 93:308-313.

Espinoza S, Lignani G, Caffino L, Maggi S, Sukhanov I, Leo D, Mus L, Emanuele M, Ronzitti G, Harmeier A, et al. (2015b) TAAR1 modulates cortical glutamate NMDA receptor function. Neuropsychopharmacology 40:2217-2227.

Espinoza S, Manago F, Leo D, Sotnikova TD, and Gainetdinov RR (2012) Role of catechol-O-methyltransferase (COMT)-dependent processes in Parkinson's disease and L-DOPA treatment. CNS Neurol Disord Drug Targets 11:251-263.

Espinoza S, Salahpour A, Masri B, Sotnikova TD, Messa M, Barak LS, Caron MG, and Gainetdinov RR (2011) Functional interaction between trace amine-associated receptor 1 and dopamine D2 receptor. Mol Pharmacol 80:416-425.

Evans PD and Maqueira B (2005) Insect octopamine receptors: a new classification scheme based on studies of cloned Drosophila G-protein coupled receptors. Invert Neurosci 5:111-118.

Eyun SI, Moriyama H, Hoffmann FG, and Moriyama EN (2016) Molecular evolution and functional divergence of trace amine-associated receptors. PLoS One 11:e0151023.

Farooqui T (2007) Octopamine-mediated neuromodulation of insect senses. Neurochem Res 32:1511-1529.

Farooqui T, Robinson K, Vaessin H, and Smith BH (2003) Modulation of early olfactory processing by an octopaminergic reinforcement pathway in the honeybee. $J$ Neurosci 23:5370-5380.

Fatsini E, Bautista R, Manchado M, and Duncan NJ (2016) Transcriptomic profiles of the upper olfactory rosette in cultured and wild Senegalese sole (Solea senegalensis) males. Comp Biochem Physiol Part D Genomics Proteomics 20:125-135.

Fayad LM, Wang X, Blakeley JO, Durand DJ, Jacobs MA, Demehri S, Subhawong TK, Soldatos T, and Barker PB (2014) Characterization of peripheral nerve sheath tumors with 3T proton MR spectroscopy. AJNR Am J Neuroradiol 35:1035-1041.

Fehler M, Broadley KJ, Ford WR, and Kidd EJ (2010) Identification of trace-amineassociated receptors (TAAR) in the rat aorta and their role in vasoconstriction by $\beta$-phenylethylamine. Naunyn Schmiedebergs Arch Pharmacol 382:385-398.

Fennema D, Phillips IR, and Shephard EA (2016) Trimethylamine and trimethylamine N-oxide, a flavin-containing monooxygenase 3 (FMO3)-mediated hostmicrobiome metabolic axis implicated in health and disease. Drug Metab Dispos 44:1839-1850. 
Fernández de Palencia P, Fernández M, Mohedano ML, Ladero V, Quevedo C, Alvarez MA, and López P (2011) Role of tyramine synthesis by food-borne Enterococcus durans in adaptation to the gastrointestinal tract environment. Appl Environ Microbiol 77:699-702.

Ferragud A, Howell AD, Moore CF, Ta TL, Hoener MC, Sabino V, and Cottone P (2017) The trace amine-associated receptor 1 agonist RO5256390 blocks compulsive, binge-like eating in rats. Neuropsychopharmacology 42:1458-1470.

Ferrero DM, Lemon JK, Fluegge D, Pashkovski SL, Korzan WJ, Datta SR, Spehr M, Fendt M, and Liberles SD (2011) Detection and avoidance of a carnivore odor by prey. Proc Natl Acad Sci USA 108:11235-11240.

Ferrero DM, Wacker D, Roque MA, Baldwin MW, Stevens RC, and Liberles SD (2012) Agonists for 13 trace amine-associated receptors provide insight into the molecular basis of odor selectivity. ACS Chem Biol 7:1184-1189.

Fetissov SO, Bensing S, Mulder J, Le Maitre E, Hulting AL, Harkany T, Ekwall O, Sköldberg F, Husebye ES, Perheentupa J, et al. (2009) Autoantibodies in autoimmune polyglandular syndrome type I patients react with major brain neurotransmitter systems. J Comp Neurol 513:1-20.

Finberg JPM and Gillman K (2011) Selective inhibitors of monoamine oxidase type B and the "cheese effect". Int Rev Neurobiol 100:169-190.

Fischer W, Neubert RHH, and Brandsch M (2010) Transport of phenylethylamine at intestinal epithelial (Caco-2) cells: mechanism and substrate specificity. Eur $J$ Pharm Biopharm 74:281-289.

Fish EW, Riday TT, McGuigan MM, Faccidomo S, Hodge CW, and Malanga CJ (2010) Alcohol, cocaine, and brain stimulation-reward in C57Bl6/J and DBA2/J mice. Alcohol Clin Exp Res 34:81-89.

Fisher A, Biggs CS, and Starr MS (1998) Differential effects of NMDA and nonNMDA antagonists on the aromatic L-amino acid decarboxylase activity in the nigrostriatal pathway of the rat. Brain Res 792:126-132.

Flecke C and Stengl M (2009) Octopamine and tyramine modulate pheromonesensitive olfactory sensilla of the hawkmoth Manduca sexta in a time-dependent manner. J Comp Physiol A Neuroethol Sens Neural Behav Physiol 195:529-545.

Fleischer J, Schwarzenbacher K, and Breer H (2007) Expression of trace amineassociated receptors in the Grueneberg ganglion. Chem Senses 32:623-631.

Fowler S, Kletzl H, Finel M, Manevski N, Schmid P, Tuerck D, Norcross RD, Hoener MC, Spleiss O, and Iglesias VA (2015) A UGT2B10 splicing polymorphism common in African populations may greatly increase drug exposure. J Pharmacol Exp Ther 352:358-367.

Frascarelli S, Ghelardoni S, Chiellini G, Galli E, Ronca F, Scanlan TS, and Zucchi R (2011) Cardioprotective effect of 3-iodothyronamine in perfused rat heart subjected to ischemia and reperfusion. Cardiovasc Drugs Ther 25:307-313.

Frenken M and Kaumann AJ (1988) Effects of tryptamine mediated through 2 states of the 5-HT2 receptor in calf coronary artery. Naunyn Schmiedebergs Arch Pharmacol 337:484-492.

Fung TC, Olson CA, and Hsiao EY (2017) Interactions between the microbiota, immune and nervous systems in health and disease. Nat Neurosci 20:145-155.

Furuzawa Y, Ohmori Y, and Watanabe T (1994) Immunohistochemical colocalization of serotonin, aromatic L-amino acid decarboxylase and polypeptide hormones in islet A- and PP-cells of the cat pancreas. J Vet Med Sci 56:911-916.

Fussnecker BL, Smith BH, and Mustard JA (2006) Octopamine and tyramine influence the behavioral profile of locomotor activity in the honey bee (Apis mellifera). J Insect Physiol 52:1083-1092.

Fuxe K, Grobecker H, and Jonsson J (1967) The effect of beta-phenylethylamine on central and peripheral monoamine-containing neurons. Eur $J$ Pharmacol 2: 202-207.

Gainetdinov RR, Premont RT, Bohn LM, Lefkowitz RJ, and Caron MG (2004) Desensitization of G protein-coupled receptors and neuronal functions. Annu Rev Neurosci 27:107-144.

Gainetdinov RR, Wetsel WC, Jones SR, Levin ED, Jaber M, and Caron MG (1999) Role of serotonin in the paradoxical calming effect of psychostimulants on hyperactivity. Science 283:397-401.

Gajda Z, Gyengési E, Hermesz E, Ali KS, and Szente M (2003) Involvement of gap junctions in the manifestation and control of the duration of seizures in rats in vivo. Epilepsia 44:1596-1600.

Gallant P, Malutan T, McLean H, Verellen L, Caveney S, and Donly C (2003) Functionally distinct dopamine and octopamine transporters in the CNS of the cabbage looper moth. Eur J Biochem 270:664-674.

Galley G, Beurier A, Décoret G, Goergler A, Hutter R, Mohr S, Pähler A, Schmid P, Türck D, Unger R, et al. (2015) Discovery and characterization of 2-aminooxazolines as highly potent, selective, and orally active TAAR1 agonists. ACS Med Chem Lett 7:192-197.

Galley G, Stalder H, Goergler A, Hoener MC, and Norcross RD (2012) Optimisation of imidazole compounds as selective TAAR1 agonists: discovery of RO5073012. Bioorg Med Chem Lett 22:5244-5248.

Gao S, Liu S, Yao J, Li N, Yuan Z, Zhou T, Li Q, and Liu Z (2017) Genomic organization and evolution of olfactory receptors and trace amine-associated receptors in channel catfish, Ictalurus punctatus. Biochim Biophys Acta 1861:644-651.

Gardini F, Özogul Y, Suzzi G, Tabanelli G, and Özogul F (2016) Technological factors affecting biogenic amine content in foods: a review. Front Microbiol 7:1218.

Gavaghan McKee CL, Wilson ID, and Nicholson JK (2006) Metabolic phenotyping of nude and normal (Alpk:ApfCD, C57BL10J) mice. J Proteome Res 5:378-384.

Ghelardoni S, Suffredini S, Frascarelli S, Brogioni S, Chiellini G, Ronca-Testoni S, Grandy DK, Scanlan TS, Cerbai E, and Zucchi R (2009) Modulation of cardiac ionic homeostasis by 3-iodothyronamine. J Cell Mol Med 13 (9B):3082-3090.

Gjedde A, Léger GC, Cumming P, Yasuhara Y, Evans AC, Guttman M, and Kuwabara H (1993) Striatal L-dopa decarboxylase activity in Parkinson's disease in vivo: implications for the regulation of dopamine synthesis. J Neurochem 61:1538-1541.

Gliem S, Schild D, and Manzini I (2009) Highly specific responses to amine odorants of individual olfactory receptor neurons in situ. Eur J Neurosci 29:2315-2326.
Gliem S, Syed AS, Sansone A, Kludt E, Tantalaki E, Hassenklöver T, Korsching SI, and Manzini I (2013) Bimodal processing of olfactory information in an amphibian nose: odor responses segregate into a medial and a lateral stream. Cell Mol Life Sci 70:1965-1984.

Gloriam DE, Bjarnadóttir TK, Schiöth HB, and Fredriksson R (2005) High species variation within the repertoire of trace amine receptors. Ann N Y Acad Sci 1040: 323-327.

Gozal EA, O’Neill BE, Sawchuk MA, Zhu H, Halder M, Chou CC, and Hochman S (2014) Anatomical and functional evidence for trace amines as unique modulators of locomotor function in the mammalian spinal cord. Front Neural Circuits 8:134

Grandy DK (2007) Trace amine-associated receptor 1-family archetype or iconoclast? Pharmacol Ther 116:355-390.

Graziano C, Wischmeijer A, Pippucci T, Fusco C, Diquigiovanni C, Nõukas M, Sauk M, Kurg A, Rivieri F, Blau N, et al. (2015) Syndromic intellectual disability: a new phenotype caused by an aromatic amino acid decarboxylase gene (DDC) variant. Gene 559:144-148.

Greenshaw AJ (1984) beta-Phenylethylamine and reinforcement. Prog Neuropsychopharmacol Biol Psychiatry 8:615-620.

Greenshaw AJ, Turrkish S, and Davis BA (2002) The enigma of conditioned taste aversion learning: stimulus properties of 2-phenylethylamine derivatives. Physiol Res 51 (Suppl 1):S13-S20.

Grillo MA, Battaglia V, Colombatto S, Rossi CA, Simonian AR, Salvi M, Khomutov AR, and Toninello A (2007) Inhibition of agmatine transport in liver mitochondria by new charge-deficient agmatine analogues. Biochem Soc Trans 35:401-404.

Grimsby J, Toth M, Chen K, Kumazawa T, Klaidman L, Adams JD, Karoum F, Gal J, and Shih JC (1997) Increased stress response and beta-phenylethylamine in MAOB-deficient mice. Nat Genet 17:206-210.

Grohmann L, Blenau W, Erber J, Ebert PR, Strünker T, and Baumann A (2003) Molecular and functional characterization of an octopamine receptor from honeybee (Apis mellifera) brain. J Neurochem 86:725-735.

Gründemann D, Hahne C, Berkels R, and Schömig E (2003) Agmatine is efficiently transported by non-neuronal monoamine transporters extraneuronal monoamine transporter (EMT) and organic cation transporter 2 (OCT2). J Pharmacol Exp Ther 304:810-817.

Gründer G, Hippius H, and Carlsson A (2009) The 'atypicality' of antipsychotics: a concept re-examined and re-defined. Nat Rev Drug Discov 8:197-202.

Grus WE and Zhang J (2008) Distinct evolutionary patterns between chemoreceptors of 2 vertebrate olfactory systems and the differential tuning hypothesis. Mol Biol Evol 25:1593-1601.

Guariento S, Tonelli M, Espinoza S, Gerasimov AS, Gainetdinov RR, and Cichero E (2018) Rational design, chemical synthesis and biological evaluation of novel biguanides exploring species-specificity responsiveness of TAAR1 agonists. Eur $J$ Med Chem 146:171-184

Guest I, Cyr DG, and Varma DR (1994) Mechanism of trimethylamine-induced inhibition of macromolecular synthesis by mouse embryos in culture. Food Chem Toxicol 32:365-371.

Guest I and Varma DR (1992) Teratogenic and macromolecular synthesis inhibitory effects of trimethylamine on mouse embryos in culture. $J$ Toxicol Environ Health 36:27-41.

Guest I and Varma DR (1993) Selective growth inhibition of the male progeny of mice treated with trimethylamine during pregnancy. Can J Physiol Pharmacol 71: 185-187.

Ha K, Shin H, Ju H, Chung CM, and Choi I (2017) Behavioral hypothermia of a domesticated lizard under treatment of the hypometabolic agent 3-iodothyronamine. Exp Anim 66:99-105.

Hackenmueller SA, Marchini M, Saba A, Zucchi R, and Scanlan TS (2012) Biosynthesis of 3-iodothyronamine (T1AM) is dependent on the sodium-iodide symporter and thyroperoxidase but does not involve extrathyroidal metabolism of T4. Endocrinology 153:5659-5667.

Hackenmueller SA and Scanlan TS (2012) Identification and quantification of 3 -iodothyronamine metabolites in mouse serum using liquid chromatographytandem mass spectrometry. J Chromatogr A 1256:89-97.

Hacker K, Maas R, Kornhuber J, Fromm MF, and Zolk O (2015) Substrate-dependent inhibition of the human organic cation transporter OCT2: a comparison of metformin with experimental substrates. PLoS One 10:e136451.

Hadjiconstantinou M, Duchemin AM, Azad A, and Neff NH (2010) Aromatic L-amino acid decarboxylase, in Biogenic Amines: Pharmacological, Neurochemical and Molecular Aspects in the CNS (Farooqui T and Farooqui AA eds) pp 25-45, Nova Biomedical, New York.

Hadjiconstantinou M, Rossetti Z, Silvia C, Krajnc D, and Neff NH (1988) Aromatic L-amino acid decarboxylase activity of the rat retina is modulated in vivo by environmental light. J Neurochem 51:1560-1564.

Hadjiconstantinou M, Rossetti ZL, Wemlinger TA, and Neff NH (1995) Dizocilpine enhances striatal tyrosine hydroxylase and aromatic L-amino acid decarboxylase activity. Eur $J$ Pharmacol 289:97-101.

Hadjiconstantinou M, Wemlinger TA, Sylvia CP, Hubble JP, and Neff NH (1993) Aromatic L-amino acid decarboxylase activity of mouse striatum is modulated via dopamine receptors. $J$ Neurochem 60:2175-2180.

Hahn SL, Hahn M, Kang UJ, and Joh TH (1993) Structure of the rat aromatic L-amino acid decarboxylase gene: evidence for an alternative promoter usage. J Neurochem 60:1058-1064.

Hammer M (1997) The neural basis of associative reward learning in honeybees. Trends Neurosci 20:245-252.

Han KA, Millar NS, and Davis RL (1998) A novel octopamine receptor with preferential expression in Drosophila mushroom bodies. $J$ Neurosci 18: 3650-3658.

Han Q, Ding H, Robinson H, Christensen BM, and Li J (2010) Crystal structure and substrate specificity of Drosophila 3,4-dihydroxyphenylalanine decarboxylase. PLoS One 5:e8826. 
Hao X, Liu X, Wang W, Ren H, Xie J, Shen P, Lin D, and Chen N (2013) Distinct metabolic profile of primary focal segmental glomerulosclerosis revealed by NMRbased metabolomics. PLoS One 8:e78531.

Harada K (1985) Feeding attraction activities of amino acids and nitrogenous bases for oriental weatherfish. Bull Jap Soc Sci Fish 51:461-466

Harkness JH, Shi X, Janowsky A, and Phillips TJ (2015) Trace amine-associated receptor 1 regulation of methamphetamine intake and related traits. Neuropsychopharmacology 40:2175-2184.

Harmeier A, Obermueller S, Meyer CA, Revel FG, Buchy D, Chaboz S, Dernick G, Wettstein JG, Iglesias A, Rolink A, et al. (2015) Trace amine-associated receptor 1 activation silences GSK3 $\beta$ signaling of TAAR1 and D2R heteromers. Eur Neuropsychopharmacol 25:2049-2061.

Harris J, Trivedi S, and Ramakrishna BL (1988) A contribution to the neuromodulator/neurotransmitter role of trace amines, in Trace Amines: Comparative and Clinical Neurobiology (Boulton AA, Juorio AV, and Downer RGH eds) pp 213-221, Humana Press, Totowa, NJ.

Hashemzadeh H, Hollingworth RM, and Voliva A (1985) Receptors for $3 \mathrm{H}-$ octopamine in the adult firefly light organ. Life Sci 37:433-440.

Hashiguchi Y, Furuta Y, and Nishida M (2008) Evolutionary patterns and selective pressures of odorant/pheromone receptor gene families in teleost fishes. PLoS One 3:e4083.

Hashiguchi Y and Nishida M (2007) Evolution of trace amine associated receptor (TAAR) gene family in vertebrates: lineage-specific expansions and degradations of a second class of vertebrate chemosensory receptors expressed in the olfactory epithelium. Mol Biol Evol 24:2099-2107.

Hauger RL, Skolnick P, and Paul SM (1982) Specific [3H] beta-phenylethylamine binding sites in rat brain. Eur J Pharmacol 83:147-148.

Haughton BG and King HK (1961) Induced formation of leucine decarboxylase in Proteus vulgaris. Biochem J 80:268-277.

Hauser F, Cazzamali G, Williamson M, Blenau W, and Grimmelikhuijzen CJ (2006) A review of neurohormone GPCRs present in the fruitfly Drosophila melanogaster and the honey bee Apis mellifera. Prog Neurobiol 80:1-19.

Hayashi M, Yamaji Y, Kitajima W, and Saruta T (1990) Aromatic L-amino acid decarboxylase activity along the rat nephron. Am $J$ Physiol 258:F28-F33.

Henry DP, Russell WL, Clemens JA, and Plebus LA (1988) Phenylethylamine and p-tyramine in the extracellular space of the rat brain: quantification using a new radioenzymatic assay and in situ microdialysis, in Trace Amines; Comparative and Clinical Neurobiology (Boulton AA, Juorio AV, and Downer RGH eds) pp 239-250, Humana Press, Totowa, NJ.

Hicks TP and McLennan H (1978) Comparison of the actions of octopamine and catecholamines on single neurones of the rat cerebral cortex. $\mathrm{Br} J$ Pharmacol 64 485-491.

Hiripi L, Juhos S, and Downer RG (1994) Characterization of tyramine and octopamine receptors in the insect (Locusta migratoria migratorioides) brain. Brain Res 633:119-126

Hiroi T, Imaoka S, and Funae Y (1998) Dopamine formation from tyramine by CYP2D6. Biochem Biophys Res Comm 249:838-843.

Hjort AM (1934) Some physiological properties of certain n-methylated-beta-phenylethylamines. J Pharmacol Exp Ther 52:101-112.

Hoefig CS, Köhrle J, Brabant G, Dixit K, Yap B, Strasburger CJ, and Wu Z (2011) Evidence for extrathyroidal formation of 3-iodothyronamine in humans as provided by a novel monoclonal antibody-based chemiluminescent serum immunoassay. $J$ Clin Endocrinol Metab 96:1864-1872.

Hoefig CS, Renko K, Piehl S, Scanlan TS, Bertoldi M, Opladen T, Hoffmann GF, Klein J, Blankenstein O, Schweizer U, et al. (2012) Does the aromatic L-amino acid decarboxylase contribute to thyronamine biosynthesis? Mol Cell Endocrinol 349: $195-201$.

Hoefig CS, Wuensch T, Rijntjes E, Lehmphul I, Daniel H, Schweizer U, Mittag J, and Kohrle $\mathrm{J}$ (2015) Biosynthesis of 3-iodothyronamine from T4 in murine in testinal tissue. Endocrinology 156:4356-4364.

Hoefig CS, Zucchi R, and Köhrle J (2016) Thyronamines and derivatives: physiological relevance, pharmacological actions, and future research directions. Thyroid 26:1656-1673.

Homberg U, Seyfarth J, Binkle U, Monastirioti M, and Alkema MJ (2013) Identification of distinct tyraminergic and octopaminergic neurons innervating the central complex of the desert locust, Schistocerca gregaria. J Comp Neurol $\mathbf{5 2 1}$ 2025-2041.

Honda K and Littman DR (2016) The microbiota in adaptive immune homeostasis and disease. Nature 535:75-84.

Horowitz LF, Saraiva LR, Kuang D, Yoon KH, and Buck LB (2014) Olfactory receptor patterning in a higher primate. $J$ Neurosci 34:12241-12252.

Hoyer SC, Eckart A, Herrel A, Zars T, Fischer SA, Hardie SL, and Heisenberg M (2008) Octopamine in male aggression of Drosophila. Curr Biol 18 $159-167$.

Hu LA, Zhou T, Ahn J, Wang S, Zhou J, Hu Y, and Liu Q (2009) Human and mouse trace amine-associated receptor 1 have distinct pharmacology towards endogenous monoamines and imidazoline receptor ligands. Biochem $J$ 424:39-45.

Huang J, Ohta H, Inoue N, Takao H, Kita T, Ozoe F, and Ozoe Y (2009) Molecular cloning and pharmacological characterization of a Bombyx mori tyramine receptor selectively coupled to intracellular calcium mobilization. Insect Biochem Mol Biol 39:842-849.

Huang J, Wu SF, Li XH, Adamo SA, and Ye GY (2012) The characterization of a concentration-sensitive $\alpha$-adrenergic-like octopamine receptor found on insect immune cells and its possible role in mediating stress hormone effects on immune function. Brain Behav Immun 26:942-950.

Hukkanen J, Dempsey D, Jacob P 3rd, and Benowitz NL (2005) Effect of pregnancy on a measure of FMO3 activity. Br J Clin Pharmacol 60:224-226.

Humbert JA, Hammond KB, and Hathaway WE (1970) Trimethylaminuria: the fishodour syndrome. Lancet 2:770-771.
Hussain A, Saraiva LR, Ferrero DM, Ahuja G, Krishna VS, Liberles SD, and Korsching SI (2013) High-affinity olfactory receptor for the death-associated odor cadaverine. Proc Natl Acad Sci USA 110:19579-19584.

Hussain A, Saraiva LR, and Korsching SI (2009) Positive Darwinian selection and the birth of an olfactory receptor clade in teleosts. Proc Natl Acad Sci USA 106: $4313-4318$

Ianculescu AG and Scanlan TS (2010) 3-Iodothyronamine (T(1)AM): a new chapter of thyroid hormone endocrinology? Mol Biosyst 6:1338-1344.

Ichinose H, Sumi-Ichinose C, Ohye T, Hagino Y, Fujita K, and Nagatsu T (1992) Tissue-specific alternative splicing of the first exon generates two types of mRNAs in human aromatic L-amino acid decarboxylase. Biochemistry 31: $11546-11550$.

Ikeda M, Iwata N, Suzuki T, Kitajima T, Yamanouchi Y, Kinoshita Y, Inada T, and Ozaki N (2005) No association of haplotype-tagging SNPs in TRAR4 with schizophrenia in Japanese patients. Schizophr Res 78:127-130.

Ikemoto K, Nishimura A, Oda T, Nagatsu I, and Nishi K (2003) Number of striatal D-neurons is reduced in autopsy brains of schizophrenics. Leg Med (Tokyo) 5 (Suppl 1):S221-S224.

Imre I, Di Rocco RT, Belanger CF, Brown GE, and Johnson NS (2014) The behavioural response of adult Petromyzon marinus to damage-released alarm and predator cues. J Fish Biol 84:1490-1502.

Irsfeld M, Spadafore M, and Prüß BM (2013) $\beta$-phenylethylamine, a small molecule with a large impact. Webmedcentral 4:4409.

Ishida Y and Ozaki M (2012) Aversive odorant causing appetite decrease downregulates tyrosine decarboxylase gene expression in the olfactory receptor neuron of the blowfly, Phormia regina. Naturwissenschaften 99:71-75.

Ito J, Ito M, Nambu H, Fujikawa T, Tanaka K, Iwaasa H, and Tokita S (2009) Anatomical and histological profiling of orphan G-protein-coupled receptor expression in gastrointestinal tract of C57BL/6J mice. Cell Tissue Res 338:257-269. Jacob MS and Presti DE (2005) Endogenous psychoactive tryptamines reconsidered an anxiolytic role for dimethyltryptamine. Med Hypotheses 64:930-937.

Jacobs JP, Goudarzi M, Singh N, Tong M, McHardy IH, Ruegger P, Asadourian M, Moon BH, Ayson A, Borneman J, et al. (2016) A disease-associated microbial and metabolomics state in relatives of pediatric inflammatory bowel disease patients. Cell Mol Gastroenterol Hepatol 2:750-766.

Jaeger CB, Ruggiero DA, Albert VR, Park DH, Joh TH, and Reis DJ (1984) Aromatic L-amino acid decarboxylase in the rat brain: immunocytochemical localization in neurons of the brain stem. Neuroscience 11:691-713.

Jaeger CB, Teitelman G, Joh TH, Albert VR, Park DH, and Reis DJ (1983) Some neurons of the rat central nervous system contain aromatic-L-amino-acid decarboxylase but not monoamines. Science 219:1233-1235.

James TD, Moffett SX, Scanlan TS, and Martin JV (2013) Effects of acute microinjections of the thyroid hormone derivative 3-iodothyronamine to the preoptic region of adult male rats on sleep, thermoregulation and motor activity. Horm Behav 64:81-88.

Janssen PA, Leysen JE, Megens AA, and Awouters FH (1999) Does phenylethylamine act as an endogenous amphetamine in some patients? Int $J$ Neuropsychopharmacol 2:229-240.

Jansson J, Willing B, Lucio M, Fekete A, Dicksved J, Halfvarson J, Tysk C, and Schmitt-Kopplin P (2009) Metabolomics reveals metabolic biomarkers of Crohn's disease. PLoS One 4:e6386.

Jing L and Li JX (2015) Trace amine-associated receptor 1: a promising target for the treatment of psychostimulant addiction. Eur J Pharmacol 761:345-352.

Jing L, Zhang Y, and Li JX (2014) Effects of the trace amine associated receptor 1 agonist RO5263397 on abuse-related behavioral indices of methamphetamine in rats. Int J Neuropsychopharmacol 18:pyu060.

John J, Kukshal P, Bhatia T, Chowdari KV, Nimgaonkar VL, Deshpande SN, and Thelma BK (2017) Possible role of rare variants in trace amine associated receptor 1 in schizophrenia. Schizophr Res 189:190-195.

Johnson MA, Tsai L, Roy DS, Valenzuela DH, Mosley C, Magklara A, Lomvardas S Liberles SD, and Barnea G (2012) Neurons expressing trace amine-associated receptors project to discrete glomeruli and constitute an olfactory subsystem. Proc Natl Acad Sci USA 109:13410-13415.

Jones RS (1982a) Noradrenaline-octopamine interactions on cortical neurones in the rat. Eur J Pharmacol 77:159-162.

Jones RS (1982b) Tryptamine modifies cortical neurone responses evoked by stimulation of nucleus raphe medianus. Brain Res Bull 8:435-437.

Jones RS and Boulton AA (1980a) Tryptamine and 5-hydroxytryptamine: actions and interactions of cortical neurones in the rat. Life Sci 27:1849-1856.

Jones RSG (1983) Trace biogenic-amines - a possible functional-role in the CNS. Trends Pharmacol Sci 4:426-429.

Jones RSG and Boulton AA (1980b) Interactions between p-tyramine, m-tyramine, or beta-phenylethylamine and dopamine on single neurones in the cortex and caudate nucleus of the rat. Can J Physiol Pharmacol 58:222-227.

Ju H, So H, Ha K, Park K, Lee JW, Chung CM, and Choi I (2011) Sustained torpidity following multi-dose administration of 3-iodothyronamine in mice. $J$ Cell Physiol 226:853-858.

Juorio AV (1979) Drug-induced changes in the formation, storage and metabolism of tyramine in the mouse. $\mathrm{Br} J$ Pharmacol 66:377-384.

Juorio AV, Greenshaw AJ, and Wishart TB (1988) Reciprocal changes in striatal dopamine and beta-phenylethylamine induced by reserpine in the presence of monoamine oxidase inhibitors. Naunyn Schmiedebergs Arch Pharmacol 338:644-648.

Juorio AV, Greenshaw AJ, Zhu MY, and Paterson IA (1991) The effects of some neuroleptics and d-amphetamine on striatal 2-phenylethylamine in the mouse. Gen Pharmacol 22:407-413.

Juorio AV, Li XM, Walz W, and Paterson IA (1993) Decarboxylation of L-dopa by cultured mouse astrocytes. Brain Res 626:306-309.

Juorio AV and Yu PH (1985a) Effects of benzene and other organic solvents on the decarboxylation of some brain aromatic-L-amino acids. Biochem Pharmacol 34: 1381-1387. 
Juorio AV and Yu PH (1985b) Effects of benzene and pyridine on the concentration of mouse striatal tryptamine and 5-hydroxytryptamine. Biochem Pharmacol 34: 3774-3776.

Kalnins G, Kuka J, Grinberga S, Makrecka-Kuka M, Liepinsh E, Dambrova M, and Tars K (2015) Structure and function of cutC choline lyase from human microbiota bacterium Klebsiella pneumoniae. J Biol Chem 290:21732-21740.

Karoum F, Linnoila M, Potter WZ, Chuang LW, Goodwin FK, and Wyatt RJ (1982) Fluctuating high urinary phenylethylamine excretion rates in some bipolar affective disorder patients. Psychiatry Res 6:215-222.

Kastner KW, Shoue DA, Estiu GL, Wolford J, Fuerst MF, Markley LD, Izaguirre JA and McDowell MA (2014) Characterization of the Anopheles gambiae octopamine receptor and discovery of potential agonists and antagonists using a combined computational-experimental approach. Malar J 13:434-447.

Kaufmann CA, Suarez B, Malaspina D, Pepple J, Svrakic D, Markel PD, Meyer J, Zambuto CT, Schmitt K, Matise TC, et al. (1998) NIMH Genetics Initiative Millenium Schizophrenia Consortium: linkage analysis of African-American pedigrees. Am J Med Genet 81:282-289.

Kellar KJ and Cascio CS (1982) [3H]Tryptamine: high affinity binding sites in rat brain. Eur J Pharmacol 78:475-478.

Khajavi N, Reinach PS, Slavi N, Skrzypski M, Lucius A, Strauß O, Köhrle J, and Mergler S (2015) Thyronamine induces TRPM8 channel activation in human conjunctival epithelial cells. Cell Signal 27:315-325.

Kidd M, Modlin IM, Gustafsson BI, Drozdov I, Hauso O, and Pfragner R (2008) Luminal regulation of normal and neoplastic human EC cell serotonin release is mediated by bile salts, amines, tastants, and olfactants. Am J Physiol Gastrointest Liver Physiol 295:G260-G272.

Kido Y, Matsson P, and Giacomini KM (2011) Profiling of a prescription drug library for potential renal drug-drug interactions mediated by the organic cation transporter 2. J Med Chem 54:4548-4558.

Kim DH, Maneen MJ, and Stahl SM (2009) Building a better antipsychotic: receptor targets for the treatment of multiple symptom dimensions of schizophrenia. Neurotherapeutics $6: 78-85$.

Kim SG, Bae HS, and Lee ST (2001) A novel denitrifying bacterial isolate that degrades trimethylamine both aerobically and anaerobically via two different pathways. Arch Microbiol 176:271-277.

Kirkwood S and Marion L (1950) The biogenesis of alkaloids I. The isolation of N-methyltyramine from barley. J Am Chem Soc 72:2522-2524.

Kitahama K, Ikemoto K, Jouvet A, Araneda S, Nagatsu I, Raynaud B, Nishimura A, Nishi K, and Niwa S (2009) Aromatic L-amino acid decarboxylaseimmunoreactive structures in human midbrain, pons, and medulla. J Chem Neuroanat 38:130-140.

Kleinau G, Pratzka J, Nürnberg D, Grüters A, Führer-Sakel D, Krude H, Köhrle J, Schöneberg T, and Biebermann H (2011) Differential modulation of betaadrenergic receptor signaling by trace amine-associated receptor 1 agonists. PLoS One 6:e27073.

Klieverik LP, Foppen E, Ackermans MT, Serlie MJ, Sauerwein HP, Scanlan TS, Grandy DK, Fliers E, and Kalsbeek A (2009) Central effects of thyronamines on glucose metabolism in rats. J Endocrinol 201:377-386.

Knight ME and Harris J (1993) Investigations into the biochemical basis of neuromodulation by 2-phenylethylamine: effect on microtubule protein. Neurochem Res 18:1221-1229

Koeth RA, Wang Z, Levison BS, Buffa JA, Org E, Sheehy BT, Britt EB, Fu X, Wu Y, $\mathrm{Li} \mathrm{L}$, et al. (2013) Intestinal microbiota metabolism of L-carnitine, a nutrient in red meat, promotes atherosclerosis. Nat Med 19:576-585.

Kojima K, Anzai R, Ohba C, Goto T, Miyauchi A, Thöny B, Saitsu H, Matsumoto N, Osaka H, and Yamagata T (2016) A female case of aromatic l-amino acid decarboxylase deficiency responsive to MAO-B inhibition. Brain Dev 38:959-963.

Könczöl Á, Rendes K, Dékány M, Müller J, Riethmüller E, and Balogh GT (2016) Blood-brain barrier specific permeability assay reveals N-methylated tyramine derivatives in standardised leaf extracts and herbal products of Ginkgo biloba. $J$ Pharm Biomed Anal 131:167-174.

Kononenko NL, Wolfenberg H, and Pflüger HJ (2009) Tyramine as an independent transmitter and a precursor of octopamine in the locust central nervous system: an immunocytochemical study. J Comp Neurol 512:433-452.

Kubo H, Shibato J, Saito T, Ogawa T, Rakwal R, and Shioda S (2015) Unraveling the rat intestine, spleen and liver genome-wide transcriptome after the oral administration of lavender oil by a two-color dye-swap DNA microarray approach. PLoS One 10:e0129951.

Kutsukake M, Komatsu A, Yamamoto D, and Ishiwa-Chigusa S (2000) A tyramine receptor gene mutation causes a defective olfactory behavior in Drosophila melanogaster. Gene 245:31-42.

Laakso A, Pohjalainen T, Bergman J, Kajander J, Haaparanta M, Solin O, Syvälahti $\mathrm{E}$, and Hietala $\mathrm{J}$ (2005) The A1 allele of the human D2 dopamine receptor gene is associated with increased activity of striatal L-amino acid decarboxylase in healthy subjects. Pharmacogenet Genomics 15:387-391.

Lam VM, Espinoza S, Gerasimov AS, Gainetdinov RR, and Salahpour A (2015) In-vivo pharmacology of trace-amine associated receptor 1. Eur J Pharmacol 763 (Pt B):136-142.

Lancaster GA and Sourkes TL (1972) Purification and properties of hog-kidney 3,4dihydroxyphenylalanine decarboxylase. Can J Biochem 50:791-797.

Lang DH, Yeung CK, Peter RM, Ibarra C, Gasser R, Itagaki K, Philpot RM, and Rettie $\mathrm{AE}$ (1998) Isoform specificity of trimethylamine N-oxygenation by human flavin-containing monooxygenase (FMO) and P450 enzymes: selective catalysis by FMO3. Biochem Pharmacol 56:1005-1012.

Lange AB (2009) Tyramine: from octopamine precursor to neuroactive chemical in insects. Gen Comp Endocrinol 162:18-26.

Laube G and Bernstein HG (2017) Agmatine: multifunctional arginine metabolite and magic bullet in clinical neuroscience? Biochem $J$ 474:2619-2640.

Laurino A, De Siena G, Saba A, Chiellini G, Landucci E, Zucchi R, and Raimondi L (2015) In the brain of mice, 3-iodothyronamine (T1AM) is converted into 3 -iodothyroacetic acid (TA1) and it is included within the signaling network connecting thyroid hormone metabolites with histamine. Eur $J$ Pharmacol 761: 130-134.

Laurino A, Matucci R, Vistoli G, and Raimondi L (2016) 3-iodothyronamine (T1AM), a novel antagonist of muscarinic receptors. Eur J Pharmacol 793:35-42.

Laurino A and Raimondi L (2017) Commentary: torpor: the rise and fall of 3-monoiodothyronamine from brain to gut-from gut to brain? Front Endocrinol (Lausanne) 8:206.

Lauweryns JM and Van Ranst L (1988) Immunocytochemical localization of aromatic L-amino acid decarboxylase in human, rat, and mouse bronchopulmonary and gastrointestinal endocrine cells. J Histochem Cytochem 36:1181-1186.

Lawford BR, Young RM, Noble EP, Sargent J, Rowell J, Shadforth S, Zhang X, and Ritchie $\mathrm{T}(2000)$ The $\mathrm{D}(2)$ dopamine receptor $\mathrm{A}(1)$ allele and opioid dependence: association with heroin use and response to methadone treatment. Am $J$ Med Genet 96:592-598

Lee DK, Lynch KR, Nguyen T, Im DS, Cheng R, Saldivia VR, Liu Y, Liu IS, Heng HH, Seeman $\mathrm{P}$, et al. (2000) Cloning and characterization of additional members of the G protein-coupled receptor family. Biochim Biophys Acta 1490:311-323.

Lee H-G, Seong C-S, Kim Y-C, Davis RL, and Han K-A (2003) Octopamine receptor $\mathrm{OAMB}$ is required for ovulation in Drosophila melanogaster. Dev Biol 264: $179-190$

Lehman HK, Schulz DJ, Barron AB, Wraight L, Hardison C, Whitney S, Takeuchi H, Paul RK, and Robinson GE (2006) Division of labor in the honey bee (Apis mellifera): the role of tyramine beta-hydroxylase. J Exp Biol 209:2774-2784.

Lenders JW, Eisenhofer G, Abeling NG, Berger W, Murphy DL, Konings CH, Wagemakers LM, Kopin IJ, Karoum F, van Gennip AH, et al. (1996) Specific genetic deficiencies of the $\mathrm{A}$ and $\mathrm{B}$ isoenzymes of monoamine oxidase are characterized by distinct neurochemical and clinical phenotypes. J Clin Invest 97: $1010-1019$

Lenders JWM and Eisenhofer G (2017) Update on modern management of pheochromocytoma and paraganglioma. Endocrinol Metab (Seoul) 32:152-161.

Leniger T, Thöne J, Bonnet U, Hufnagel A, Bingmann D, and Wiemann M (2004) Levetiracetam inhibits Na+-dependent Cl-/HCO3- exchange of adult hippocampal CA3 neurons from guinea-pigs. Br J Pharmacol 142:1073-1080.

Leo D, Mus L, Espinoza S, Hoener MC, Sotnikova TD, and Gainetdinov RR (2014) Taar1-mediated modulation of presynaptic dopaminergic neurotransmission: role of D2 dopamine autoreceptors. Neuropharmacology 81:283-291.

Leo D, Sukhanov I, Zoratto F, Illiano P, Caffino L, Sanna F, Messa G, Emanuele M, Esposito A, Dorofeikova M, et al. (2018) Pronounced hyperactivity, cognitive dysfunctions, and BDNF dysregulation in dopamine transporter knock-out rats. $J$ Neurosci 38:1959-1972.

Leonti M and Casu L (2014) Soma, food of the immortals according to the Bower Manuscript (Kashmir, 6th century A.D.). J Ethnopharmacol 155:373-386.

Levinson DF, Holmans P, Straub RE, Owen MJ, Wildenauer DB, Gejman PV, Pulver AE, Laurent C, Kendler KS, Walsh D, et al. (2000) Multicenter linkage study of schizophrenia candidate regions on chromosomes $5 \mathrm{q}, 6 \mathrm{q}, 10 \mathrm{p}$, and 13q: schizophrenia linkage collaborative group III. Am J Hum Genet 67:652-663.

Li G, Regunathan S, Barrow CJ, Eshraghi J, Cooper R, and Reis DJ (1994) Agmatine: an endogenous clonidine-displacing substance in the brain. Science 263:966-969.

$\mathrm{Li} \mathrm{J}$ and Meltzer HY (2014) A genetic locus in 7p12.2 associated with treatment resistant schizophrenia. Schizophr Res 159:333-339.

Li Q, Korzan WJ, Ferrero DM, Chang RB, Roy DS, Buchi M, Lemon JK, Kaur AW, Stowers L, Fendt M, et al. (2013) Synchronous evolution of an odor biosynthesis pathway and behavioral response. Curr Biol 23:11-20.

Li Q, Tachie-Baffour Y, Liu Z, Baldwin MW, Kruse AC, and Liberles SD (2015) Nonclassical amine recognition evolved in a large clade of olfactory receptors. eLife $\mathbf{4}$ : e10441.

Li W-G, Yu Y, Zhang Z-D, Cao H, and Xu T-L (2010) ASIC3 channels integrate agmatine and multiple inflammatory signals through the nonproton ligand sensing domain. Mol Pain 6:88-102.

Li XM, Juorio AV, Paterson IA, and Boulton AA (1992a) Absence of 2-phenylethylamine binding after monoamine oxidase inhibition in rat brain. Eur J Pharmacol 210:189-193.

Li XM, Juorio AV, Paterson IA, Walz W, Zhu MY, and Boulton AA (1992b) Gene expression of aromatic L-amino acid decarboxylase in cultured rat glial cells. $J$ Neurochem 59:1172-1175.

Li Y, Li L, Stephens MJ, Zenner D, Murray KC, Winship IR, Vavrek R, Baker GB, Fouad K, and Bennett DJ (2014) Synthesis, transport, and metabolism of serotonin formed from exogenously applied 5-HTP after spinal cord injury in rats. $J \mathrm{Neu}$ rophysiol 111:145-163.

Libants S, Carr K, Wu H, Teeter JH, Chung-Davidson YW, Zhang Z, Wilkerson C, and Li W (2009) The sea lamprey Petromyzon marinus genome reveals the early origin of several chemosensory receptor families in the vertebrate lineage. $B M C$ Evol Biol 9:180.

Liberles SD (2014) Mammalian pheromones. Annu Rev Physiol 76:151-175.

Liberles SD (2015) Trace amine-associated receptors: ligands, neural circuits, and behaviors. Curr Opin Neurobiol 34:1-7.

Liberles SD and Buck LB (2006) A second class of chemosensory receptors in the olfactory epithelium. Nature 442:645-650.

Lichtenberger LM, Delansorne R, and Graziani LA (1982) Importance of amino acid uptake and decarboxylation in gastrin release from isolated G cells. Nature $\mathbf{2 9 5}$ $698-700$

Lichtenberger LM, Gardner JW, Barreto JC, and Morriss FH Jr (1991) Evidence for a role of volatile amines in the development of neonatal hypergastrinemia. J Pediatr Gastroenterol Nutr 13:342-346.

Lim J, Sabandal PR, Fernandez A, Sabandal JM, Lee HG, Evans P, and Han KA (2014) The octopamine receptor Oct $\beta 2 R$ regulates ovulation in Drosophila melanogaster. PLoS One 9:e104441.

Lindemann L, Ebeling M, Kratochwil NA, Bunzow JR, Grandy DK, and Hoener MC (2005) Trace amine-associated receptors form structurally and functionally distinct subfamilies of novel G protein-coupled receptors. Genomics 85:372-385. 
Lindemann L and Hoener MC (2005) A renaissance in trace amines inspired by a novel GPCR family. Trends Pharmacol Sci 26:274-281.

Lindemann L and Hoener MC (2008) Trace amines, in Encyclopedia of Molecular Pharmacology (Offermanns S and Rosenthal W eds) pp 1217-1223, Springer, Berlin.

Lindemann L, Meyer CA, Jeanneau K, Bradaia A, Ozmen L, Bluethmann H, Bettler B, Wettstein JG, Borroni E, Moreau JL, et al. (2008) Trace amine-associated receptor 1 modulates dopaminergic activity. J Pharmacol Exp Ther 324:948-956.

Lindström P and Sehlin J (1983) Mechanisms underlying the effects of 5-hydroxytryptamine and 5-hydroxytryptophan in pancreatic islets. A proposed role for L-aromatic amino acid decarboxylase. Endocrinology 112:1524-1529.

Linnoila RI, Gazdar AF, Funa K, and Becker KL (1993) Long-term selective culture of hamster pulmonary endocrine cells. Anat Rec 236:231-240.

Liu J-F, Seaman R Jr, Johnson B, Zhang B, and Li J-X (2017a) Effects of the TAAR1 partial agonist RO5263397 on morphine-related behaviors. Neuropsychopharmacology 42:S637.

Liu J-F, Seaman R Jr, Siemian JN, Bhimani R, Johnson B, Zhang Y, Zhu Q, Hoener MC, Park J, Dietz DM, et al. (2018) Role of trace amine-associated receptor 1 in nicotine's behavioral and neurochemical effects. Neuropsychopharmacology [published ahead of print].

Liu JF, Siemian JN, Seaman R Jr, Zhang Y, and Li JX (2017b) Role of TAAR1 within the subregions of the mesocorticolimbic dopaminergic system in cocaine-seeking behavior. J Neurosci 37:882-892.

Liu JF, Thorn DA, Zhang Y, and Li JX (2016) Effects of trace amine-associated receptor 1 agonists on the expression, reconsolidation, and extinction of cocaine reward memory. Int J Neuropsychopharmacol 19:pyw009.

Liu X, Grandy DK, and Janowsky A (2014) Ractopamine, a livestock feed additive, is a full agonist at trace amine-associated receptor 1. J Pharmacol Exp Ther 350: 124-129.

Livingstone MS and Tempel BL (1983) Genetic dissection of monoamine neurotransmitter synthesis in Drosophila. Nature 303:67-70.

Lovenberg W, Weissbach H, and Udenfriend S (1962) Aromatic L-amino acid decarboxylase. $J$ Biol Chem 237:89-93.

Lucius A, Khajavi N, Reinach PS, Köhrle J, Dhandapani P, Huimann P, Ljubojevic N, Grötzinger C, and Mergler S (2016) 3-Iodothyronamine increases transient receptor potential melastatin channel 8 (TRPM8) activity in immortalized human corneal epithelial cells. Cell Signal 28:136-147.

Ludewick HP, Schwab SG, Albus M, Lerer B, Maier W, Trixler M, and Wildenauer DB (2008) No support for an association with TAAR6 and schizophrenia in a linked population of European ancestry. Psychiatr Genet 18:208-210.

Luethi D, Trachsel D, Hoener MC, and Liechti ME (2017) Monoamine receptor in teraction profiles of 4-thio-substituted phenethylamines (2C-T drugs). Neuropharmacology [published ahead of print].

Luo A, Leach ST, Barres R, Hesson LB, Grimm MC, and Simar D (2017) The microbiota and epigenetic regulation of T helper 17/regulatory $\mathrm{T}$ cells: in search of a balanced immune system. Front Immunol 8:417.

Luo Y, Zhu J, and Gao Y (2012) Metabolomic analysis of the plasma of patients with high-altitude pulmonary edema (HAPE) using 1H NMR. Mol Biosyst 8:1783-1788.

Luqman A, Nega M, Nguyen M-T, Ebner P, and Götz F (2018) SadA-expressing staphylococci in the human gut show increased cell adherence and internalization. Cell Reports 22:535-545.

Lynch LJ, Sullivan KA, Vallender EJ, Rowlett JK, Platt DM, and Miller GM (2013) Trace amine associated receptor 1 modulates behavioral effects of ethanol. Subst Abuse 7:117-126.

Ma JZ, Beuten J, Payne TJ, Dupont RT, Elston RC, and Li MD (2005) Haplotype analysis indicates an association between the DOPA decarboxylase (DDC) gene and nicotine dependence. Hum Mol Genet 14:1691-1698.

Ma Z, Guo X, Lei H, Li T, Hao S, and Kang L (2015) Octopamine and tyramine respectively regulate attractive and repulsive behavior in locust phase changes. $S c i$ Rep 5:8036.

Maguire JJ, Parker WA, Foord SM, Bonner TI, Neubig RR, and Davenport AP (2009) International Union of Pharmacology. LXXII. Recommendations for trace amine receptor nomenclature. Pharmacol Rev 61:1-8.

Maitre L, Fthenou E, Athersuch T, Coen M, Toledano MB, Holmes E, Kogevinas M, Chatzi L, and Keun HC (2014) Urinary metabolic profiles in early pregnancy are associated with preterm birth and fetal growth restriction in the Rhea mother-child cohort study. BMC Med 12:110.

Maitre L, Lau CE, Vizcaino E, Robinson O, Casas M, Siskos AP, Want EJ, Athersuch T, Slama R, Vrijheid M, et al. (2017) Assessment of metabolic phenotypic variability in children's urine using ${ }^{1} \mathrm{H}$ NMR spectroscopy. Sci Rep 7:46082.

Manni ME, De Siena G, Saba A, Marchini M, Dicembrini I, Bigagli E, Cinci L, Lodovici M, Chiellini G, Zucchi R, et al. (2012) 3-Iodothyronamine: a modulator of the hypothalamus-pancreas-thyroid axes in mice. Br J Pharmacol 166:650-658.

Manni ME, De Siena G, Saba A, Marchini M, Landucci E, Gerace E, Zazzeri M, Musilli C, Pellegrini-Giampietro D, Matucci R, et al. (2013) Pharmacological effects of 3-iodothyronamine (T1AM) in mice include facilitation of memory acquisition and retention and reduction of pain threshold. $\mathrm{Br} J$ Pharmacol 168 354-362.

Maqueira B, Chatwin H, and Evans PD (2005) Identification and characterization of a novel family of Drosophila beta-adrenergic-like octopamine G-protein coupled receptors. J Neurochem 94:547-560.

Marcobal A, de las Rivas B, and Muñoz R (2006) First genetic characterization of a bacterial beta-phenylethylamine biosynthetic enzyme in Enterococcus faecium RM58. FEMS Microbiol Lett 258:144-149.

Mariotti V, Melissari E, Iofrida C, Righi M, Di Russo M, Donzelli R, Saba A, Frascarelli S, Chiellini G, Zucchi R, et al. (2014) Modulation of gene expression by 3-iodothyronamine: genetic evidence for a lipolytic pattern. PLoS One 9:e106923.

Maxwell GD, Moore MM, and Hildebrand JG (1980) Metabolism of tyramine in the central nervous system of the moth Manduca sexta. Insect Biochem 10: $657-665$.
McClung C and Hirsh J (1998) Stereotypic behavioral responses to free-base cocaine and the development of behavioral sensitization in Drosophila. Curr Biol 8 109-112.

McConnell HW, Mitchell SC, Smith RL, and Brewster M (1997) Trimethylaminuria associated with seizures and behavioural disturbance: a case report. Seizure 6: $317-321$

McCoole MD, Atkinson NJ, Graham DI, Grasser EB, Joselow AL, McCall NM, Welker AM, Wilsterman EJ Jr, Baer KN, Tilden AR, et al. (2012) Genomic analyses of aminergic signaling systems (dopamine, octopamine and serotonin) in Daphnia pulex. Comp Biochem Physiol Part D Genomics Proteomics 7:35-58.

McCormack JK, Beitz AJ, and Larson AA (1986) Autoradiographic localization of tryptamine binding sites in the rat and dog central nervous system. J Neurosci 6 : 94-101.

McGuire PS and Seiden LS (1980) Differential effects of imipramine in rats as a function of DRL schedule value. Pharmacol Biochem Behav 13:691-694.

Meana C, Rubin JM, Bordallo C, Suarez L, Bordallo J, and Sanchez M (2016) Correlation between endogenous polyamines in human cardiac tissues and clinical parameters in patients with heart failure. J Cell Mol Med 20:302-312.

Meyer JM and Stahl SM (2009) The metabolic syndrome and schizophrenia. Acta Psychiatr Scand 119:4-14.

Meyer T and Hesch RD (1983) Triiodothyronamine-a beta-adrenergic metabolite of triiodothyronine? Horm Metab Res 15:602-606.

Miao J, Ling AV, Manthena PV, Gearing ME, Graham MJ, Crooke RM, Croce KJ, Esquejo RM, Clish CB, Vicent D, et al.; Morbid Obesity Study Group (2015) Flavincontaining monooxygenase 3 as a potential player in diabetes-associated atherosclerosis. Nat Commun 6:6498.

Michaelides M, Thanos PK, Volkow ND, and Wang GJ (2012) Dopamine-related frontostriatal abnormalities in obesity and binge-eating disorder: emerging evidence for developmental psychopathology. Int Rev Psychiatry 24:211-218.

Miller GM, Verrico CD, Jassen A, Konar M, Yang H, Panas H, Bahn M, Johnson R, and Madras BK (2005) Primate trace amine receptor 1 modulation by the dopamine transporter. J Pharmacol Exp Ther 313:983-994.

Miller-Fleming L, Olin-Sandoval V, Campbell K, and Ralser M (2015) Remaining mysteries of molecular biology: the role of polyamines in the cell. $J$ Mol Biol 427: $3389-3406$

Miner NB, Elmore JS, Baumann MH, Phillips TJ, and Janowsky A (2017) Trace amine-associated receptor 1 regulation of methamphetamine-induced neurotoxicity. Neurotoxicology 63:57-69.

Mitchell SC and Smith RL (2001) Trimethylaminuria: the fish malodor syndrome. Drug Metab Dispos 29:517-521.

Mitchell SC and Smith RL (2010) A physiological role for flavin-containing monooxygenase (FMO3) in humans? Xenobiotica 40:301-305.

Mitchell SC and Smith RL (2016) Trimethylamine-the extracorporeal envoy. Chem Senses 41:275-279.

Miyamoto S, Miyake N, Jarskog LF, Fleischhacker WW, and Lieberman JA (2012) Pharmacological treatment of schizophrenia: a critical review of the pharmacology and clinical effects of current and future therapeutic agents. Mol Psychiatry 17: $1206-1227$.

Moghaddam B and Javitt D (2012) From revolution to evolution: the glutamate hypothesis of schizophrenia and its implication for treatment. Neuropsychopharmacology 37:4-15.

Molderings GJ and Haenisch B (2012) Agmatine (decarboxylated L-arginine): physiological role and therapeutic potential. Pharmacol Ther 133:351-365.

Molinoff PB and Axelrod J (1972) Distribution and turnover of octopamine in tissues. J Neurochem 19:157-163.

Monastirioti M, Linn CE Jr, and White K (1996) Characterization of Drosophila tyramine beta-hydroxylase gene and isolation of mutant flies lacking octopamine. J Neurosci 16:3900-3911.

Montioli R, Paiardini A, Kurian MA, Dindo M, Rossignoli G, Heales SJR, Pope S, Voltattorni CB, and Bertoldi M (2016) The novel R347g pathogenic mutation of aromatic amino acid decarboxylase provides additional molecular insights into enzyme catalysis and deficiency. Biochim Biophys Acta 1864:676-682.

Moore CF, Sabino V, and Cottone P (2018) Trace amine associated receptor 1 (TAAR1) modulation of food reward. Front Pharmacol 9:129.

Morton DB and Evans PD (1984) Octopamine release from an identified neurone in the locust. J Exp Biol 113:269-287.

Mosnaim AD, Callaghan OH, Hudzik T, and Wolf ME (2013) Rat brain-uptake index for phenylethylamine and various monomethylated derivatives. Neurochem Res 38 : 842-846.

Mueller JC, Steiger S, Fidler AE, and Kempenaers B (2008) Biogenic trace amineassociated receptors (TAARS) are encoded in avian genomes: evidence and possible implications. J Hered 99:174-176.

Mühlhaus J, Dinter J, Jyrch S, Teumer A, Jacobi SF, Homuth G, Kühnen P, Wiegand S, Grüters A, Völzke H, et al. (2017) Investigation of naturally occurring singlenucleotide variants in human TAAR1. Front Pharmacol 8:807.

Mühlhaus J, Dinter J, Nürnberg D, Rehders M, Depke M, Golchert J, Homuth G, Yi CX, Morin S, Köhrle J, et al. (2014) Analysis of human TAAR8 and murine Taar8b mediated signaling pathways and expression profile. Int $J$ Mol Sci $\mathbf{1 5}$ 20638-20655.

Müller DJ, Chiesa A, Mandelli L, De Luca V, De Ronchi D, Jain U, Serretti A and Kennedy JL (2010) Correlation of a set of gene variants, life events and personality features on adult ADHD severity. J Psychiatr Res 44:598-604.

Murdoch TB, Fu H, MacFarlane S, Sydora BC, Fedorak RN, and Slupsky CM (2008) Urinary metabolic profiles of inflammatory bowel disease in interleukin-10 genedeficient mice. Anal Chem 80:5524-5531.

Nagaya Y, Kutsukake M, Chigusa SI, and Komatsu A (2002) A trace amine, tyramine, functions as a neuromodulator in Drosophila melanogaster. Neurosci Let 329:324-328.

Naila A, Flint S, Fletcher G, Bremer P, and Meerdink G (2010) Control of biogenic amines in food-existing and emerging approaches. J Food Sci 75:R139-R150. 
Nassiri-Asl M, Zamansoltani F, and Zangivand AA (2008) The inhibitory effect of trimethylamine on the anticonvulsant activities of quinine in the pentylenetetrazole model in rats. Prog Neuropsychopharmacol Biol Psychiatry 32:1496-1500.

Nazimek J, Perini F, Capitao L, McKie S, Browning M, Harmer C, and Deakin B (2016) A phase I functional neuroimaging study of SEP-363856 in healthy volunteers with high or low stereotypy. Neuropsychopharmacology 41:S393-S394.

Neff NH, Wemlinger TA, Duchemin AM, and Hadjiconstantinou M (2006) Clozapine modulates aromatic L-amino acid decarboxylase activity in mouse striatum. J Pharmacol Exp Ther 317:480-487.

Nelson DA, Tolbert MD, Singh SJ, and Bost KL (2007) Expression of neuronal trace amine-associated receptor (Taar) mRNAs in leukocytes. J Neuroimmunol 192 $21-30$.

Nelson TM, Borgogna JL, Brotman RM, Ravel J, Walk ST, and Yeoman CJ (2015) Vaginal biogenic amines: biomarkers of bacterial vaginosis or precursors to vaginal dysbiosis? Front Physiol 6:253.

Nishimura K, Kitamura Y, Inoue T, Umesono Y, Yoshimoto K, Taniguchi T, and Agata K (2008) Characterization of tyramine beta-hydroxylase in planarian Dugesia japonica: cloning and expression. Neurochem Int 53:184-192.

Nishimura K, Utsumi K, Yuhara M, Fujitani Y, and Iritani A (1989) Identification of puberty-accelerating pheromones in male mouse urine. J Exp Zool 251:300-305.

Niwa T, Murayama N, Umeyama H, Shimizu M, and Yamazaki H (2011) Human liver enzymes responsible for metabolic elimination of tyramine; a vasopressor agent from daily food. Drug Metab Lett 5:216-219.

Noble EP (2003) D2 dopamine receptor gene in psychiatric and neurologic disorders and its phenotypes. Am J Med Genet B Neuropsychiatr Genet 116B:103-125.

O'Donnell JM and Seiden LS (1983) Differential-reinforcement-of-low-rate 72-second schedule: selective effects of antidepressant drugs. J Pharmacol Exp Ther 224 80-88.

O'Hara BF, Smith SS, Bird G, Persico AM, Suarez BK, Cutting GR, and Uhl GR (1993) Dopamine D2 receptor RFLPs, haplotypes and their association with substance use in black and Caucasian research volunteers. Hum Hered 43:209-218.

O'Malley KL, Harmon S, Moffat M, Uhland-Smith A, and Wong S (1995) The human aromatic L-amino acid decarboxylase gene can be alternatively spliced to generate unique protein isoforms. J Neurochem 65:2409-2416.

Ohta H, Takebe Y, Murakami Y, Takahama Y, and Morimura S (2017) Tyramine and $\beta$-phenylethylamine, from fermented food products, as agonists for the human trace amine-associated receptor 1 (hTAAR1) in the stomach. Biosci Biotechnol Biochem 81:1002-1006.

Orchard I and Lange AB (1987) The release of octopamine and proctolin from an insect visceral muscle: effects of high-potassium saline and neural stimulation. Brain Res 413:251-258.

Pacifico R, Dewan A, Cawley D, Guo C, and Bozza T (2012) An olfactory subsystem that mediates high-sensitivity detection of volatile amines. Cell Reports 2:76-88.

Pae CU, Drago A, Kim JJ, Patkar AA, Jun TY, De Ronchi D, and Serretti A (2010) TAAR6 variations possibly associated with antidepressant response and suicidal behavior. Psychiatry Res 180:20-24.

Pae CU, Drago A, Kim JJ, Patkar AA, Jun TY, Lee C, Mandelli L, De Ronchi D, Paik IH, and Serretti A (2008a) TAAR6 variation effect on clinic presentation and outcome in a sample of schizophrenic in-patients: an open label study. Eur Psychiatry 23:390-395.

Pae CU, Drago A, Patkar AA, Jun TY, and Serretti A (2009) Epistasis between a set of variations located in the TAAR6 and HSP-70 genes toward schizophrenia and response to antipsychotic treatment. Eur Neuropsychopharmacol 19:806-811.

Pae CU, Yu HS, Amann D, Kim JJ, Lee CU, Lee SJ, Jun TY, Lee C, Paik IH, Patkar AA, et al. (2008b) Association of the trace amine associated receptor 6 (TAAR6) gene with schizophrenia and bipolar disorder in a Korean case control sample. $J$ Psychiatr Res 42:35-40.

Paetsch PR, Baker GB, and Greenshaw AJ (1993) Induction of functional down-regulation of beta-adrenoceptors in rats by 2-phenylethylamine. J Pharm Sci 82:22-24.

Paetsch PR and Greenshaw AJ (1993) Down-regulation of beta-adrenergic and dopaminergic receptors induced by 2-phenylethylamine. Cell Mol Neurobiol 13: 203-215.

Panas HN, Lynch LJ, Vallender EJ, Xie Z, Chen GL, Lynn SK, Scanlan TS, and Miller GM (2010) Normal thermoregulatory responses to 3-iodothyronamine, trace amines and amphetamine-like psychostimulants in trace amine associated receptor 1 knockout mice. J Neurosci Res 88:1962-1969.

Panas MW, Xie Z, Panas HN, Hoener MC, Vallender EJ, and Miller GM (2012) Trace amine associated receptor 1 signaling in activated lymphocytes. $J$ Neuroimmune Pharmacol 7:866-876.

Pankiw T and Page RE Jr (2003) Effect of pheromones, hormones, and handling on sucrose response thresholds of honey bees (Apis mellifera L.). J Comp Physiol A Neuroethol Sens Neural Behav Physiol 189:675-684.

Parker EM and Cubeddu LX (1988) Comparative effects of amphetamine, phenylethylamine and related drugs on dopamine efflux, dopamine uptake and mazindol binding. $J$ Pharmacol Exp Ther 245:199-210.

Paterson IA (1988) The potentiation of cortical neurone responses to noradrenaline by beta-phenylethylamine: effects of lesions of the locus coeruleus. Neurosci Lett 87:139-144.

Paterson IA (1993) The potentiation of cortical neuron responses to noradrenaline by 2-phenylethylamine is independent of endogenous noradrenaline. Neurochem Res 18:1329-1336

Paterson IA and Boulton AA (1988) beta-Phenylethylamine enhances single cortical neurone responses to noradrenaline in the rat. Brain Res Bull 20:173-177.

Paterson IA, Juorio AV, Berry MD, and Zhu MY (1991) Inhibition of monoamine oxidase-B by (-)-deprenyl potentiates neuronal responses to dopamine agonists but does not inhibit dopamine catabolism in the rat striatum. J Pharmacol Exp Ther 258:1019-1026.

Paulos MA and Tessel RE (1982) Excretion of beta-phenethylamine is elevated in humans after profound stress. Science 215:1127-1129.
Peers EM, Lyles GA, and Callingham BA (1980) The deamination of isoamylamine by monamine oxidase in mitochondrial preparations from rat liver and heart: a comparison with phenylethylamine. Biochem Pharmacol 29:1097-1102.

Pegg AE (2016) Functions of polyamines in mammals. J Biol Chem 291: 14904-14912.

Pei Y, Asif-Malik A, and Canales JJ (2016) Trace amines and the trace amineassociated receptor 1: pharmacology, neurochemistry, and clinical implications. Front Neurosci 10:148.

Pei Y, Asif-Malik A, Hoener M, and Canales JJ (2017) A partial trace amineassociated receptor 1 agonist exhibits properties consistent with a methamphetamine substitution treatment. Addict Biol 22:1246-1256.

Pei Y, Lee J, Leo D, Gainetdinov RR, Hoener MC, and Canales JJ (2014) Activation of the trace amine-associated receptor 1 prevents relapse to cocaine seeking. Neuropsychopharmacology 39:2299-2308.

Pei Y, Mortas P, Hoener MC, and Canales JJ (2015) Selective activation of the trace amine-associated receptor 1 decreases cocaine's reinforcing efficacy and prevents cocaine-induced changes in brain reward thresholds. Prog Neuropsychopharmacol Biol Psychiatry 63:70-75

Pellicciari A, Posar A, Cremonini MA, and Parmeggiani A (2011) Epilepsy and trimethylaminuria: a new case report and literature review. Brain Dev 33:593-596.

Perälä J, Suvisaari J, Saarni SI, Kuoppasalmi K, Isometsä E, Pirkola S, Partonen T, Tuulio-Henriksson A, Hintikka J, Kieseppä T, et al. (2007) Lifetime prevalence of psychotic and bipolar I disorders in a general population. Arch Gen Psychiatry 64: $19-28$

Pérez-Gómez A, Bleymehl K, Stein B, Pyrski M, Birnbaumer L, Munger SD Leinders-Zufall T, Zufall F, and Chamero P (2015) Innate predator odor aversion driven by parallel olfactory subsystems that converge in the ventromedial hypothalamus. Curr Biol 25:1340-1346.

Perry DC (1986) [3H]tryptamine autoradiography in rat brain and choroid plexus reveals two distinct sites. J Pharmacol Exp Ther 236:548-559.

Persico AM, Bird G, Gabbay FH, and Uhl GR (1996) D2 dopamine receptor gene TaqI $\mathrm{A} 1$ and $\mathrm{B} 1$ restriction fragment length polymorphisms: enhanced frequencies in psychostimulant-preferring polysubstance abusers. Biol Psychiatry 40:776-784.

Pessione E and Cirrincione S (2016) Bioactive molecules released in food by lactic acid bacteria: encrypted peptides and biogenic amines. Front Microbiol 7:876.

Philips SR and Boulton AA (1979) The effect of monoamine oxidase inhibitors on some arylalkylamines in rate striatum. $J$ Neurochem 33:159-167.

Piehl S, Heberer T, Balizs G, Scanlan TS, Smits R, Koksch B, and Köhrle J (2008) Thyronamines are isozyme-specific substrates of deiodinases. Endocrinology 149: 3037-3045.

Piehl S, Hoefig CS, Scanlan TS, and Köhrle J (2011) Thyronamines-past, present, and future. Endocr Rev 32:64-80.

Pietsch CA, Scanlan TS, and Anderson RJ (2007) Thyronamines are substrates for human liver sulfotransferases. Endocrinology 148:1921-1927.

Piletz JE, Aricioglu F, Cheng JT, Fairbanks CA, Gilad VH, Haenisch B, Halaris A, Hong S, Lee JE, Li J, et al. (2013) Agmatine: clinical applications after 100 years in translation. Drug Discov Today 18:880-893.

Pirri JK, McPherson AD, Donnelly JL, Francis MM, and Alkema MJ (2009) A tyramine-gated chloride channel coordinates distinct motor programs of a Caenorhabditis elegans escape response. Neuron 62:526-538.

Pribbenow B and Erber J (1996) Modulation of antennal scanning in the honeybee by sucrose stimuli, serotonin, and octopamine: behavior and electrophysiology. $\mathrm{Neu}$ robiol Learn Mem 66:109-120.

Price MA and Vandenbergh JG (1992) Analysis of puberty-accelerating pheromones. J Exp Zool 264:42-45.

Pugh CEM and Quastel JH (1937) Oxidation of aliphatic amines by brain and other tissues. Biochem $J$ 31:286-291.

Qi YX, Xu G, Gu GX, Mao F, Ye GY, Liu W, and Huang J (2017) A new Drosophila octopamine receptor responds to serotonin. Insect Biochem Mol Biol 90:61-70.

Raab S, Wang H, Uhles S, Cole N, Alvarez-Sanchez R, Künnecke B, Ullmer C, Matile $\mathrm{H}$, Bedoucha M, Norcross RD, et al. (2015) Incretin-like effects of small molecule trace amine-associated receptor 1 agonists. Mol Metab 5:47-56.

Raasch W, Schäfer U, Chun J, and Dominiak P (2001) Biological significance of agmatine, an endogenous ligand at imidazoline binding sites. Br J Pharmacol 133 $755-780$

Rahman MK, Nagatsu T, and Kato T (1981) Aromatic L-amino acid decarboxylase activity in central and peripheral tissues and serum of rats with L-DOPA and L-5hydroxytryptophan as substrates. Biochem Pharmacol 30:645-649.

Raiteri M, Del Carmine R, Bertollini A, and Levi G (1977) Effect of sympathomimetic amines on the synaptosomal transport of noradrenaline, dopamine and 5-hydroxytryptamine. Eur J Pharmacol 41:133-143.

Rajput AH, Fenton ME, Di Paolo T, Sitte H, Pifl C, and Hornykiewicz O (2004) Human brain dopamine metabolism in levodopa-induced dyskinesia and wearingoff. Parkinsonism Relat Disord 10:221-226.

Reale V, Hannan F, Midgley JM, and Evans PD (1997) The expression of a cloned Drosophila octopamine/tyramine receptor in Xenopus oocytes. Brain Res 769: 309-320

Reed C, Baba H, Zhu Z, Erk J, Mootz JR, Varra NM, Williams RW, and Phillips TJ (2018) A spontaneous mutation in Taar1 impacts methamphetamine-related traits exclusively in DBA/2 mice from a single vendor. Front Pharmacol 8:993.

Reese EA, Bunzow JR, Arttamangkul S, Sonders MS, and Grandy DK (2007) Trace amine-associated receptor 1 displays species-dependent stereoselectivity for isomers of methamphetamine, amphetamine, and para-hydroxyamphetamine. $J$ Pharmacol Exp Ther 321:178-186.

Regard JB, Kataoka H, Cano DA, Camerer E, Yin L, Zheng YW, Scanlan TS, Hebrok $\mathrm{M}$, and Coughlin SR (2007) Probing cell type-specific functions of Gi in vivo identifies GPCR regulators of insulin secretion. J Clin Invest 117:4034-4043.

Regard JB, Sato IT, and Coughlin SR (2008) Anatomical profiling of G proteincoupled receptor expression. Cell 135:561-571. 
Reith J, Benkelfat C, Sherwin A, Yasuhara Y, Kuwabara H, Andermann F, Bachneff S, Cumming P, Diksic M, Dyve SE, et al. (1994) Elevated dopa decarboxylase activity in living brain of patients with psychosis. Proc Natl Acad Sci USA 91: 11651-11654.

Revel FG, Meyer CA, Bradaia A, Jeanneau K, Calcagno E, Andre CB, Haenggi M, Miss MT, Galley G, Norcross RD, et al. (2012a) Brain-specific overexpression of trace amine-associated receptor 1 alters monoaminergic neurotransmission and decreases sensitivity to amphetamine. Neuropsychopharmacology 37:2580-2592.

Revel FG, Moreau JL, Gainetdinov RR, Bradaia A, Sotnikova TD, Mory R, Durkin S, Zbinden KG, Norcross R, Meyer CA, et al. (2011) TAAR1 activation modulates monoaminergic neurotransmission, preventing hyperdopaminergic and hypoglutamatergic activity. Proc Natl Acad Sci USA 108:8485-8490.

Revel FG, Moreau JL, Gainetdinov RR, Ferragud A, Velázquez-Sánchez C, Sotnikova TD, Morairty SR, Harmeier A, Groebke Zbinden K, Norcross RD, et al. (2012b) Trace amine-associated receptor 1 partial agonism reveals novel paradigm for neuropsychiatric therapeutics. Biol Psychiatry 72:934-942.

Revel FG, Moreau JL, Pouzet B, Mory R, Bradaia A, Buchy D, Metzler V, Chaboz S, Groebke Zbinden K, Galley G, et al. (2013) A new perspective for schizophrenia: TAAR1 agonists reveal antipsychotic- and antidepressant-like activity, improve cognition and control body weight. Mol Psychiatry 18:543-556.

Reynolds GP and Gray DO (1978) Gas chromatographic detection of N-methyl-2 phenylethylamine: a new component of human urine. J Chromatogr A 145: 137-140.

Reynolds GP and Kirk SL (2010) Metabolic side effects of antipsychotic drug treatment-pharmacological mechanisms. Pharmacol Ther 125:169-179.

Reynolds GP, Seakins JW, and Gray DO (1978) The urinary excretion of 2-phenylethylamine in phenylketonuria. Clin Chim Acta 83:33-39.

Riba J, Valle M, Urbano G, Yritia M, Morte A, and Barbanoj MJ (2003) Human pharmacology of ayahuasca: subjective and cardiovascular effects, monoamine metabolite excretion, and pharmacokinetics. J Pharmacol Exp Ther 306:73-83.

Rigby LM and Merritt DJ (2011) Roles of biogenic amines in regulating bioluminescence in the Australian glowworm Arachnocampa flava. $J$ Exp Biol 214: 3286-3293.

Rillich J, Schildberger K, and Stevenson PA (2011) Octopamine and occupancy: an aminergic mechanism for intruder-resident aggression in crickets. Proc Biol Sci 278:1873-1880.

Ringstad N, Abe N, and Horvitz HR (2009) Ligand-gated chloride channels are receptors for biogenic amines in C. elegans. Science 325:96-100.

Robacker DC, Garcia JA, and Bartelt RJ (2000) Volatiles from duck feces attractive to Mexican fruit fly. J Chem Ecol 26:1849-1867.

Robb S, Cheek TR, Hannan FL, Hall LM, Midgley JM, and Evans PD (1994) Agonistspecific coupling of a cloned Drosophila octopamine/tyramine receptor to multiple second messenger systems. EMBO J 13:1325-1330.

Roeder T (2005) Tyramine and octopamine: ruling behavior and metabolism. Annu Rev Entomol 50:447-477.

Roeder T (2016) Trace amines: an overview, in Trace Amines and Neurological Disorders: Potential Mechanisms and Risk Factors (Farooqui T and Farooqui AA eds) pp 3-9, Academic Press, Boston.

Roeder T, Degen J, Dyczkowski C, and Gewecke M (1995) Pharmacology and molecular biology of octopamine receptors from different insect species. Prog Brain Res 106:249-258.

Roeder T and Gewecke M (1989) Octopamine uptake systems in thoracic ganglia and leg muscles of Locusta migratoria. Comp Biochem Physiol C Toxicol Pharmacol 94: 143-147.

Roeder T, Seifert M, Kähler C, and Gewecke M (2003) Tyramine and octopamine: antagonistic modulators of behavior and metabolism. Arch Insect Biochem Physiol 54:1-13.

Rorsman F, Husebye ES, Winqvist O, Björk E, Karlsson FA, and Kämpe O (1995) Aromatic-L-amino-acid decarboxylase, a pyridoxal phosphate-dependent enzyme, is a beta-cell autoantigen. Proc Natl Acad Sci USA 92:8626-8629.

Rossetti Z, Krajnc D, Neff NH, and Hadjiconstantinou M (1989) Modulation of retinal aromatic L-amino acid decarboxylase via alpha 2 adrenoceptors. $J$ Neurochem $\mathbf{5 2}$ : 647-652.

Rossetti ZL, Silvia CP, Krajnc D, Neff NH, and Hadjiconstantinou M (1990) Aromatic L-amino acid decarboxylase is modulated by $\mathrm{D} 1$ dopamine receptors in rat retina. $J$ Neurochem 54:787-791.

Roy G, Placzek E, and Scanlan TS (2012) ApoB-100-containing lipoproteins are major carriers of 3-iodothyronamine in circulation. J Biol Chem 287:1790-1800.

Roy S and Trinchieri G (2017) Microbiota: a key orchestrator of cancer therapy. Nat Rev Cancer 17:271-285.

Saavedra JM (1974) Enzymatic isotopic assay for and presence of betaphenylethylamine in brain. $J$ Neurochem 22:211-216.

Saavedra JM and Axelrod J (1973) Effect of drugs on the tryptamine content of rat tissues. J Pharmacol Exp Ther 185:523-529.

Saba A, Chiellini G, Frascarelli S, Marchini M, Ghelardoni S, Raffaelli A, Tonacchera M, Vitti P, Scanlan TS, and Zucchi R (2010) Tissue distribution and cardiac metabolism of 3-iodothyronamine. Endocrinology 151:5063-5073.

Sabelli H, Fink P, Fawcett J, and Tom C (1996) Sustained antidepressant effect of PEA replacement. J Neuropsychiatry Clin Neurosci 8:168-171.

Sabelli HC and Javaid JI (1995) Phenylethylamine modulation of affect: therapeutic and diagnostic implications. J Neuropsychiatry Clin Neurosci 7:6-14.

Sabelli HC and Mosnaim AD (1974) Phenylethylamine hypothesis of affective behavior. Am J Psychiatry 131:695-699.

Sabelli HC, Vazquez AJ, Mosnaim AD, and Madrid-Pedemonte L (1974) 2-Phenylethylamine as a possible mediator for delta9-tetrahydrocannabinol-induced stimulation. Nature 248:144-145.

Safratowich BD, Hossain M, Bianchi L, and Carvelli L (2014) Amphetamine potentiates the effects of $\beta$-phenylethylamine through activation of an amine-gated chloride channel. J Neurosci 34:4686-4691.
Sánchez M, Suárez L, Andrés MT, Flórez BH, Bordallo J, Riestra S, and Cantabrana B (2017) Modulatory effect of intestinal polyamines and trace amines on the spontaneous phasic contractions of the isolated ileum and colon rings of mice. Food Nutr Res 61:1321948.

Sanders AR, Duan J, Levinson DF, Shi J, He D, Hou C, Burrell GJ, Rice JP, Nertney DA, Olincy A, et al. (2008) No significant association of 14 candidate genes with schizophrenia in a large European ancestry sample: implications for psychiatric genetics. Am J Psychiatry 165:497-506.

Santoru ML, Piras C, Murgia A, Palmas V, Camboni T, Liggi S, Ibba I, Lai MA, Orrù $\mathrm{S}$, Blois S, et al. (2017) Cross sectional evaluation of the gut-microbiome metabolome axis in an Italian cohort of IBD patients. Sci Rep 7:9523.

Santos PS, Courtiol A, Heidel AJ, Höner OP, Heckmann I, Nagy M, Mayer F, Platzer M, Voigt CC, and Sommer S (2016) MHC-dependent mate choice is linked to a trace-amine-associated receptor gene in a mammal. Sci Rep 6:38490.

Saraiva LR, Kondoh K, Ye X, Yoon KH, Hernandez M, and Buck LB (2016) Combinatorial effects of odorants on mouse behavior. Proc Natl Acad Sci USA 113:E3300-E3306.

Saraswati S, Fox LE, Soll DR, and Wu CF (2004) Tyramine and octopamine have opposite effects on the locomotion of Drosophila larvae. J Neurobiol 58:425-441.

Saudou F, Amlaiky N, Plassat JL, Borrelli E, and Hen R (1990) Cloning and characterization of a Drosophila tyramine receptor. EMBO J 9:3611-3617.

Sayyah M, Rezaie M, Haghighi S, and Amanzadeh A (2007) Intra-amygdala all-trans retinoic acid inhibits amygdala-kindled seizures in rats. Epilepsy Res 75:97-103.

Scanlan TS, Suchland KL, Hart ME, Chiellini G, Huang Y, Kruzich PJ, Frascarelli S Crossley DA, Bunzow JR, Ronca-Testoni S, et al. (2004) 3-Iodothyronamine is an endogenous and rapid-acting derivative of thyroid hormone. Nat Med 10:638-642.

Scheiner R, Plückhahn S, Oney B, Blenau W, and Erber J (2002) Behavioural pharmacology of octopamine, tyramine and dopamine in honey bees. Behav Brain Res 136:545-553.

Scheiner R, Toteva A, Reim T, Søvik E, and Barron AB (2014) Differences in the phototaxis of pollen and nectar foraging honey bees are related to their octopamine brain titers. Front Physiol 5:116.

Schulz DJ, Elekonich MM, and Robinson GE (2003) Biogenic amines in the antennal lobes and the initiation and maintenance of foraging behavior in honey bees. $J$ Neurobiol 54:406-416.

Schulz DJ and Robinson GE (2001) Octopamine influences division of labor in honey bee colonies. J Comp Physiol A Neuroethol Sens Neural Behav Physiol 187:53-61. Schwartz MD, Black SW, Fisher SP, Palmerston JB, Morairty SR, Hoener MC, and Kilduff TS (2017) Trace amine-associated receptor 1 regulates wakefulness and EEG spectral composition. Neuropsychopharmacology 42:1305-1314.

Schwartz MD, Palmerston JB, Lee DL, Hoener MC, and Kilduff TS (2018) Deletion of trace amine-associated receptor 1 attenuates behavioral responses to caffeine. Front Pharmacol 9:35.

Serretti A, Pae CU, Chiesa A, Mandelli L, and De Ronchi D (2009) Influence of TAAR6 polymorphisms on response to aripiprazole. Prog Neuropsychopharmacol Biol Psychiatry 33:822-826.

Sessa B (2017) MDMA and PTSD treatment: "PTSD: from novel pathophysiology to innovative therapeutics". Neurosci Lett 649:176-180.

Shannon HE and Thompson WA (1984) Behavior maintained under fixed-interval and second-order schedules by intravenous injections of endogenous noncatecholic phenylethylamines in dogs. J Pharmacol Exp Ther 228:691-695.

Shao L, Campbell JE, Hewitt MC, Campbell U, and Hanania TG (2011) inventors, Sunovion Pharmaceuticals Inc. and Psychogenics Inc., assignees. Multicyclic compounds and methods of use thereof. Patent WO 2011/069063 A2. 2011 Jun 9.

Shao X, Lakhina V, Dang P, Cheng RP, Marcaccio CL, and Raper JA (2017) Olfactory sensory axons target specific protoglomeruli in the olfactory bulb of zebrafish. Neural Dev 12:18.

Shaw JE, Sicree RA, and Zimmet PZ (2010) Global estimates of the prevalence of diabetes for 2010 and 2030. Diabetes Res Clin Pract 87:4-14.

Shepherd RM, Hashmi MN, Kane C, Squires PE, and Dunne MJ (1996) Elevation of cytosolic calcium by imidazolines in mouse islets of Langerhans: implications for stimulus-response coupling of insulin release. $\mathrm{Br} J$ Pharmacol 119:911-916.

Shi W, Mersfelder J, and Hille R (2005) The interaction of trimethylamine dehydrogenase and electron-transferring flavoprotein. $J$ Biol Chem 280: 20239-20246.

Shifman S, Levit A, Chen ML, Chen CH, Bronstein M, Weizman A, Yakir B, Navon R, and Darvasi A (2006) A complete genetic association scan of the 22q11 deletion region and functional evidence reveal an association between DGCR2 and schizophrenia. Hum Genet 120:160-170.

Shimizu M, Cashman JR, and Yamazaki H (2007) Transient trimethylaminuria related to menstruation. BMC Med Genet 8:2.

Siemian JN, Zhang Y, and Li JX (2017) Trace amine-associated receptor 1 agonists RO5263397 and RO5166017 attenuate quinpirole-induced yawning but not hypothermia in rats. Behav Pharmacol 28:590-593.

Sikkema JM, Franx A, Fijnheer R, Nikkels PGJ, Bruinse HW, and Boomsma F (2002) Semicarbazide-sensitive amine oxidase in pre-eclampsia: no relation with markers of endothelial cell activation. Clin Chim Acta 324:31-38.

Silkaitis RP and Mosnaim AD (1976) Pathways linking L-phenylalanine and 2-phenylethylamine with p-tyramine in rabbit brain. Brain Res 114:105-115.

Simmler LD, Buchy D, Chaboz S, Hoener MC, and Liechti ME (2016) In vitro characterization of psychoactive substances at rat, mouse, and human trace amineassociated receptor 1. J Pharmacol Exp Ther 357:134-144.

Sims KL and Bloom FE (1973) Rat brain L-3,4-dihydroxyphenylalanine and L-5-hydroxytryptophan decarboxylase activities: differential effect of 6-hydroxydopamine. Brain Res 49:165-175.

Sims KL, Davis GA, and Bloom FE (1973) Activities of 3,4-dihydroxy-Lphenylalanine and 5-hydroxy-L-tryptophan decarboxylases in rat brain: assay characteristics and distribution. J Neurochem 20:449-464.

Siow YL and Dakshinamurti K (1985) Effect of pyridoxine deficiency on aromatic L-amino acid decarboxylase in adult rat brain. Exp Brain Res 59:575-581. 
Skorupski P (1996) Octopamine induces steady-state reflex reversal in crayfish thoracic ganglia. J Neurophysiol 76:93-108.

Sloley BD (2004) Metabolism of monoamines in invertebrates: the relative importance of monoamine oxidase in different phyla. Neurotoxicology 25:175-183.

Smith I, Kellow AH, and Hanington E (1970) A clinical and biochemical correlation between tyramine and migraine headache. Headache 10:43-52.

Smith SB, Maixner DW, Fillingim RB, Slade G, Gracely RH, Ambrose K, Zaykin DV, Hyde C, John S, Tan K, et al. (2012) Large candidate gene association study reveals genetic risk factors and therapeutic targets for fibromyalgia. Arthritis Rheum 64:584-593.

Smith TA (1977) Phenethylamine and related compounds in plants. Phytochemistry 16:9-18.

Snead AN, Santos MS, Seal RP, Miyakawa M, Edwards RH, and Scanlan TS (2007) Thyronamines inhibit plasma membrane and vesicular monoamine transport. ACS Chem Biol 2:390-398.

Snoddy AM, Heckathorn D, and Tessel RE (1985) Cold-restraint stress and urinary endogenous beta-phenylethylamine excretion in rats. Pharmacol Biochem Behav 22:497-500.

Snodgrass SR and Iversen LL (1974) Formation and release of 3H-tryptamine from $3 \mathrm{H}$-tryptophan in rat spinal cord slices. Adv Biochem Psychopharmacol 10:141-150.

Sombati S and Hoyle G (1984) Central nervous sensitization and dishabituation of reflex action in an insect by the neuromodulator octopamine. $J$ Neurobiol 15:455-480.

Sonnenburg JL and Bäckhed F (2016) Diet-microbiota interactions as moderators of human metabolism. Nature 535:56-64.

Sotnikova TD, Beaulieu JM, Espinoza S, Masri B, Zhang X, Salahpour A, Barak LS, Caron MG, and Gainetdinov RR (2010) The dopamine metabolite 3-methoxytyramine is a neuromodulator. PLoS One 5:e13452.

Sotnikova TD, Budygin EA, Jones SR, Dykstra LA, Caron MG, and Gainetdinov RR (2004) Dopamine transporter-dependent and -independent actions of trace amine beta-phenylethylamine. J Neurochem 91:362-373.

Sotnikova TD, Caron MG, and Gainetdinov RR (2009) Trace amine-associated receptors as emerging therapeutic targets. Mol Pharmacol 76:229-235.

Sotnikova TD and Gainetdinov RR (2009) Octopamine and other monoamines in invertebrates, in Encyclopedia of Neuroscience (Squire LR ed) pp 9-17, Academic Press, Cambridge, MA.

Sotnikova TD, Zorina OI, Ghisi V, Caron MG, and Gainetdinov RR (2008) Trace amine associated receptor 1 and movement control. Parkinsonism Relat Disord 14 (Suppl 2):S99-S102.

Spitz MR, Shi H, Yang F, Hudmon KS, Jiang H, Chamberlain RM, Amos CI, Wan Y, Cinciripini P, Hong WK, et al. (1998) Case-control study of the D2 dopamine receptor gene and smoking status in lung cancer patients. J Natl Cancer Inst $\mathbf{9 0}$ 358-363.

Spivak M, Masterman R, Ross R, and Mesce KA (2003) Hygienic behavior in the honey bee (Apis mellifera L.) and the modulatory role of octopamine. $J$ Neurobiol 55: 341-354

Srinivasa S, Fitch KV, Lo J, Kadar H, Knight R, Wong K, Abbara S, Gauguier D, Capeau $\mathrm{J}$, Boccara F, et al. (2015) Plaque burden in HIV-infected patients is associated with serum intestinal microbiota-generated trimethylamine. AIDS 29:443-452.

Sriram U, Cenna JM, Haldar B, Fernandes NC, Razmpour R, Fan S, Ramirez SH and Potula R (2016) Methamphetamine induces trace amine-associated receptor 1 (TAAR1) expression in human $\mathrm{T}$ lymphocytes: role in immunomodulation. J Leukoc Biol 99:213-223.

Sriram U, Haldar B, Cenna JM, Gofman L, and Potula R (2015) Methamphetamine mediates immune dysregulation in a murine model of chronic viral infection. Front Microbiol 6:793.

Stalder H, Hoener MC, and Norcross RD (2011) Selective antagonists of mouse trace amine-associated receptor 1 (mTAAR1): discovery of EPPTB (RO5212773). Bioorg Med Chem Lett 21:1227-1231.

Stäubert C, Böselt I, Bohnekamp J, Römpler H, Enard W, and Schöneberg T (2010) Structural and functional evolution of the trace amine-associated receptors TAAR3, TAAR4 and TAAR5 in primates. PLoS One 5:e11133.

Stavrou S, Gratz M, Tremmel E, Kuhn C, Hofmann S, Heidegger H, Peryanova M, Hermelink K, Hutter S, Toth B, et al. (2018) TAAR1 induces a disturbed GSK3 $\beta$ phosphorylation in recurrent miscarriages through the ODC. Endocr Connect 7 : 372-384.

Stelinski LL, Miller JR, Ressa NE, and Gut LJ (2003) Increased EAG responses of tortricid moths after prolonged exposure to plant volatiles: evidence for octopamine-mediated sensitization. J Insect Physiol 49:845-856.

Stevenson PA, Dyakonova V, Rillich J, and Schildberger K (2005) Octopamine and experience-dependent modulation of aggression in crickets. $J$ Neurosci 25 1431-1441.

Stoff DM, Jeste DV, Gillin JC, Moja EA, Cohen L, Stauderman KA, and Wyatt RJ (1984) Behavioral supersensitivity to beta-phenylethylamine after chronic administration of haloperidol. Biol Psychiatry 19:101-106.

Stohs SJ and Hartman MJ (2015) A review of the receptor binding and pharmacological effects of N-methyltyramine. Phytother Res 29:14-16.

Sugimoto M, Saruta J, Matsuki C, To M, Onuma H, Kaneko M, Soga T, Tomita M, and Tsukinoki K (2013) Physiological and environmental parameters associated with mass spectrometry-based salivary metabolomic profiles. Metabolomics 9:454-463.

Sukhanov I, Caffino L, Efimova EV, Espinoza S, Sotnikova TD, Cervo L, Fumagalli F, and Gainetdinov RR (2016) Increased context-dependent conditioning to amphetamine in mice lacking TAAR1. Pharmacol Res 103:206-214.

Sukhanov I, Dorofeikova M, Dolgorukova A, Dorotenko A, and Gainetdinov RR (2018) Trace amine-associated receptor 1 modulates the locomotor and sensitization effects of nicotine. Front Pharmacol 9:329.

Sukhanov I, Espinoza S, Yakovlev DS, Hoener MC, Sotnikova TD, and Gainetdinov RR (2014) TAAR1-dependent effects of apomorphine in mice. Int $J$ Neuropsychopharmacol 17:1683-1693.

Sumi-Ichinose C, Hasegawa S, Ichinose H, Sawada H, Kobayashi K, Sakai M, Fujii T, Nomura H, Nomura T, Nagatsu I, et al. (1995) Analysis of the alternative promoters that regulate tissue-specific expression of human aromatic L-amino acid decarboxylase. J Neurochem 64:514-524.
Syed AS, Sansone A, Röner S, Bozorg Nia S, Manzini I, and Korsching SI (2015) Different expression domains for two closely related amphibian TAARs generate a bimodal distribution similar to neuronal responses to amine odors. Sci Rep 5:13935.

Szabo A (2015) Psychedelics and immunomodulation: novel approaches and therapeutic opportunities. Front Immunol 6:358.

Szabo A, Billett E, and Turner J (2001) Phenylethylamine, a possible link to the antidepressant effects of exercise? Br J Sports Med 35:342-343.

Szumska J, Qatato M, Rehders M, Führer D, Biebermann H, Grandy DK, Köhrle J, and Brix K (2015) Trace amine-associated receptor 1 localization at the apical plasma membrane domain of fisher rat thyroid epithelial cells is confined to cilia. Eur Thyroid J 4 (Suppl 1):30-41.

Taksande BG, Kotagale NR, Tripathi SJ, Ugale RR, and Chopde CT (2009) Antidepressant like effect of selective serotonin reuptake inhibitors involve modulation of imidazoline receptors by agmatine. Neuropharmacology 57:415-424

Taquet N, Philippe C, Reimund J-M, and Muller CD (2012) Inflammatory bowel disease G-protein coupled receptors (GPCRs) expression profiling with microfluidic cards, in Crohn's Disease (Karoui S ed) pp 59-86, IntechOpen, London.

Tashiro S, Taniguchi E, Eto M, and Maekawa K (1974) Isoamylamine as the possible neuroactive metabolite of l-leucine. Agric Biol Chem 39:569-570.

Tchercansky DM, Acevedo C, and Rubio MC (1994) Studies of tyramine transfer and metabolism using an in vitro intestinal preparation. J Pharm Sci 83:549-552.

Tessarolo JA, Tabesh MJ, Nesbitt M, and Davidson WS (2014) Genomic organization and evolution of the trace amine-associated receptor (TAAR) repertoire in Atlantic salmon (Salmo salar). G3 (Bethesda) 4:1135-1141.

Thaiss CA, Zmora N, Levy M, and Elinav E (2016) The microbiome and innate immunity. Nature 535:65-74.

Thomas P, Alptekin K, Gheorghe M, Mauri M, Olivares JM, and Riedel M (2009) Management of patients presenting with acute psychotic episodes of schizophrenia. CNS Drugs 23:193-212.

Thorn DA, Jing L, Qiu Y, Gancarz-Kausch AM, Galuska CM, Dietz DM, Zhang Y, and $\mathrm{Li} \mathrm{JX}$ (2014a) Effects of the trace amine-associated receptor 1 agonist RO5263397 on abuse-related effects of cocaine in rats. Neuropsychopharmacology 39:2309-2316.

Thorn DA, Zhang C, Zhang Y, and Li JX (2014b) The trace amine associated receptor 1 agonist RO5263397 attenuates the induction of cocaine behavioral sensitization in rats. Neurosci Lett 566:67-71.

Tiihonen J, Vilkman H, Räsänen P, Ryynänen OP, Hakko H, Bergman J, Hämäläinen T, Laakso A, Haaparanta-Solin M, Solin O, et al. (1998) Striatal presynaptic dopamine function in type 1 alcoholics measured with positron emission tomography. Mol Psychiatry 3:156-161.

Todd WA (1979) Psychosocial problems as the major complication of an adolescent with trimethylaminuria. J Pediatr 94:936-937.

Toro-Funes N, Bosch-Fuste J, Latorre-Moratalla ML, Veciana-Nogués MT, and Vidal-Carou MC (2015) Biologically active amines in fermented and nonfermented commercial soybean products from the Spanish market. Food Chem 173:1119-1124.

Toye AA, Dumas ME, Blancher C, Rothwell AR, Fearnside JF, Wilder SP, Bihoreau MT, Cloarec O, Azzouzi I, Young S, et al. (2007) Subtle metabolic and liver gene transcriptional changes underlie diet-induced fatty liver susceptibility in insulinresistant mice. Diabetologia 50:1867-1879.

Tsutsumi E, Kanai S, Ohta M, Suwa Y, and Miyasaka K (2010) Stimulatory effect of N-methyltyramine, a congener of beer, on pancreatic secretion in conscious rats. Alcohol Clin Exp Res 34 (Suppl 1):S14-S17.

Ungar F, Mosnaim AD, Ungar B, and Wolf ME (1977) Tyramine-binding by synaptosomes from rat brain: effect of centrally active drugs. Biol Psychiatry 12:661-668

Unoki S, Matsumoto Y, and Mizunami M (2005) Participation of octopaminergic reward system and dopaminergic punishment system in insect olfactory learning revealed by pharmacological study. Eur J Neurosci 22:1409-1416.

Vaccari A (1986) High affinity binding of $[3 \mathrm{H}]$-tyramine in the central nervous system. Br J Pharmacol 89:15-25.

Vallender EJ, Xie Z, Westmoreland SV, and Miller GM (2010) Functional evolution of the trace amine associated receptors in mammals and the loss of TAAR 1 in dogs. BMC Evol Biol 10:51.

van Nguyen T, Paterson IA, Juorio AV, Greenshaw AJ, and Boulton AA (1989) Tryptamine receptors: neurochemical and electrophysiological evidence for postsynaptic and functional binding sites. Brain Res 476:85-93.

Vanden Broeck J, Vulsteke V, Huybrechts R, and De Loof A (1995) Characterization of a cloned locust tyramine receptor cDNA by functional expression in permanently transformed Drosophila S2 cells. J Neurochem 64:2387-2395.

Vanti WB, Muglia P, Nguyen T, Cheng R, Kennedy JL, George SR, and O'Dowd BF (2003) Discovery of a null mutation in a human trace amine receptor gene. Genomics 82:531-536.

Vassilacopoulou D, Sideris DC, Vassiliou AG, and Fragoulis EG (2004) Identification and characterization of a novel form of the human L-dopa decarboxylase mRNA. Neurochem Res 29:1817-1823.

Vattai A, Akyol E, Kuhn C, Hofmann S, Heidegger H, von Koch F, Hermelink K, Wuerstlein R, Harbeck N, Mayr D, et al. (2017) Increased trace amine-associated receptor 1 (TAAR1) expression is associated with a positive survival rate in patients with breast cancer. $J$ Cancer Res Clin Oncol 143:1637-1647.

Venditti P, Napolitano G, Di Stefano L, Chiellini G, Zucchi R, Scanlan TS, and Di Meo S (2011) Effects of the thyroid hormone derivatives 3-iodothyronamine and thyronamine on rat liver oxidative capacity. Mol Cell Endocrinol 341:55-62.

Venken T, Claes S, Sluijs S, Paterson AD, van Duijn C, Adolfsson R, Del-Favero J, and Van Broeckhoven C (2005) Genomewide scan for affective disorder susceptibility Loci in families of a northern Swedish isolated population. Am J Hum Genet 76:237-248.

Verlinden H, Vleugels R, Marchal E, Badisco L, Pflüger HJ, Blenau W, and Broeck JV (2010a) The role of octopamine in locusts and other arthropods. J Insect Physiol 56: 854-867.

Verlinden H, Vleugels R, Marchal E, Badisco L, Tobback J, Pflüger HJ, Blenau W, and Vanden Broeck J (2010b) The cloning, phylogenetic relationship and 
distribution pattern of two new putative GPCR-type octopamine receptors in the desert locust (Schistocerca gregaria). J Insect Physiol 56:868-875.

Vieira-Coelho MA and Soares-da-Silva P (1993) Dopamine formation, from its immediate precursor 3,4-dihydroxyphenylalanine, along the rat digestive tract. Fundam Clin Pharmacol 7:235-243.

Vierk R, Pflueger HJ, and Duch C (2009) Differential effects of octopamine and tyramine on the central pattern generator for Manduca flight. J Comp Physiol A Neuroethol Sens Neural Behav Physiol 195:265-277.

Vladimirov V, Thiselton DL, Kuo PH, McClay J, Fanous A, Wormley B, Vittum J, Ribble R, Moher B, van den Oord E, et al. (2007) A region of $35 \mathrm{~kb}$ containing the trace amine associate receptor 6 (TAAR6) gene is associated with schizophrenia in the Irish study of high-density schizophrenia families. Mol Psychiatry 12:842-853.

Vladimirov VI, Maher BS, Wormley B, O'Neill FA, Walsh D, Kendler KS, and Riley $\mathrm{BP}(2009)$ The trace amine associated receptor (TAAR6) gene is not associated with schizophrenia in the Irish Case-Control Study of Schizophrenia (ICCSS) sample. Schizophr Res 107:249-254.

Wainscott DB, Little SP, Yin T, Tu Y, Rocco VP, He JX, and Nelson DL (2007) Pharmacologic characterization of the cloned human trace amine-associated receptor1 (TAAR1) and evidence for species differences with the rat TAAR1. $J$ Pharmacol Exp Ther 320:475-485.

Walker RJ and Kerkut GA (1978) The first family (adrenaline, noradrenaline, dopamine, octopamine, tyramine, phenylethanolamine and phenylethylamine). Comp Biochem Physiol C Toxicol Pharmacol 61:261-266.

Wallrabenstein I, Kuklan J, Weber L, Zborala S, Werner M, Altmüller J, Becker C, Schmidt A, Hatt H, Hummel T, et al. (2013) Human trace amine-associated receptor TAAR5 can be activated by trimethylamine. PLoS One 8:e54950.

Wallrabenstein I, Singer M, Panten J, Hatt H, and Gisselmann G (2015) Timberol® inhibits TAAR5-mediated responses to trimethylamine and influences the olfactory threshold in humans. PLoS One 10:e0144704.

Wang D, Ma JZ, and Li MD (2005) Mapping and verification of susceptibility loci for smoking quantity using permutation linkage analysis. Pharmacogenomics $J$ 5:166-172.

Wang X, Corin K, Rich C, and Zhang S (2011) Study of two G-protein coupled receptor variants of human trace amine-associated receptor 5. Sci Rep 1:102.

Wasik AM, Millan MJ, Scanlan T, Barnes NM, and Gordon J (2012) Evidence for functional trace amine associated receptor-1 in normal and malignant B cells. Leuk Res 36:245-249.

Wienecke J, Ren LQ, Hultborn H, Chen M, Møller M, Zhang Y, and Zhang M (2014) Spinal cord injury enables aromatic L-amino acid decarboxylase cells to synthesize monoamines. J Neurosci 34:11984-12000.

Williams BB, Van Benschoten AH, Cimermancic P, Donia MS, Zimmermann M, Taketani M, Ishihara A, Kashyap PC, Fraser JS, and Fischbach MA (2014) Discovery and characterization of gut microbiota decarboxylases that can produce the neurotransmitter tryptamine. Cell Host Microbe 16:495-503.

Willoughby D, Thomas R, and Schwiening C (2001) The effects of intracellular $\mathrm{pH}$ changes on resting cytosolic calcium in voltage-clamped snail neurones. J Physiol 530:405-416.

Wolf EP (1921) Experimental studies on inflammation. I. The influence of chemicals upon the chemotaxis of leucocytes in vitro. J Exp Med 34:375-396.

Wolf EP (1923) Experimental studies on inflammation: II. Experimental chemical inflammation in vivo. J Exp Med 37:511-524.

Wolf ME and Mosnaim AD (1983) Phenylethylamine in neuropsychiatric disorders Gen Pharmacol 14:385-390.

Wolinsky TD Swanson CJ, Smith KE, Zhong H, Borowsky B, Seeman P, Branchek T, and Gerald CP (2007) The trace amine 1 receptor knockout mouse: an animal model with relevance to schizophrenia. Genes Brain Behav 6:628-639.

Wood WJ, Geraci T, Nilsen A, DeBarber AE, and Scanlan TS (2009) Iodothyronamines are oxidatively deaminated to iodothyroacetic acids in vivo. ChemBioChem 10:361-365.

Wright TR (1987) The genetics of biogenic amine metabolism, sclerotization, and melanization in Drosophila melanogaster. Adv Genet 24:127-222.

Wu SF, Xu G, and Ye GY (2015) Characterization of a tyramine receptor type 2 from hemocytes of rice stem borer, Chilo suppressalis. J Insect Physiol 75:39-46.

Xie Z and Miller GM (2008) Beta-phenylethylamine alters monoamine transporter function via trace amine-associated receptor 1: implication for modulatory roles of trace amines in brain. J Pharmacol Exp Ther 325:617-628.

Xie Z, Vallender EJ, Yu N, Kirstein SL, Yang H, Bahn ME, Westmoreland SV, and Miller GM (2008a) Cloning, expression, and functional analysis of rhesus monkey trace amine-associated receptor 6: evidence for lack of monoaminergic association. J Neurosci Res 86:3435-3446.

Xie Z, Westmoreland SV, and Miller GM (2008b) Modulation of monoamine transporters by common biogenic amines via trace amine-associated receptor 1 and monoamine autoreceptors in human embryonic kidney 293 cells and brain synaptosomes. J Pharmacol Exp Ther 325:629-640.
Xue Z, Siemian JN, Johnson BN, Zhang Y, and Li JX (2018) Methamphetamineinduced impulsivity during chronic methamphetamine treatment in rats: effects of the TAAR 1 agonist RO5263397. Neuropharmacology 129:36-46.

Yang HY and Neff NH (1973) Beta-phenylethylamine: a specific substrate for type B monoamine oxidase of brain. J Pharmacol Exp Ther 187:365-371.

Yang XC and Reis DJ (1999) Agmatine selectively blocks the N-methyl-D-aspartate subclass of glutamate receptor channels in rat hippocampal neurons. $J$ Pharmacol Exp Ther 288:544-549.

Yang YX, Mu CL, Luo Z, and Zhu WY (2015a) Bromochloromethane, a methane analogue, affects the microbiota and metabolic profiles of the rat gastrointestina tract. Appl Environ Microbiol 82:778-787.

Yang Z, Yu Y, Zhang V, Tian Y, Qi W, and Wang L (2015b) Octopamine mediates starvation-induced hyperactivity in adult Drosophila. Proc Natl Acad Sci USA 112: 5219-5224.

Yen YR, Wang YH, Wang LN, Chen LC, Lu FJ, and Wang SR (2016) Novel function of isoamylamine improves survival in endotoxemic mice by ameliorating coagulopathy and attenuating MMP-9 expression through p-ERK/p-p38 signaling at early stage. Shock 47:772-779.

Yokoo Y, Kohda H, Kusumoto A, Naoki H, Matsumoto N, Amachi T, Suwa Y, Fukazawa H, Ishida H, Tsuji K, et al. (1999) Isolation from beer and structural determination of a potent stimulant of gastrin release. Alcohol Alcohol 34: $161-168$.

Youdim MB, Harshak N, Yoshioka M, Araki H, Mukai Y, and Gotto G (1991) Novel substrates and products of amine oxidase-catalysed reactions. Biochem Soc Trans 19:224-228.

Young EA, Neff NH, and Hadjiconstantinou M (1993) Evidence for cyclic AMPmediated increase of aromatic L-amino acid decarboxylase activity in the striatum and midbrain. J Neurochem 60:2331-2333.

Young EA, Neff NH, and Hadjiconstantinou M (1994) Phorbol ester administration transiently increases aromatic L-amino acid decarboxylase activity of the mouse striatum and midbrain. J Neurochem 63:694-697.

Yu AM, Granvil CP, Haining RL, Krausz KW, Corchero J, Küpfer A, Idle JR, and Gonzalez FJ (2003) The relative contribution of monoamine oxidase and cytochrome p450 isozymes to the metabolic deamination of the trace amine tryptamine. J Pharmacol Exp Ther 304:539-546.

Zeng H, Loughton BG, and Jennings KR (1996) Tissue specific transduction systems for octopamine in the locust (Locusta migratoria). J Insect Physiol 42: $765-769$.

Zhang A, Liu Q, Zhao H, Zhou X, Sun H, Nan Y, Zou S, Ma CW, and Wang X (2016) Phenotypic characterization of nanshi oral liquid alters metabolic signatures during disease prevention. Sci Rep 6:19333.

Zhang AQ, Mitchell SC, and Smith RL (1999) Dietary precursors of trimethylamine in man: a pilot study. Food Chem Toxicol 37:515-520.

Zhang J, Pacifico R, Cawley D, Feinstein P, and Bozza T (2013) Ultrasensitive detection of amines by a trace amine-associated receptor. J Neurosci 33:3228-3239.

Zhang LS and Davies SS (2016) Microbial metabolism of dietary components to bioactive metabolites: opportunities for new therapeutic interventions. Genome Med 8:46.

Zheng X, Xie G, Zhao A, Zhao L, Yao C, Chiu NH, Zhou Z, Bao Y, Jia W, Nicholson JK, et al. (2011) The footprints of gut microbial-mammalian co-metabolism. J Proteome Res 10 $5512-5522$.

Zhu G, Wang L, Tang W, Wang X, and Wang C (2017) Identification of olfactory receptor genes in the Japanese grenadier anchovy Coilia nasus. Genes Genomics 39:521-532.

Zhu MY, Juorio AV, Paterson IA, and Boulton AA (1992) Regulation of aromatic L-amino acid decarboxylase by dopamine receptors in the rat brain. $J$ Neurochem 58:636-641.

Zhu MY, Juorio AV, Paterson IA, and Boulton AA (1993) Regulation of striatal aromatic L-amino acid decarboxylase: effects of blockade or activation of dopamine receptors. Eur J Pharmacol 238:157-164.

Zhu M-Y, Juorio AV, Paterson IA, and Boulton AA (1994) Regulation of aromatic L-amino acid decarboxylase in rat striatal synaptosomes: effects of dopamine receptor agonists and antagonists. Br J Pharmacol 112:23-30.

Zhu Y, Jameson E, Crosatti M, Schäfer H, Rajakumar K, Bugg TD, and Chen Y (2014) Carnitine metabolism to trimethylamine by an unusual Rieske-type oxygenase from human microbiota. Proc Natl Acad Sci USA 111:4268-4273.

Zornik E, Paisley K, and Nichols R (1999) Neural transmitters and a peptide modulate Drosophila heart rate. Peptides 20:45-51.

Zucchi R, Accorroni A, and Chiellini G (2014) Update on 3-iodothyronamine and its neurological and metabolic actions. Front Physiol 5:402

Zucchi R, Ghelardoni S, and Chiellini G (2010) Cardiac effects of thyronamines. Heart Fail Rev 15:171-176. 